Innovations for Navigation Projects Research Program

\title{
Analysis of Impact Loads from Full-Scale, Low-Velocity, Controlled Barge Impact Experiments, December 1998
}

José Ramón Arroyo, Robert M. Ebeling, and

April 2003 Bruce C. Barker

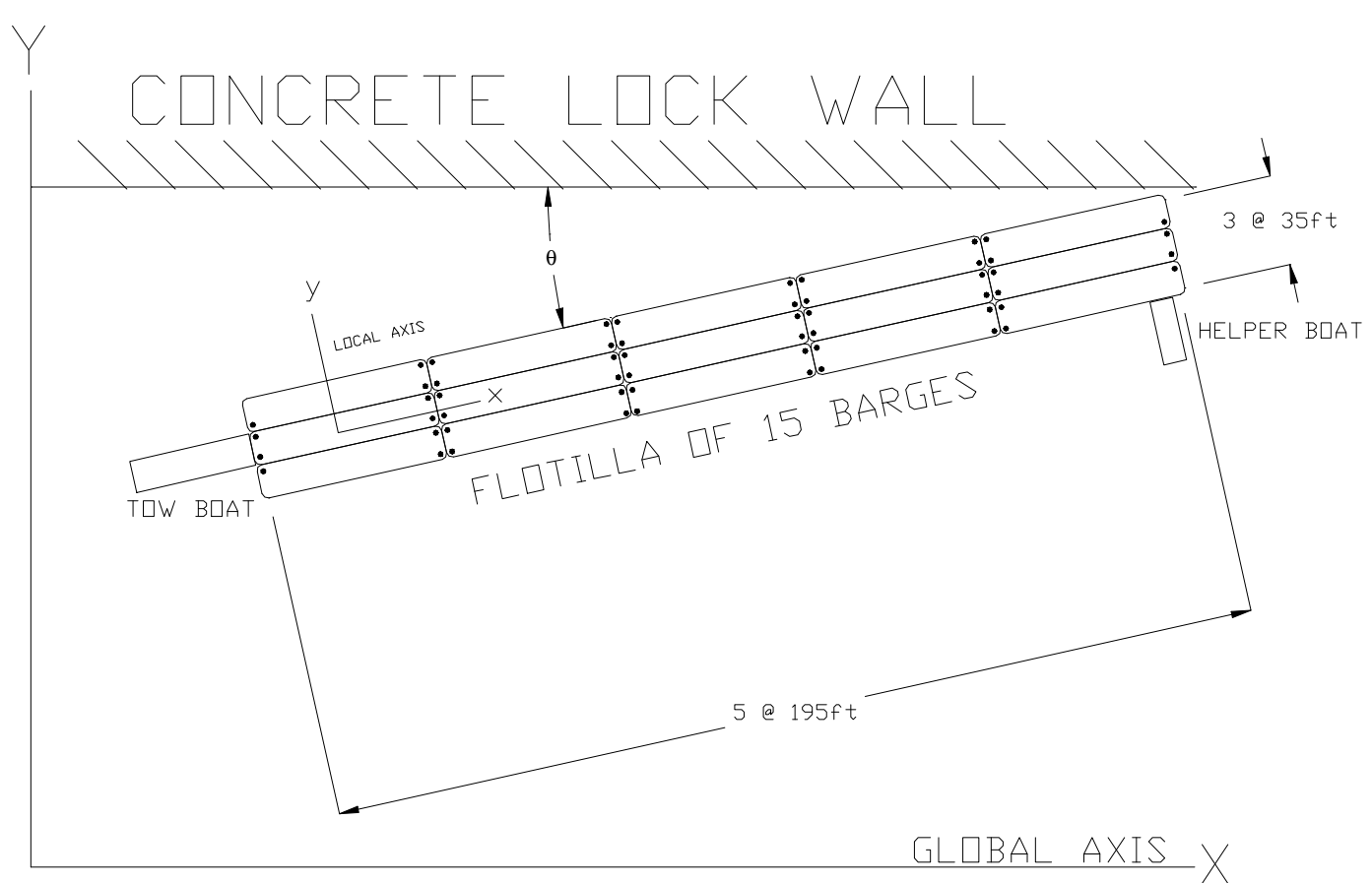


The contents of this report are not to be used for advertising, publication, or promotional purposes. Citation of trade names does not constitute an official endorsement or approval of the use of such commercial products.

The findings of this report are not to be construed as an official Department of the Army position, unless so designated by other authorized documents. 


\section{Analysis of Impact Loads from Full-Scale, Low- Velocity, Controlled Barge Impact Experiments, December 1998}

by José Ramón Arroyo

General Engineering Department

University of Puerto Rico

PO Box 9044

Mayagüez, PR 00681

Robert M. Ebeling, Bruce C. Barker

Information Technology Laboratory

U.S. Army Engineer Research and Development Center 3909 Halls Ferry Road

Vicksburg, MS 39180-6199

Final report

Approved for public release; distribution is unlimited

Prepared for U.S. Army Corps of Engineers

Washington, DC 20314-1000

Under

INP Work Unit 33143 


\section{Contents}

Conversion Factors, Non-SI to SI Units of Measurement............................ xi

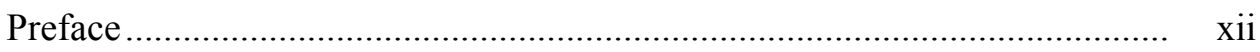

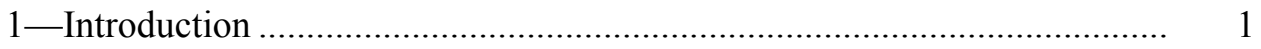

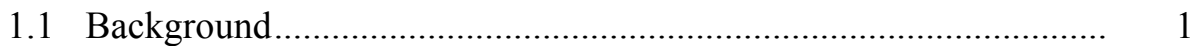

1.2 Summary of Full-Scale Barge Impact Experiments ........................ 3

1.3 Impulse and Linear Momentum Principle ...................................... 13

2-Impulse and Linear Momentum Principle Applied to Barge Flotilla

Model ........................................................................................ 21

3-Equilibrium Formulation with Assumed Coefficient of Friction .............. 28

3.1 Background ............................................................................ 28

3.2 Baltay and Gjelsvik (1990) Concrete-to-Steel Coefficient of Friction Results ........................................................................ 36

4-Equilibrium Formulation with Energy Method Application ................... 41

5-Comparison of Models Presented in Chapters 3 and 4............................ 51

5.1 Interpretation of Results from the Initial Configuration

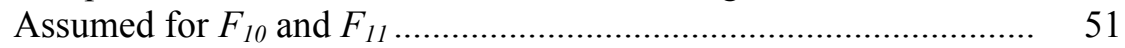

5.2 Configuration with Recorded $F_{10}$ and $F_{11}$ Outside the Radial Direction ........................................................................................ 55

5.3 Configuration with New Location of the Arc Beam and Recorded $F_{10}$ and $F_{11}$ Outside the Radial Direction....................... 59

5.4 ETL 1110-2-338 Engineering Procedure........................................... 63

$5.5 \quad F_{w}$ Time-Histories .................................................................. 65

6-Scaled Impulsive Force Formulation and Empirical Correlation .............. 72

6.1 Scaled Impulsive Force Formulation ................................................ 72

6.2 ETL 1110-2-338 Engineering Procedure Comparison with

6.2 Scaled Impulse Force Formulation Results ..................................... 78

6.3 Empirical Correlation between $\left(F_{w}\right)_{\max }$ and Linear

6.4 ETL 1110-2-338 Engineering Procedure Comparison with Empirical Correlation Results.................................................... 83 
6.5 Empirical Correlation Between $\left(F_{w}\right)_{\max }$ and Kinetic Energy

Normal to the Wall .................................................................... 84

6.6 Summary, Conclusions, and Recommendation ............................ 87

7—Possible Layout for Future Experiments .................................................. 88

8-Conclusions and Recommendations................................................... 90

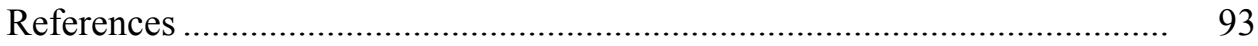

Appendix A: Summary of Experimental Results ....................................... A 1

Appendix B: FORTRAN Source Programs and Maple Worksheets............. B1

Appendix C: Numerical Integration .................................................. C1

Appendix D: Statistical Theory ................................................................ D1

SF 298

\section{List of Figures}

Figure 1.1. Robert C. Byrd Lock and Dam, Gallipolis Ferry, WV ............. 3

Figure 1.2. Fifteen-barge tow configured for impact experiments ............... 4

Figure 1.3. Barge impacting on lock wall without armor ........................... 5

Figure 1.4. Load bumper mounted to the front barge corner....................... 6

Figure 1.5. Load bumper as configured for Experiments 22-27................. 6

Figure 1.6. Load measurements, Experiment 41 ...................................... 8

Figure 1.7. Load measurements, Experiment 43 ….................................. 8

Figure 1.8. Initial configuration and recorded load direction ................... 10

Figure 1.9. Second configuration and recorded load direction................... 11

Figure 1.10. Final configuration and recorded load direction ..................... 12

Figure 1.11. Idealization and free-body diagram of the bumper ................. 16

Figure 1.12. Initial configuration and forces acting on load bumper ........... 17

Figure 1.13. Second configuration and forces acting on load bumper ......... 18

Figure 1.14. Third and final configuration and forces acting on load bumper........................................................................ 19

Figure 2.1. System of particles .............................................................. 21

Figure 2.2. Flotilla-wall system ......................................................... 23 
Figure 2.3. Free-body diagram of flotilla-wall system ............................ 23

Figure 2.4. Diagram of the Impulse and Linear Momentum Principle....... 26

Figure 3.1. Instrumented circular arc beam ............................................. 29

Figure 3.2. Structure, idealization, and free-body diagram of the bumper-assumed coefficient of friction method.................... $\quad 30$

Figure 3.3. Free-body diagram used in the first configuration modelassumed coefficient of friction method ..................................... 31

Figure 3.4. Idealization of the bumper structure for the finite element analysis

Figure 3.5. VisualAnalysis arc bumper model for $?=18 \mathrm{deg} \ldots \ldots \ldots \ldots \ldots \ldots \ldots . . . . . . . .33$

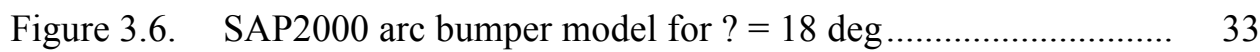

Figure 3.7. Coefficient of friction for machined mild steel surface ........... 38

Figure 3.8. Coefficient of friction for mild steel surface with mild scale.... 38

Figure 4.1. Structure, idealization, and free-body diagram of the bumper - energy method ................................................... 42

Figure 4.2. Configuration and free-body diagram used in the energy method model .............................................................................. 43

Figure 4.3. Idealization of the bumper structure for the finite element analysis ......................................................................... 46

Figure 4.4. VisualAnalysis model for $?=18$ deg-energy method............ 46

Figure 4.5. SAP2000 model for $?=18 \mathrm{deg}$ —energy method …................. 46

Figure 5.1. Initial configuration and recorded load direction .................... 52

Figure 5.2. Second load cell and arc location layout ................................ 56

Figure 5.3. Support reaction geometry layout: Support A, $F_{11}$, and Support B, $F_{10}$

Figure 5.4. Proposed (third) load cell and arc location layout................... 60

Figure 5.5. Support reaction geometry layout of proposed model:

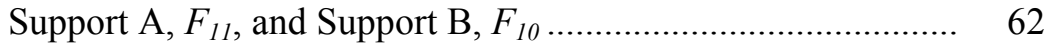

Figure 5.6. $\quad F_{10}, F_{11}$, and $F_{w}$ time-histories for Experiment 29................ 67

Figure 5.7. $\quad F_{10}, F_{11}$, and $F_{w}$ time-histories for Experiment $30 \ldots \ldots \ldots \ldots \ldots \ldots . . . . . .68$

Figure 5.8. $\quad F_{10}, F_{11}$, and $F_{w}$ time-histories for Experiment $31 \ldots \ldots \ldots \ldots \ldots \ldots . . . . . .68$

Figure 5.9. $\quad F_{10}, F_{11}$, and $F_{w}$ time-histories for Experiment $37 \ldots \ldots \ldots \ldots \ldots \ldots . . . . . .69$

Figure 5.10. $F_{10}, F_{11}$, and $F_{w}$ time-histories for Experiment $38 \ldots \ldots \ldots \ldots \ldots \ldots \ldots . . . . . . .69$ 
Figure 5.11. $F_{10}, F_{11}$, and $F_{w}$ time-histories for Experiment $39 \ldots \ldots \ldots \ldots \ldots \ldots . . . . . . . . \quad 70$

Figure 5.12. $F_{10}, F_{11}$, and $F_{w}$ time-histories for Experiment $41 \ldots \ldots \ldots \ldots \ldots \ldots . . . . . . . .70$

Figure 5.13. $F_{10}, F_{11}$, and $F_{w}$ time-histories for Experiment $42 \ldots \ldots \ldots \ldots \ldots \ldots . . . . . . . . .71$

Figure 6.1. Typical experimental load time-history ................................ 73

Figure 6.2. Scaled impulse relationship................................................. 77

Figure 6.3 Empirical correlation between $\left(F_{w}\right)_{\max }$ and linear momentum normal to the wall ............................................ 81

Figure 6.4 Empirical correlation using the kinetic energy concept ........... 85

Figure A.1. Experiment configuration diagram....................................... A2

Figure A.2. Experiment 22-Time variation of recorded bumper forces $F_{10}$ and $F_{11}$ during barge impact with an approach velocity of $0.88 \mathrm{fps}$ and a 10-deg impact angle .................................. A3

Figure A.3. Experiment 27-Time variation of recorded bumper forces $F_{10}$ and $F_{11}$ during barge impact with an approach velocity of $2.2 \mathrm{fps}$ and an 8-deg impact angle

Figure A.4. Experiment 23-Time variation of recorded bumper forces $F_{10}$ and $F_{11}$ during barge impact with an approach velocity of $0.81 \mathrm{fps}$ and a 15.5 -deg impact angle.

Figure A.5. Experiment 24-Time variation of recorded bumper forces $F_{10}$ and $F_{11}$ during barge impact with an approach velocity of $1.1 \mathrm{fps}$ and an 18-deg impact angle.

Figure A.6. Experiment 25-Time variation of recorded bumper forces $F_{10}$ and $F_{11}$ during barge impact with an approach velocity of $2.2 \mathrm{fps}$ and a 16.25-deg impact angle.

Figure A.7. Experiment 26-Time variation of recorded bumper forces $F_{10}$ and $F_{11}$ during barge impact with an approach velocity of $1.1 \mathrm{fps}$ and a 23.75-deg impact angle.

Figure A.8. Experiment 28-Time variation of recorded bumper forces $F_{10}$ and $F_{11}$ during barge impact with an approach velocity of $2.35 \mathrm{fps}$ and a 12.5-deg impact angle.

Figure A.9. Experiment 29-Time variation of recorded bumper forces $F_{10}$ and $F_{11}$ during barge impact with an approach velocity of 2.2 fps and a 15-deg impact angle

Figure A.10. Experiment 30-Time variation of recorded bumper forces $F_{10}$ and $F_{11}$ during barge impact with an approach velocity of $2.35 \mathrm{fps}$ and a 15-deg impact angle

Figure A.11. Experiment 31-Time variation of recorded bumper forces $F_{10}$ and $F_{11}$ during barge impact with an approach velocity of $1.61 \mathrm{fps}$ and a 13.25-deg impact angle 
Figure A.12. Experiment 37-Time variation of recorded bumper forces $F_{10}$ and $F_{11}$ during barge impact with an approach velocity of $1.95 \mathrm{fps}$ and a 12.5 -deg impact angle.

Figure A.13. Experiment 38-Time variation of recorded bumper forces $F_{10}$ and $F_{11}$ during barge impact with an approach velocity of $1.83 \mathrm{fps}$ and a 14.25 -deg impact angle

Figure A.14. Experiment 39-Time variation of recorded bumper forces $F_{10}$ and $F_{11}$ during barge impact with an approach velocity of 1.61 fps and a 17.25-deg impact angle

Figure A.15. Experiment 40-Time variation of recorded bumper forces $F_{10}$ and $F_{11}$ during barge impact with an approach velocity of $1.91 \mathrm{fps}$ and a 20.25-deg impact angle

Figure A.16. Experiment 41-Time variation of recorded bumper forces $F_{10}$ and $F_{11}$ during barge impact with an approach velocity of $2.86 \mathrm{fps}$ and an 11.5-deg impact angle

Figure A.17. Experiment 42-Time variation of recorded bumper forces $F_{10}$ and $F_{11}$ during barge impact with an approach velocity of $1.83 \mathrm{fps}$ and an 18.5-deg impact angle

Figure A.18. Experiment 43-Time variation of recorded bumper forces $F_{10}$ and $F_{11}$ during barge impact with an approach velocity of $0.88 \mathrm{fps}$ and a 25 -deg impact angle

Figure A.19. Experiment 44-Time variation of recorded bumper forces $F_{10}$ and $F_{11}$ during barge impact with an approach velocity of $1.22 \mathrm{fps}$ and a 23 -deg impact angle

Figure A.20. Differential GPS instrument locations for Experiments 22-44 A25

Figure A.21. Route of Experiment 29 and wall alignment A25

Figure A.22. Route of Experiment 30 and wall alignment A26

Figure A.23. Route of Experiment 31 and wall alignment A26

Figure A.24. Route of Experiment 37 GPS-2 and wall alignment A27

Figure A.25. Route of Experiment 38 GPS-2 and wall alignment A27

Figure A.26. Route of Experiment 39 and wall alignment A28

Figure A.27. Route of Experiment 40 and wall alignment A28

Figure A.28. Route of Experiment 41 and wall alignment A29

Figure A29. Route of Experiment 42 and wall alignment A29

Figure A.30. Route of Experiment 43 and wall alignment. A30 
Figure A.31. GPS-1 and GPS-2 route of Experiment 29 and wall aligment during $9 \mathrm{sec}$ of impact.

Figure A.32. GPS-1 and GPS-2 route of Experiment 30 and wall aligment during $9 \mathrm{sec}$ of impact.

Figure A.33. GPS-1 and GPS-2 route of Experiment 31 and wall aligment during $9 \mathrm{sec}$ of impact.

Figure A.34. GPS-1 and GPS-2 route of Experiment 39 and wall aligment during $9 \mathrm{sec}$ of impact.

Figure A.35. GPS-1 and GPS-2 route of Experiment 41 and wall aligment during $9 \mathrm{sec}$ of impact.

Figure A.36. GPS-1 and GPS-2 route of Experiment 42 and wall aligment during $9 \mathrm{sec}$ of impact.....

Figure C.1. Numerical integration scheme

Figure D.1. Empirical correlation between $\left(F_{w}\right)_{\max }$ and linear momentum normal to the wall, straight line with nonzero intercept.

Figure D.2. Empirical correlation between $\left(F_{w}\right)_{\max }$ and linear momentum normal to the wall, straight line with zero intercept

Figure D.3. Empirical correlation between $\left(F_{w}\right)_{\max }$ and kinetic energy normal to the wall, straight line with zero intercept

\section{List of Tables}

Table 1.1 Impact Velocity/Angle Data for Bumper Experiments............. 7

Table 3.1. Comparison of Results, Assumed Coefficient of Friction Method-Approach Angle 21.5 deg .................................... 35

Table 3.2. Comparison of Results, Assumed Coefficient of Friction Method-Approach Angle $18 \mathrm{deg}$.......................................... 35

Table 3.3. Static Coefficients of Friction Between Concrete and Steel ..... 37

Table 3.4. Kinetic Coefficients of Friction Between Concrete and Steel

Table 4.1. Comparison of Results, Energy Method-Approach Angle $21.5 \mathrm{deg}$

Table 4.2. Comparison of Results, Energy Method-Approach Angle $18 \mathrm{deg}$ 
Table 5.1. Comparison of Model Using Experimental Data and Arc

Geometry of 7 and $36 \mathrm{deg}$

Table 5.2. Comparison of Models Using Recorded Forces Outside the

Radial Direction and Arc Layout of 7 and $36 \mathrm{deg}$....

Table 5.3. Comparison of Models Using Recorded Forces Outside the

Radial Direction and Arc Layout of 3.5 and $32.5 \mathrm{deg}$

Table 5.4. Values of $\left(F_{w}\right)_{\max }$, Time of End Collision, and Deformation of Barge at Contact Point at End of Collision by ETL 1110-2-338 Engineering Procedure

Table 5.5. Comparison Between Table 5.3 $\left(F_{w}\right)_{\max }$ Values and $\left(F_{w}\right)_{\max }$ by ETL 1110-2-338 Engineering Procedure

Table 5.6. Comparison of Maximum Recorded Load Cells and Maximum Force Normal to the Wall .....

Table 6.1. $\left(F_{w}\right)_{\max }$ Scaled Method

Table 6.2. Comparison Between Table $5.3\left(F_{w}\right)_{\max }$ Values and the Figure 6.2 Best-Fit Straight-Line $\left(F_{w}\right)_{\max }$ Values of the Scaled Impulsive Relationship ....

Table 6.3. Comparison Between Figure 6.4 Best-Fit Straight-Line $\left(F_{w}\right)_{\max }$ Values of the Scaled Impulsive Relationship and $\left(F_{w}\right)_{\max }$ by ETL 1110-2-338 Engineering Procedure

Table 6.4. Comparison Between Figure 6.2 Scaled Impulsive

Relationship for $\left(F_{w}\right)_{\max }$ and $\left(F_{w}\right)_{\max }$ by the ETL 1110-2338 Engineering Procedure

Table 6.5. $\left(F_{w}\right)_{\max }$ Empirical Correlation.

Table 6.6. Comparison Between Table $5.3\left(F_{w}\right)_{\max }$ Values and the Figure 6.3 Best-Fit Straight-Line $\left(F_{w}\right)_{\max }$ Values of the Empirical Correlation.

Table 6.7. Comparison Between Table 6.3 Best-Fit Straight-Line $\left(F_{w}\right)_{\max }$ Values of the Empirical Correlation and $\left(F_{w}\right)_{\max }$ by ETL 1110-2-338 Engineering Procedure

Table 6.8. Comparison Between Figure 6.3 Empirical Correlation for $\left(F_{w}\right)_{\max }$ and $\left(F_{w}\right)_{\max }$ by the ETL 1110-2-338 Engineering Procedure.

Table 6.9. Comparison Between Table $5.3\left(F_{w}\right)_{\max }$ Values and the Figure 6.4 Best-Fit Straight-Line $\left(F_{w}\right)_{\max }$ Values of the Empirical Correlation Using the Kinetic Energy Concept........

Table 7.1. Testing Range Values for Future Experiments ....................... 89

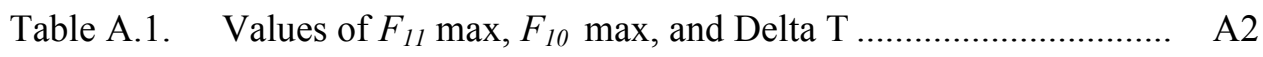

Table A.2. Time Maximum Load and Time of Contact of Experiment..... A3 
Table A.3. Angles and Velocity for Each Experiment............................. A23

Table A.4. Tonnage of Barge Flotilla—Barges, Coal, and Boats .............. A24

Table D.1. Linear Momentum Normal to the Wall and Maximum Force Normal to the Wall for Eight Barge Impact

Experiments............................................................... D3

Table D.2. Kinetic Energy Normal to the Wall and Maximum Force

Normal to the Wall for Eight Barge Impact Experiments D10 


\section{Conversion Factors, Non-SI to SI Units of Measurement}

Non-SI units of measurement used in this report can be converted to SI units as follows:

\begin{tabular}{|l|c|l||}
\hline Multiply & By & To Obtain \\
\hline degrees (angle) & 0.01745329 & radians \\
\hline feet & 0.3048 & meters \\
\hline inches & 25.4 & millimeters \\
\hline kips (force) & 4.448222 & kilonewtons \\
\hline kips (force) per square inch & 6.894757 & megapascals \\
\hline miles (U.S. statute) & 1.609347 & kilometers \\
\hline pounds (force) per square inch & 6.894757 & kilopascals \\
\hline square inches & 6.4516 & square centimeters \\
\hline tons (short, 2000 lb) & 907.1847 & kilograms \\
\hline \hline
\end{tabular}




\section{Preface}

The research described in this report was authorized by Headquarters, U.S. Army Corps of Engineers (HQUSACE), as part of the Innovations for Navigation Projects (INP) Research Program. This study was conducted under Work Unit 33143, "Design of Innovative Lock Walls for Barge Impact." This research was initiated by Mr. Robert C. Patev, former Principal Investigator of the work unit. Current Principal Investigator and author of the scope of work for the research effort discussed in this report is Dr. Robert M. Ebeling of the U.S. Army Engineer Research and Development Center (ERDC) Information Technology Laboratory (ITL).

Dr. Tony C. Liu was the INP Coordinator at the Directorate of Research and Development, HQUSACE; Research Area Manager was Mr. Barry Holliday, HQUSACE; and Program Monitors were Mr. Mike Kidby and Ms. Anjana Chudgar, HQUSACE. Mr. William H. McAnally of the ERDC Coastal and Hydraulics Laboratory (CHL) was the Lead Technical Director for Navigation Systems, and Dr. Stanley C. Woodson, ERDC Geotechnical and Structures Laboratory (GSL), was the INP Program Manager.

This research was conducted and the report prepared by Dr. José Ramón Arroyo, General Engineering Department, University of Puerto Rico at Mayagüez; Dr. Ebeling, Engineering and Informatic Systems Division (EISD), ITL; and Mr. Bruce C. Barker, Chief, Data Acquisition and Integration Branch, EISD, ITL. The authors of this report would like to acknowledge the assistance of Messrs. Abelardo González and Carlos Rivera, graduate students of the Civil Engineering Department, University of Puerto Rico at Mayagüez, in conducting this research.

The authors of this report would also like to acknowledge the ERDC team who participated in the series of full-scale, low-velocity, controlled barge impact experiments conducted at Robert C. Byrd Lock and Dam, Gallipolis Ferry, WV. Data from select instrumentation mounted on the barges and recorded during these impact experiments were evaluated and used in the research. At the time of the December 1998 full-scale barge impact experiments, Mr. Patev, the Principal Investigator, provided overall project management in the field during these landmark experiments.

The primary ITL instrumentation team consisted of Mr. Barker, the overall instrumentation coordinator; Mr. Leo V. Koestler III, lead engineer for bargemounted data acquisition; Mr. S. Wallace Guy, lead engineer for shore-based 
measurements; Mr. Tony N. Brogdon, who provided strain-gage installation; and Mr. Terry W. Warren, who provided software and data-processing support. Global positioning systems and conventional survey points were provided by Messrs. Terry N. Waller, Don C. Wilson, and David N. Maggio, ERDC CHL. Photographers David E. Ray (deceased) and Gary E. Dill, ITL, were responsible for high-speed film and video coverage of the impact events, as well as documentary still photography. Mr. Vince Chiarito, GSL, provided design guidance for the barge load bumper. The evolution in the design of the bumper used in the full-scale experiments was developed by Messrs. Patev and Barker in consultation with Mr. Chiarito.

The research was monitored by Dr. Ebeling, under the supervision of Mr. H. Wayne Jones, Assistant Technical Director for Computational Science and Engineering, ITL; Dr. Jeffery P. Holland, Director, ITL; and Dr. David W. Pittman, Acting Director, GSL.

At the time of preparation of this report, Dr. James R. Houston was Director of ERDC, and COL John W. Morris III, EN, was Commander and Executive Director.

The contents of this report are not to be used for advertising,

publication, or promotional purposes. Citation of trade names does not constitute an official endorsement or approval of the use of such commercial products. 


\section{Introduction}

\subsection{Background}

One of the most frequent loads applied to the locks of the inland waterway system is the impact made by a barge flotilla as it transits the lock. Consequently, this load case represents one of the primary design loads considered by the U.S. Army Corps of Engineers for lock walls, approach walls, guide walls, and guard walls. The primary focus of engineers performing these impact computations has been the lock approaches, where the worst-case loads are likely to occur.

In 1993, the Headquarters, U.S. Army Corps of Engineers, issued the first formal Corps-wide analysis procedure, providing guidance for analyzing the effects of barge impact loading on navigation structures in the form of an engineer technical letter designated as ETL 1110-2-338. This ETL gives the basic equations of an engineering procedure for the collision of a barge flotilla with a rigid structure. According to the ETL 1110-2-338 engineering procedure, the magnitude of the impact forces generated by a particular collision event is dependent on the mass (including hydrodynamic added mass of the barge flotilla), the approach velocity, the approach angle, the barge flotilla moment of inertia, damage sustained by the barge structure, and friction between the barge and the wall.

A major distinction between this procedure and the traditional Navy method for determining berthing forces is the estimation of collision energy dissipated in deformation of the barge structure and transferred to the rotation of the barge flotilla. The analytical method uses the structural interaction mechanism of Minorsky (see ETL 1110-2-338), which provides an empirical relationship between the (nonrecoverable) hull deformation and the energy absorbed in a collision. The relationship between kinetic energy lost in a collision and the volume of in-plane (barge) material damaged is used to determine impact force as a relationship to instantaneous contact area of damaged structure.

Minorsky used the conservation laws of momentum and energy and the principles of rigid body mechanics to estimate the kinetic energy lost during a collision between two vessels. He then calculated a resistance factor that is essentially the volume of material damaged in the bow of the striking ship and in the side of the struck ship. Minorsky reasoned that the principal resistance to collision penetration is provided by deep structure that suffers in-plane damage. For the case of a barge striking a fixed wall, the main deck, the bottom plate, the head $\log$, and the transverse frames would offer resistance to damage. Minorsky 
selected and analyzed 26 actual ship collisions and correlated the energy absorbed in the collision with the Minorsky resistance factor. Using the equivalency between energy absorbed and the work performed in deforming the structure, a constant described as the force per unit of damaged surface area was defined $(=13.7 \mathrm{ksi}){ }^{1}$

The Minorsky structural interaction mechanism is a constant pressure process operating with a pressure of $13.7 \mathrm{ksi}$ acting over the instantaneous face area of the damaged element. This allows for the definition of an equivalent, linear spring constant representing the crushing of the barge structure in the ETL 11102-338 analytical formulation. It is important to note that the entire structural interaction mechanism is modeled as a linear spring in the direction of collision corresponding to the energy absorption in the crushed barge structure. The formulation becomes one of an initial value problem for barge flotilla collision with a rigid wall, representing a lock wall in this case, and leads to the solution given in ETL 1110-2-338.

Two significant concerns have been raised since the ETL 1110-2-338 procedure was released. First, a key aspect of the ETL 1110-2-338 engineering formulation is computation of collision energy dissipated in nonrecoverable, plastic hull deformation of (i.e., damage to) the corner of the barge where impact with the wall occurs. However, the majority of the impacts made by barge flotillas transiting Corps locks do not result in damage to the barge structure or to the walls. Second, several engineers who have used the ETL 1110-2-338 engineering procedure have questioned the accuracy of the computed results.

To investigate these issues as well as to provide a basis for the development of an improved numerical impact model, a fully instrumented, full-scale impact experiment was devised to directly measure the impact forces. This report addresses the interpretation of the resulting December 1998 full-scale, lowvelocity, controlled impact, barge flotilla impact experiments conducted at the decommissioned Gallipolis Lock at Robert C. Byrd Lock and Dam. A comparison between measured impact forces for these full-scale, barge flotilla impact tests and corresponding computations made using the ETL 1110-2-338 engineering procedure is included in this report.

In addition, a easy to use empirical correlation is derived that reports the maximum impact force (normal to the wall) as a function of the linear momentum normal to the wall (immediately prior to impact), using the results from the impact forces measured during these full-scale impact experiments. The authors envision that this new empirical correlation will be used for impacts that do not involve damage during impact to either the corner barge of a barge flotilla or to the wall. An alternate empirical correlation is given for the maximum impact force (normal to the wall) as a function of the kinetic energy normal to the wall (immediately prior to impact).

\footnotetext{
${ }^{1}$ A table of factors for converting non-SI units of measurement to SI units is presented on page xi.
} 


\subsection{Summary of Full-Scale Barge Impact Experiments}

In December 1998, full-scale, low-velocity, controlled impact barge experiments were conducted at the decommissioned Gallipolis Lock at Robert C. Byrd Lock and Dam, Gallipolis Ferry, WV (Figure 1.1). The primary goal of these experiments was to measure the actual impact forces normal to the wall using a load-measuring device. The focus of the experiments was to obtain and measure the baseline response of an inland waterway barge, quantify a multipledegree-of-freedom system during the impact, and investigate the use of energyabsorbing fenders.

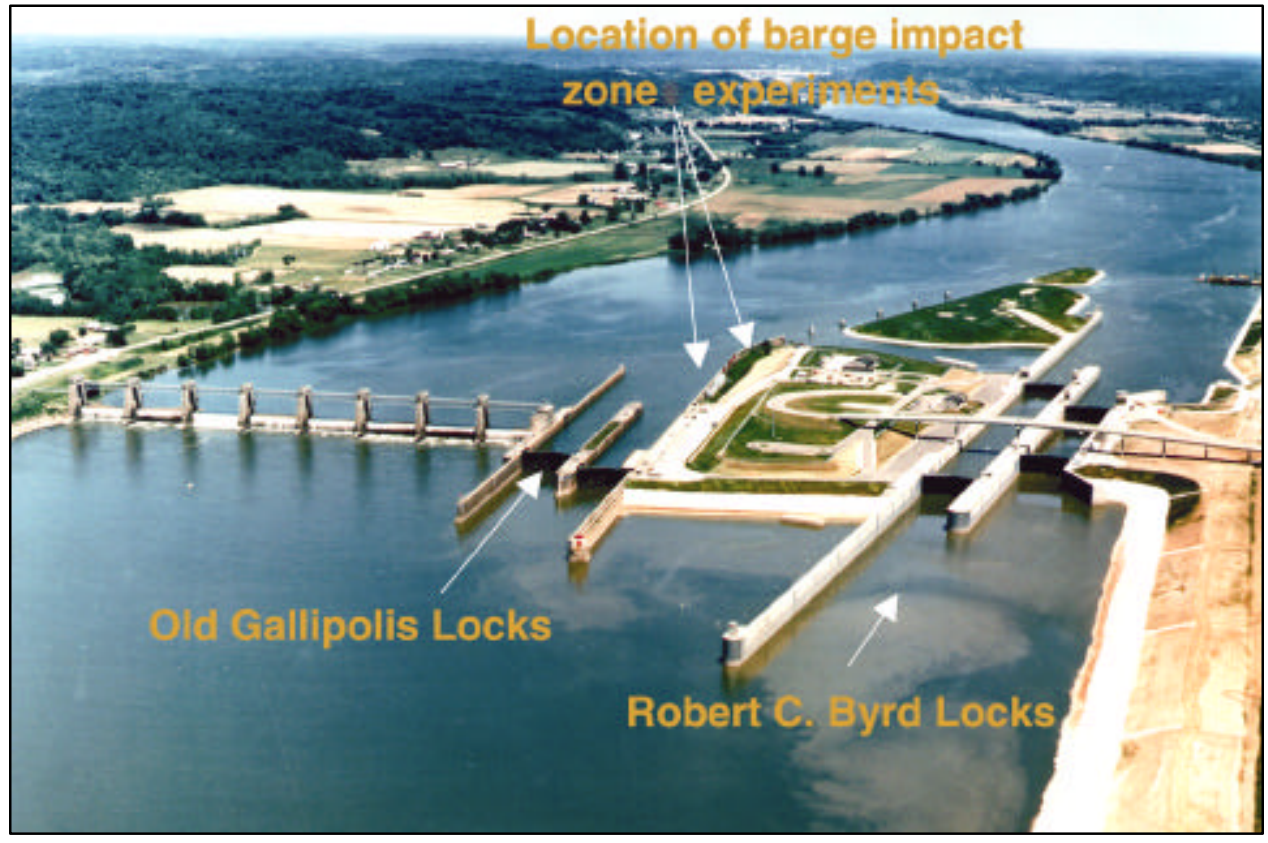

Figure 1.1. Robert C. Byrd Lock and Dam, Gallipolis Ferry, WV

The full-scale experiment used a 15-barge commercial flotilla (Figure 1.2). Each barge was a jumbo open-hopper design ( 35 by $195 \mathrm{ft}$ ) with rake barges at the front of the tow. The barges were ballasted with anthracite coal to a draft of $9 \mathrm{ft}$. The total weight of the flotilla was 30,012 short tons. The total mass is $1,865.59$ $\mathrm{k}-\mathrm{sec}^{2} / \mathrm{ft}$, equal to the total weight divided by the gravitational constant, $g$.

The target area was the rigid concrete upper guide wall (see Figure 1.1), lacking the friction-reducing steel armor found on modern lock walls. A total of 44 impact experiments were successfully conducted against the unaltered guide wall and a prototype fendering system. The angle of impacts ranged from 5 to $25 \mathrm{deg}$, with velocities of 0.5 to $4 \mathrm{fps}$. Of these, 21 were baseline impact tests, with no alterations to the corner barge. For the remaining 23 impact tests, the corner barge was replaced with an identical barge that had been fitted with an in-house-designed load-measuring beam. This device will be discussed thoroughly later in this report. 
Fourteen of the impact experiments were made against the fendering system. These tests, although interesting, are not the focus of this report and will not be discussed further.

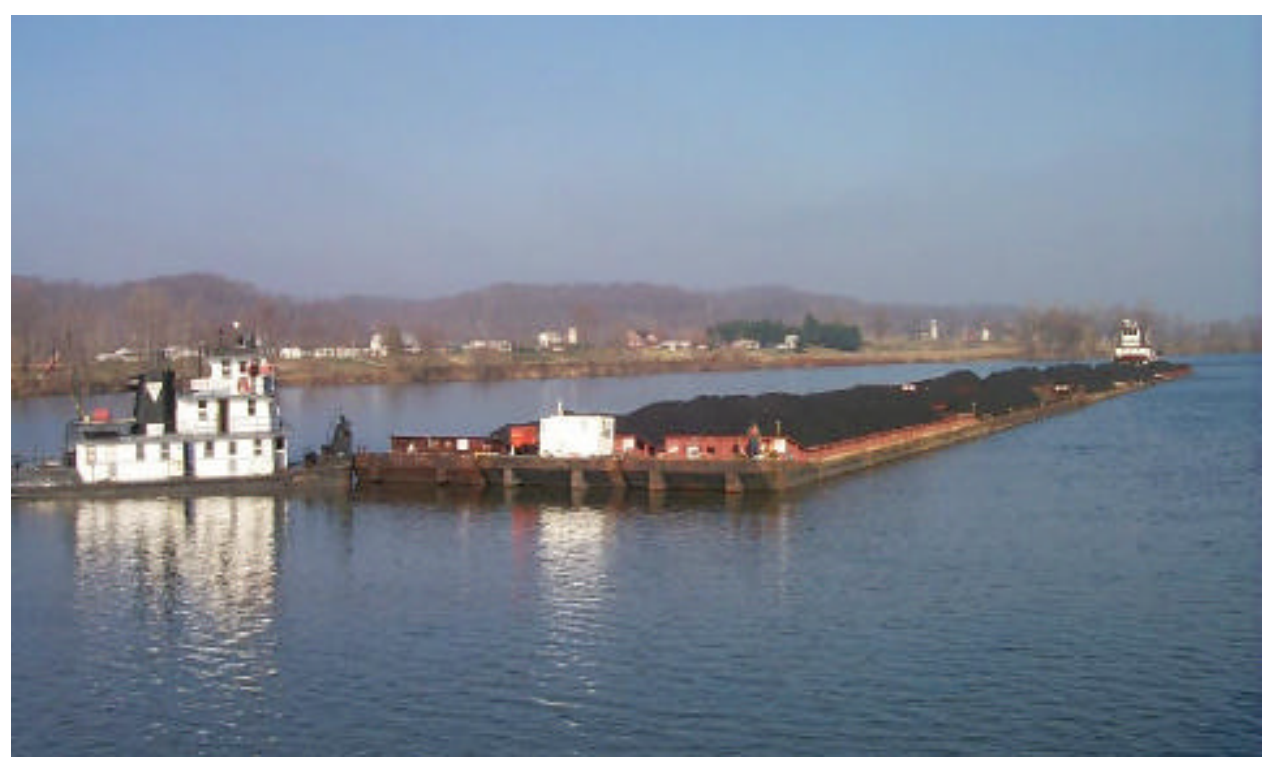

Figure 1.2. Fifteen-barge tow configured for impact experiments

Instrumentation mounted on the barge tow consisted of 55 measurements (data channels) for the baseline experiments and 44 measurements for tests with the load bumper-equipped barge. The instruments included 15 axial capacitiveaccelerometers on the impact corner; 10 servo-accelerometers to monitor motion at key locations on the tow; strain gages installed on principal steel in the impact area (17 on the baseline barge, six on the bumper-equipped barge); two pressure cells to monitor any hydrodynamic loading as the tow approached the wall; nine clevis-pin load cells in the lashings that secure the tow; and two additional highrange, clevis-type load cells, integral to the load bumper.

The tow-mounted instrumentation was cabled to an instrument enclosure located on the center-front barge. This structure housed the signal-conditioning electronics, data acquisition computer, and system operators throughout the project. In addition to the tow-mounted instrumentation, servo-accelerometers were located on either side of the joints of the guide wall impact monolith. Data from the shore-mounted instrumentation will not be discussed in this report.

The precise tow position during the 44 impact experiments was determined using kinematic differential global positioning system (DGPS) instruments. Two DGPS units were deployed along the port side of the corner barge, with a third unit on the stern area of the center barge. These units recorded tow position each second to an accuracy of $2 \mathrm{~cm}$. A fourth DGPS unit was used in the pilothouse of the towboat to monitor and control the tow's approach speed. The accuracy of this unit, operated in real-time mode, was limited to $3 \mathrm{~m}$.

These experiments were conducted over a period of 3 days in December 1998 on a highly compressed schedule. The first day consisted of installing cable 
and instruments, calibrating systems, and surveying instrument locations and other key points on the tow. The baseline experiments were begun early on the second day and were completed by late evening. These consisted of 12 wellvaried impacts (Experiments 1-12) conducted on the unarmored lock wall (see Figure 1.3), and nine impacts (Experiments 13-21) on the fender-equipped section. Instruments were removed from the corner barge at the end of the workday. During the night, the tow crew replaced the standard corner barge with a second barge that had been equipped the previous week with the corner load beam.

On the morning of the third day, instrumentation was remounted to the new corner barge, with testing commencing shortly before noon. Ten more impacts (Experiments 22-31) were made against the same unarmored section of wall that was the focus of the tests conducted the previous day. The tow was moved to another location along the wall where the five fender impact tests (Experiments 32-36) were conducted. Then, the tow was repositioned to complete the test matrix at the primary target area (Experiments 37-44). Testing was completed in the early evening of the third day of testing.

The operational procedures followed by the tow and helper boat are crucial to understanding the force system applied in

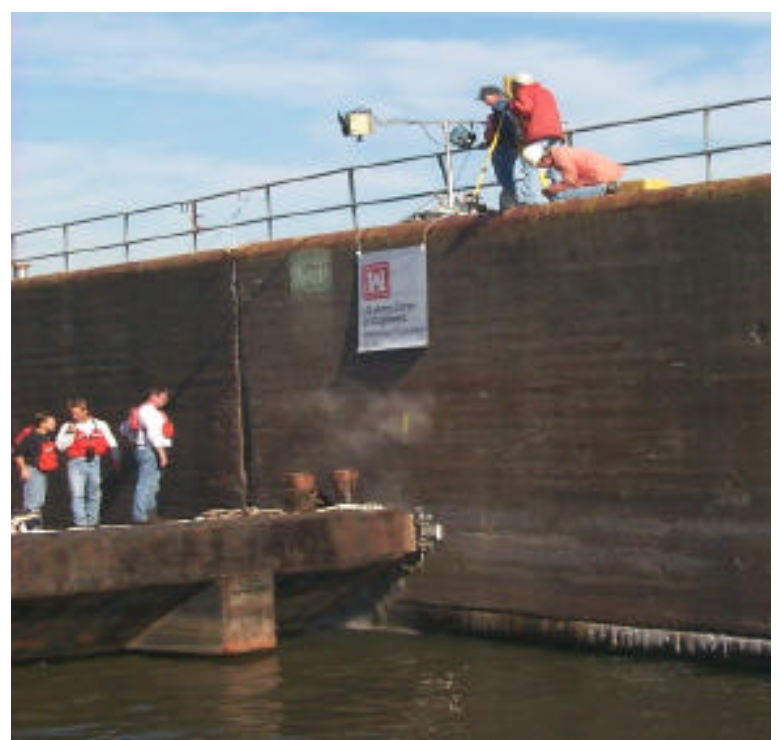

Figure 1.3. Barge impacting on lock wall without armor (note concrete dust) these experiments. For each experiment the tow pilot, assisted by the helper boat positioned at the starboard bow, would align the tow with the target at the desired angle of attack. This angle was verified with a wall-based survey transit. Once positioned, the towboat's engines were powered up to bring the flotilla to the required speed, which was verified with the GPS unit in the pilothouse of the towboat. Just prior to impact, the tow pilot would cut power to idle and drift the flotilla into the wall. Several seconds after impact, the towboat's engines were reversed, while the helper boat would throttle up and push the corner against the wall to further reduce the forward momentum. The tow was then repositioned for the next experiment.

As stated previously, the primary goal of this project was to quantify the normal force the barge tow imparts to the lock wall. The design load for this system was estimated (prior to experiments) to be less than 1,000 kips. Two approaches to making this measurement were considered. The first option considered was to build a load-measuring platform into the lock wall. This option would optimize testing efficiency, as no swapping of the corner barge was needed; however, it was unclear how reliably the 1,100-ft tow could be steered onto a small target. A further concern was that a second system would have to be built into the fender section. 
The second option was to fit the load-measuring system to the corner barge itself, using a heavy curved beam as a load bumper, and two clevis-type 600-kip load cells configured to measure the normal load transferred to the barge. This second option was chosen because, not only did it eliminate the concern about hitting a target zone, it was also much less complex and less expensive to install. The initial load bumper design called for a pin connection at the front of the beam with a roller connection at the rear attachment. With this design, no shear loads would be transferred to the barge at the roller support. As construction began on this design, it became clear that the load beam would be poorly supported at the rear, and that this weakness would most likely damage the frontmounted load cell. The solution (since the investigators were not overly interested in the shear component) was to weld both the front and rear pin supports to the barge. This created an indeterminate pin-pin connection with two reactions at each pin.

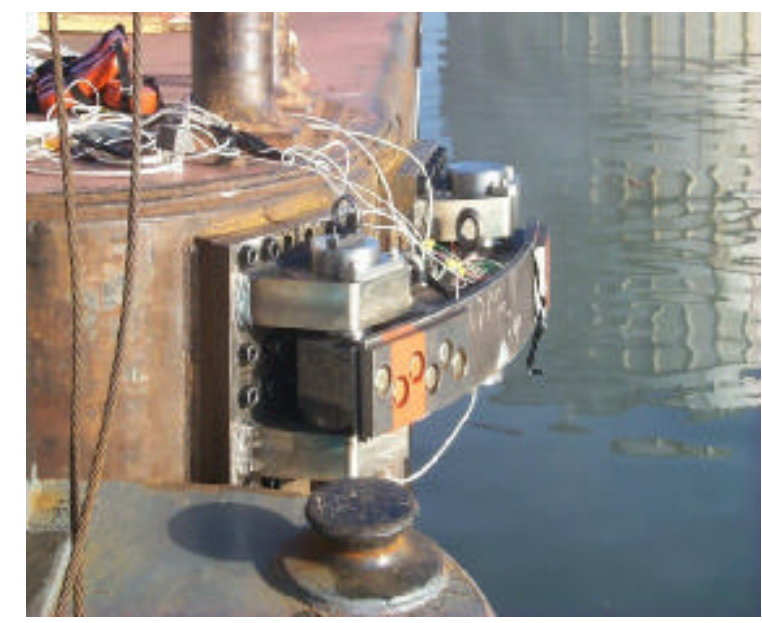

Figure 1.4. Load bumper mounted to the front barge corner

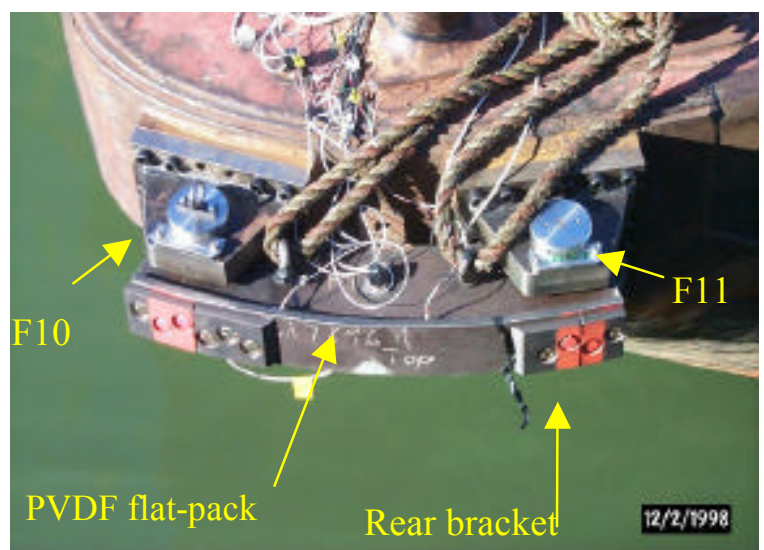

Figure 1.5. Load bumper as configured for Experiments 22-27
The load bumper, installed on the barge corner, is shown in Figures 1.4 and 1.5. The load beam was constructed of mild-steel with an outer radius of 72.6 in., outer arc-length of 43.6 in., a cross section measuring 9 in. in width by 5 in.

in height, with a separation between the 6-in.-diam load pins of 35.5 in.

It should be noted here that a second load-sensing device, intended as a backup, was added to the outer surface of the load beam. This device used three polyvinylidene fluoride (PVDF) thin-film pressure sensors configured in a $1 / 8$-in.thick flat-pack, sandwiched between two steel plates. This system proved ineffective, as it caused excessive shear drag at the rear brackets that secured the PVDF material to the bumper. For this reason, it was removed after Experiment 27 , creating a smooth, continuous impact surface. Load data from Experiments 22-27, especially for the lower angles of impact, was adversely affected by this drag, and should be used with caution. These data were therefore discarded for the subsequent discussion of the forces derived from the $F_{10}$ and $F_{11}$ clevis-pin load cells. The PVDF sensors will not be discussed further in this report. 
The approach angle and velocity for the 12 most credible bumper experiments (Experiments 28-31 and Experiments 37-44) are summarized in Table 1.1. Impact velocity for these experiments ranges from 0.88 to $2.87 \mathrm{fps}$, with approach angles ranging from 8.8 to $21.1 \mathrm{deg}$. This table was constructed using the DGPS data from the two instruments located on the corner barge. The time and point of impact were obtained through the positioning plots of the forwardmost DGPS station (see Appendix A, Figures A.20-A.30). This station followed the general course of the tow up to the time of impact. After impact, the front of the barge tracked parallel to the lock wall.

\section{Table 1.1}

Impact Velocity/Angle Data for Bumper Experiment

\begin{tabular}{||l|l|l|l|l|l||}
\hline \multirow{2}{*}{$\begin{array}{l}\text { Experiment } \\
\text { Number }\end{array}$} & \multirow{2}{*}{$\begin{array}{l}\text { Impact } \\
\text { Angle, deg }\end{array}$} & \multicolumn{3}{|c|}{ Velocity } & \multicolumn{2}{c||}{ Velocity Normal to the Wall } \\
\cline { 3 - 6 } & fps & mph & fps & mph \\
\hline \hline 28 & 9.7 & 2.41 & 1.64 & 0.41 & 0.28 \\
\hline 29 & 12.7 & 2.21 & 1.50 & 0.48 & 0.33 \\
\hline 30 & 12.2 & 2.35 & 1.60 & 0.50 & 0.34 \\
\hline 31 & 10.6 & 1.62 & 1.10 & 0.30 & 0.20 \\
\hline 37 & 10.3 & 1.96 & 1.33 & 0.35 & 0.24 \\
\hline 38 & 11.9 & 1.84 & 1.25 & 0.38 & 0.26 \\
\hline 39 & 14.1 & 1.62 & 1.10 & 0.39 & 0.27 \\
\hline 40 & 17.5 & 1.91 & 1.30 & 0.57 & 0.39 \\
\hline 41 & 8.8 & 2.87 & 1.95 & 0.44 & 0.30 \\
\hline 42 & 17.5 & 1.84 & 1.25 & 0.55 & 0.38 \\
\hline 43 & 21.1 & 0.88 & 0.60 & 0.32 & 0.22 \\
\hline 44 & 20.9 & 1.22 & 0.83 & 0.44 & 0.30 \\
\hline
\end{tabular}

Once the time of impact was identified, the impact angle (the angle formed by the port side of the corner barge with the lock wall) was determined from the DGPS data corrected for the relative positions of DGPS stations 1 and 2 on the barge (see Appendix A, Table A.3). This angle is critical to the bumper geometry and resulting force system. Velocity (actually speed) is simply calculated from the displacement of the front corner GPS unit per unit time $(1 \mathrm{sec})$. Data typical of the $F_{10}$ and $F_{11}$ load cells are presented in Figures 1.6 and 1.7. During Experiment 41 (Figure 1.6), the angle of attack is very shallow, $8.8 \mathrm{deg}$, with a substantial velocity of $2.87 \mathrm{fps}$. The point of impact on the load bumper is slightly in front of the $F_{11}$ (rear) load cell. As expected, the loads are distributed with the major portion of the force on the rear cell. Peak loads for the front and rear cells were measured at 29.5 and 315.5 kips, respectively (see Appendix A, Table A.1). The rise time for this measurement, defined here as $\Delta t_{1}$ between contact and peak load, was measured at $164.8 \mathrm{msec}$ (see Appendix A, Table A.2). Total contact time with the lock wall for this experiment and all others was approximately $9 \mathrm{sec}$.

For Experiment 43 (Figure 1.7), the impact angle is $21.1 \mathrm{deg}$, but with a reduced speed of only $0.88 \mathrm{fps}$. For this orientation, the impact point on the bumper is several inches forward of the midpoint between the load pins. In this 


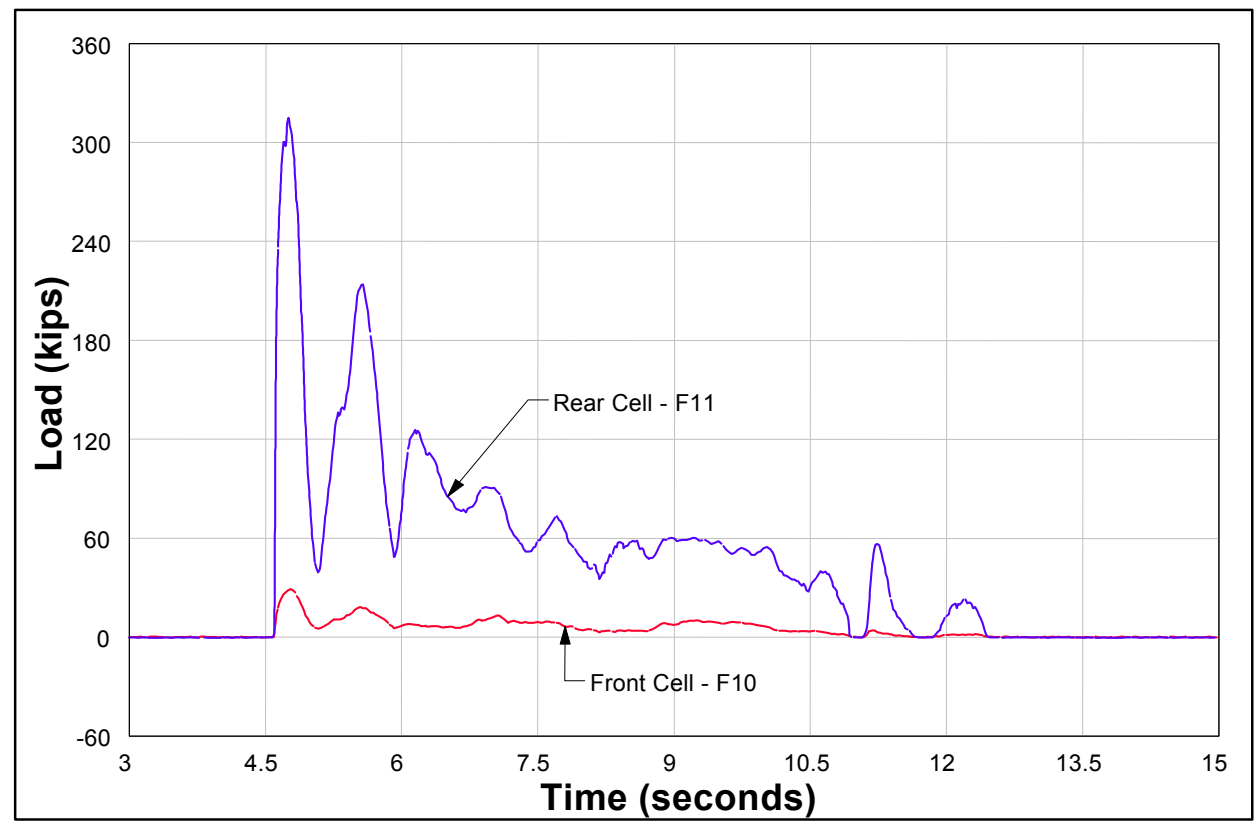

Figure 1.6. Load measurements, Experiment 41 (2.87 fps at $8.8 \mathrm{deg})$

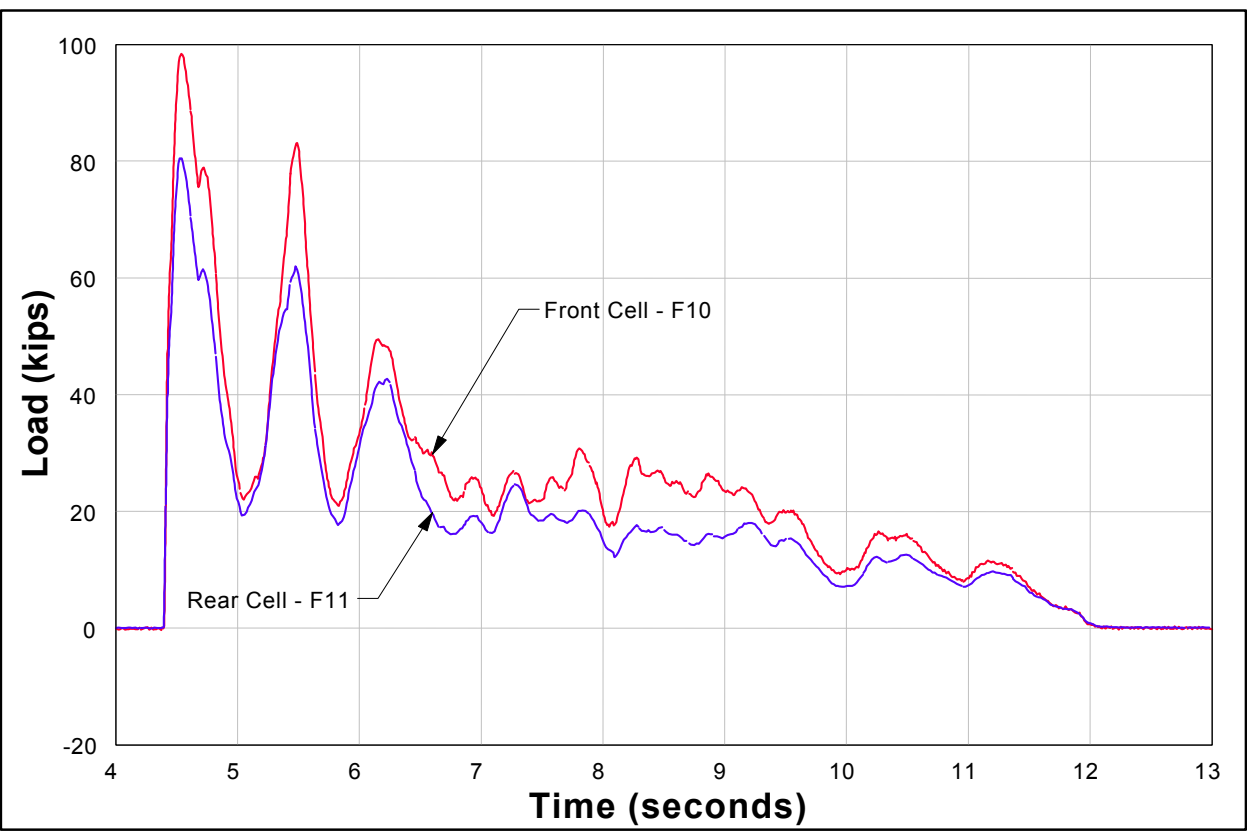

Figure 1.7. Load measurements, Experiment 43 (0.88 fps at $21.1 \mathrm{deg})$

case, the maximum force was measured at the front cell at 98.7 kips versus 80.7 kips at the rear cell. The rise time for this impact was slightly faster at $142.2 \mathrm{msec}$. The characteristic signature in all the bumper load measurements is the decaying oscillation at a base frequency of approximately $1 \mathrm{~Hz}$. The source of this low-frequency "ring" is not entirely clear, but one possibility is that it reflects the coefficient of restitution of the guide wall, rather than the bumper. A 
significant portion of this report will deal with the resolving of the reactions in the bumper. and transferring these reactions to the lock wall.

The initial orientation of the bumper relative to the longitudinal axis of the barges was adopted to be $54 \mathrm{deg}$ from the longitudinal axis (local axis of the model) of the barges. Figure 1.8 shows a near-vertical view of the impact site captured from video, and the initial orientation of the bumper and the recorded forces at the pins, which were assumed to be in the radial direction of the bumper. The force notation of $S_{P A}, S_{P B}$ used in the bumper analysis is $F_{11}$ and $F_{10}$, respectively. The designations " 10 " for forces at the front pin and " 11 " for the rear pin have been carried through from the measurement numbers $F_{10}$ and $F_{11}$ for these load-measuring clevis-pins. The precise orientation of the bumper on the barge is critical to this effort. The as-built orientation of the bumper was then developed from a combination of design drawings and documentary photos. The survey data were intended for this purpose; however, the uncertainty caused by the barges shifting and the tow drifting against its moorings between sightings compromised the accuracy of these measurements sufficiently to make them unusable for this purpose.

Subsequently, it was established from the design drawings and documentary photos that the recorded forces' orientation was not aligned in the radial direction. Taking into account this observed discrepancy, a new recorded forces $\left(F_{11}\right.$ and $F_{10}$ ) orientation was established. Figure 1.9 shows the bumper-arc geometry, with the angle and separation of the load pins indicated. The system of forces based on this arc geometry is also shown in the figure. This second configuration was analyzed, and considering the magnitude of the angles indicating the support reactions orientation, an impossible geometrical arrangement was produced.

A final configuration was established based on the range of probable angles for the forces' orientations relative to the radial direction, the location of the bumper related to the longitudinal axis of the barges, and the appropriate coefficient of friction between concrete and steel. This configuration is shown in Figure 1.10. The forces $F_{11}$ and $F_{10}$ are out the radial direction 5.5 and $1.5 \mathrm{deg}$, respectively. The location of the bumper with respect to the longitudinal axis of the barge also changes, from an initial approximation of 54 to $57.5 \mathrm{deg}$. It will be demonstrated that this final configuration produces reasonable results based on the values of the coefficient of friction between the wall and the steel bumper found in technical literature, and using the fact that the bumper must be in compression during the impact process. (Note that it is impossible for the bumper to be in tension during the impact process.)

The systems of forces for each of the three configurations for the indeterminate load bumper are shown in Figures 1.8-1.10. A total of six forces are present:

Two known forces: $\quad F_{10}$ and $F_{11}$ (labeled in the figures as $S_{P B}$ and $S_{P A}$, respectively)

Four unknown forces: $F_{w}, S_{w}$ (friction force), $F_{N A}$, and $F_{N B}$ 


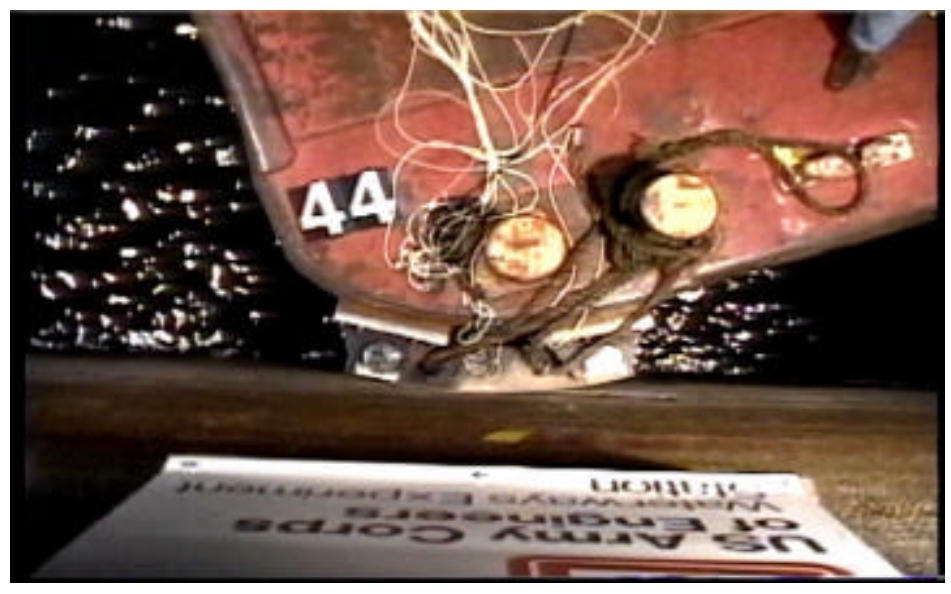

a. Overhead photo of barge with bumper about to impact the lock wall

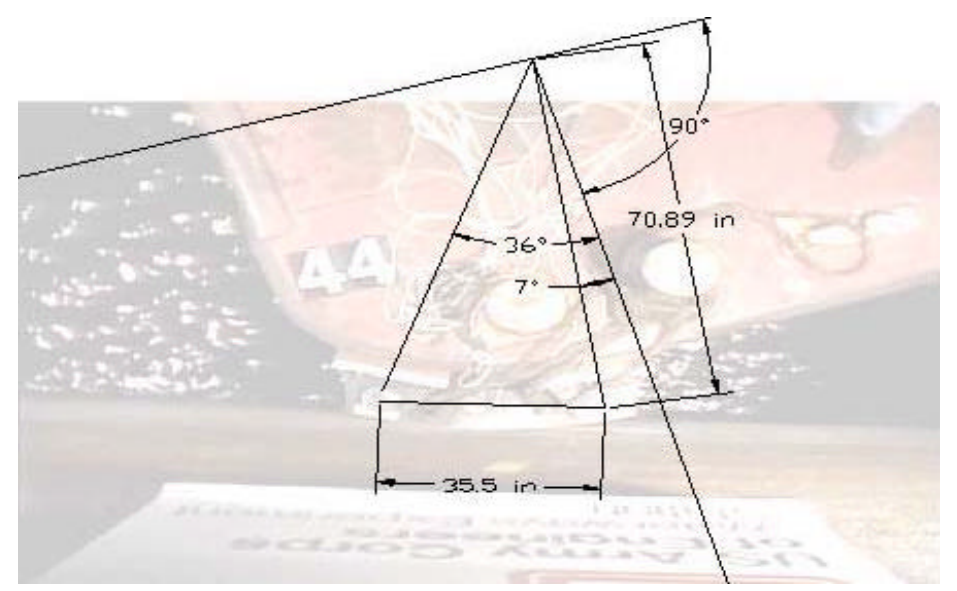

b. Arc geometry used for force analysis

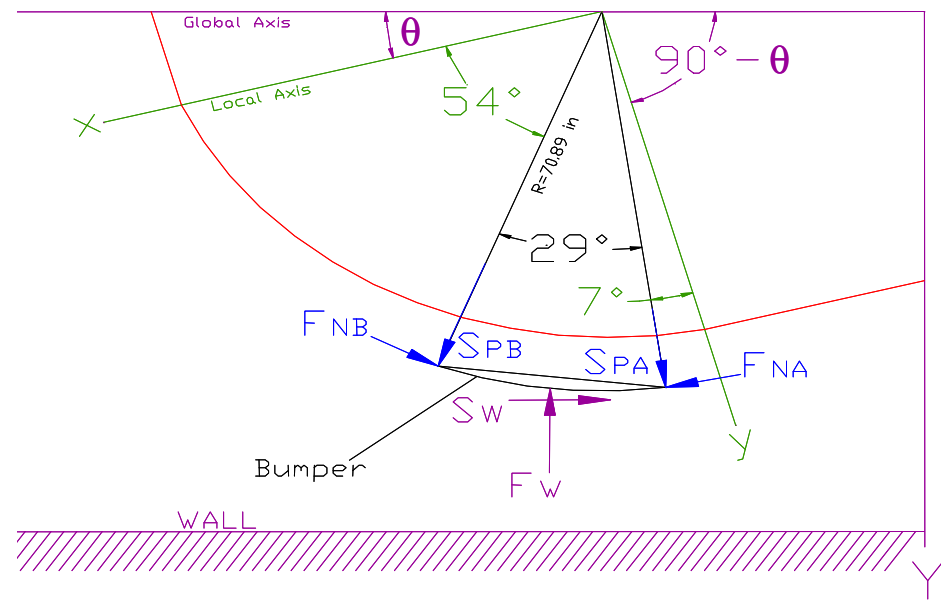

c. Forces acting on load bumper-initial configuration

Figure 1.8. Initial configuration and recorded load direction 


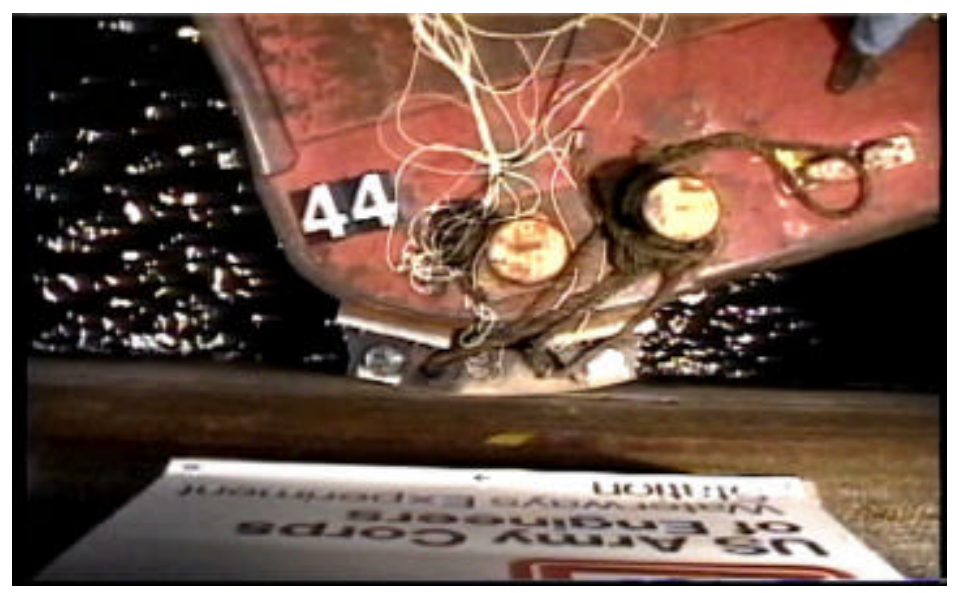

a. Overhead photo of barge with bumper about to impact the lock wall

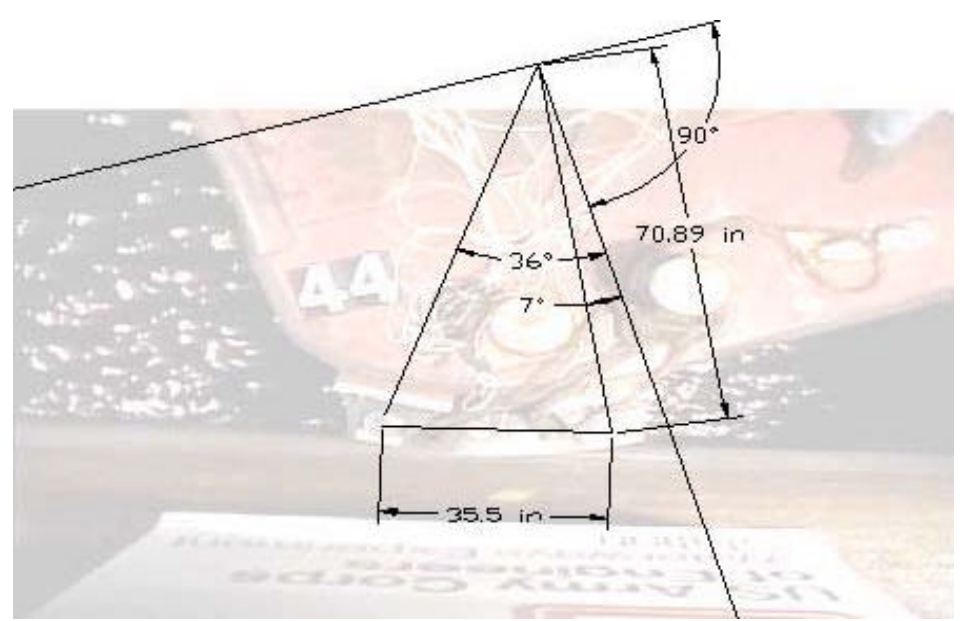

b. Arc geometry used for force analysis

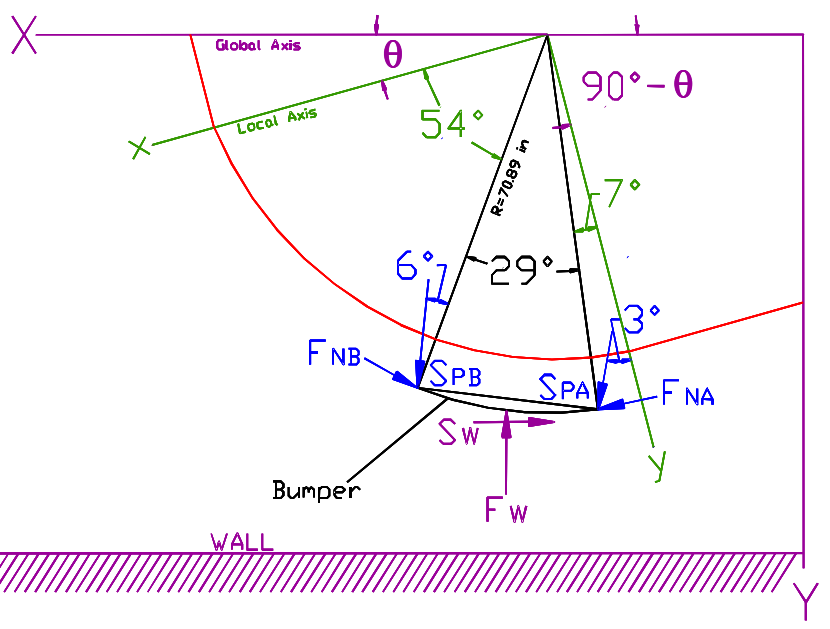

c. Forces acting on load bumper

Figure 1.9. Second configuration and recorded load direction 


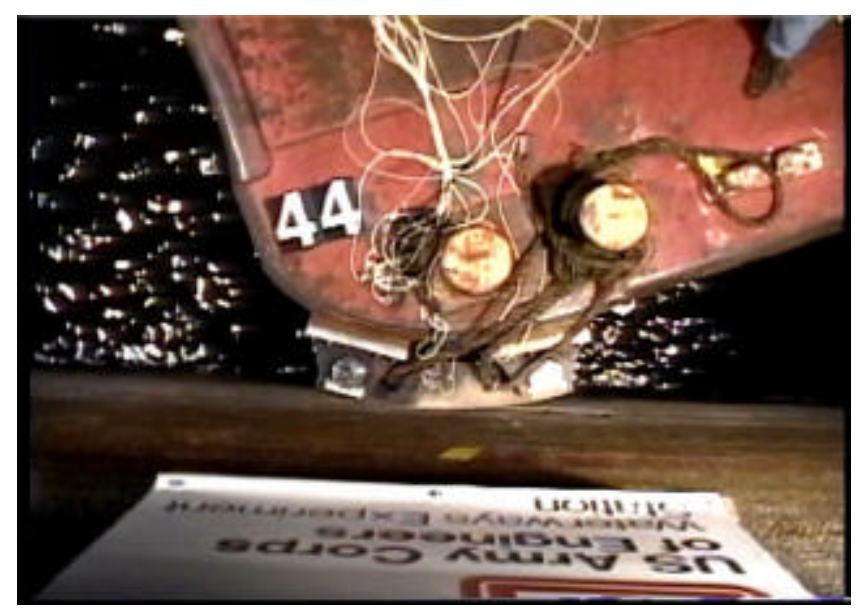

a. Overhead photo of barge with bumper about to impact the lock wall

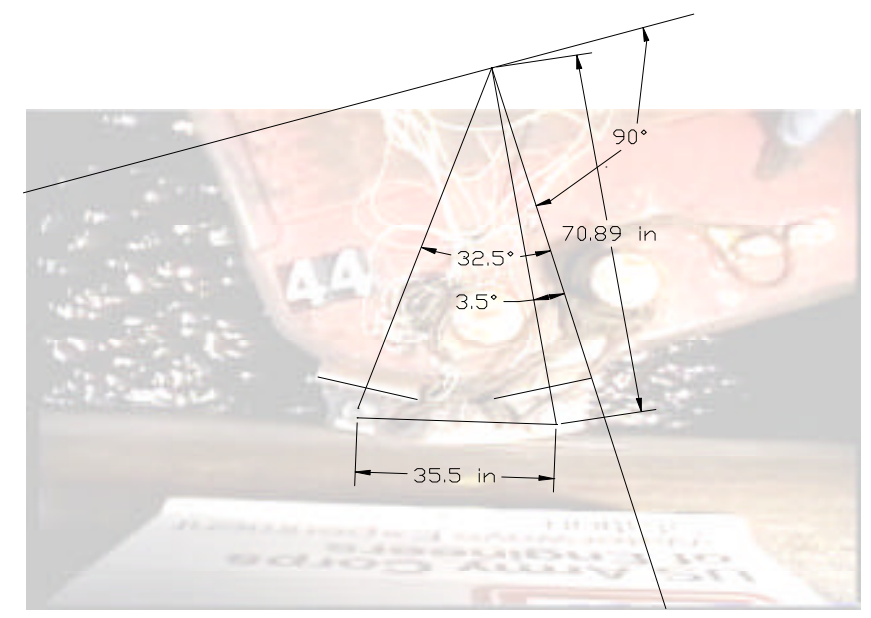

b. Arc geometry used for force analysis

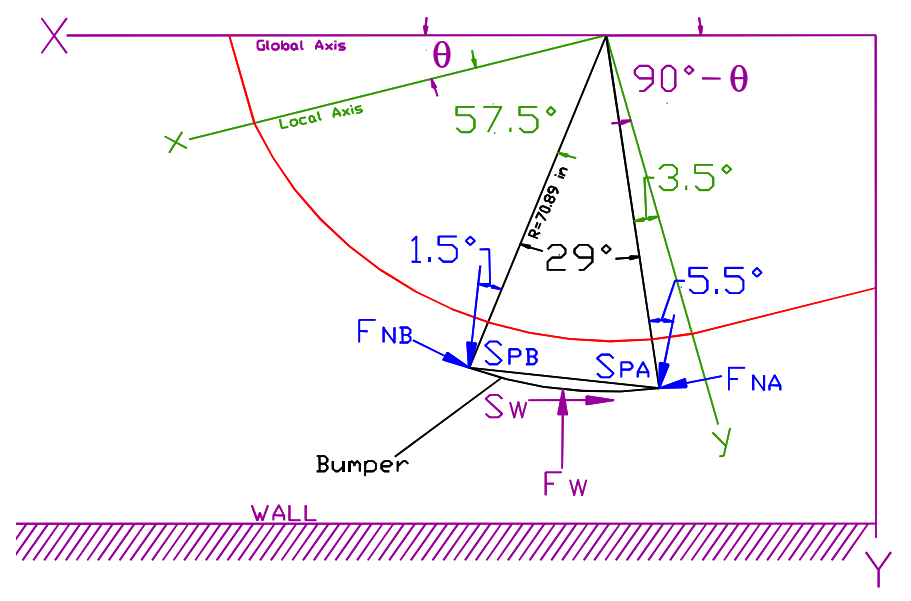

c. Forces acting on load bumper

Figure 1.10. Final configuration and recorded load direction 
The pair of unknown forces acting at the point of contact (during impact) between the bumper and the wall is designated as $F_{w}, S_{w}$. The unknown forces acting in the direction normal to the measured pin reaction forces are $F_{N A}$ and $F_{N B}$ at each of the pins. Four equations will be required to solve for these four unknown forces. The first three governing equations are the equilibrium equations:

$$
\begin{aligned}
& \sum F_{x}=0 \\
& \sum F_{y}=0 \\
& \sum M_{B}=0
\end{aligned}
$$

Two methods will be used to formulate the fourth equation. One of the methods investigated assumes a value for the coefficient of friction, $\mu$, between concrete and steel. This equation takes the form

$$
S_{w}=\mu * F_{w}
$$

This formulation will be referred to in the report as the equilibrium formulation with a fixed assumed value for the coefficient of friction. Note that this method fixes the value for $S_{w}$ to $F_{w}$ by this equation using the value assumed for $\mu$. This relationship, in conjunction with the three equations of equilibrium, is developed in Chapter 3 to solve for the four unknowns.

An alternative formulation investigated during the course of this research for the required fourth equation is referred to in this report as the energy method. The energy method uses Castigiliano's theorem, which states that the partial derivative of the total strain energy of the arc of the beam with respect to one external load is equal to the displacement in the direction of the external applied load. In this case (a first-degree indeterminate system), one of the support reactions was selected as the redundant. All the internal forces (axial, shear, and moment) were expressed in terms of the redundant force located in cell 10 (the front load cell). The additional equation is the displacement expression obtained from Castigiliano's theorem, which is equal to zero because the redundant was taken in the support. The relationship (developed in Chapter 4) results in the fourth equation, which is used in conjunction with the three equilibrium equations.

\subsection{Impulse and Linear Momentum Principle}

This report presents the analysis of the experimental results to obtain the applied forces to the lock wall due to the impact of a barge flotilla. The study of the motion of particles is based upon axioms and laws of nature gained from experience, first formulated by Isaac Newton. Newton's laws assume that one can define a frame of reference, which is fixed in space, called an inertial frame of reference or a Newtonian frame of reference. Only in this frame of reference 
will Newton's second law be valid. For most purposes, a frame of reference attached to a star will serve as an inertial reference frame. However, any nonrotating reference frame moving at a constant velocity relative to an inertial frame can also be considered an inertial frame.

The concept of mass arises in two of Newton's laws. In the second law, inertial mass is considered to be a measure of a particle's resistance to acceleration. In Newton's fourth law, gravitational mass is defined as the property of the particle that influences its gravitational attraction. Newton further assumed that these two concepts of mass were equivalent. The mathematical form of Newton's second law states that a resultant external force applied to a body is equal to the mass of the body multiplied by the absolute acceleration the body experiences. Also, it can be expressed in terms of the absolute velocity of the body by introducing the first derivative with respect to time of the velocity, which is the acceleration.

One useful tool that can be derived from Newton's second law, $F=m a$, is obtained by integrating both sides of the equation with respect to time. This integration can be done only if the forces acting on the particle are known functions of time. The external forces acting on the particle change the linear momentum. The mathematical form of the resulting expression after the process of integration states that the impulse during a period of time due to the applied impulsive force is equal to the difference in linear momentum during the same interval of time.

This relationship establishes the impulse and linear momentum principle. The units of both, impulse and momentum, are force and time, and therefore, impulse and momentum are expressed in N•s or kips $\bullet$. The impulsive force is a function of time and, in general, varies during its period of application. A large force that acts over a short period of time is called an impulsive force and occurs during phenomena such as the impact of a bat with a ball, collisions of cars, or a barge impacting a lock wall. If the average impulse force is zero, the linear momentum does not change during that interval of time.

The impulse and linear momentum principle will be used in the next chapters to develop a tool to determine the normal force in a lock wall due to the impact of a barge flotilla. It will be done by using the results from the full-scale, lowvelocity, controlled barge impact experiments at Robert C. Byrd Lock in December 1998. Several models were generated to determine the load that a barge applied to a lock wall, based on these experiments. The load between the barge and the wall was transferred by a curved beam mounted on the corner of the barge, as described in the preceding section. This indeterminate beam was analyzed using two approaches.

The first model that was developed considers the three global equilibrium equations - the equation that relates the shear force in the wall and the normal force in the wall due to the contact, and the axis transformation at both supports. Both terms, the normal and shear force in the wall, were related by the use of the dynamic coefficient of friction. A review of the technical literature indicates that the coefficient for steel-concrete interface typically ranges in value from 0.3 to 0.7. That is, the shear force is 0.3 to 0.7 the magnitude of the normal force. 
Values for the unknown forces were obtained by solving Equations 1.1 through 1.4. As shown in Figure 1.11, the known forces are the $F_{10}$ and $F_{11}\left(S_{P B}\right.$ and $S_{P A}$, respectively) measured during the experiments, and the unknowns are the shear force in the wall, the normal force in the wall, and the other two reactions at the pin supports. This model will be developed, explained, and validated in Chapter 3.

The second model consists of using the three global equilibrium equations (Eqs. 1.1-1.3), the equations obtained from an energy method, and the axis transformation at both supports. This means that the beam was considered as a deformable body and not as a rigid body (as is the case for the first model). This additional (fourth) equation was obtained from the global strain energy of the beam. The methodology used is also known in the mechanics of material field as the Castigliano's theorem, which states that the displacement in the direction of an external applied load can be calculated by differentiating the internal force equations with respect to the external load in the direction of the required displacement. In this problem, the selected force was one of the reactions providing that the displacement should be equal to zero. In Chapter 4, this model is presented and validated against results from finite element models of the bumper.

During the course of this research, three possible reaction force configurations acting on the bumper were studied, as was mentioned earlier. During the course of the study, these conclusions were reached:

a. The forces were not measured in the radial direction.

$b$. A possible configuration was estimated using design drawings and documentary photos.

c. A third configuration was adopted based on the reasonable values of coefficient of friction between concrete and steel and with the fact that the bumper must be in compression during impact.

Chapter 5 presents the comparisons of these three models. Each of the configurations is distinguished by

a. The fixed location where the bumper was attached relative to the longitudinal axis of the barges.

$b$. The orientations of the measured forces $F_{10}$ and $F_{11}$.

These three configurations are shown in Figures 1.12-1.14, respectively. Chapter 6 presents the use of the Impulse and Linear Momentum Principle as applied to our case, and the third configuration studied, shown in Figure 1.14. In this case, structural indeterminacy is related to the three external forces that were applied during the impact and were not measured. These forces are the drag force, the towboat force, and the helper boat force. With this principle, we have fewer equations than unknowns - thus, an indeterminate system. A simple approach was developed to calculate the forces applied to the wall based on the 


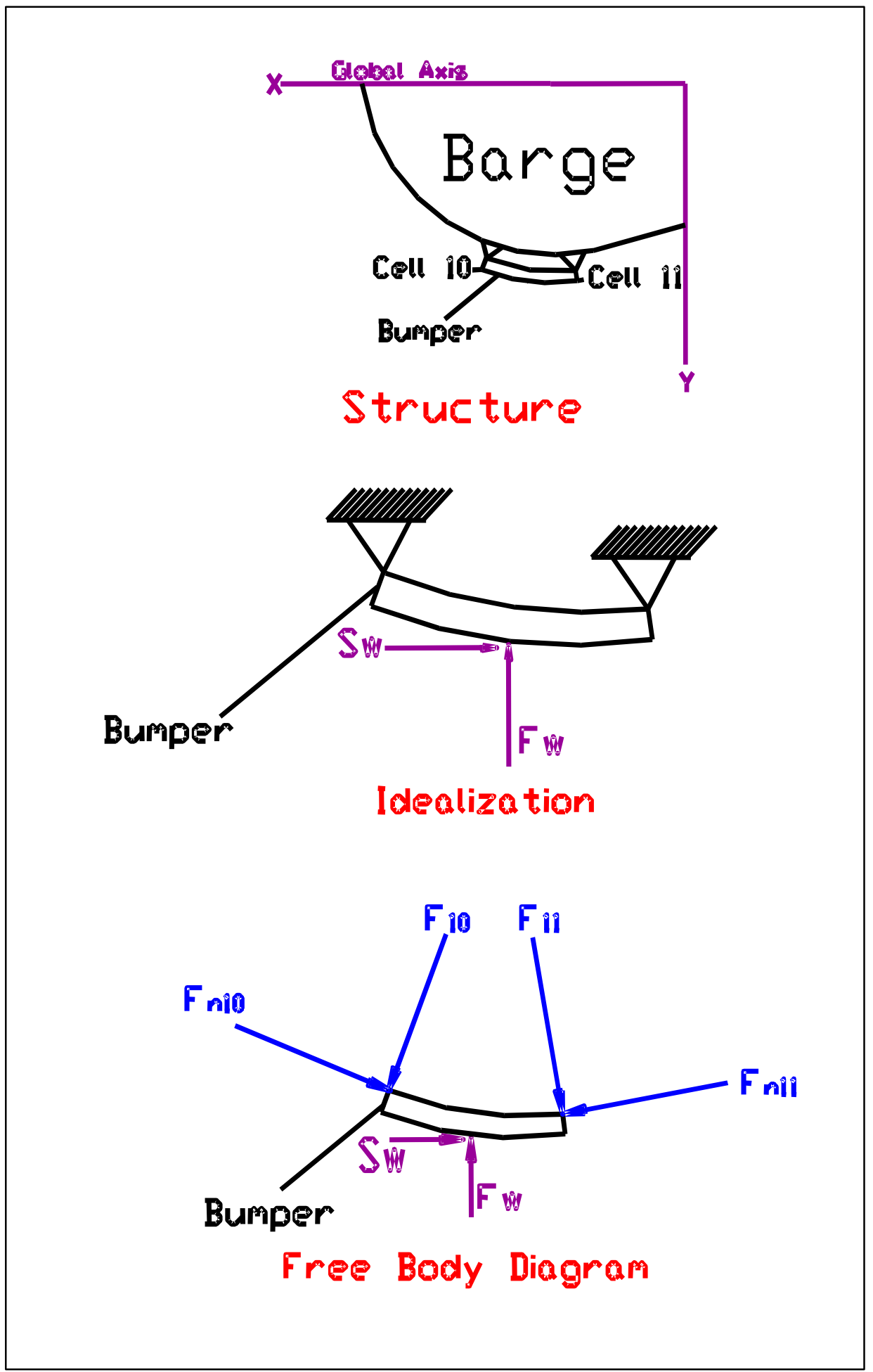

Figure 1.11. Idealization and free-body diagram of the bumper 


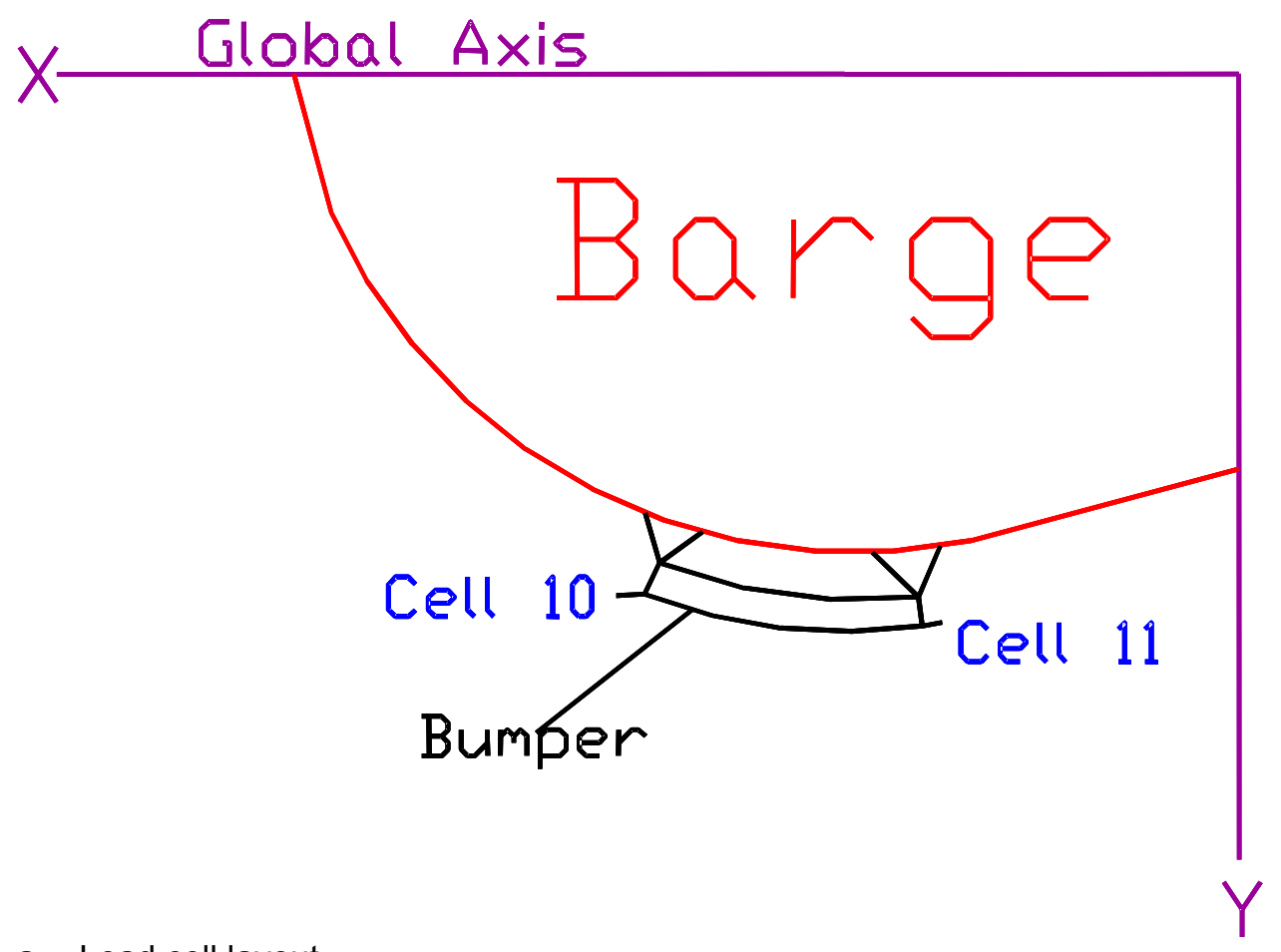

a. Load cell layout

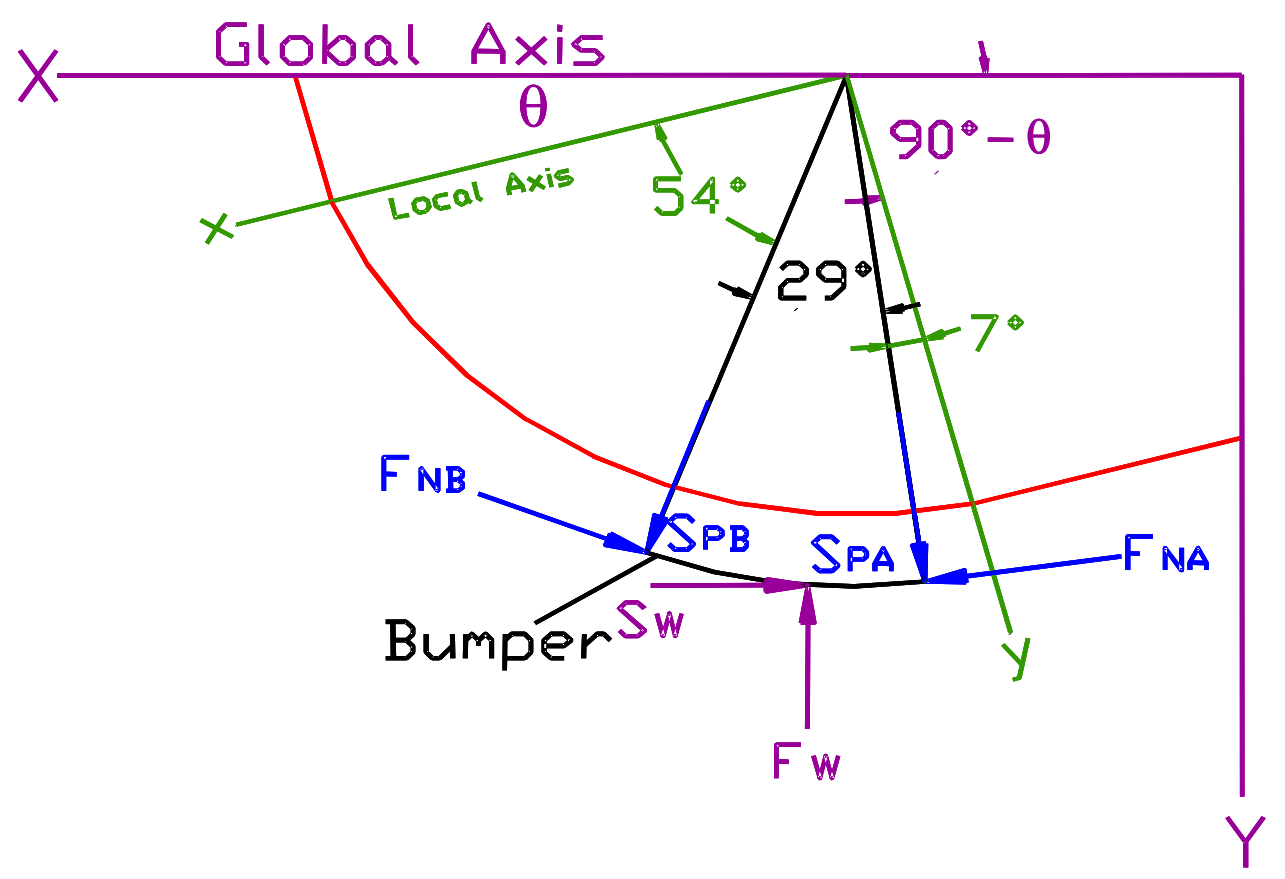

b. Configuration and forces acting on load bumper

Figure 1.12. Initial configuration and forces acting on load bumper 


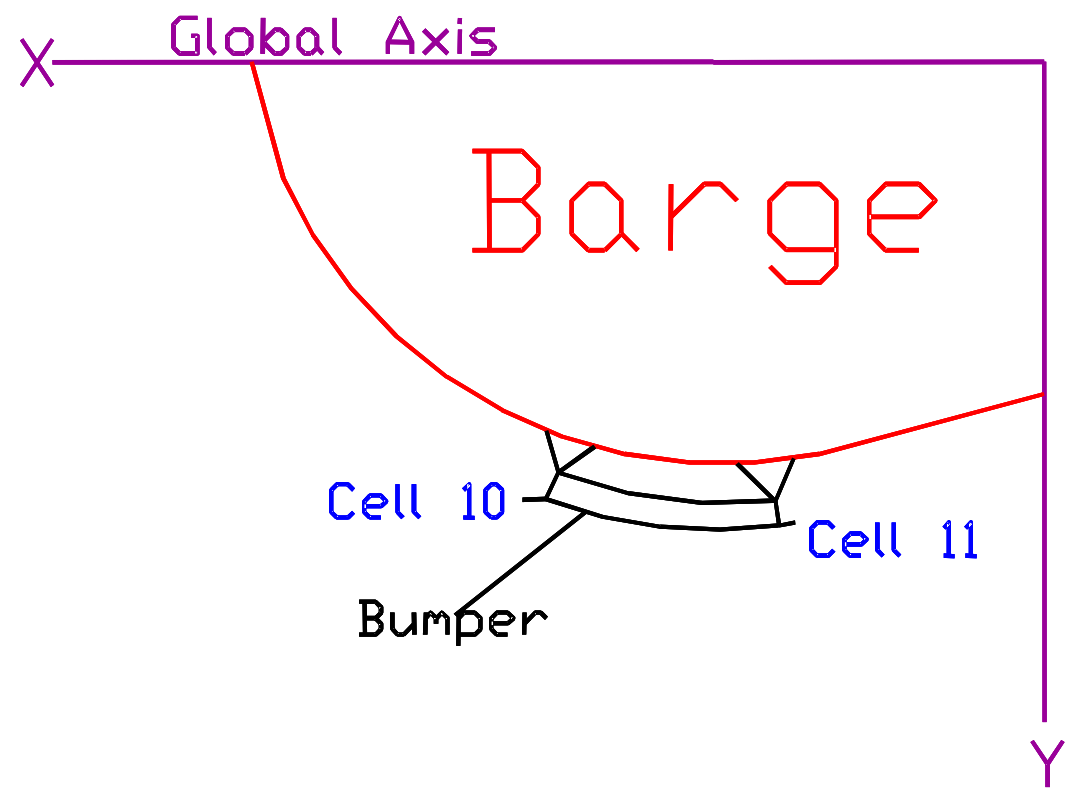

a. Load cell layout

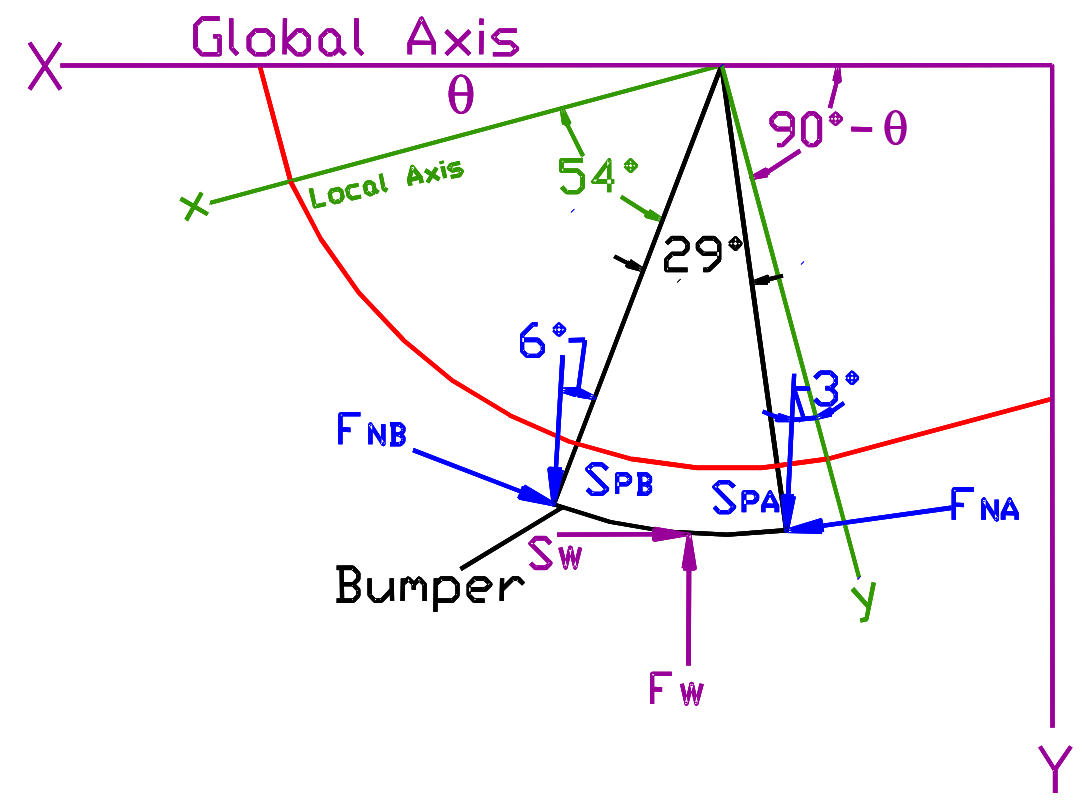

b. Configuration and forces acting on load bumper

Figure 1.13. Second configuration and forces acting on load bumper 


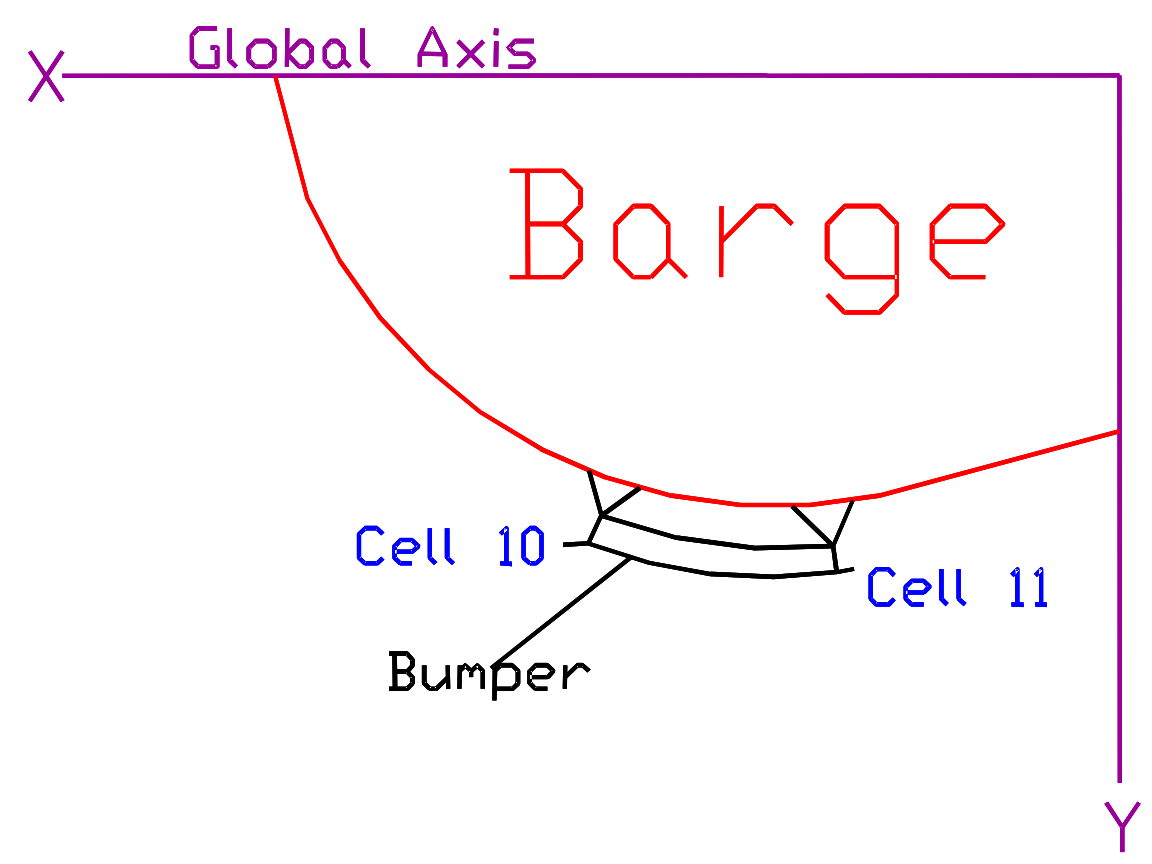

a. Load cell layout

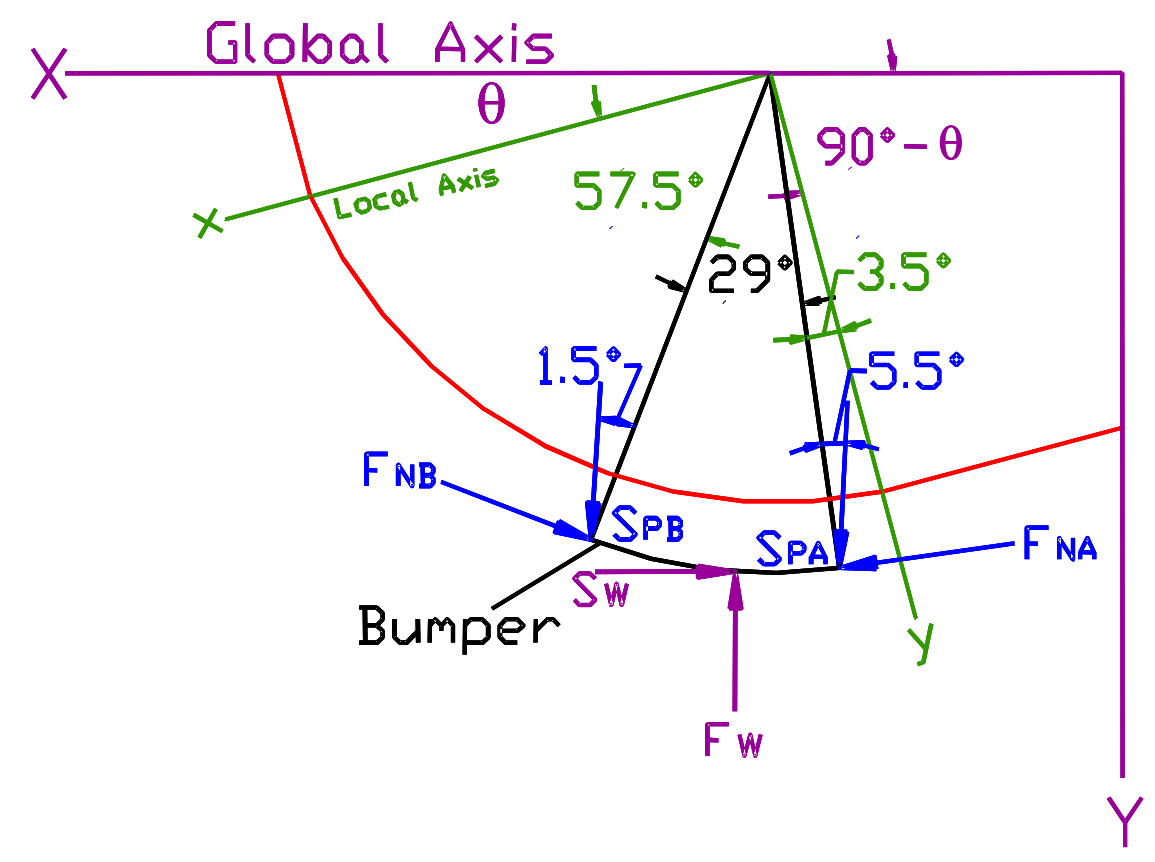

b. Configuration and forces acting on load bumper

Figure 1.14. Third and final configuration and forces acting on load bumper 
calculated force time-histories normal to the wall for eight of the 12 instrumented bumper experiments presented in Chapter 5. Chapter 7 suggests the layout for future experiments that would avoid the highest degree of indeterminacy of the system. Conclusions and recommendations for the numerical model developed in this study are presented in Chapter 8 .

Supplemental information on this research is presented in the four report appendixes: A, Summary of experimental results; B, FORTRAN source programs and Maple worksheets; C, Numerical integration; and D, Statistical theory. 


\section{Impulse and Linear Momentum Principle Applied to Barge Flotilla Model}

The principle of impulse and linear momentum for a system of particles moving relative to an inertial reference frame, as illustrated in Figure 2.1, is obtained from the equation of motion

$$
\sum \vec{F}_{i}=\sum m_{i} \vec{a}_{i}
$$

which can be expressed as

$$
\sum_{i=1}^{n} \vec{F}_{i}=\sum_{i=1}^{n} m_{i} \frac{d \vec{v}_{i}}{d t}
$$

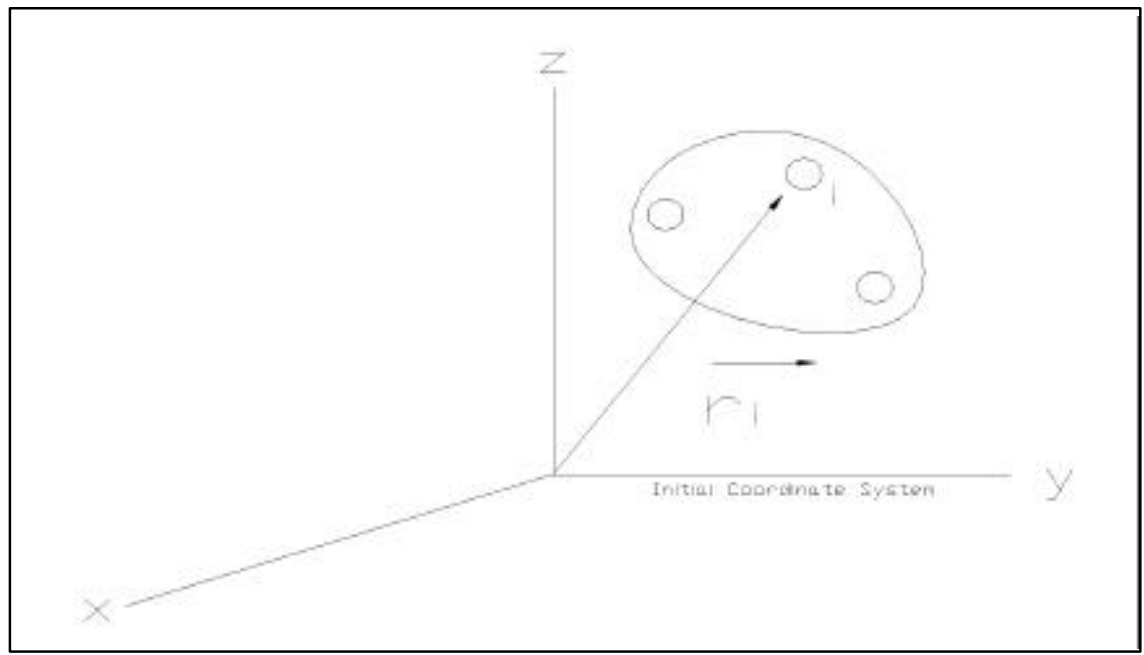

Figure 2.1. System of particles 
The term on the left side represents only the sum of all external forces acting on the system of particles. The internal forces between the particles do not appear with this summation, since by Newton's third law they occur in equal but opposite collinear pairs and therefore cancel out. Multiplying both sides by $d t$, and integrating between the limits time $t=t_{1}$, velocity $\vec{v}_{i}=\left(\vec{v}_{i}\right)_{1}$, and time $t=t_{2}$, velocity $\vec{v}_{i}=\left(\vec{v}_{i}\right)_{2}$, yields

$$
\sum_{i=1}^{n} m_{i}\left(\vec{v}_{i}\right)_{1}+\sum_{i=1}^{n} \int_{t_{1}}^{t_{2}} \vec{F}_{i} d t=\sum_{i=1}^{n} m_{i}\left(\vec{v}_{i}\right)_{2}
$$

Equation 2.2 states that the initial momentum of the system added vectorially to the impulse of all the "external forces" acting on the system during the time period $t_{1}$ to $t_{2}$ is equal to the system final linear momentum, where $t_{1}$ is the time when impact of the flotilla with the wall begins and $t_{2}$ is the time when the impact terminates (approximately $9 \mathrm{sec}$ after $t_{l}$ for the 11 most credible bumper experiments). If each of the vectors in Equation 2.2 is resolved into its $x, y$, and $z$ components, we can symbolically write the following three scalar equations:

$$
\begin{aligned}
& \sum_{i=1}^{n} m_{i}\left(v_{x_{i}}\right)_{1}+\sum_{i=1}^{n} \int_{t_{1}}^{t_{2}} F_{x} d t=\sum_{i=1}^{n} m_{i}\left(v_{x_{i}}\right)_{2} \\
& \sum_{i=1}^{n} m_{i}\left(v_{y_{i}}\right)_{1}+\sum_{i=1}^{n} \int_{t_{1}}^{t_{2}} F_{y} d t=\sum_{i=1}^{n} m_{i}\left(v_{y_{i}}\right)_{2} \\
& \sum_{i=1}^{n} m_{i}\left(v_{z_{i}}\right)_{1}+\sum_{i=1}^{n} \int_{t_{1}}^{t_{2}} F_{z} d t=\sum_{i=1}^{n} m_{i}\left(v_{z_{i}}\right)_{2}
\end{aligned}
$$

These equations represent the impulse and linear momentum principle for the system of particles in the $x, y$, and $z$ directions, respectively.

The flotilla-wall system consists of a rigid concrete wall, and 15 barges joined together by lashings form the assumed rigid body flotilla. The dynamic event occurs during the impact of the flotilla with the wall. Figure 2.2 shows the system to be analyzed in the global coordinates system.

The free-body diagram of the system is shown as Figure 2.3. Applying the Impulse and Linear Momentum Principle in the global coordinates, parallel and perpendicular to the wall, respectively, produces the following expressions:

$$
\begin{gathered}
m_{\text {flotilla }} v_{1 x}+\int_{t_{1}}^{t_{2}} F_{\text {tow }_{x}} d t-\int_{t_{1}}^{t_{2}} S_{w} d t-\int_{t_{1}}^{t_{2}} F_{\text {helper }_{x}} d t-\int_{t_{1}}^{t_{2}} F_{\text {drag }} d t \\
=m_{\text {flotilla }} v_{2 x} \quad \rightarrow \oplus
\end{gathered}
$$




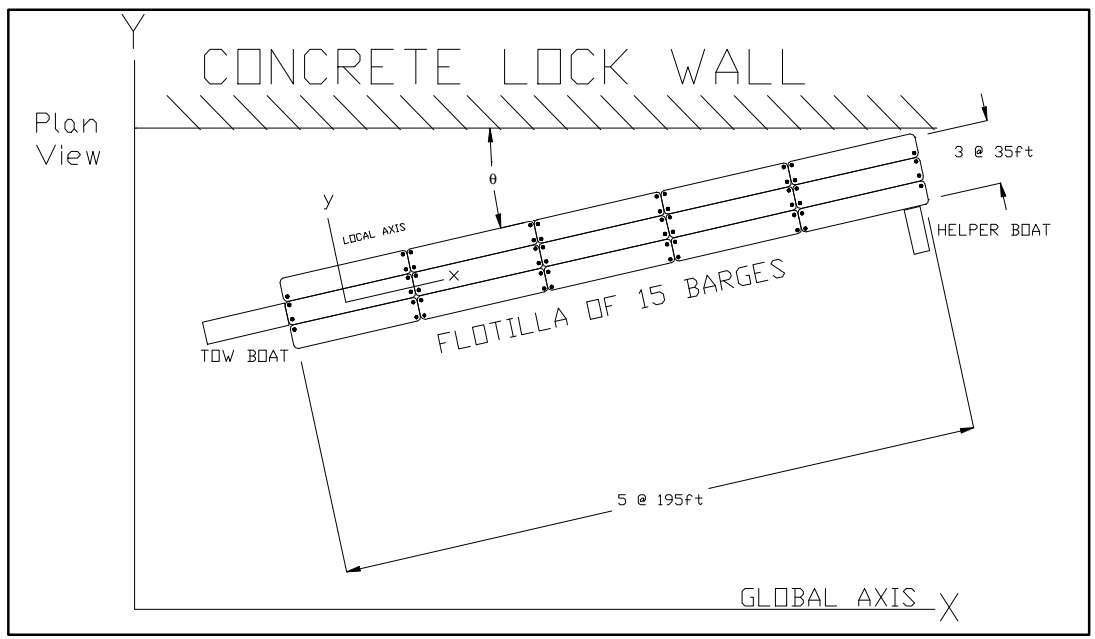

Figure 2.2. Flotilla-wall system

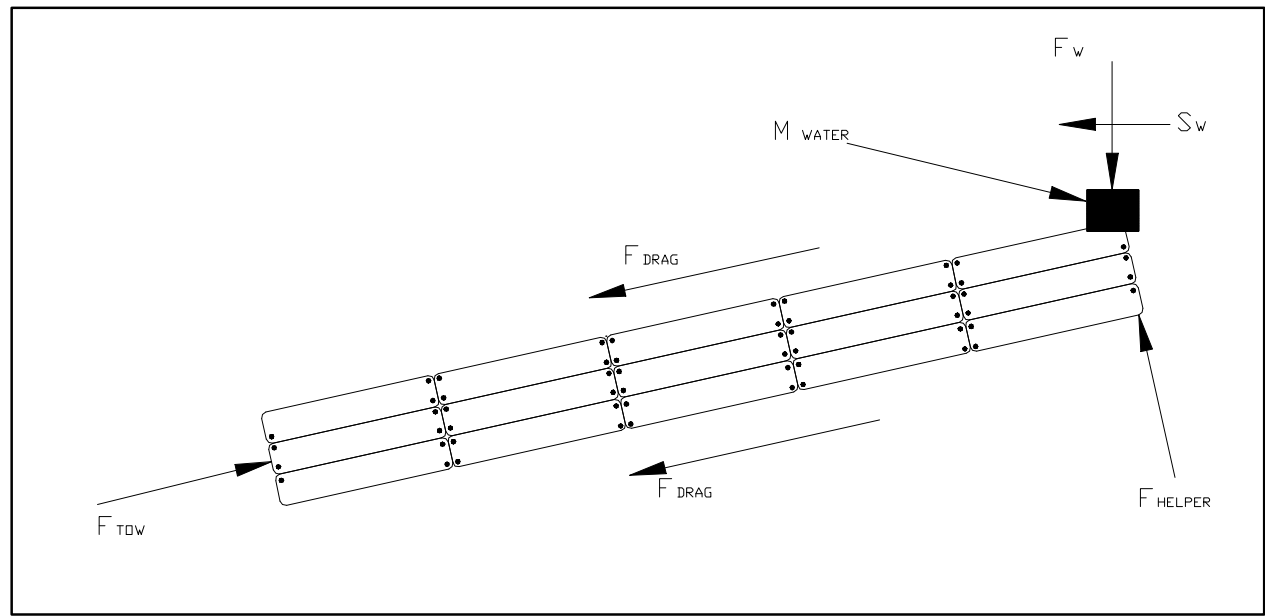

Figure 2.3. Free-body diagram of flotilla-wall system

$$
\begin{gathered}
m_{\text {flotilla }} v_{1 y}+\int_{t_{1}}^{t_{2}} F_{\text {tow }} d t-\int_{t_{1}}^{t_{2}} F_{w} d t+\int_{t_{1}}^{t_{2}} F_{\text {helper }} d t-\int_{t_{1}}^{t_{2}} F_{\text {drag }} d t \\
=m_{\text {flotilla }} v_{2 y} \quad \uparrow \oplus
\end{gathered}
$$

where

$$
\begin{aligned}
& m_{\text {flotilla }}=\begin{array}{l}
\text { mass of the flotilla (including the tow boat and the helper } \\
\text { boat }
\end{array} \\
& F_{\text {tow }}=\text { force the tow boat applies to the flotilla during impact }
\end{aligned}
$$


$S_{w} \quad=\quad$ shear force parallel to the wall during impact with the front corner of the barge as the flotilla slides along the wall

$F_{\text {helper }}=$ force the helper boat applies to the flotilla during impact

$F_{\text {drag }}=$ total drag force on the flotilla as it moves through the water during impact

$F_{w} \quad=$ force component normal to the wall during impact with the front corner of the barge as the flotilla slides along the wall

The force provided by the towboat can be estimated using the power definition. Power is defined as the amount of work performed per unit of time, and can be expressed as

$$
P=\frac{d U}{d t}=\vec{F} \bullet \vec{v}=F v \cos \phi
$$

where $\phi$ is the angle between the force and velocity vector.

If the power is known during the time interval from $t_{1}$ and $t_{2}$, then, $F_{\text {tow }}$ can be calculated as

$$
F_{\text {tow }}=\frac{P}{v_{1}} \therefore \quad \phi=0^{\circ}
$$

Then, the components of this force in the global coordinate system are

$$
\begin{aligned}
& F_{\text {tow }_{x}}=\frac{P_{\text {tow }}}{v_{1}} \cos \theta \\
& F_{\text {tow }_{y}}=\frac{P_{\text {tow }}}{v_{1}} \sin \theta
\end{aligned}
$$

An additional modification to these expressions has to be made to take into account the fact that the power that affects the system being considered is the power provided by the propeller to the water, and not the power provided by the engine to the propeller. However, similar expressions can be used to define the force applied to the water by the propeller. In the same way, the force provided by the helper boat can be estimated using this approach. Then, the force provided by the helper boat to the system can be calculated by the following expressions:

$$
\begin{aligned}
& F_{\text {helper }_{x}}=\frac{P_{\text {helper }}}{v_{1}} \sin \theta \\
& F_{\text {helper }_{y}}=\frac{P_{\text {helper }}}{v_{1}} \cos \theta
\end{aligned}
$$


Note that to use these expressions for the forces $F_{\text {tow }}$ and $F_{\text {helper }}$, the power terms $P_{\text {tow }}$ and $P_{\text {helper }}$ must reflect the power that the propellers of the tow and helper boats provide to the water (and not the power the engines provide to the propeller shafts of the tow and helper boats) during the approximately $9 \mathrm{sec}$ of impact with the lock wall. Measurements leading to the definition of these power terms were not made during the full-scale, low-velocity, controlled barge impact experiments at Robert C. Byrd Lock in December 1998.

The drag force is a resistance force that the water presents opposite to the motion of the flotilla. To calculate this force, it is necessary to introduce hydrodynamics terminology and technology (e.g., see Martin 1989, p 33).

All these forces $\left(F_{\text {tow }}, S_{w}, F_{\text {helper }}, F_{\text {drag }}\right.$, and $\left.F_{w}\right)$ produce impulse to the system. In addition, the added mass of water due to the approach of the barge to the wall must be included. The additional mass added to the system due to this effect compared with the mass of the flotilla is unknown at this time. This effect is presented in Figure 2.3 as a concentrated mass in the point of impact between the bodies. This water mass has the effect of cushioning the impact.

The hydrodynamic effect due to the approach of the flotilla to the wall (motion of mass of water) can be included as a change in linear momentum of the water particle. Now, considering that the flotilla travels almost with constant velocity before and after impact in these experiments, the Impulse and Linear Momentum Principle for this system of particles can be illustrated as shown in Figure 2.4.

Following Figure 2.4, Equations 2.6 and 2.7 can be written as

$$
\begin{gathered}
m_{\text {flotilla }} v_{1} \cos \theta+\int_{t_{1}}^{t_{2}} F_{\text {tow }} \cos \theta d t-\int_{t_{1}}^{t_{2}} S_{w} d t-\int_{t_{1}}^{t_{2}} F_{\text {helper }} \sin \theta d t \\
-\int_{t_{1}}^{t_{2}} F_{\text {drag }} \cos \theta d t=m_{\text {flotilla }} v_{2} \cos \theta \\
\left(m_{\text {flotilla }}-m_{\text {water }}\right) v_{1} \sin \theta+\int_{t_{1}}^{t_{2}} F_{\text {tow }} \sin \theta d t-\int_{t_{1}}^{t_{2}} F_{w} d t \\
+\int_{t_{1}}^{t_{2}} F_{\text {helper }} \cos \theta d t-\int_{t_{1}}^{t_{2}} F_{\text {drag }} \sin \theta d t=m_{\text {flotilla }} v_{2} \sin \theta
\end{gathered}
$$

where the effect of the (hydrodynamic) cushioning "force" was introduced, reducing the initial linear momentum by subtracting the mass of water.

Finally, rearranging terms, we obtain

$$
\begin{aligned}
& m_{\text {flotilla }} v_{1} \cos \theta-m_{\text {flotilla }} v_{2} \cos \theta+\int_{t_{1}}^{t_{2}} F_{\text {tow }} \cos \theta d t-\int_{t_{1}}^{t_{2}} F_{\text {helper }} \sin \theta d t \\
& -\int_{t_{1}}^{t_{2}} F_{\text {drag }} \cos \theta d t=\int_{t_{1}}^{t_{2}} S_{w} d t
\end{aligned}
$$



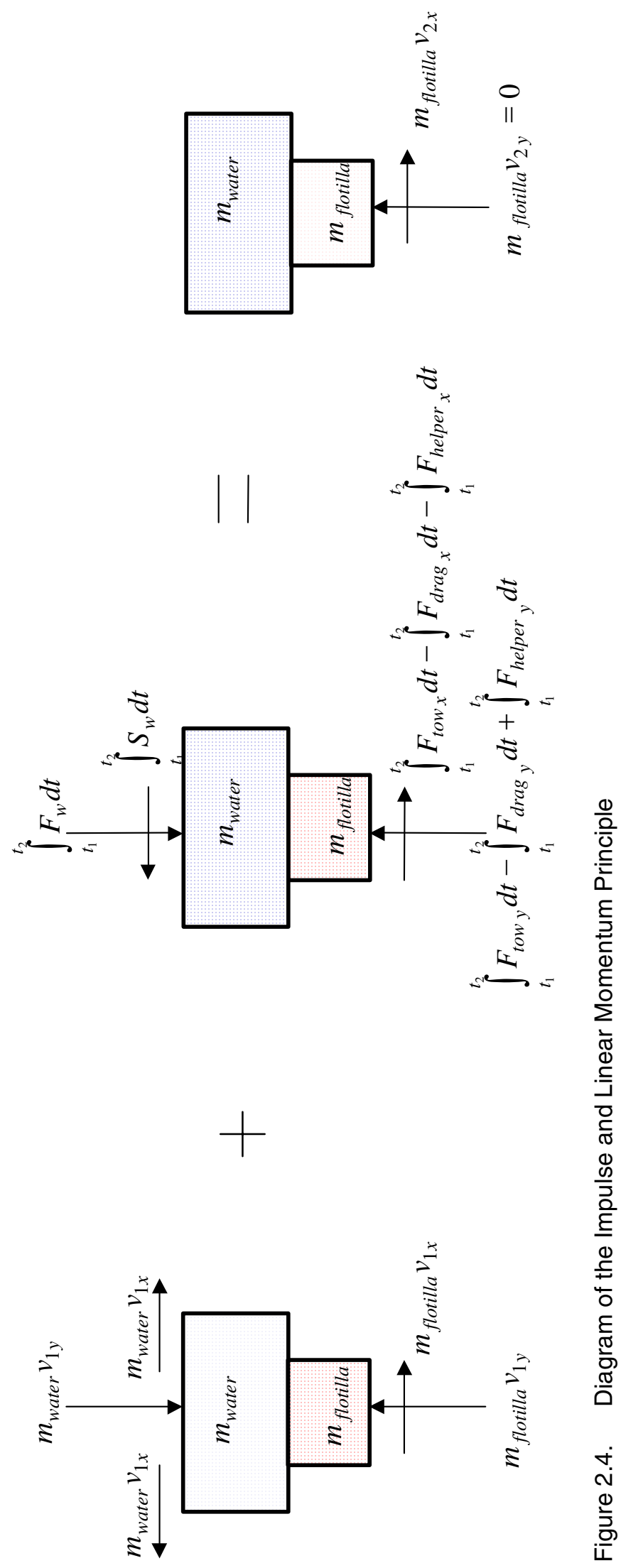


$$
\begin{aligned}
\left(m_{\text {flotilla }}-m_{\text {water }}\right) v_{1} \sin \theta & +\int_{t_{1}}^{t_{2}} F_{\text {tow }} \sin \theta d t+\int_{t_{1}}^{t_{2}} F_{\text {helper }} \cos \theta d t \\
& -\int_{t_{1}}^{t_{2}} F_{\text {drag }} \sin \theta d t=\int_{t_{1}}^{t_{2}} F_{w} d t
\end{aligned}
$$

One important detail regarding Equation 2.17 is that the velocity normal to the wall during impact is equal to zero. Thus, the linear momentum normal to the wall is also zero during impact (that is, from $t_{1}$ to $t_{2}$ ). Then, Equations 2.16 and 2.17 provide the impulse due to the shear and normal force in the wall during impact, respectively.

Measurements leading to the definition of the forces $F_{\text {tow }}, F_{\text {helper }}$, and $F_{\text {drag }}$ and the hydrodynamics added-mass term $m_{\text {water }}$ were not made during the fullscale, low-velocity, controlled barge impact experiments at Robert C. Byrd Lock in December 1998. However, measurements were made during these experiments leading to the definition of forces $S_{w}$, and $F_{w}$ and will be discussed in subsequent chapters. 


\section{Equilibrium Formulation with Assumed Coefficient of Friction}

\subsection{Background}

To apply the Impulse and Linear Momentum Principle as presented in Equations 2.16 and 2.17, it is necessary to determine the normal force timehistory applied to the wall and the shear force acting along the wall during the impact. The determination of these time-histories can be done using the timehistories recorded during the experiments. These time-histories were obtained from the pin load cells located at the supports of the curved beam bumper. The recorded force time-histories, designated as $F_{10}$ and $F_{11}$, are presented in Appendix A. The model presented herein considers the recorded load in the radial direction of the circular arc beam. It was the initial specification, from those in charge of the experiments, of the first assumed geometrical configuration to be analyzed in this study. Using this first model, a procedure to determine the unknown external loads for the indeterminate circular arc is presented in this chapter. Later, in Chapter 5, the analysis using this procedure with two other configurations will be presented.

The structural "bumper" system consists of a circular arc beam with a constant rectangular cross section made of A-36 steel. The instrumented bumper is shown in Figure 3.1. This pin-pin connection produces an indeterminate structure to the first degree. As shown in Figure 3.2, the four unknowns are the normal force in the wall, the shear force in the wall, and two support reactions that were not recorded during the experiments $\left(F_{N 10}\right.$ and $\left.F_{N 11}\right)$. The two known forces are the $F_{10}$ and $F_{11}$, which were assumed in this first model to act in the radial direction. Using Figure 3.3, the three equilibrium equations in global coordinates are

$$
\begin{aligned}
& \rightarrow \oplus \quad \sum F_{x}=0 \therefore \quad A_{x}+B_{x}-S_{w}=0 \\
& \uparrow \oplus \quad \sum F_{y}=0 \therefore \quad A_{y}+B_{y}-F_{w}=0
\end{aligned}
$$




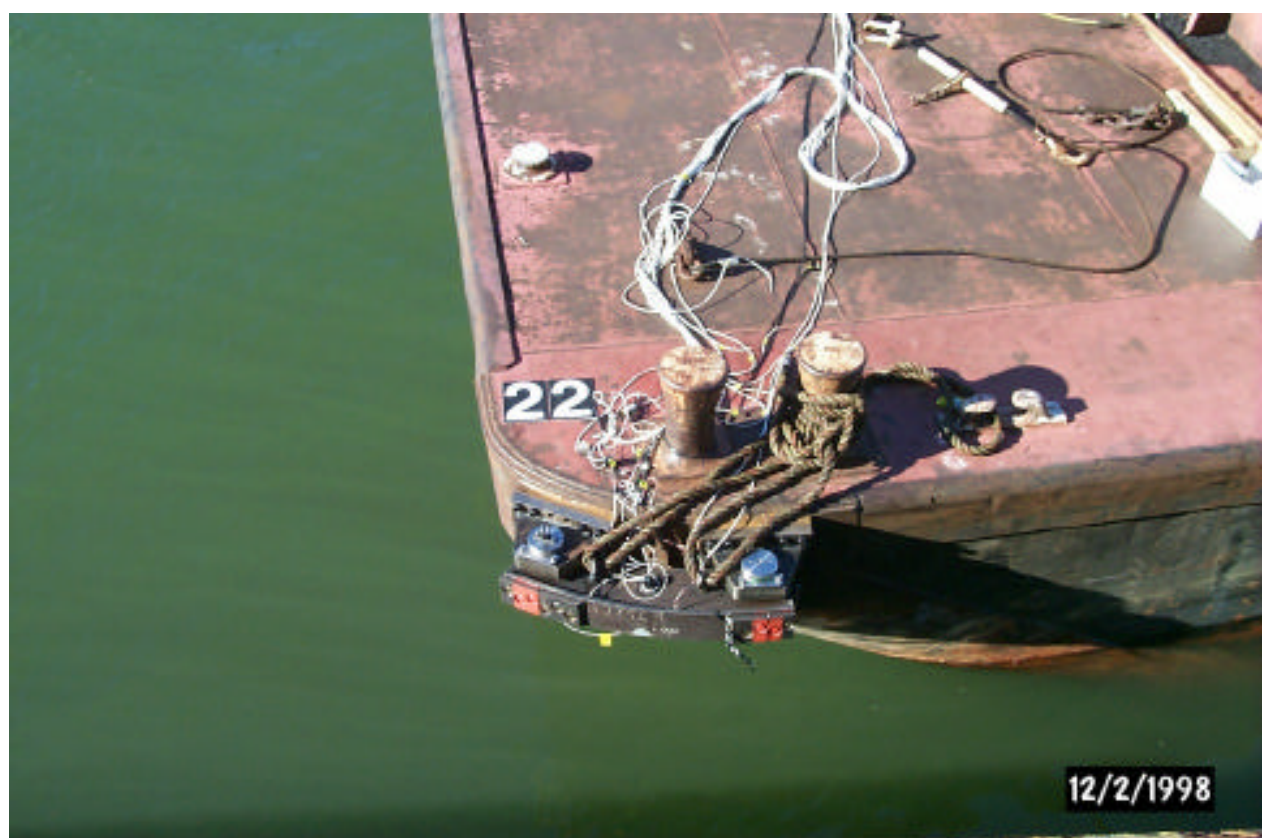

Figure 3.1. Instrumented circular arc beam (bumper)

$$
\begin{aligned}
\sum M_{A}= & 0 \therefore F_{w} R \cos (97-\theta)-S_{w} R[1-\sin (97-\theta)] \\
& -B_{y} R[\cos (54+\theta)+\cos (97-\theta)] \\
& -B_{x} R[\sin (97-\theta)-\sin (54+\theta)]=0
\end{aligned}
$$

In addition to the three equilibrium equations, it is possible to introduce the axis transformation from local to global coordinates. These four new equations are

$$
\begin{aligned}
& A_{x}=F_{N A} \cos (\theta-7)-S_{P A} \sin (\theta-7) \\
& A_{y}=F_{N A} \sin (\theta-7)+S_{P A} \cos (\theta-7) \\
& B_{x}=-F_{N B} \cos (36-\theta)+S_{P B} \sin (36-\theta) \\
& B_{y}=F_{N B} \sin (36-\theta)+S_{P B} \cos (36-\theta)
\end{aligned}
$$

Note that in these four equations, the use of angles 7 and 36 deg establishes that the orientation of the bumper is $54 \mathrm{deg}$ relative to the longitudinal axis of the barges (local axis) and also defines the orientation of the pairs of reaction forces at each pin, which can be observed in Figure 3.3. 


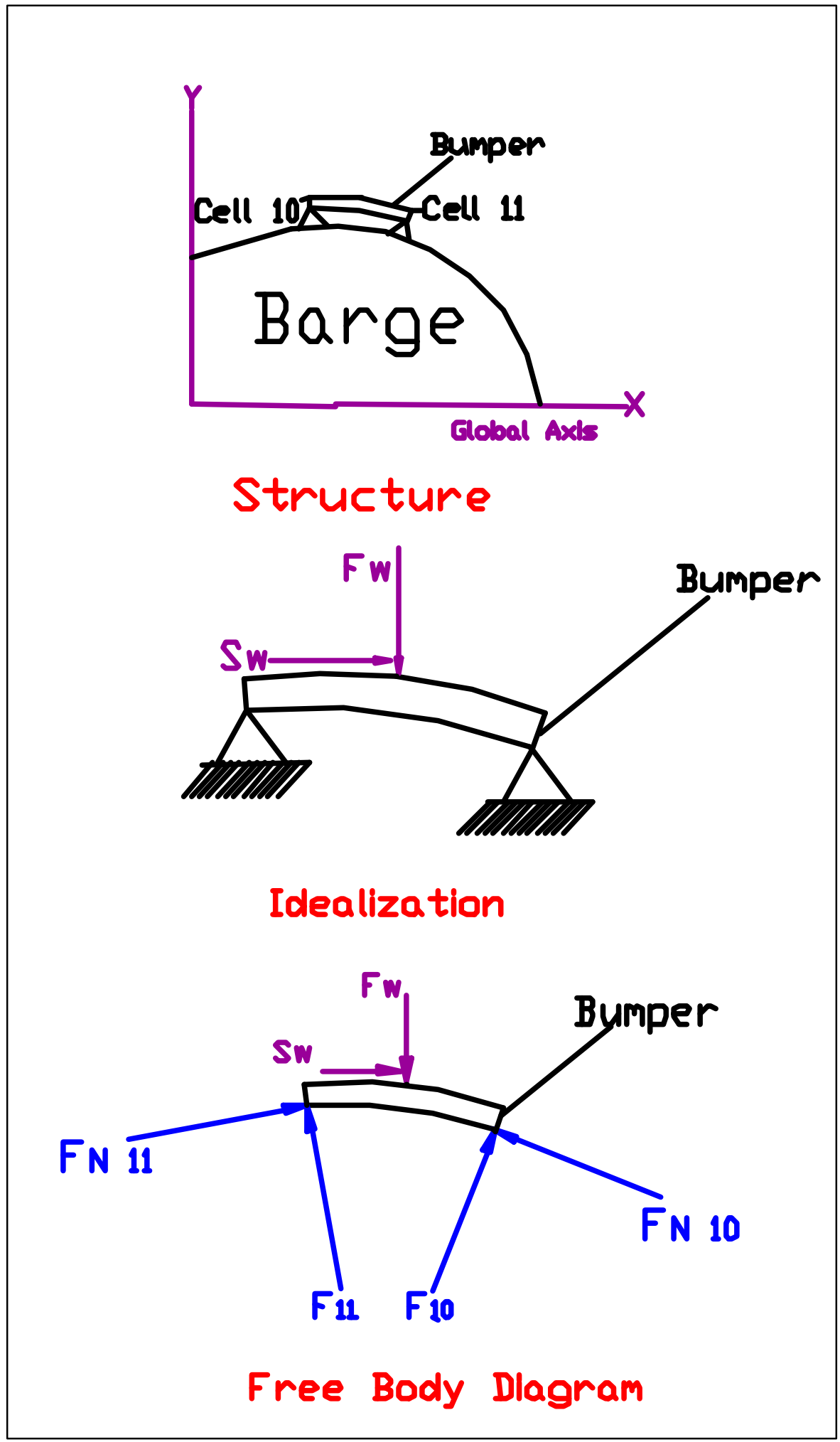

Figure 3.2. Structure, idealization, and free-body diagram of the bumper for the assumed coefficient of friction method 


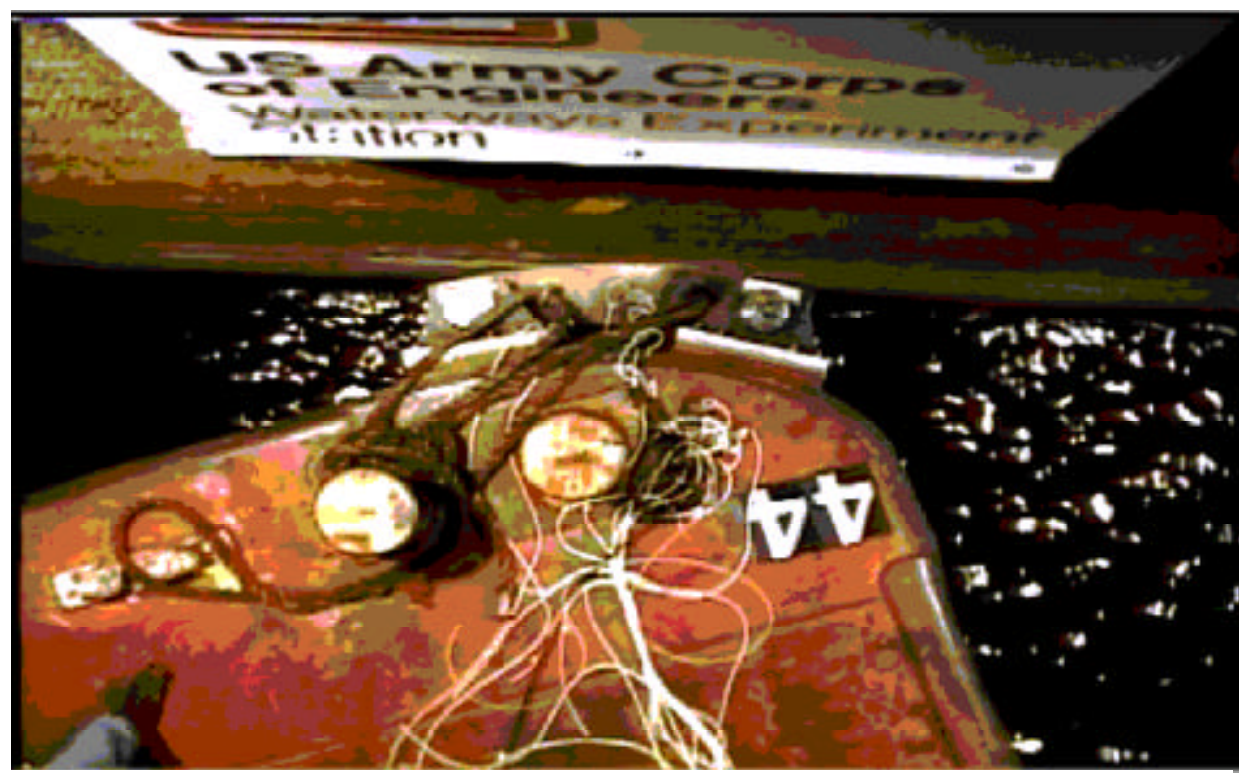

a. Overhead photo of the barge with bumper about to impact the lock wall

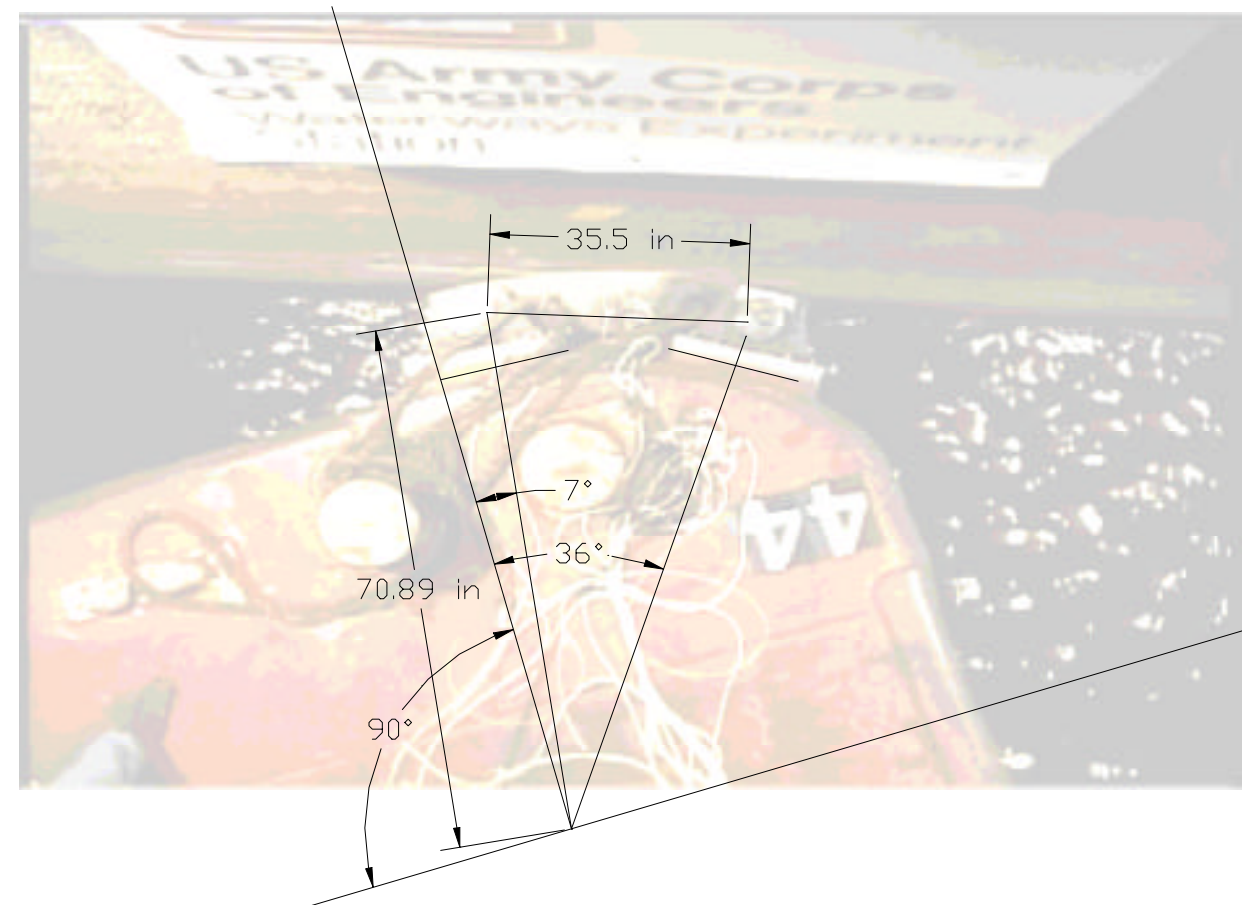

b. Arc geometry used for force analysis

Figure 3.3. Free-body diagram used in the first configuration model (Assumed Coefficient of Friction Method) (Continued) 


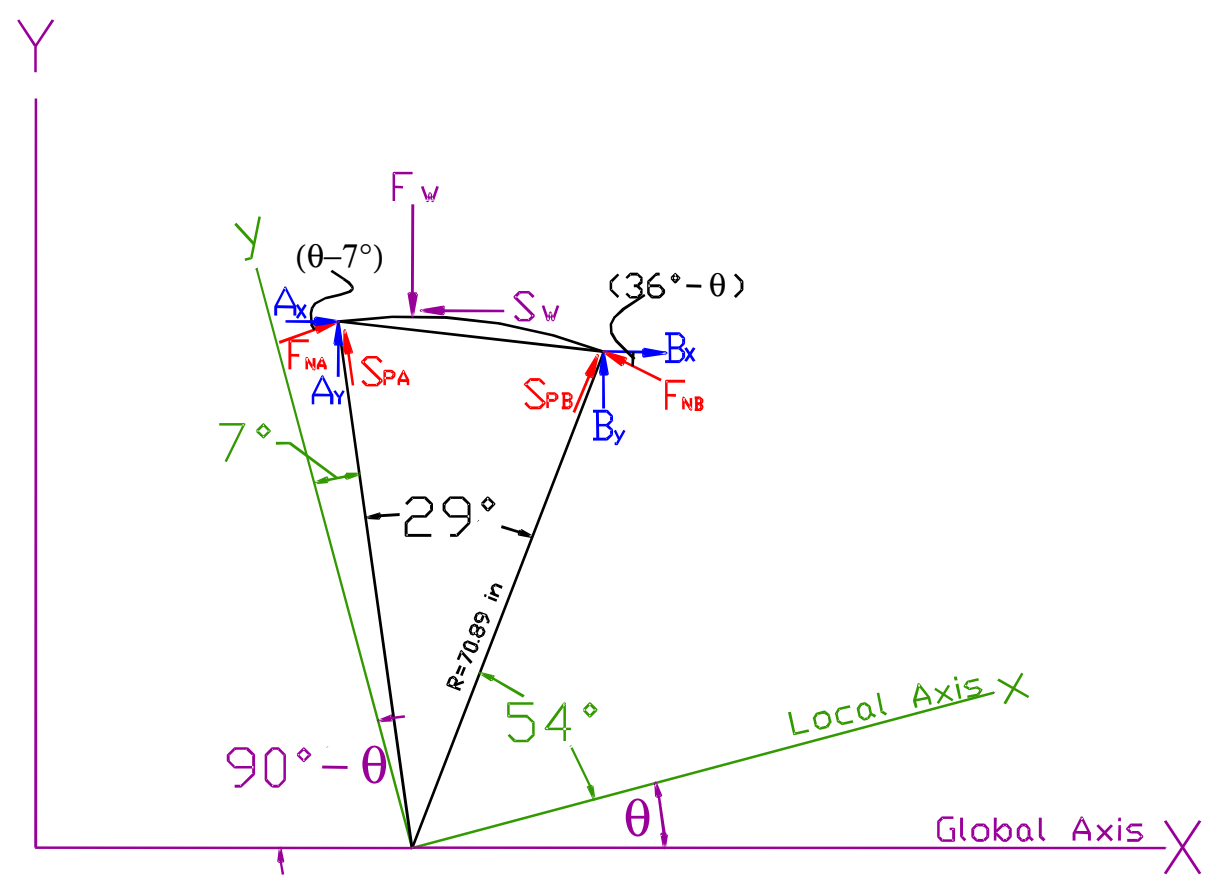

c. Forces acting on load bumper

Figure 3.3. (Concluded)

One additional equation is introduced to produce a determinate system. As was found in the review of the technical literature, the value for dynamic coefficient of friction between steel and concrete is usually within the range of 0.3 to 0.7 . An additional equation being used is

$$
S_{w}=\mu_{k} F_{w}
$$

Solving these eight equations, the problem is transformed to a determinate system. Now the known forces are $S_{P A}$ (load cell 11) and $S_{P B}$ (load cell 10), which are the radial forces measured during the experiments ( $F_{11}$ and $F_{10}$, respectively). The unknowns are the reactions in global coordinates $\left(A_{x}, A_{y}, B_{x}\right.$, and $\left.B_{y}\right)$, the forces in the wall $\left(F_{w}\right.$ and $\left.S_{w}\right)$, and the two reactions normal to the cross section of the beam in local coordinates $\left(F_{N A}\right.$ and $\left.F_{N B}\right)$.

Three computer software programs were developed to calculate these forces. First, a spreadsheet using Excel was built. Second, a Maple worksheet was created to calculate numerically and symbolically the expressions for $F_{w}$ and $S_{w}$. Finally, a FORTRAN computer program was developed to compute the load time-histories for the experiments.

To determine if the results provided by the proposed formulation are accurate, two finite element models of the bumper were studied using the computer programs SAP2000 (Computer \& Structures, Inc. 2000) and VisualAnalysis (Integrated Engineering Software 1998). The models were constructed fixing the approach angle $\theta$ to 18 and $21.5 \mathrm{deg}$. Thus, we have the same structure but with different positions in the global coordinate system. 
Figure 3.4 shows the idealization of the bumper structure, and Figures 3.5 and 3.6 show the arc layout for the VisualAnalysis and SAP2000 model for $\theta$

$=18 \mathrm{deg}$, respectively. The properties of the beam elements used in these models are as follows:

Cross-sectional area $=45$ in. $^{2}$ Modulus of elasticity $=29,000 \mathrm{ksi}$
Moment of inertia $=303.75$ in. $^{4}$

Cord length $=35.5$ in.

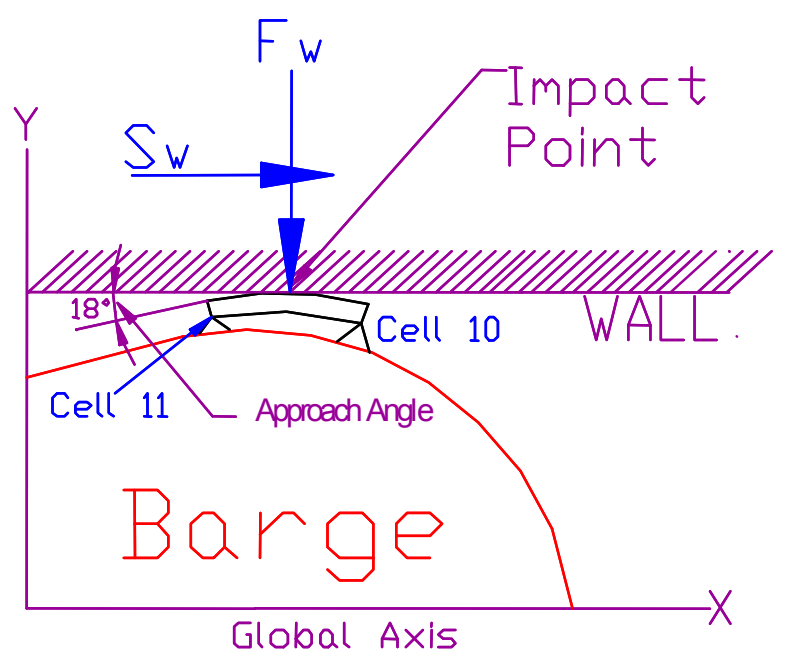

Figure 3.4. Idealization of the bumper structure for the finite element analysis

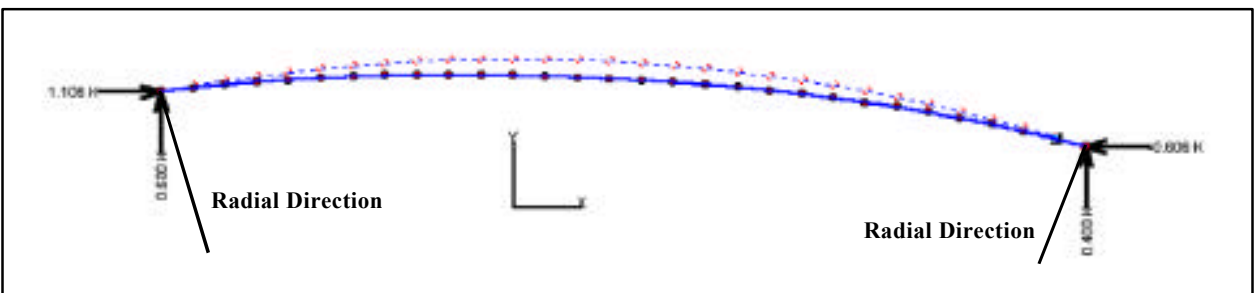

Figure 3.5. VisualAnalysis arc bumper model for $\theta=18 \mathrm{deg}$

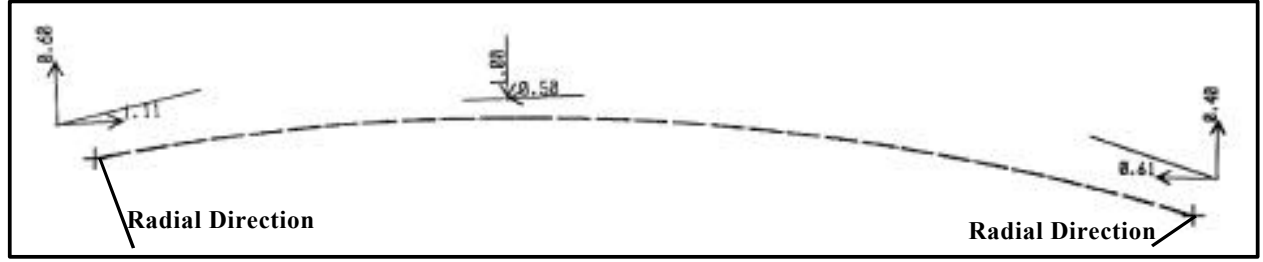

Figure 3.6. SAP2000 arc bumper model for $\theta=18 \mathrm{deg}$ 
The sectional properties were calculated using the dimensions 5 by 9 in. for the arc bumper. The external applied loads were 1.0 kips for $F_{w}$ and 0.50 for $S_{w}$. These are assumed values, which correspond to a coefficient of friction of 0.50 . The support reactions were obtained from the finite element analysis. Using the support reactions obtained from the VisualAnalysis and SAP2000 analyses, the proposed formulation was used to calculate the external applied loads $\left(F_{w}\right.$ and $\left.S_{w}\right)$. The results produced by each of the three models are presented in Tables 3.1 and 3.2 .

The procedure used in these analyses is as follows:

a. An assumed $F_{w}$ and $S_{w}$ value was adopted based on a coefficient of friction of 0.5. These are the shaded cells (input data for the model) in the last two rows in Tables 3.1 and 3.2.

$b$. The $\theta_{1}$ (load cell 11) and $\theta_{2}($ load cell 10$)$ values are the resulting approach angles used in the finite element analysis at each support. These are different from the exact values $\theta=18 \mathrm{deg}$ and $\theta=21.5 \mathrm{deg}$, for Table 3.1 and 3.2, respectively, because the arc is modeled using straight-line elements. One important observation is that the average of $\left(\theta_{1}+\theta_{2}\right)$ produces the exact approach angle value used in the equilibrium and fixed coefficient of friction method. [For example: (21.030 deg $+21.970 \mathrm{deg}) / 2=21.5 \mathrm{deg}$.]

c. Using these values as input data, the supports' reactions were calculated in the global direction using the SAP2000 and VisualAnalysis programs, as shown in Figures 3.5 and 3.6.

d. The forces that are needed in the Equilibrium and Fixed Coefficient of Friction method are the radial direction forces $\left(F_{10}\right.$ and $\left.F_{11}\right)$ - the same as the recorded forces during the experimental procedure in 1998. Using Equations 3.4-3.7, the values of $S_{P A}$ (load cell 11) and $S_{P B}$ (load cell 10) can be calculated.

e. Using these two forces and an approximate approach angle as input data (shaded cells in the Equivalent and Fixed Coefficient of Friction method), the $F_{w}$ and $S_{w}$ forces are calculated.

$f$. Finally, the resulting coefficient of friction obtained using the Equivalent and Fixed Coefficient of Friction method is the same, $\mu_{\mathrm{k}}=0.5$, as was assumed initially in the finite element analyses.

From Tables 3.1 and 3.2, we can observe good agreement between the first developed model (equilibrium formulation with a fixed value for the coefficient of friction) and the finite element models. One important point is that the arc was modeled in the finite element model using straight lines. Because of this, the initial and final angles for the arc at the support reaction differ for the equilibrium and fixed coefficient of friction model by a half-degree. For the model developed in this research, the angle $\theta_{1}$, and $\theta_{2}$ changed by small amounts, as shown in Tables 3.1 and 3.2. These small changes did not affect the computed results. This 


\begin{tabular}{|c|c|c|c|c|}
\hline$\underset{\frac{\pi}{0}}{\frac{\pi}{0}}$ & * & $\begin{array}{l}8 \\
\text { \&. } \\
0\end{array}$ & ్ํㅇ & 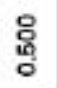 \\
\hline 플 & के & $\begin{array}{l}8 \\
\text { 品 } \\
0\end{array}$ & 总 & $\begin{array}{l}8 \\
\stackrel{8}{\circ} \\
\text { a }\end{array}$ \\
\hline$\frac{\coprod}{\sigma}$ & $w^{3}$ & $\stackrel{8}{8}$ & $\stackrel{8}{\circ}$ & $\stackrel{8}{\circ}$ \\
\hline$\frac{0}{0}$ & $\alpha^{2}$ & $\underset{\substack{\mathrm{g} \\
\mathrm{g}}}{\mathrm{g}}$ & 占 & 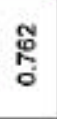 \\
\hline $\begin{array}{l}\frac{0}{0} \\
\frac{0}{0} \\
0\end{array}$ & $\alpha^{\Sigma}$ & $\underset{7}{\stackrel{7}{\tau}}$ & $\stackrel{\bar{y}}{\bar{y}}$ & సָ ָָ \\
\hline $\begin{array}{l}8 \\
\frac{0}{0} \\
6\end{array}$ & ตั & $\begin{array}{l}\text { 号 } \\
\text { f } \\
0\end{array}$ & 苂 & 움 \\
\hline 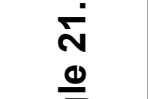 & $\Phi^{*}$ & $\begin{array}{l}8 \\
6 \\
8\end{array}$ & $\begin{array}{l}0 \\
8 \\
0 \\
9\end{array}$ & $\begin{array}{l}8 \\
\stackrel{\circ}{\circ} \\
9\end{array}$ \\
\hline 인 & $\&$ & $\begin{array}{l}\text { \% } \\
\text { : }\end{array}$ & స్ & $\begin{array}{l}\text { o. } \\
\text { : } \\
0\end{array}$ \\
\hline $\begin{array}{l}0 \\
\stackrel{0}{0} \\
\frac{0}{2}\end{array}$ & $z$ & 옹 & 8 & $\stackrel{8}{\stackrel{8}{7}}$ \\
\hline & $\stackrel{0 \%}{50}$ & 络 & 总 & 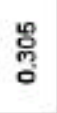 \\
\hline 占 & क्रे & 颁 & 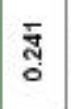 & ֻू \\
\hline 은 & $u^{\frac{\pi}{2}}$ & 웅 & : & g: \\
\hline 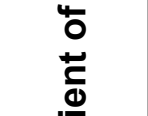 & $u_{u^{5}}^{5}$ & $\stackrel{\mathbb{g}}{\underset{7}{\tau}}$ & $\stackrel{\circledast}{=}$ & $\stackrel{\frac{\pi}{2}}{\longrightarrow}$ \\
\hline 㐫 & $\begin{array}{c}\infty \\
i \\
\vdots \\
1 \\
1 \\
0 \\
0\end{array}$ & 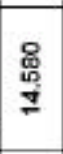 & 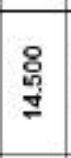 & 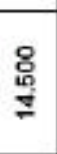 \\
\hline 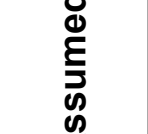 & $\begin{array}{l}1 \\
1 \\
i \\
1 \\
5\end{array}$ & $\begin{array}{l}\text { đ্ } \\
\text { J }\end{array}$ & 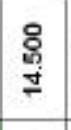 & $\begin{array}{l}\stackrel{8}{0} \\
\underset{\ddagger}{*}\end{array}$ \\
\hline $\begin{array}{l}\text { 区ं } \\
\frac{0}{5}\end{array}$ & $\infty$ & $\frac{\text { สู่ }}{\text { ल }}$ & $\frac{8}{4}$ & $\frac{8}{\stackrel{4}{*}}$ \\
\hline 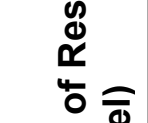 & $\mathcal{E}$ & $\frac{\text { శ్ }}{\frac{\pi}{N}}$ & $\frac{8}{\frac{R}{N}}$ & $\frac{\mathfrak{o}}{\mathrm{N}}$ \\
\hline 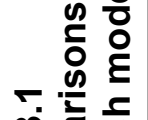 & 5 & $\frac{\text { đु }}{\pi}$ & 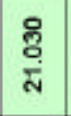 & 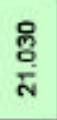 \\
\hline 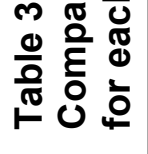 & 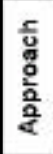 & 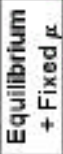 & 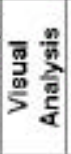 & : \\
\hline
\end{tabular}

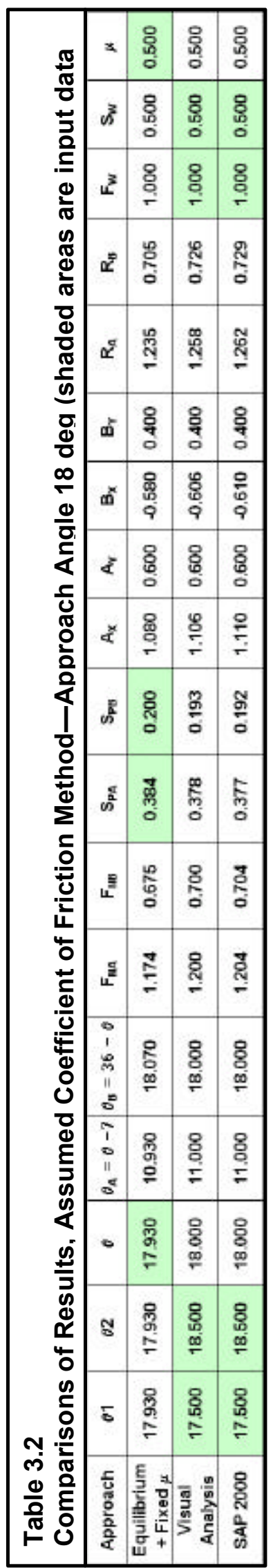


analysis provides an independent check of the accuracy of the Equilibrium and Fixed Coefficient of Friction method because, using the results from the finite element analyses as input data in the proposed method, the same coefficient of friction was obtained $\left(\mu_{k}=0.5\right)$.

This numerical model solves for the unknowns, by using the $S_{P A}$ (at pin A where load cell 11 is located) and $S_{P B}$ (at pin B where load cell 10 is located) as input data. In any traditional arc beam the known values are the applied forces, and the unknown values are the support reactions. This means that, in this problem, we are going in an inverse direction as in the traditional problems. One special case was found in the solution process of the numerical model presented in this chapter, and must be mentioned. The special case occurs when the approach angle $\theta$ has a value that produces impact at the midpoint between the supports, and the same magnitude for the input data $\left(S_{P A}\right.$ at pin A where load cell 11 is located and $S_{P B}$ at pin B where load cell 10 is located) forces is used. In the case presented in this chapter, the value of $\theta$ that produces this situation is $18.5 \mathrm{deg}$. If the same input forces are used for an approach angle of $18.5 \mathrm{deg}$, the model will produce unreasonable results for the unknowns. This results because it is impossible to have the same support reactions if the two applied loads are placed at the center of the arc. The behavior of the arc when the horizontal load $S_{w}$ is applied is to produce a different distribution of support reactions as if only the normal force $F_{w}$ is applied.

\subsection{Baltay and Gjelsvik (1990) Concrete-to-Steel Coefficient of Friction Results}

In order for the model presented in this chapter, which is based on an assumed coefficient of friction, to be successful, it is necessary to adopt a realistic value for the coefficient of friction. Based on the literature research that was conducted, the range of coefficient that could be acceptable ranges in value from 0.13 to 0.70 . Table 3.3 presents different values for the static coefficient of friction and for the kinetic coefficient of friction, found or adopted in other research. In the current study, the kinetic coefficient of friction was in this magnitude for two reasons. First, the low-velocity problem moves this coefficient to approach the static value. Second, the contact area ( 5 by 7.25 in. $=36.25$ in. $^{2}$ ) produces normal stresses in a range found in other research, which produces a coefficient of friction in this range. The normal stress in all experiments was between 7.03 and $17.63 \mathrm{ksi}$, as shown in Chapter 5. The magnitudes of stress in each experiment are high and agree with the stresses presented in other research, which produced a coefficient of friction in the range mentioned above.

Baltay and Gjelsvik (1990) conducted a study that dealt with the coefficient of friction for steel on concrete at high normal stress. These researchers concluded that the average coefficient of friction between the machined mild steel and concrete was found to be 0.47 for stress levels between 1 and 68,000 psi, as shown in Figure 3.7. Also, the coefficient of friction for a mill scale steel surface is less than that for the machined surface for stress levels below 10,000 psi, as shown in Figure 3.8. It was observed that, at medium stress levels of 100 to $1,000 \mathrm{psi}$, the steel surfaces were heavily scratched while the 


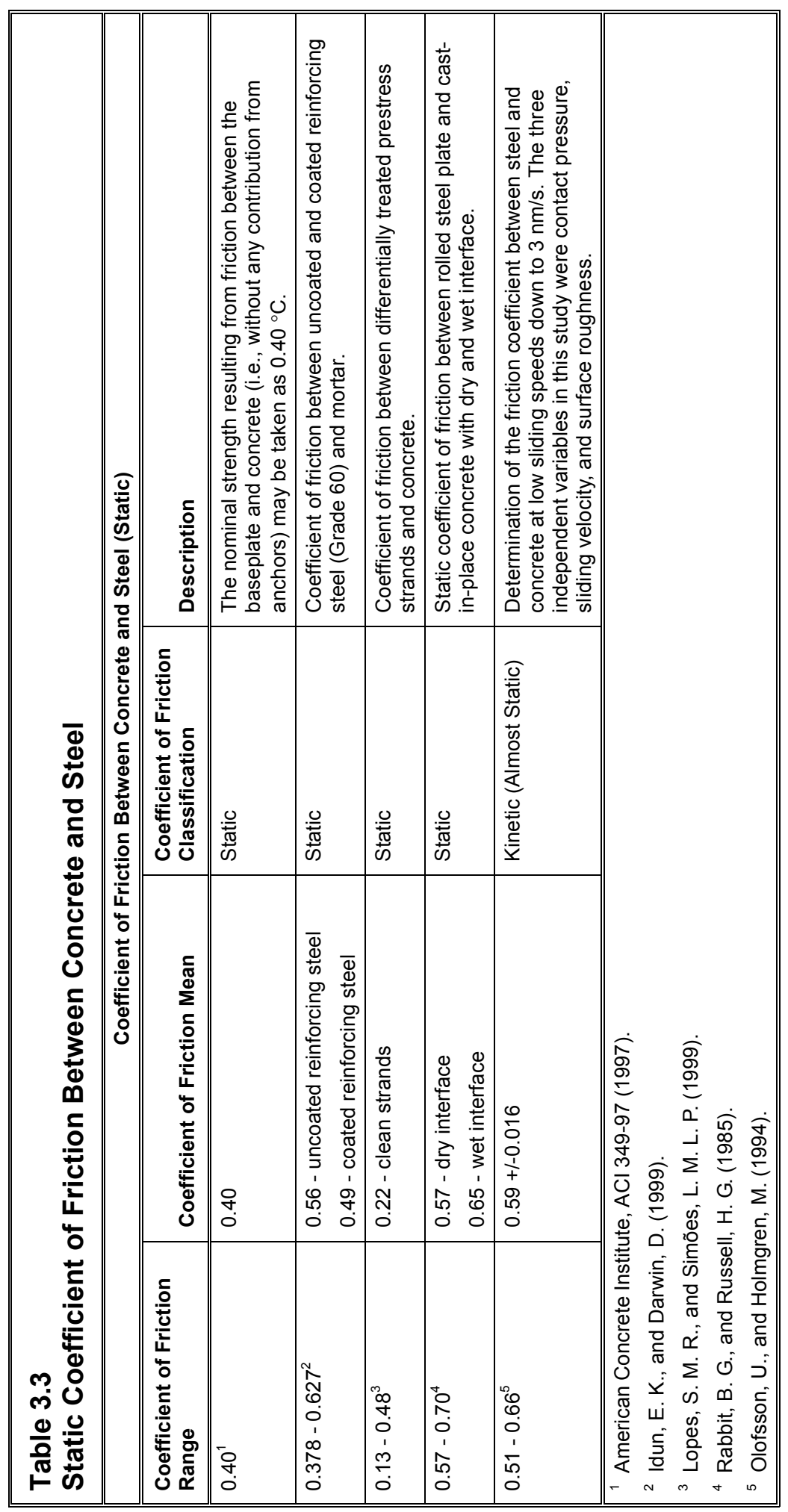




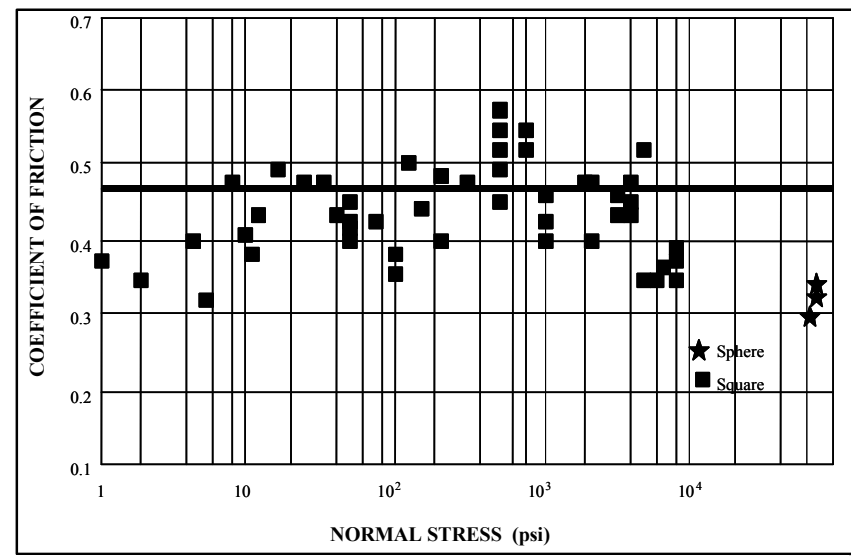

Figure 3.7. Coefficients of friction for machined mild steel surface (after Figure 3 Baltay and Gjelsvik 1990)

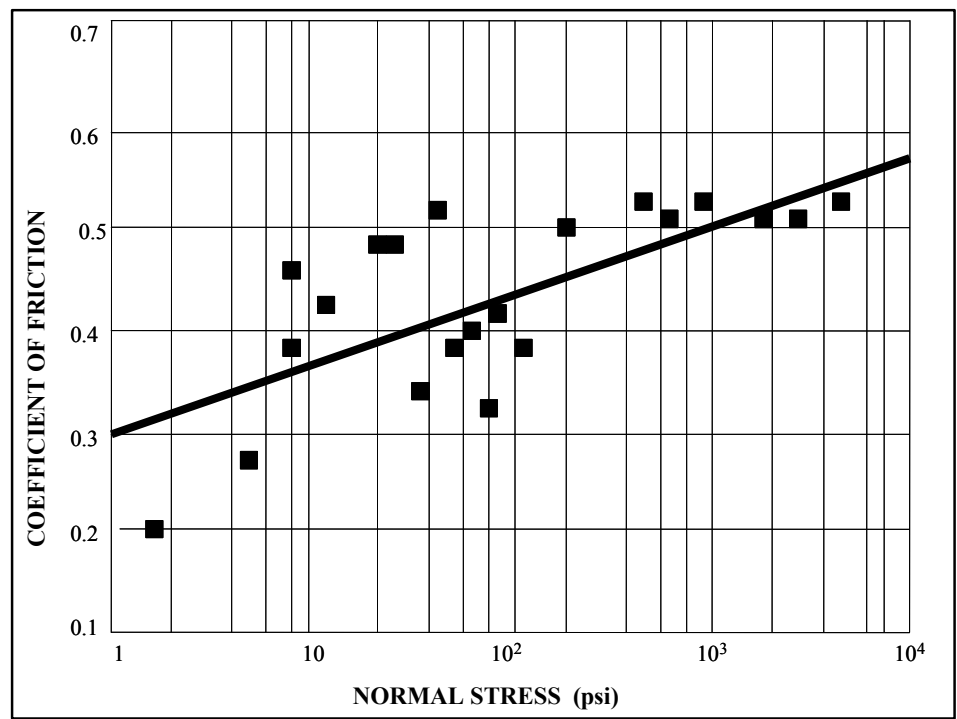

Figure 3.8. Coefficients of friction for mild steel surface with mill scale (after Figure 4 of Baltay and Gjelsvik 1990)

concrete was (or appeared to be) unscathed. Steel particles were left behind on the concrete.

In addition, Baltay and Gjelsvik concluded that, at high stress levels, above $10,000 \mathrm{psi}$, the steel gouged into the concrete. When the steel was removed, small sand particles from the concrete were found between the steel and concrete. Finally, the orientation of the machining cuts on the steel surface had no effect on the coefficient of friction, and the coefficients of friction obtained are very close to values obtained by other authors at low stress levels (Rabbat and Russell 1985) and in classic experiments of steel on stone. 
Friction is a phenomenon of plastic surface yielding (Bowden and Tabor 1950). Between two different materials, friction is due in part to the deformation of one of the materials. With steel and concrete, it appears that the steel yields to the harder particles in the concrete mixture, resulting in gouges in the steel. However, at higher stress levels as the concrete begins to crush, small particles are locally torn free from the concrete, and the steel begins to plow a path through the concrete. It seems that the value of the coefficient of friction is governed by the steel, that is, by the local plowing of hard particles through the steel. This was also confirmed by the tests with mill scale. The mill scale is harder than the steel and is therefore not penetrated by the concrete particles at stress levels, resulting in a lower coefficient of friction. As shown in the second row of Table 3.4, the range of values for the coefficient of friction between concrete and steel is around 0.3 and 0.58 for stress levels lower than 10,000 psi. These stress levels were similar to the stress levels reached in the barge impact experiments in 1998. 


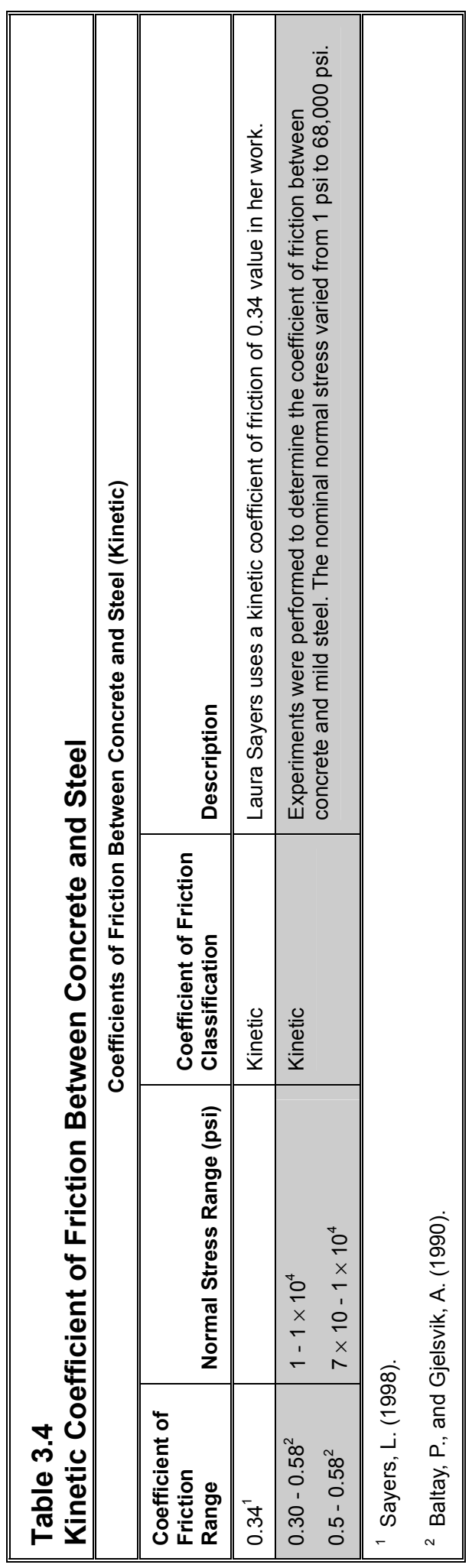




\section{Equilibrium Formulation with Energy Method Application}

In this chapter, the energy formulation is introduced in a formulation to calculate the forces applied to the wall due to the impact. This method uses Castigliano's theorem, which states that the partial derivative of the total strain energy of the arc beam with respect to one external load is equal to the displacement in the direction of the applied external load. Our case is a firstdegree indeterminate system, and one of the support reactions was selected as the redundant. All the internal forces (axial, shear, and moment) were expressed in terms of the redundant force located in cell 10 (or equivalently, pin B). The first configuration, mentioned in Chapter 1, is used here to compare the results with the values obtained in Chapter 3. Referring to Figures 4.1 and 4.2, the equilibrium equations are

$$
\begin{gathered}
\rightarrow \oplus \quad \sum F_{x}=0 \therefore \quad A_{x}+B_{x}-S_{w}=0 \\
\uparrow \oplus \quad \sum F_{y}=0 \therefore \quad A_{y}+B_{y}-F_{w}=0 \\
\sum M_{A}=0 \therefore \quad F_{w} R \sin (b)-S_{w} R[1-\sin (e)]-B_{y} R[\sin (e)-\sin (a)] \\
-B_{x} R[\cos (a)+\sin (b)]=0
\end{gathered}
$$

where

$$
\begin{aligned}
& a=54+\theta \\
& b=\theta-7 \\
& c=90+b \\
& d=90-a \\
& e=90-b
\end{aligned}
$$




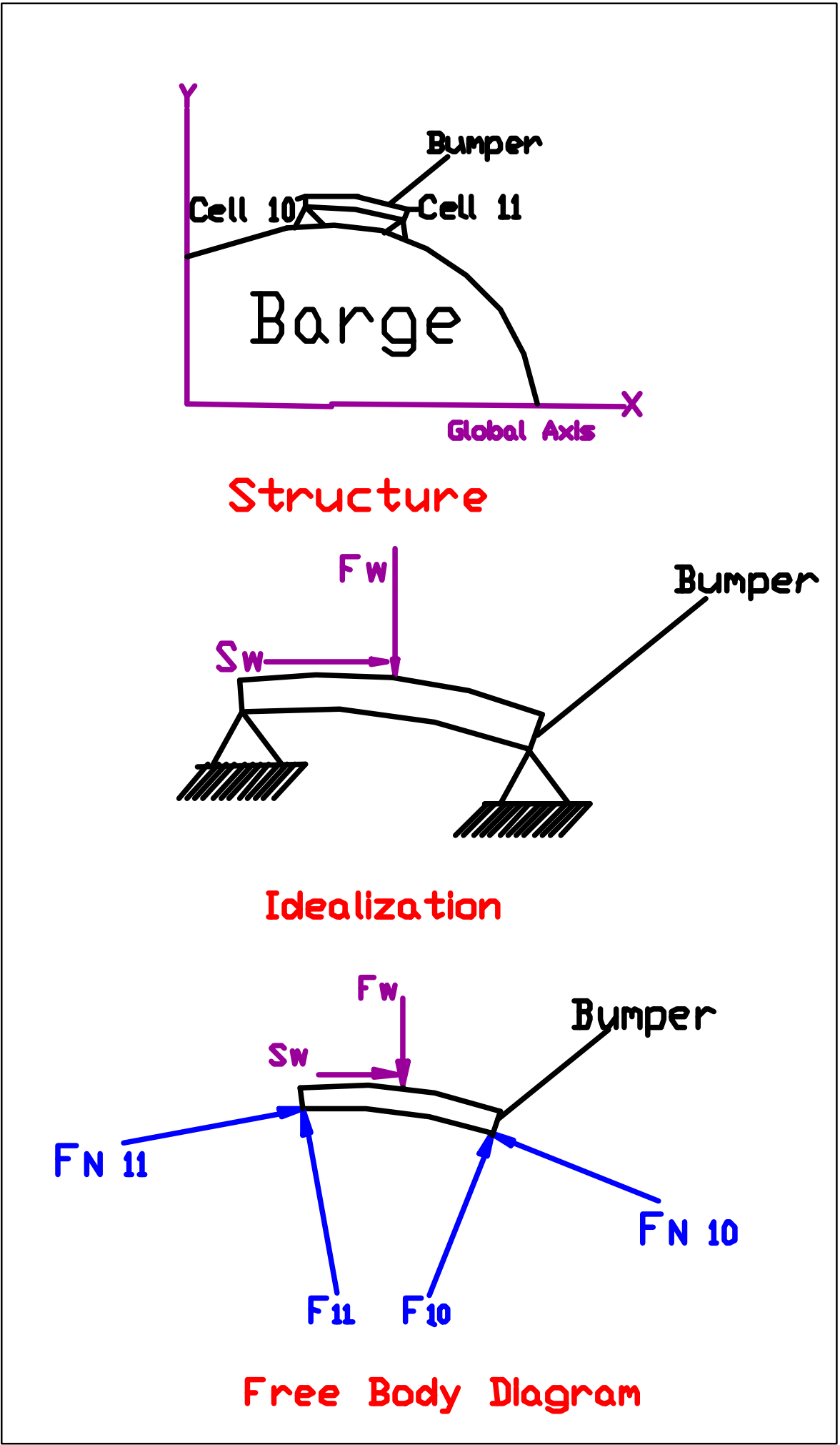

Figure 4.1. Structure, idealization, and free-body diagram of the bumper-energy method 


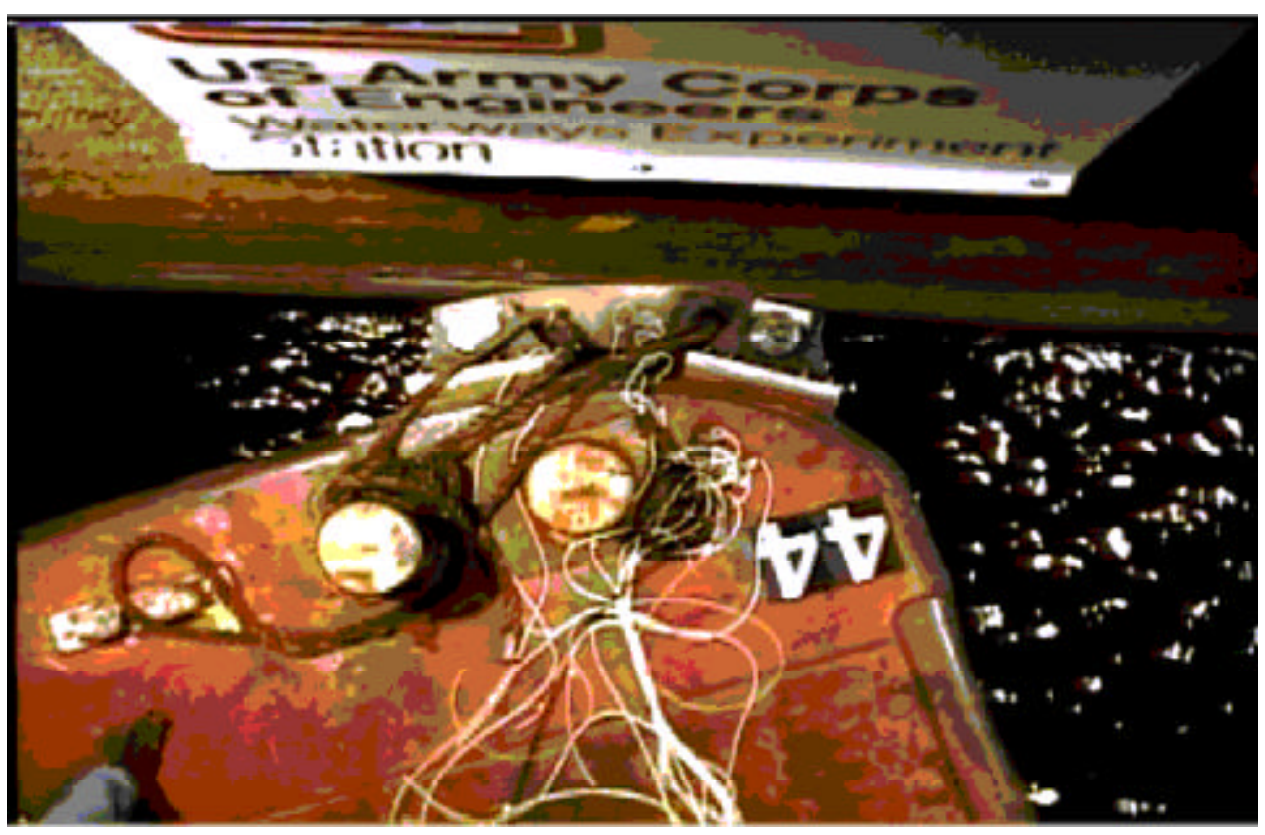

a. Overhead photo of barge with bumper about to impact the lock wall

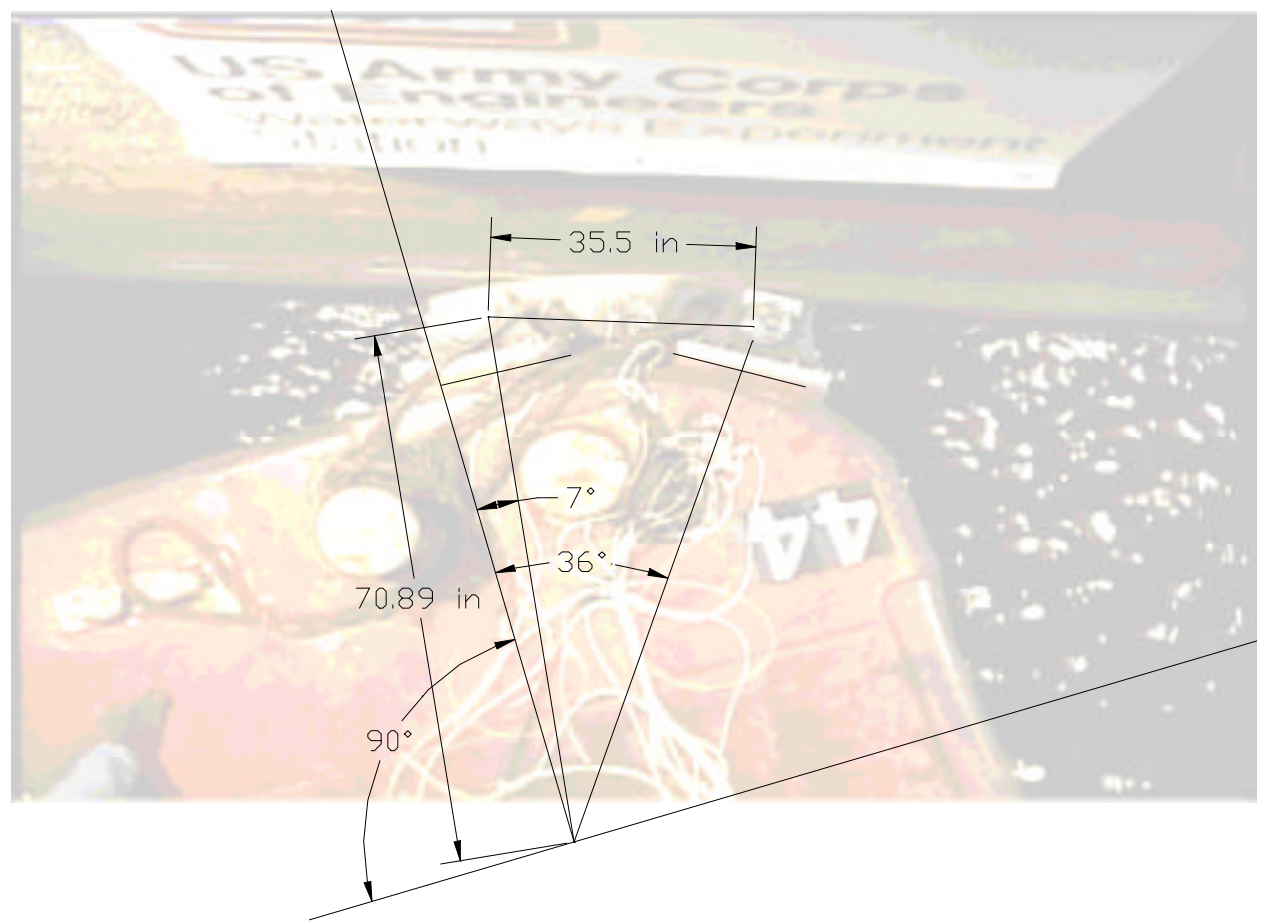

b. Arc geometry used for force analysis

Figure 4.2. Configuration and free-body diagram used in the energy method model (Continued) 


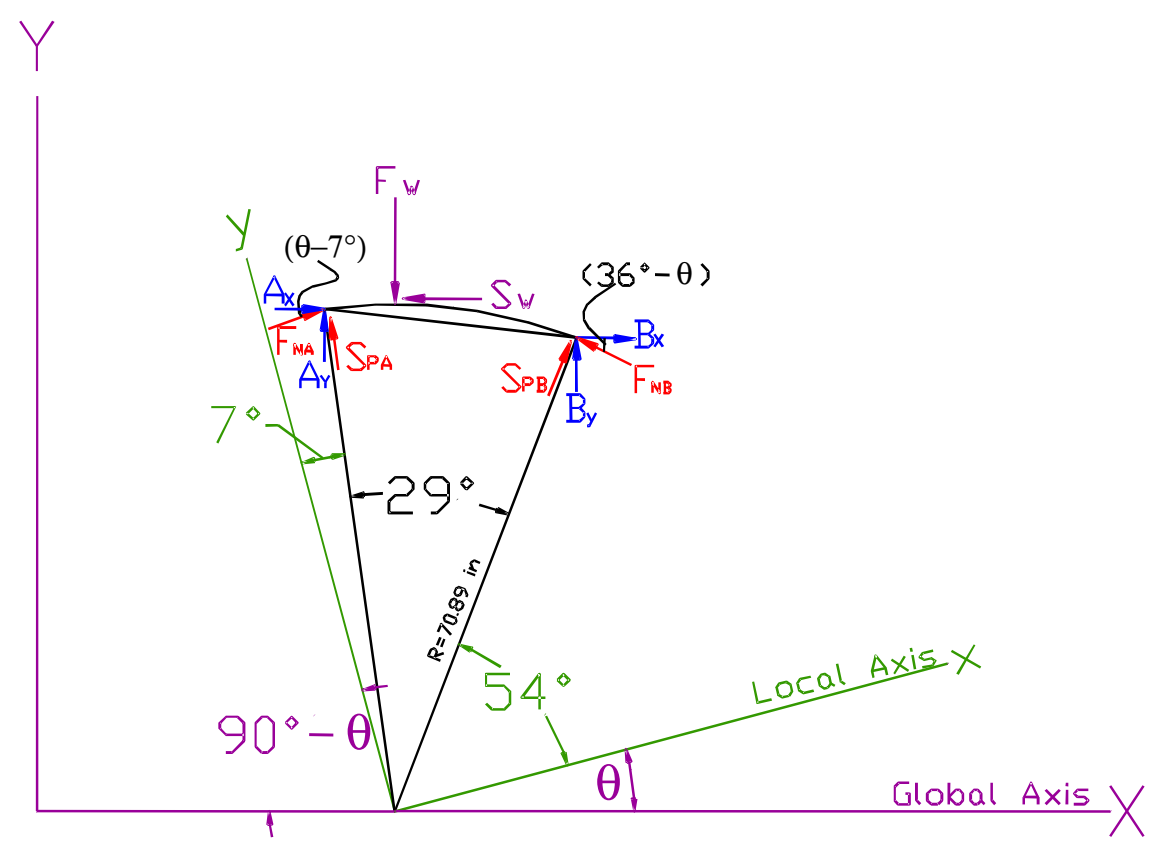

c. Forces acting on load bumper

Figure 4.2. (Concluded)

Note that the values assigned to angles $a$ through $e$ assume that the orientation of the arc is the same as the first configuration used to analyze the system, and the forces $S_{P A}$ (load cell 11) and $S_{P B}$ (load cell 10) are oriented in the radial direction (Figure 4.2c). In addition to the three equilibrium equations, we can introduce the axis transformation equations, which transform the local to global coordinates. These four new equations are

$$
\begin{aligned}
& A_{x}=F_{N A} \cos (\theta-7)-S_{P A} \sin (\theta-7) \\
& A_{y}=F_{N A} \sin (\theta-7)+S_{P A} \cos (\theta-7) \\
& B_{x}=-F_{N B} \cos (36-\theta)+S_{P B} \sin (36-\theta) \\
& B_{y}=F_{N B} \sin (36-\theta)+S_{P B} \cos (36-\theta)
\end{aligned}
$$

The additional equation is the displacement expression obtained from Castigliano's theorem, which is equal to zero because the redundant was taken in the support. The general expressions of this equation are

$$
\begin{aligned}
& \delta_{B_{x}}=\frac{\partial U}{\partial B_{x}}=\int \frac{N}{E A} \frac{\partial N}{\partial B_{x}} d s+\int \frac{V}{G A} \frac{\partial V}{\partial B_{x}} d s+\int \frac{M}{E I} \frac{\partial M}{\partial B_{x}} d s=0 \\
& d s=R d \theta
\end{aligned}
$$


where $N, V$, and $M$ are the internal normal, shear forces, and internal moment expressed in terms of the reaction $B_{x}$. The arc beam was divided into two segments - one from support $B$ to the vertical global axis (point of application of $F_{w}$ and $S_{w}$ ), and the second from support $B$ to a section after the application of $F_{w}$ and $S_{w}$. In other words, the limits of the integrals in the problem are from $a$ $(a=5 \mathrm{deg}+\theta)$ to $90 \mathrm{deg}$ and from $90 \mathrm{deg}$ to $c(c=90 \mathrm{deg}-7 \mathrm{deg})$.

This new formulation did not introduce any assumption regarding the value of the coefficient of friction and did not consider the arc beam as a rigid body, but considered it as a flexible body. Solving these eight equations, the problem is transformed to a determinate system. Now, our knowns are $S_{P A}$ (load cell 11) and $S_{P B}$ (load cell 10), which are the radial forces measured during the experiments. The unknowns are the reactions in global coordinates $\left(A_{x}, A_{y}, B_{x}\right.$, and $\left.B_{y}\right)$, the forces in the wall $\left(F_{w}\right.$ and $\left.S_{w}\right)$, and the two reactions normal to the cross section of the beam in local coordinates $\left(F_{N A}\right.$ and $\left.F_{N B}\right)$. In this case, a Maple worksheet, presented in Appendix B, was created to calculate numerically the values for $F_{w}$ and $S_{w}$.

To determine if the results provided by the energy model formulations are accurate, two finite element models of the bumper were studied using the computer programs SAP2000 and VisualAnalysis. The two models were constructed by fixing the approach angle to 18 and $21.5 \mathrm{deg}$. This results in the same model structure but with different positions in the global coordinate system. Figure 4.3 shows the arc layout used for the finite element analyses for $\theta=18 \mathrm{deg}$. Figure 4.4 shows the arc layout for the VisualAnalysis model for $\theta=18 \mathrm{deg}$, and Figure 4.5 shows the model for $\theta=18 \mathrm{deg}$ built using SAP2000. The properties of the beam elements used in these models are as follows:

$$
\begin{aligned}
& \text { Cross-sectional area }=45 \mathrm{in}^{2} \\
& \text { Moment of inertia }=303.75 \mathrm{in}^{4} \\
& \text { Modulus of elasticity }(E)=29,000 \mathrm{ksi} \\
& \text { Shear modulus }(G)=\frac{E}{2(1+v)} \\
& \text { Poisson ratio }(\bar{v})=0.33
\end{aligned}
$$

The sectional properties were calculated using the dimensions of 5 by $9 \mathrm{in}$. In this case, the same approach as in Chapter 3 was used. A unit load $F_{w}$ and a load of $0.50 \mathrm{kip}$ for $S_{w}$ was applied to the finite element models, corresponding to a coefficient of friction of 0.50 (shaded cells in second and third rows of Tables 4.1 and 4.2). Then, the values of the supports' reactions were computed from the finite elements models using both computer programs. The proposed equilibrium formulation with energy method was then used with these support reactions as input data, to calculate the resulting normal and shear force applied to the arc beam. Remember that the problem of the barge impact is an inverse problem. That is, the known forces are two reactions, and the unknown forces are the other two reactions at the pins and the forces normal and parallel to the wall at the point of contact. It is a common practice to apply a traditional procedure, which states that, with a known external applied load, the reactions and internal forces are calculated. The case with which we are dealing in the barge impact problem is the opposite of this traditional procedure. 


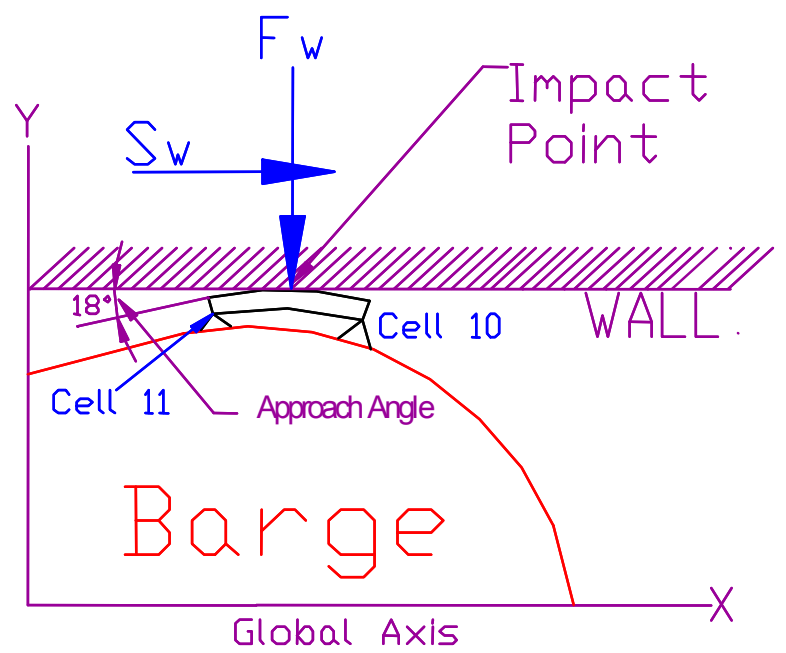

Figure 4.3. Idealization of the bumper structure for the finite element analysis

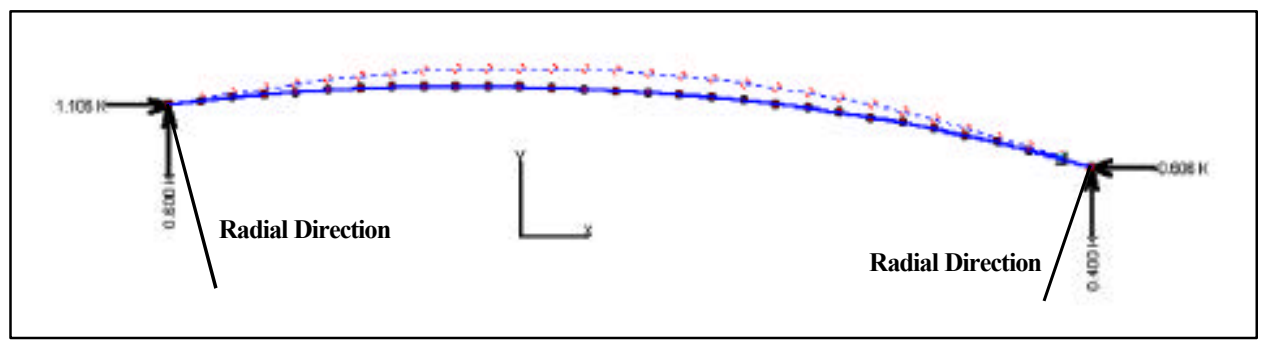

Figure 4.4. VisualAnalysis model for $\theta=18 \mathrm{deg}$ —energy method

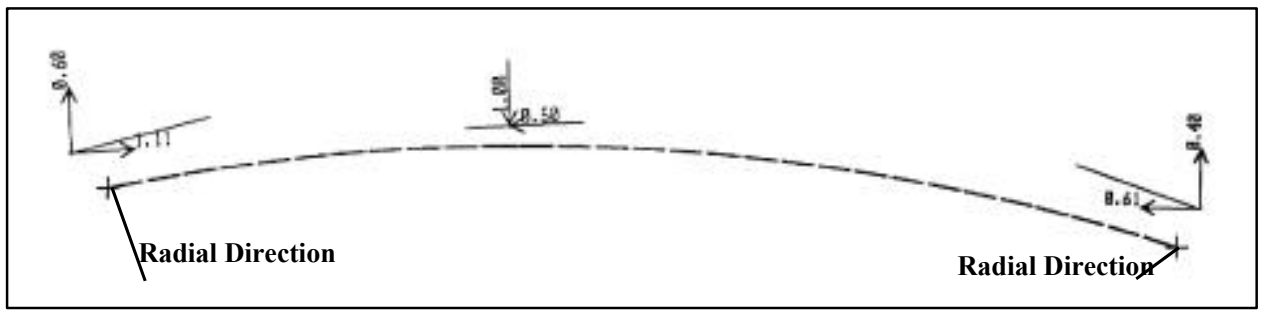

Figure 4.5. SAP2000 model for $\theta=18 \mathrm{deg}$ —energy method 

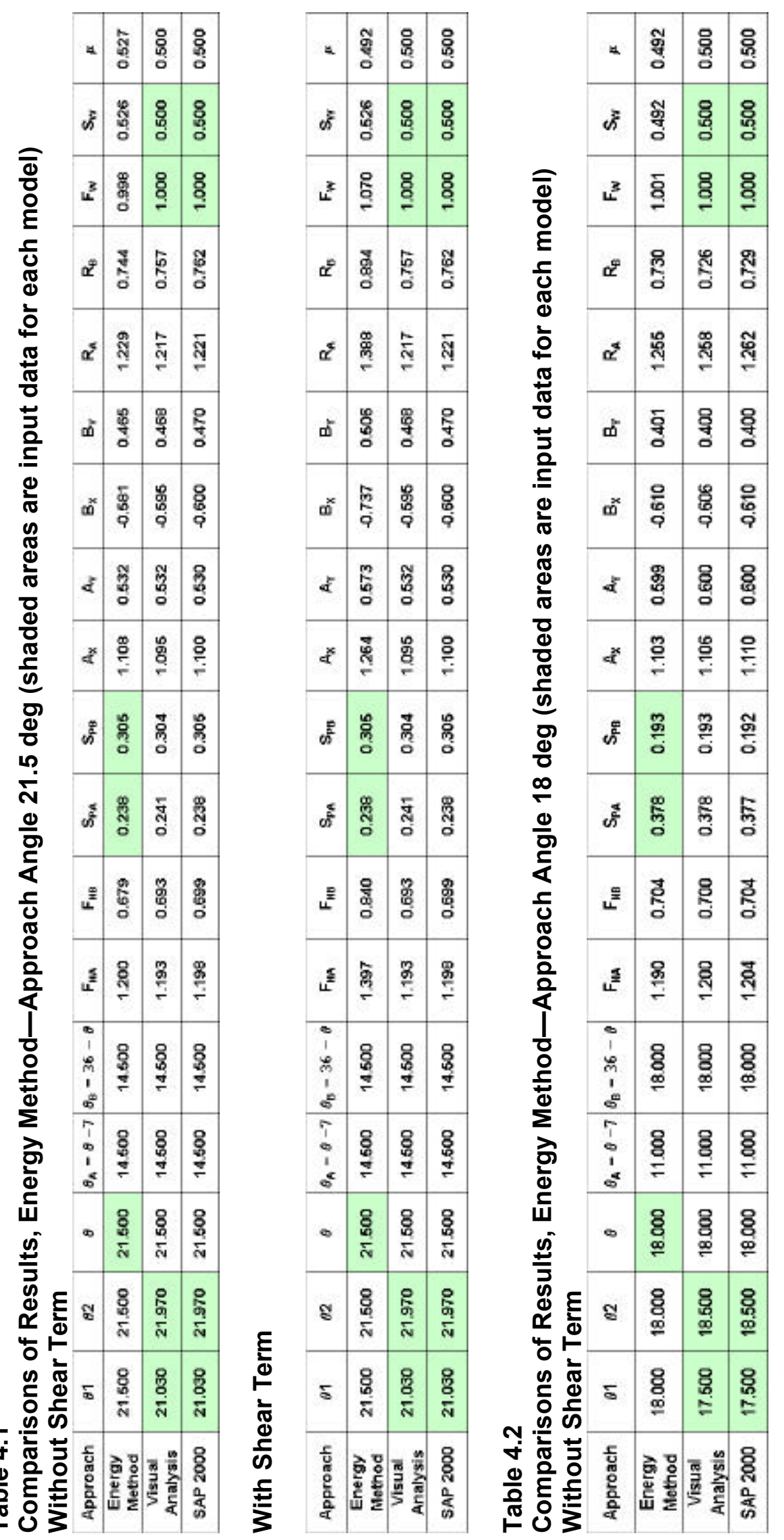

\begin{tabular}{|c|c|c|c|}
\hline$\approx$ & 兽 & 总 & 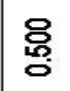 \\
\hline 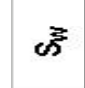 & 冚 & 융 & 융 \\
\hline 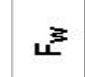 & 옹 & $\underset{8}{8}$ & 응 \\
\hline $2^{\infty}$ & $\stackrel{\infty}{\infty}$ & : & 융 \\
\hline$\alpha^{\approx}$ & 夿 & 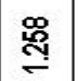 & ণ্ণิ \\
\hline م & 㞼 & 导 & 导 \\
\hline م & 형 & : & 응 \\
\hline$x^{2}$ & 寻 & 융 & 융 \\
\hline$x^{x}$ & $\stackrel{\mathscr{m}}{\stackrel{2}{*}}$ & $\stackrel{\circ}{\check{ }}$ & 을 \\
\hline 心 & 용 & $\stackrel{\frac{2}{2}}{\circ}$ & \% \\
\hline ळ & 통 & 悉 & E \\
\hline עִ & 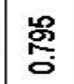 & $\stackrel{8}{8}$ & 总 \\
\hline$\frac{a}{4}$ & 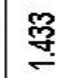 & ণ্ণָ & ণ্ডָ \\
\hline $\begin{array}{l}\infty \\
1 \\
\infty \\
11 \\
\infty \\
\infty\end{array}$ & 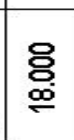 & $\begin{array}{l}\stackrel{8}{8} \\
\stackrel{0}{0}\end{array}$ & 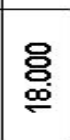 \\
\hline $\begin{array}{l}5 \\
\infty \\
11 \\
\infty^{\infty}\end{array}$ & 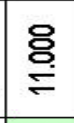 & $\stackrel{\text { o }}{\rightleftarrows}$ & 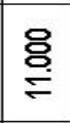 \\
\hline$\infty$ & 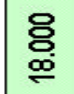 & 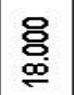 & 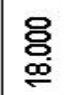 \\
\hline § & 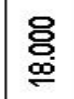 & $\begin{array}{l}\text { 足 } \\
\text { 足 } \\
\text { 足 }\end{array}$ & $\begin{array}{l}\text { 员 } \\
\text { 足 }\end{array}$ \\
\hline$\Phi$ & $\begin{array}{l}\text { 灾 } \\
\stackrel{\infty}{\infty}\end{array}$ & $\stackrel{8}{8}$ & 怘 \\
\hline $\begin{array}{l}\text { 등 } \\
\text { o } \\
\text { 흥 }\end{array}$ & & & 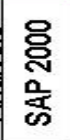 \\
\hline
\end{tabular}


The comparisons between the results produced by each model are presented in Tables 4.1 and 4.2. For the model presented in this chapter, the coefficient of friction is calculated from the ratio of $S_{w}$ divided by $F_{w}$. The results obtained with this model produce a coefficient of friction in the range that was found in the technical literature review (e.g., Baltay and Gjelsvik 1990). The procedure to obtain these results was as follows (data presented are obtained from Table 4.1, without shear term):

a. The arc was fixed using a specific $\theta$ value. Due to the use of straight elements to model the arc, the angles that make the initial element at each support with the horizontal (global axis) have a small difference from the exact values $(\theta-7 \mathrm{deg})$ and $(36 \mathrm{deg}-\theta)$ for pin A (load cell 11) and pin B (load cell 10), respectively. These values are specified by $\theta_{1}$ and $\theta_{2}$ in the last two rows of Tables 4.1 and 4.2. Although they are different angles, the average value results in the exact approach angle, $\theta$, used in the proposed method, as shown in the first row in Tables 4.1 and 4.2. For example, the finite element models (in Table 4.1) have $\left(\theta_{1}+\theta_{2}\right) / 2=(21.03 \mathrm{deg}+21.97 \mathrm{deg}) / 2=21.5 \mathrm{deg}$.

b. Using SAP2000 and VisualAnalysis, the model was constructed.

c. The $F_{w}=1.0$ and a coefficient of friction (0.5) were applied to the structure $\left(F_{w}=1.0 \mathrm{kip}, S_{w}=0.5 \mathrm{kip}\right.$, and $\left.\mu=F w / S_{w}=0.5\right)$.

d. The reactions in the global coordinates were calculated $\left(A_{x}=1.108 \mathrm{kip}\right.$, $A_{y}=0.532 \mathrm{kip}, B_{x}=-0.581 \mathrm{kip}$, and $B_{y}=0.465 \mathrm{kip}$ ) (Pin A $=$ load cell 11; Pin $\mathrm{B}=$ load cell 10).

e. The components in the local coordinates were obtained $\left(S_{P A}=0.238 \mathrm{kip}\right.$; $S_{P B}=0.305$ kip).

$f$. The radial forces $\left(S_{P A}\right.$ and $\left.S_{P B}\right)$ were used as input data for the equilibrium formulation with energy model.

g. The $F_{w}$ and $S_{w}$ were determinate using the equilibrium formulation with energy model $\left(F_{w}=0.998 \mathrm{kip} ; S_{w}=0.526 \mathrm{kip}\right)$.

$h$. The coefficient of friction was calculated as $S_{w} / F_{w}\left(\mu=F_{w} / S_{w}=0.527\right)$.

The coefficient of friction obtained with the equilibrium formulation with energy model, after following this procedure, was very close to the initial assumption of $\mu=0.5$. From this point of view, Tables 4.1 and 4.2 show the good agreement between the energy model and the finite element models.

Recall that the proposed method includes the shear, axial, and bending effects in the arc beam, as shown in Equation 4.8. The finite element models used in these analyses consider the axial and bending effects only. It can be observed from Tables 4.1 and 4.2 that a difference occurs in the results when the shear term is considered via the energy method. If the shear term is not considered, as in the finite elements models used here, the Castigliano's theorem takes the 
following form, which is the formulation used to obtain the results presented in Tables 4.1 and 4.2 without shear term.

$$
\delta_{B_{x}}=\frac{\partial U}{\partial B_{x}}=\int \frac{N}{E A} \frac{\partial N}{\partial B_{x}} d s+\int \frac{M}{E I} \frac{\partial M}{\partial B_{x}} d s=0
$$

The procedure to obtain the $F_{w}$ and $S_{w}$ when the shear term is considered is the same as the approach presented earlier in this chapter. For example, the results using the energy method presented in Table 4.1 with shear term are as follows:

a. The arc was fixed using a specific $\theta$ value. Due to the use of straight elements to model the arc, the angles that make the initial element at each support with the horizontal (global axis) have a small difference from the exact values $(\theta-7 \mathrm{deg})$ and $(36 \mathrm{deg}-\theta)$ for pin A (load cell 11) and pin B (load cell 10), respectively. These values are specified by $\theta_{1}$ and $\theta_{2}$ in the last two rows of Tables 4.1 and 4.2. Although they are different angles, the average value results in the exact approach angle, $\theta$, used in the proposed method, as shown in the first row in Tables 4.1 and 4.2. For example, the finite element models in Table 4.1 have $\left(\theta_{1}+\theta_{2}\right) / 2$ $=(21.03 \mathrm{deg}+21.97 \mathrm{deg}) / 2=21.5 \mathrm{deg}$.

b. Using SAP2000 and VisualAnalysis, the model was constructed.

c. The $F_{w}=1.0$ and a coefficient of friction of 0.5 were applied to the structure $\left(F_{w}=1.0 \mathrm{kip}, S_{w}=0.5 \mathrm{kip}\right.$, and $\left.\mu=F_{w} / S_{w}=0.5\right)$.

d. The reactions in the global coordinates were calculated $\left(A_{x}=1.264\right.$ kip, $A_{y}=0.573 \mathrm{kip}, B_{x}=-0.737 \mathrm{kip}$, and $\left.B_{y}=0.506 \mathrm{kip}\right)(\mathrm{Pin} \mathrm{A}=$ load cell 11; Pin $\mathrm{B}=$ load cell 10).

e. The components in the local coordinates were obtained $\left(S_{P A}=0.238 \mathrm{kip}\right.$; $S_{P B}=0.305$ kip).

$f$. The radial forces $\left(S_{P A}\right.$ and $\left.S_{P B}\right)$ were used as input data for the equilibrium formulation with energy model.

$g$. The $F_{w}$ and $S_{w}$ were determinate using the equilibrium formulation with energy model $\left(F_{w}=1.07 \mathrm{kip}\right.$, and $\left.S_{w}=0.526 \mathrm{kip}\right)$.

$h$. The coefficient of friction was calculated as $S_{w} / F_{w}\left(\mu=F_{w} / S_{w}=0.492\right)$.

After following this procedure, the coefficient of friction obtained with the equilibrium formulation and the energy method including the shear term was very close to the initial assumption of $\mu=0.5$. From this point of view, Tables 4.1 and 4.2 show the good agreement between the energy model and the finite element models if the shear term is or is not included in the formulation. Almost the same coefficient of friction is obtained if the shear term is or is not included. However, the force normal to the wall is not the same. For example, the 
value of $F_{w}$ is 7 percent greater when the shear term is considered than the result obtained without the shear effect, as shown in Table 4.1. This validation is presented to confirm that the energy formulation agrees with the results obtained with the finite elements programs. From now on, all the analyses done with the energy formulation will include the shear term because it has a significant contribution to the internal energy of the arc beam. That is, in Chapter 5, when the energy formulation is used, the three internal effects (axial, shear and moment) are considered in the formulation.

In the solution process of the numerical model presented in this chapter, we found two special cases of the model that should be mentioned. These cases occur if the load is applied directly over the supports. That is, if $\theta=7 \operatorname{deg}$ or $\theta$ $=36 \mathrm{deg}$, the equilibrium formulation with energy model does not work. The reason for this problem is that one of the equations in the system (energy equation) has to have the loads over the beam to produce internal forces resulting from internal deflection. If the external load is applied over the supports, no internal energy is developed inside the arc beam. This leads us to a system of equations with more unknowns than equations. To use the energy model, the $F_{w}$ and $S_{w}$ loads should be placed between the supports to avoid an indeterminate system. Suppose that the $F_{w}$ and $S_{w}$ loads are applied over the support $A$ (load cell 11), which means that $\theta=7 \mathrm{deg}$, taking the moment at support $A$ (load cell 11) produces zero reactions at $\mathrm{B}$ (load cell 10). Then, making the summation of forces in the vertical direction, $F_{w}$ is equal to $A_{y}$. Finally, making the summation of forces in the horizontal direction, we obtain one equation and two unknowns $\left(A_{x}\right.$ and $\left.S_{w}\right)$. The energy equation cannot be used because the internal forces are zero, resulting in an indeterminate system. 


\section{Comparison Between the Assumed Coefficient of Friction Method and the Energy Method}

\subsection{Interpretation of Results from the Initial Configuration Assumed for $F_{10}$ and $F_{11}$}

Several cases will be presented in this chapter that compare the results between the assumed coefficient of friction model and the energy model. The initial configuration (Figure 1.8) was used with the energy method to determine the forces normal and parallel to the wall. This configuration assumed the arc beam to be at 54 deg with the longitudinal axis of the barges, and the measured loads were oriented in the radial direction, as shown in Figure 5.1.

With the exception of the results for Experiment 43, this configuration produces unreasonable values of coefficient of friction when compared with the values reported in the technical literature (e.g., Table 3.4). The values for the coefficient of friction for this initial model range from a low of 0.59 to a high of 5.69 , with a coefficient of friction well above unity for nearly all impact experiments. These are clearly well above the 0.3 to 0.58 values reported by Baltay and Gjelsvik (1990). Also, in some experiments, this configuration produced tension in the arc. Tension is observed in the values of the horizontal reactions. As shown in Figure 3.3c, the reaction $B_{x}$ (load cell 10) has to be negative to produce compression in the arc. For example, the reaction $B_{x}$ (load cell 10) in Experiments 29, 30, 31, 37, 39, 40, and 41 is positive, indicating tension in the arc. Then, the assumed coefficient of friction method was used with the unreasonable values of coefficient of friction as input data obtained with the energy method to check the energy methods results. The comparisons of these results are presented in Table 5.1. Good agreement between the methods can be observed; however, the unreasonable results obtained (high values of coefficient of friction or tension in the arc) must be evaluated. 


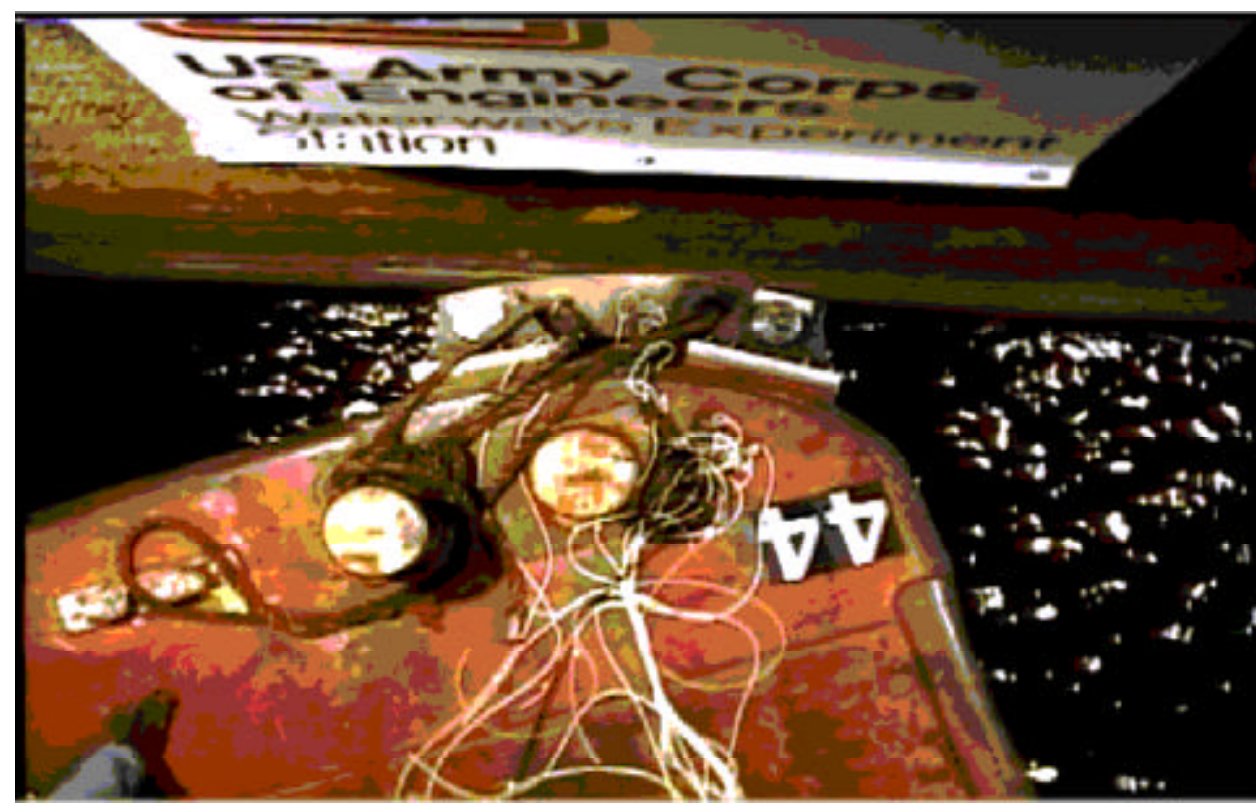

a. Overhead photo of barge with bumper about to impact the lock wall

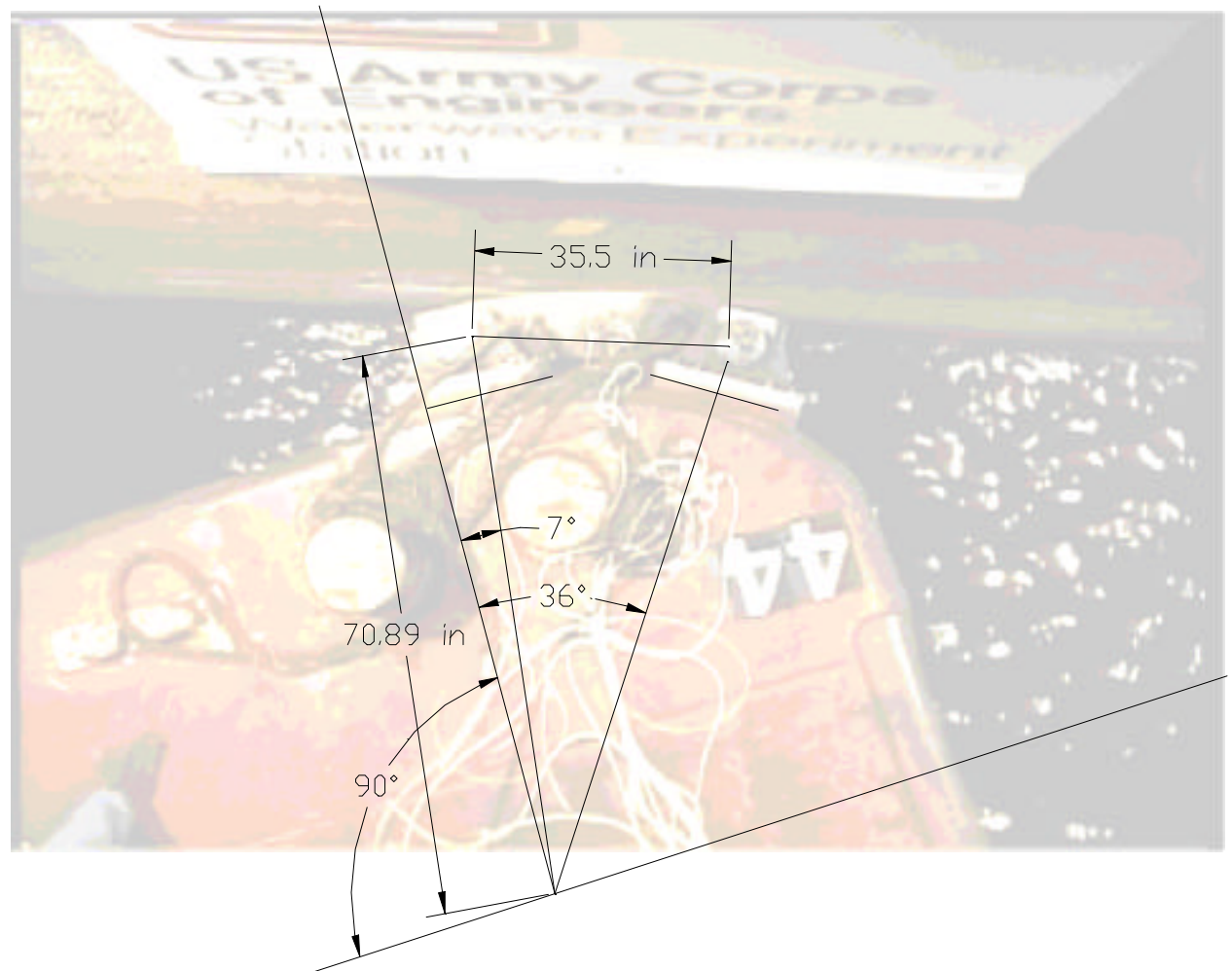

b. Arc geometry used for force analysis

Figure 5.1. Initial configuration and recorded load direction (Continued) 


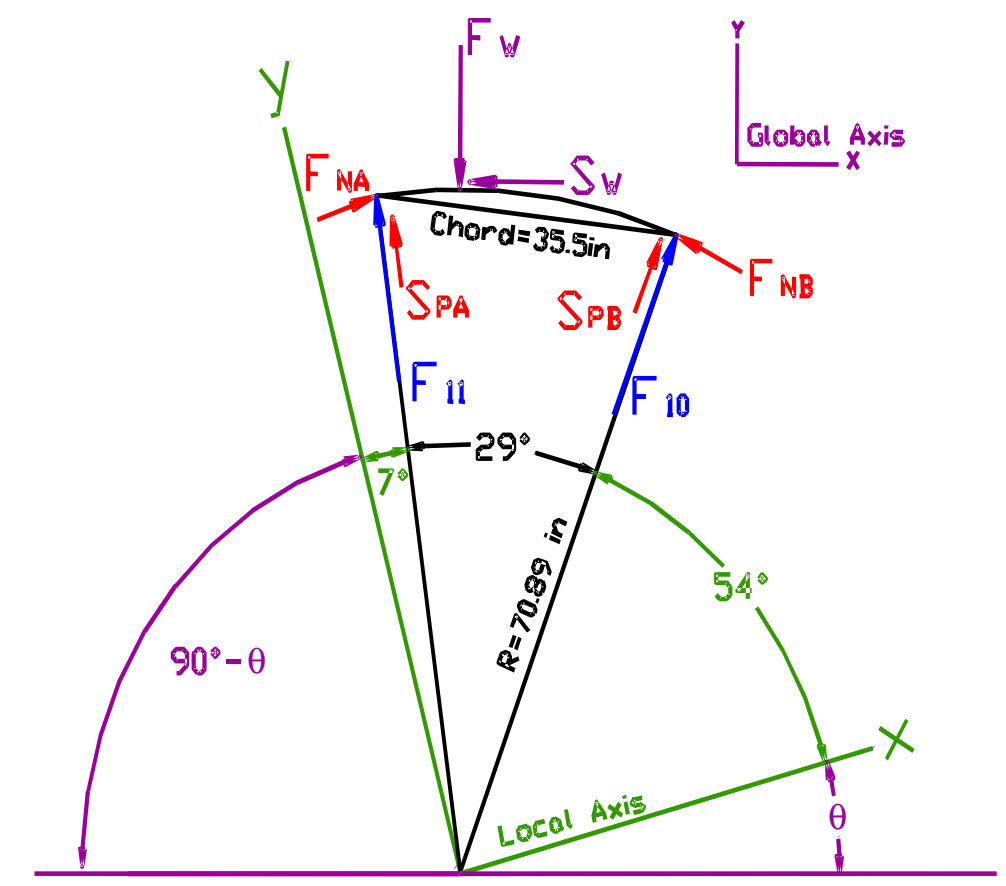

c. Forces acting on load bumper

Figure 5.1. (Concluded)

After a detailed analysis, three possible sources of error in the recorded data were found. The proposed two methods (Chapter 3 and 4) use, as input data, the (1) approach angle of the barges, (2) arc geometry, and (3) location of the arc and the orientation of the recorded forces. Each one of these possible sources of error will be discussed.

After analyzing the approach angle, $\theta$, it was concluded that it has the lower probability of error since it was measured using GPS technology. From Table A.3, we observe that for the last $5 \mathrm{sec}$ prior to impact in each experiment, the values for the approach angles are about the same. This indicates that the approach angle was almost constant before impact occurs. In addition, the registered approach angle obtained during the experiments was corrected to align the line joining the two global positioning systems used with the barge's longitudinal axis. This correction was made, and has a value of $0.4468 \mathrm{deg}$ in all experiments. The nearly constant approach angle values obtained during the last $5 \mathrm{sec}$ before impact are supported by the small values computed for the coefficient of variation (COV) in the GPS approach angle data for each experiment. The largest COV is computed equal to 2 percent for Experiment 30. In the other experiments, this coefficient had a value of less than 1 percent.

The second possible source of error was the wrong determination of the arc geometry. This kind of error has also a low probability of being responsible for the unreasonable results obtained in the original configuration studied. The 
Mำ

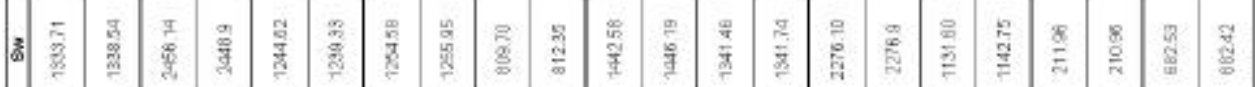

3 竞

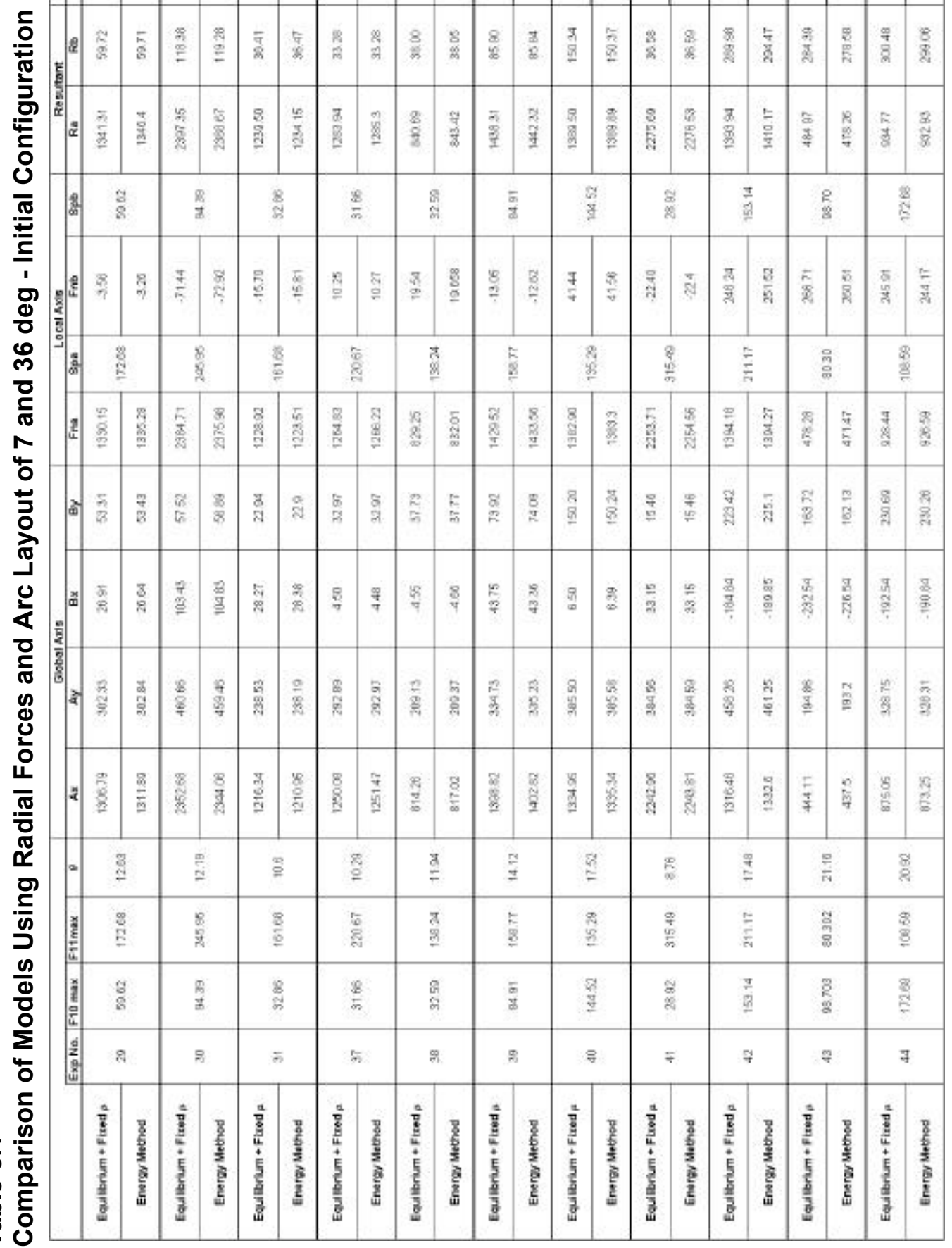


reason for assigning a low probability is because the arc bumper was made in a machine shop with specific requirements set forth by shop drawings. These requirements can be measured after the beam was constructed. The two intrinsic values of the arc are the central angle made by the radial directions, which is $29 \mathrm{deg}$, and the chord between the cell pins, which is 35.5 inches. Both items were measured before and after the experiments, and were unchanged. For that reason, this possibility was determined to be an unlikely source of error in the models.

The third source of error is the most probable, because the exact position of the arc on the barge and the exact load cell orientation were not precisely measured after mounting, nor checked after each experiment. With this in mind, two additional configurations were studied. These two configurations will be discussed in detail in Sections 5.2 and 5.3.

The second configuration was the same as the first one, but with a change in the load cell orientation. This configuration was obtained from a combination of design drawings and documentary photos taken during the experiments. The angle obtained from the drawings and photos were $3 \mathrm{deg}$ from the radial direction at support $A$ (load cell 11) and $6 \mathrm{deg}$ from the radial direction at support $B$ (load cell 10). After a detailed geometrical analysis, this model was rejected because unreasonable values of coefficient of friction were obtained.

The third configuration was obtained after performing a parametric analysis. In this case, the values of several geometrical parameters were changed until reasonable values of coefficient of friction and compression in the arc were obtained. A final geometrical configuration was obtained, and it was very similar to the first and second configurations studied. The resulting value for the location of the arc was $57.5 \mathrm{deg}$ from the longitudinal axis of the barge instead of $54 \mathrm{deg}$ as used in the previous configurations. In this third configuration, the recorded forces at the supports are oriented 5.5 and $1.5 \mathrm{deg}$ outside the radial direction at supports $A$ (load cell 11) and $B$ (load cell 10), respectively.

\subsection{Configuration with Recorded $F_{10}$ and $F_{11}$ Outside the Radial Direction}

After the initial configuration was analyzed, and unreasonable index values of coefficient of friction were computed for all the experiments, a second configuration was developed from a combination of design drawings and documentary photos taken during the experiments. This second assessment established that the arc bumper was placed $54 \mathrm{deg}$ from the longitudinal axis of the barge. In addition, the recorded forces $F_{10}$ and $F_{11}$ were oriented 6 and $3 \mathrm{deg}$ outside the radial direction, respectively. This configuration is presented in Figure 5.2. If the recorded forces are outside the radial direction, a new set of coordinate transformation has to be included. This set of equations has the following form: 


$$
\begin{aligned}
& S_{P A}=F_{11} \cos \delta-F_{11 n} \sin \delta \\
& F_{N A}=F_{11} \cos \delta+F_{11 n} \sin \delta \\
& S_{P B}=F_{10} \cos \varsigma-F_{10 n} \sin \varsigma \\
& F_{N B}=F_{10} \cos \varsigma+F_{10 n} \sin \varsigma
\end{aligned}
$$

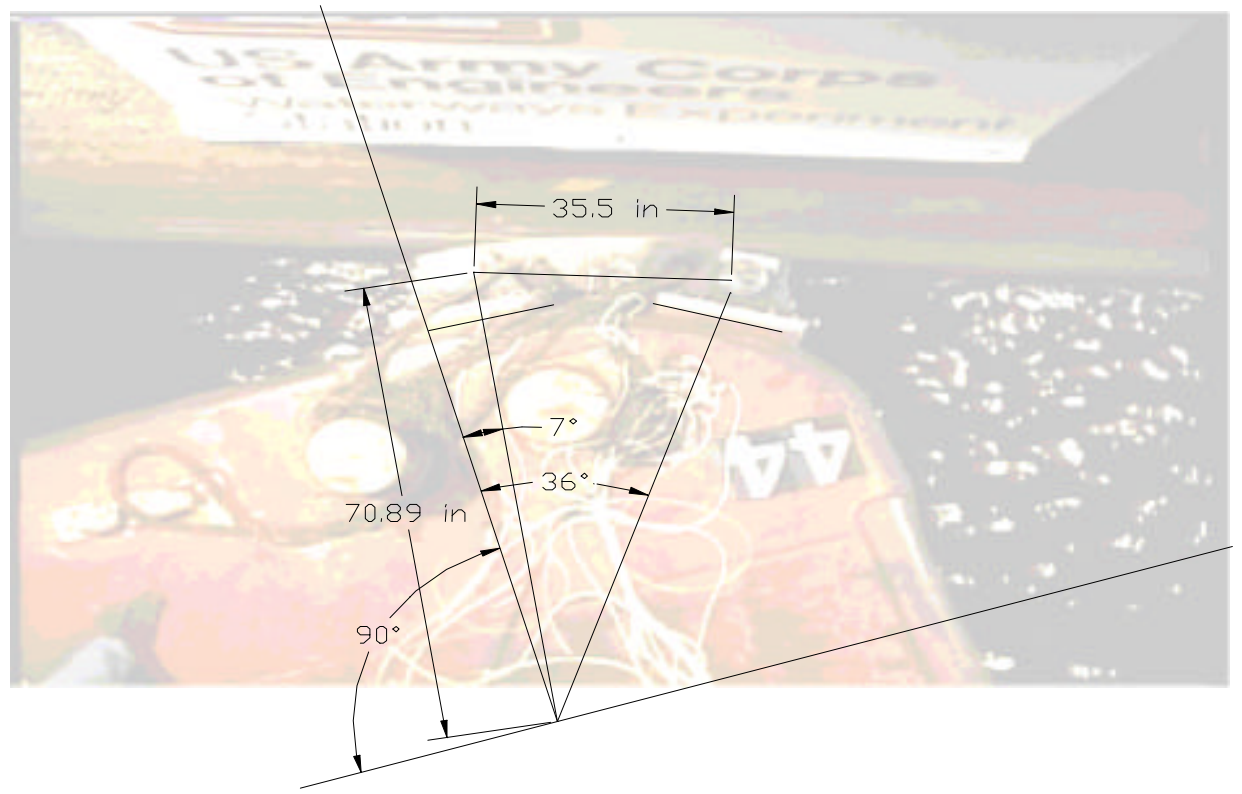

a. Arc geometry used for forced analysis

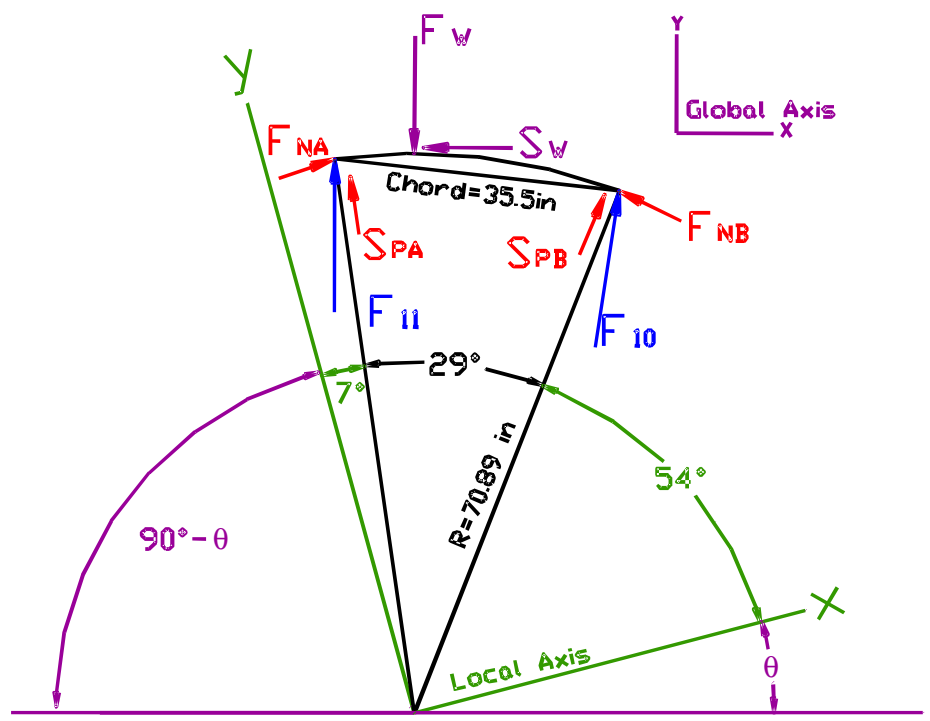

b. Forces acting on load bumper

Figure 5.2. Second load cell and arc location layout 
where $F_{10 n}$ and $F_{11 n}$ are the new unknown support reactions acting perpendicular to the recorded forces $F_{10}$ and $F_{11}$. Angles $\delta$ and $\zeta$ are those that the recorded forces $F_{11}$ and $F_{10}$ make with the radial direction. With this modification of the formulation, the energy method was applied to determine the normal and shear forces in the wall generated during impact. Again, the model produced unreasonable results, as can be observed in Table 5.2.

The values for the coefficient of friction for this second model range from a low of -0.82 to a high of 5.53 , with a coefficient of friction above unity for a majority of the impact experiments. This value is clearly well above the 0.3 to 0.58 values reported by Baltay and Gjelsvik (1990). However, in this second configuration, the arc is in compression in all the experiments. Compression in the arc is observed in the values of the horizontal global reactions. As shown in Figure $3.3 \mathrm{c}$, the reaction $B_{x}$ (load cell 10) has to be negative to produce compression in the arc, as is the case with this second configuration, as shown in Table 5.2.

To check the results obtained with the energy method, the fixed coefficient of friction method was employed using the coefficient of friction obtained from the energy method. The same results were obtained, indicating that two models produce the same behavior. That is, the high values of coefficient of friction and, even worse, negative $S_{w}$ force, as in Experiments 43 and 44, indicate that it acts in the direction of the motion, which is impossible. That is, this second configuration produces a negative shear force $S_{w}$, or equivalently a shear force in the direction of the motion, according to Figure 3.3c.

The explanation for this odd behavior was found after a detailed analysis of the geometry of the system. First, a detailed drawing of the supports was made to see if the angles adopted from the combination of design drawings and documentary photos taken during the experiments follow all geometrical rules. Figure 5.3 shows the triangle that forms the radial axis, the load direction, and the local axis of the barges. For support $B$ where $F_{10}$ was recorded, no problem was found because the summation of the internal angles of the triangle formed by the action line of the force $F_{10}$, the longitudinal axis of the barge (local axis), and the radial direction is equal to $180 \mathrm{deg}$. A different situation occurs at support $A$ where $F_{11}$ was recorded.

As shown in Figure 5.3, it is geometrically impossible that the summation of the internal angles of a triangle be greater than $180 \mathrm{deg}$. In other words, if the recorded force $F_{11}$ makes an angle of $3 \mathrm{deg}$ with the perpendicular to the longitudinal axis of the barge, then the location of the arc bumper could not be $54 \mathrm{deg}$ with the longitudinal axis of the barges. That is, the $54 \mathrm{deg}$ with the longitudinal axis produces an angle of $7 \mathrm{deg}$ with the perpendicular axis because the central angle of the arc is $29 \mathrm{deg}$. Then, as shown in Figure 5.3, the $7 \mathrm{deg}$ plus the $\delta$ angle must be equal to the external $3 \mathrm{deg}$, which is impossible. This is why the second configuration produces unreasonable results. 


\begin{tabular}{|c|c|c|c|c|c|c|c|c|c|c|c|c|c|c|c|c|c|c|c|c|c|c|c|}
\hline 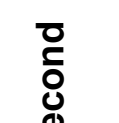 & $\mid$ & $\stackrel{B}{N}$ & $\stackrel{8}{8}$ & $\underset{\sim}{*}$ & $\begin{array}{l}* \\
2 \\
2\end{array}$ & $\stackrel{8}{8}$ & $\stackrel{8}{N}$ & $\stackrel{\circ}{N}$ & $\stackrel{9}{N}$ & $\stackrel{8}{7}$ & $\stackrel{2}{3}$ & 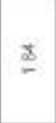 & $\underline{x}$ & $\cong$ & 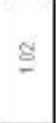 & 8 & 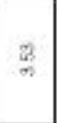 & జ્ & & $\stackrel{\approx}{\sigma}$ & \% & $\overline{\bar{a}}$ & $\overline{\bar{q}}$ \\
\hline ? & 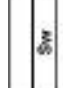 & $\frac{z}{8}$ & $\overline{\bar{g}}$ & 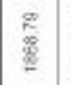 & $\begin{array}{l}\frac{2}{2} \\
3 \\
\underline{3}\end{array}$ & $\frac{8}{8}$ & $\begin{array}{l}\tilde{F} \\
\tilde{z} \\
\tilde{w}\end{array}$ & $\frac{8}{8}$ & $\frac{Q}{\frac{Q}{a}}$ & $\begin{array}{l}\frac{7}{6} \\
\frac{8}{4}\end{array}$ & $\begin{array}{l}\tilde{E} \\
z \\
z\end{array}$ & $\frac{8}{8}$ & $\frac{8}{8}$ & $\frac{8}{8}$ & $\overline{\overline{8}}$ & $\frac{g}{3}$ & $\frac{g}{3}$ & $\frac{m}{3}$ & $\frac{9}{3}$ & $\frac{8}{d}$ & $\frac{4}{7}$ & $\begin{array}{l}8 \\
8\end{array}$ & $\begin{array}{l}8 \\
4\end{array}$ \\
\hline ర్ల & 2 & \begin{tabular}{l}
$\stackrel{8}{8}$ \\
\multirow{7}{*}{}
\end{tabular} & $\frac{\mathscr{0}}{\frac{8}{\sigma}}$ & 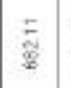 & $\begin{array}{l}\frac{5}{6} \\
\frac{1}{8}\end{array}$ & 8 & $\stackrel{8}{8}$ & $\frac{8}{5}$ & $\frac{\pi}{\Delta}$ & 点 & $\begin{array}{l}8 \\
8 \\
8 \\
8\end{array}$ & $\begin{array}{l}\overline{4} \\
8 \\
4\end{array}$ & $\begin{array}{l}\frac{7}{7} \\
\vdots \\
i\end{array}$ & 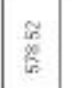 & $\begin{array}{l}0 \\
0 \\
0 \\
6\end{array}$ & $\frac{4}{8}$ & $\begin{array}{l}\approx \\
b \\
w\end{array}$ & 8 & 8 & $\frac{\bar{c}}{\bar{d}}$ & $\frac{8}{d}$ & $\frac{5}{6}$ & $\frac{\infty}{20}$ \\
\hline 先 & 㦴 & $\begin{array}{l}\varpi \\
\dddot{\Xi}\end{array}$ & 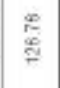 & 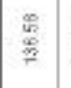 & 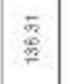 & $\frac{5}{4}$ & $\frac{8}{8}$ & $\frac{v}{E}$ & $\stackrel{8}{8}$ & $\frac{7}{5}$ & $\frac{\pi}{5}$ & 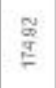 & 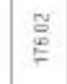 & 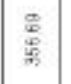 & $\begin{array}{l}\frac{5}{8} \\
\text { 采 }\end{array}$ & $\begin{array}{l}\mathbb{E} \\
\mathbb{g}\end{array}$ & $\begin{array}{l}\tilde{g} \\
\bar{w}\end{array}$ & $\begin{array}{l}\frac{\pi}{2} \\
0 \\
6\end{array}$ & $\begin{array}{l}\overline{5} \\
\overline{0} \\
\bar{b}\end{array}$ & $\frac{\vec{b}}{5}$ & $\begin{array}{l}\text { \%ँ } \\
\text { ฟु }\end{array}$ & $\begin{array}{l}\frac{\pi}{2} \\
0 \\
0 \\
0\end{array}$ & $\begin{array}{l}\text { E } \\
\text { w } \\
\text { w }\end{array}$ \\
\hline خั & क्षे & $\stackrel{q}{\underline{\underline{x}}}$ & $\begin{array}{l}\frac{2}{2} \\
\stackrel{2}{6} \\
\stackrel{5}{=}\end{array}$ & 总 & 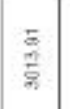 & 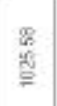 & $\begin{array}{l}\frac{2}{2} \\
=\end{array}$ & $\frac{3}{8}$ & $\frac{88}{8}$ & 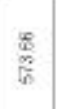 & $\overline{\tilde{N}}$ & 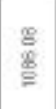 & $\underset{\tilde{z}}{\tilde{E}}$ & $\begin{array}{l}\overline{5} \\
\overline{8}\end{array}$ & $\frac{8}{8}$ & 常 & 章 & $\underset{\substack{\mathbb{B} \\
\text { d. }}}{\mathrm{R}}$ & 路 & है & $\stackrel{8}{8}$ & $\bar{c}$ & $\frac{m}{6}$ \\
\hline U. & : & $\begin{array}{l}8 \\
\text { ga }\end{array}$ & $\frac{8}{6}$ & $\frac{4}{3}$ & $\begin{array}{l}8 \\
3 \\
3\end{array}$ & $\frac{2}{8}$ & $\stackrel{\approx}{\approx}$ & $\frac{\text { के }}{c}$ & $\frac{m}{i n}$ & $\mathrm{~d}$ & 공 & $\begin{array}{l}8 \\
8 \\
8\end{array}$ & $\ddot{z}$ & 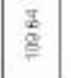 & $\begin{array}{l}\overline{\mathrm{G}} \\
\mathrm{g}\end{array}$ & 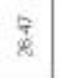 & $\overline{8}$ & 票 & $\stackrel{8}{a}$ & 8 & $\begin{array}{l}3 \\
4 \\
4\end{array}$ & 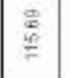 & 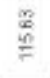 \\
\hline $\begin{array}{l}\frac{0}{\sigma} \\
\frac{1}{0} \\
\text { o }\end{array}$ & 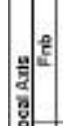 & 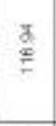 & $\frac{\mathrm{g}}{\mathrm{f}}$ & $\begin{array}{l}8 \\
\frac{8}{8}\end{array}$ & $\begin{array}{l}8 \\
5 \\
5\end{array}$ & $\frac{8}{4}$ & $\begin{array}{l}8 \\
7 \\
7\end{array}$ & $\underset{\infty}{\infty}$ & $\mathbb{R}$ & $\frac{\sigma}{\frac{\sigma}{\dot{*}}}$ & 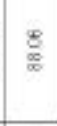 & $\stackrel{8}{\mathbb{Z}}$ & $\mathbb{Z}$ & $\stackrel{7}{8}$ & $\bar{B}$ & 息 & 紊 & 原 & 8 & $\frac{4}{4}$ & $\stackrel{8}{\frac{8}{7}}$ & $\frac{5}{8}$ & $\frac{2}{5}$ \\
\hline త્ & $\approx$ & $\frac{8}{2}$ & $\begin{array}{l}\frac{6}{2} \\
\text { है }\end{array}$ & $\begin{array}{l}\mathbb{E} \\
3\end{array}$ & \begin{tabular}{|l|l|l}
2 \\
2 \\
3
\end{tabular} & $\frac{T}{\frac{\pi}{3}}$ & $\frac{2}{2}$ & $\frac{r}{8}$ & $\begin{array}{l}\text { \& } \\
\text { gू }\end{array}$ & $\begin{array}{l}\stackrel{E}{E} \\
\stackrel{D}{T}\end{array}$ & 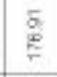 & 蛋 & $\frac{8}{8}$ & है & 8 & $\begin{array}{l}8 \\
7 \\
7\end{array}$ & $\frac{8}{8}$ & $\frac{\pi}{8}$ & $\frac{8}{8}$ & $\stackrel{8}{\mathscr{E}}$ & $\stackrel{8}{8}$ & $\begin{array}{l}\frac{7}{7} \\
7\end{array}$ & $\frac{8}{7}$ \\
\hline$\frac{0}{\frac{\pi}{\pi}}$ & $\frac{\pi}{4}$ & $\frac{\pi}{8}$ & $\begin{array}{l}8 \\
8 \\
8\end{array}$ & $\begin{array}{l}8 \\
5 \\
5\end{array}$ & \begin{tabular}{|l|}
$\overline{\mathbf{b}}$ \\
$\mathbf{z}$ \\
$\underline{\underline{z}}$
\end{tabular} & $\stackrel{8}{8}$ & $\begin{array}{l}\tilde{z} \\
\stackrel{\tilde{w}}{\sigma}\end{array}$ & $\frac{\infty}{8}$ & $\tilde{E}$ & $\begin{array}{l}\frac{5}{6} \\
\frac{8}{6}\end{array}$ & $\frac{\pi}{7}$ & $\underset{\mathbb{8}}{\stackrel{E}{8}}$ & $\begin{array}{l}\mathbb{B} \\
\mathbb{B} \\
\end{array}$ & $\begin{array}{l}\bar{g} \\
\mathbb{8} \\
\end{array}$ & $\begin{array}{l}5 \\
8\end{array}$ & 要 & $\begin{array}{l}E \\
\text { 要 }\end{array}$ & $\begin{array}{l}8 \\
\& \\
\&\end{array}$ & $\begin{array}{l}8 \\
8 \\
8\end{array}$ & $\begin{array}{l}x \\
E\end{array}$ & $\frac{B}{E}$ & $\frac{8}{6}$ & $\frac{E}{4}$ \\
\hline $\begin{array}{l}\stackrel{\alpha}{\otimes} \\
\stackrel{\phi}{f}\end{array}$ & $\approx$ & $\frac{9}{8}$ & $\frac{\pi}{8}$ & 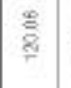 & $\stackrel{\leftrightarrow}{\stackrel{2}{*}}$ & 8 & $\frac{8}{7}$ & 8 & 5 & $\frac{7}{65}$ & $\frac{2}{6}$ & $\overline{5}$ & $\stackrel{\mathscr{\Xi}}{\approx}$ & $\stackrel{t}{t}$ & $\stackrel{\infty}{=}$ & $\mathscr{\&}$ & $\frac{2}{5}$ & 密 & 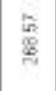 & $\stackrel{\infty}{q}$ & 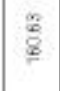 & घี & $\overline{8}$ \\
\hline $\begin{array}{l}\frac{\overline{0}}{0} \\
\frac{1}{3} \\
0\end{array}$ & $\frac{\pi}{*}$ & 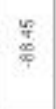 & $\begin{array}{l}\text { 善 } \\
\text { 案 }\end{array}$ & 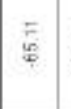 & $\frac{\pi}{4}$ & $\frac{\nexists}{5}$ & 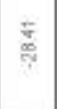 & 蛋 & $\begin{array}{c}8 \\
\substack{5 \\
4}\end{array}$ & $\frac{\infty}{7}$ & 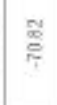 & $\begin{array}{l}\stackrel{0}{\pi} \\
\approx\end{array}$ & 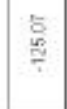 & $\frac{9}{8}$ & $\frac{4}{8}$ & $\underset{\phi}{\bar{\phi}}$ & $\frac{8}{8}$ & $\frac{\pi}{\frac{\pi}{6}}$ & 商 & \& & $\begin{array}{l}5 \\
\overline{5}\end{array}$ & $\begin{array}{l}\text { I: } \\
\frac{1}{6}\end{array}$ & 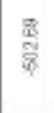 \\
\hline $\begin{array}{l}\text { \& } \\
\text { U⿺乚 } \\
\text { o }\end{array}$ & 읜. & $\underset{7}{\overline{3}}$ & $\begin{array}{l}\frac{1}{2} \\
\frac{2}{3}\end{array}$ & $\stackrel{8}{8}$ & $\begin{array}{c}8 \\
8 \\
3\end{array}$ & $\stackrel{\infty}{\nexists}$ & $\begin{array}{l}\mathscr{y} \\
\mathbb{8}\end{array}$ & 8 & $\frac{5}{8}$ & $\frac{8}{8}$ & 胥 & $\nexists$ & $\frac{8}{8}$ & $\frac{8}{8}$ & 8 & \begin{tabular}{|l}
8 \\
$\frac{8}{6}$
\end{tabular} & $\frac{5}{\frac{5}{20}}$ & $\frac{8}{8}$ & $\bar{H}$ & z & 告 & $\frac{8}{x}$ & $\begin{array}{l}5 \\
8 \\
x\end{array}$ \\
\hline$\frac{0}{0}$ & 2 & $\begin{array}{l}3 \\
3 \\
8\end{array}$ & 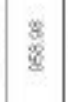 & $\frac{8}{d}$ & $\frac{8}{\not}$ & $\frac{8}{8}$ & 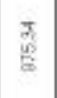 & $\frac{7}{8}$ & 8 & 8 & है & 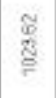 & $\frac{8}{8}$ & $\frac{8}{8}$ & 8 & 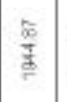 & 部 & $\overline{\frac{1}{8}}$ & $\frac{\bar{c}}{8}$ & $\underline{\underline{T}}$ & $\underset{\Psi}{ \pm}$ & 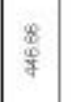 & $\stackrel{8}{\frac{8}{\alpha}}$ \\
\hline ه్ & . & \multicolumn{2}{|c|}{ 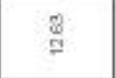 } & & \multicolumn{2}{|c|}{$\stackrel{8}{9}$} & \multicolumn{2}{|c|}{$\stackrel{8}{a}$} & \multicolumn{2}{|c|}{$\stackrel{\pi}{\underline{2}}$} & & & \multicolumn{2}{|c|}{$\underset{\infty}{E}$} & \multicolumn{2}{|c|}{$\stackrel{p}{=}$} & & \multicolumn{2}{|c|}{$\frac{g}{e}$} \\
\hline & \multicolumn{2}{|c|}{$\frac{\pi}{2}$} & & & & & \multicolumn{2}{|c|}{ 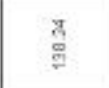 } & \multicolumn{2}{|c|}{$\begin{array}{l}\text { E. } \\
\text { : }\end{array}$} & & & \multicolumn{2}{|c|}{$\stackrel{E}{\bar{A}}$} & \multicolumn{2}{|c|}{9} & \multicolumn{2}{|c|}{$\begin{array}{l}\stackrel{g}{\mathrm{~g}} \\
\stackrel{\mathrm{g}}{\mathrm{N}}\end{array}$} \\
\hline$\frac{0}{0}$ & $\frac{x}{2}$ & \multicolumn{2}{|c|}{ 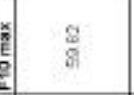 } & \multicolumn{2}{|c|}{ व } & \multicolumn{2}{|c|}{ लै } & & \multicolumn{2}{|c|}{ मे } & & $\bar{z}$ & $\begin{array}{l}\text { g } \\
\pm\end{array}$ & & 영 & & $g$ & & 8 & $\frac{8}{2}$ & 罚 & 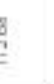 \\
\hline $\mathbb{Z}_{0}^{2}$ & 递 & 8 & ช & मा & ק. & $=$ & $\bar{n}$ & $\Rightarrow$ & 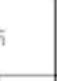 & : & \% & & \% & o & & $\bar{q}$ & & $=$ & & $\therefore$ & 9 & J & $q$ \\
\hline 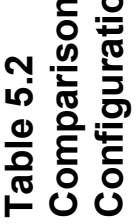 & & 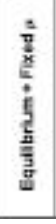 & 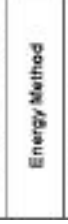 & 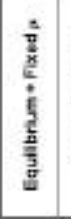 & 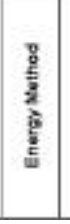 & 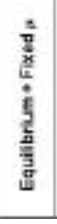 & 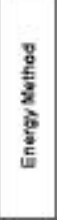 & 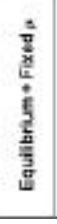 & 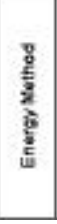 & 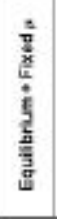 & 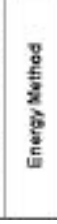 & 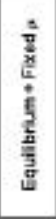 & 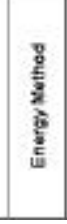 & 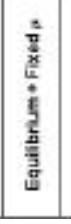 & 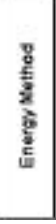 & 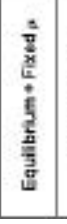 & 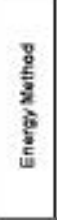 & 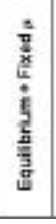 & 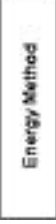 & 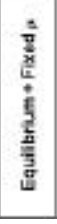 & 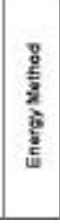 & 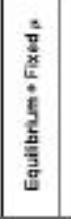 & 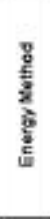 \\
\hline
\end{tabular}




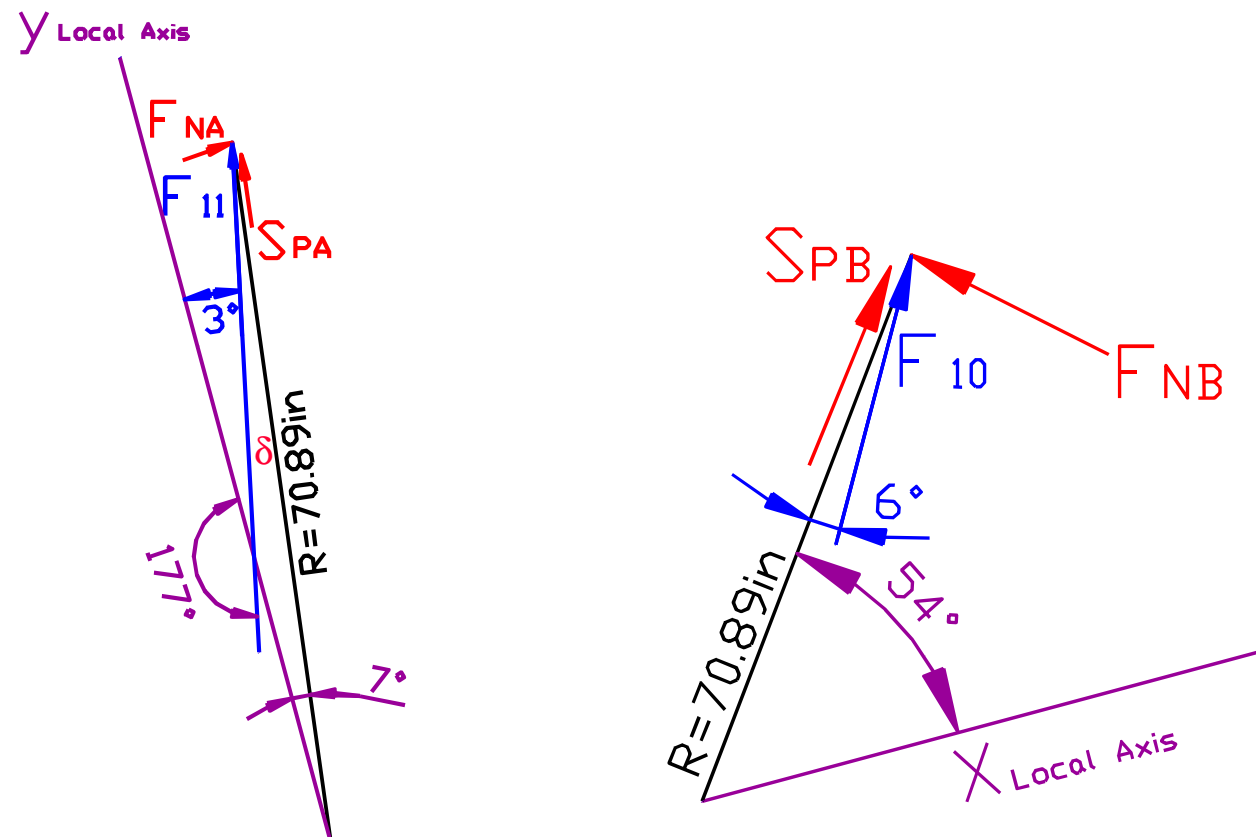

Figure 5.3. Support reaction geometry layout: (left) support $A, F_{11}$, and (right) support $B, F_{10}$

\subsection{Configuration with New Location of the Arc Beam and Recorded $F_{10}$ and $F_{11}$ Outside the Radial Direction}

After the analysis of the second proposed configuration was concluded, a new configuration for the arc beam was proposed. Recall that it is necessary to change the arc position because the angle that is made with the radial direction must be less than the external angle, as was demonstrated in the previous section (Figure 5.3). After several attempts, a new configuration was derived (shown in Figure 5.4) and was adopted because it was the only configuration (of the three) that produced reasonable results in terms of the coefficient of friction and compression in the arc. Also, the normal stresses developed at the instant of maximum normal force $\left(F_{w}\right)_{\max }$ are in the range established in other research (Table 3.4). Now the arc bumper is located at $57.5 \mathrm{deg}$ from the longitudinal axis of the barges and the support reactions' geometry agrees with the basic geometric law that the internal angle of a triangle sum $180 \mathrm{deg}$, as shown in Figure 5.5. In this configuration, the coordinates' transformations (presented in Equation 5.1) were also used.

To check the energy model, the fixed coefficient of friction model was used with the coefficient of friction obtained from the energy model calculation. The values presented in Table 5.3 indicate the good agreement between both models, and the reasonable coefficient of friction values obtained with both models. For example, in Experiment 29, the resulting $F_{w}$ and $S_{w}$ are practically the same in the two models. We can compare the 286.78 and 286.63 kips for the fixed coefficient of friction and the energy method, respectively. 


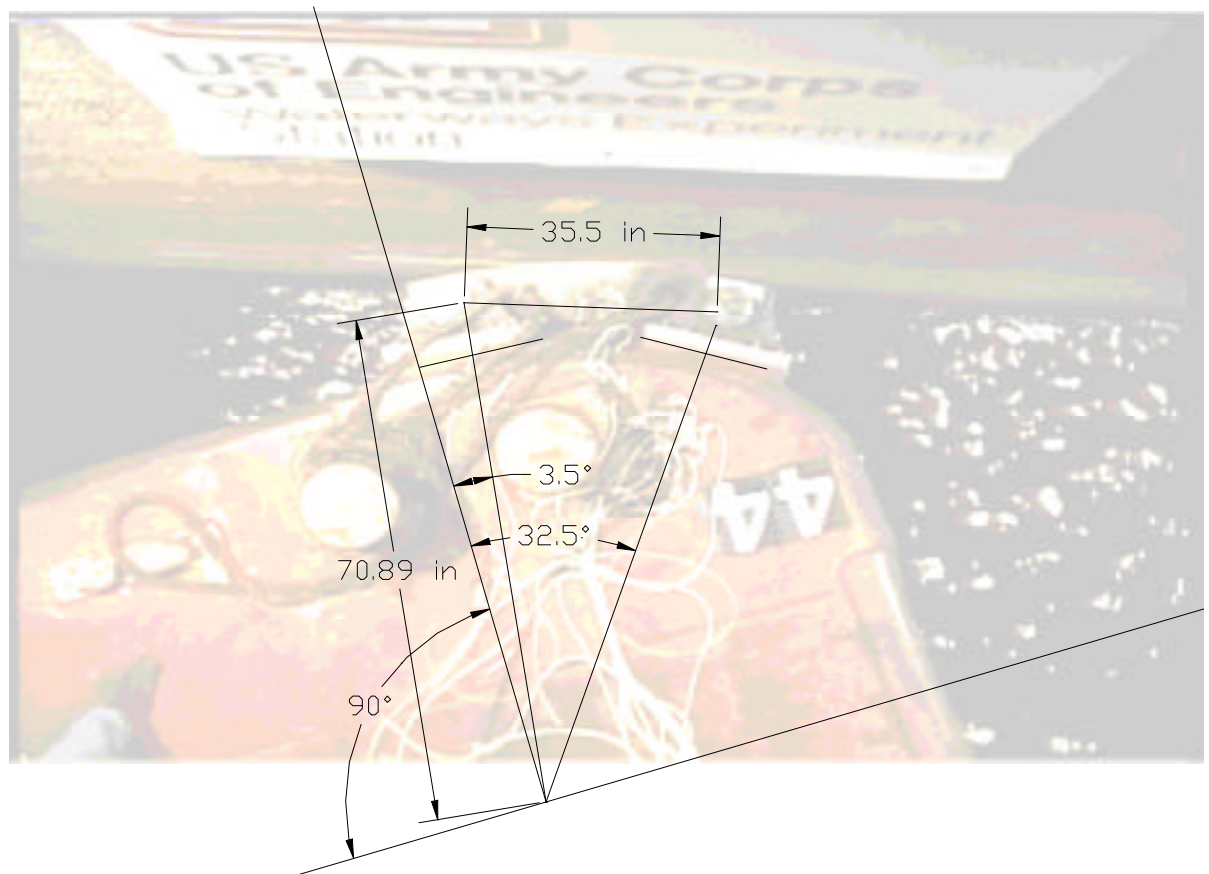

a. Arc geometry used for force analysis

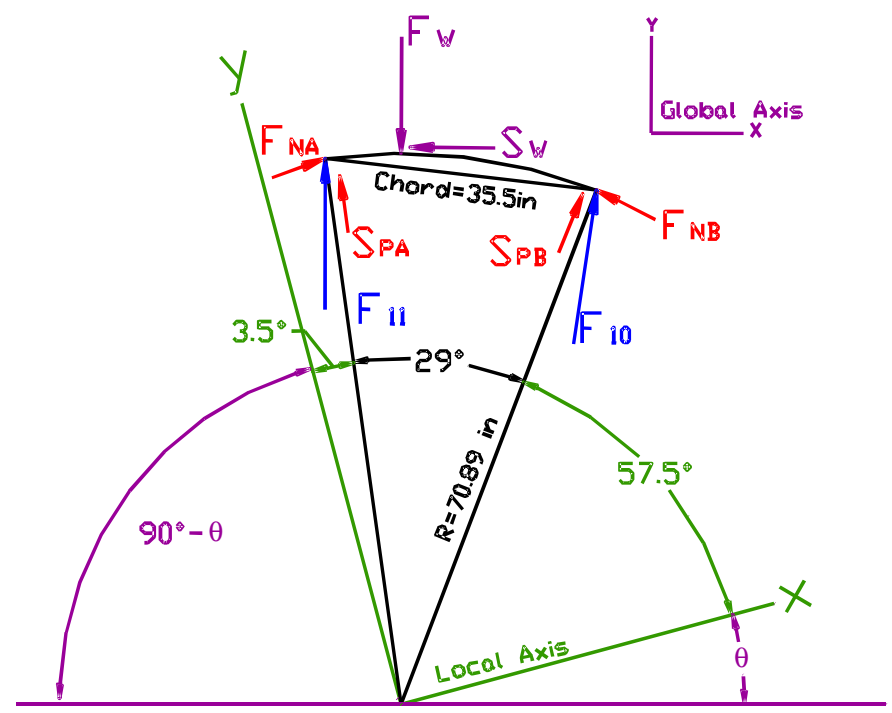

b. Forces acting on load bumper

Figure 5.4. Proposed (third) load cell and arc location layout 


\begin{tabular}{|c|c|c|c|c|c|c|c|c|c|c|c|c|c|c|c|c|c|}
\hline & 点和 & $\overline{5}$ & $\overline{5}$ & $\stackrel{\&}{g}$ & $\stackrel{2}{\cong}$ & 8 & है & 8 & 8 & $\frac{3}{8}$ & : & 8 & $\stackrel{\%}{+}$ & $\stackrel{5}{=}$ & $\stackrel{5}{=}$ & $\stackrel{8}{8}$ & $\begin{array}{l}8 \\
0 \\
-1\end{array}$ \\
\hline 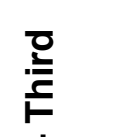 & 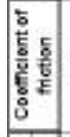 & 8 & g & 嗠 & g & g & gै & 용 & జี & 5 & 5 & 힘 & $\overline{8}$ & $\overline{5}$ & $\overline{8}$ & 8 & 8 \\
\hline$\frac{1}{0}$ & ตุ & $\stackrel{\text { 点 }}{g}$ & 点 & $\begin{array}{l}\overline{\mathbf{S}} \\
\underline{E}\end{array}$ & 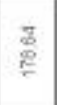 & $\overline{5}$ & $\begin{array}{l}\text { 点 } \\
\stackrel{c}{g}\end{array}$ & $\begin{array}{l}\text { E } \\
\stackrel{E}{E}\end{array}$ & 蛋 & $\bar{y}$ & 西 & $\overline{\underline{m}}$ & 息 & 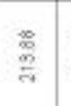 & 률 & $\frac{b}{b}$ & 폼 \\
\hline กั & $z$ & 兽 & $\begin{array}{l}m \\
y\end{array}$ & 苋 & $\frac{4}{13}$ & कू & $\stackrel{d}{\sharp}$ & 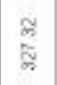 & 僖 & 骨 & Æֶ. & $\frac{m}{E}$ & $\frac{\mathrm{E}}{\mathrm{H}}$ & $\frac{\alpha}{\frac{\alpha}{\sigma}}$ & $\frac{8}{7}$ & $\begin{array}{l}\text { व } \\
\text { है }\end{array}$ & 章 \\
\hline $\begin{array}{l}\bar{\pi} \\
\text { م) } \\
\text { ñ }\end{array}$ & $5^{2}$ & $\frac{\mathscr{2}}{g}$ & $=$ & $\begin{array}{l}8 \\
\stackrel{2}{=}\end{array}$ & $\begin{array}{l}\stackrel{5}{6} \\
= \\
=\end{array}$ & $\stackrel{8}{\rightleftarrows}$ & $\stackrel{?}{\rightleftarrows}$ & $\begin{array}{l}q y \\
\underline{z} \\
\underline{z}\end{array}$ & 要 & 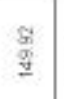 & $\begin{array}{l}9 \\
\stackrel{g}{2} \\
9\end{array}$ & $\frac{g}{g}$ & $\frac{8}{8}$ & $\stackrel{\circ}{\circ}$ & $\bar{g}$ & $\frac{z}{\bar{x}}$ & $\frac{a}{\pi}$ \\
\hline 苛 & $\vec{x}$ & $\stackrel{8}{8}$ & $\frac{9}{3}$ & $\frac{9}{3}$ & $\begin{array}{l}Z \\
⿱ 乛 \\
\$\end{array}$ & $\begin{array}{l}8 \\
8 \\
8\end{array}$ & 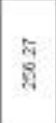 & $\frac{9}{\frac{7}{7}}$ & $\frac{2}{\frac{2}{4}}$ & $\frac{2}{5}$ & $\begin{array}{l}8 \\
8 \\
8\end{array}$ & g & 8 & $\frac{8}{8}$ & $\begin{array}{l}8 \\
8 \\
8\end{array}$ & 8 & $\begin{array}{l}y \\
y \\
y\end{array}$ \\
\hline ِّ & $\frac{2}{m_{0}}$ & 8 & $\overline{9}$ & 蚂 & $\frac{4}{8}$ & 每 & 8 & 争 & జ & 趂 & 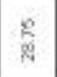 & ॠ & $\stackrel{8}{8}$ & है & ते & $\begin{array}{l}8 \\
2 \\
2\end{array}$ & $\begin{array}{l}8 \\
9 \\
9\end{array}$ \\
\hline 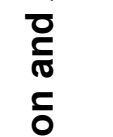 & 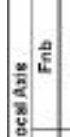 & E & E. & $\frac{x}{2}$ & $\frac{8}{8}$ & 兽 & $\stackrel{\text { tg }}{\underline{\underline{g}}}$ & 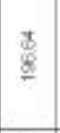 & $\$$ & $\frac{\underline{Z}}{\underline{I}}$ & $\begin{array}{l}8 \\
\stackrel{8}{I} \\
I\end{array}$ & कू & $\begin{array}{l}\bar{x} \\
\bar{B}\end{array}$ & 若 & \& & $\frac{8}{8}$ & $\begin{array}{l}\text { 댕. } \\
\text { : }\end{array}$ \\
\hline 苞 & $\frac{\vec{m}}{\hat{m}}$ & 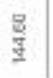 & 童 & 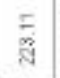 & $\overrightarrow{\bar{i}}$ & $\frac{\underline{B}}{\underline{I}}$ & $\frac{5}{\underline{y}}$ & $\begin{array}{l}\stackrel{q}{ \pm} \\
\stackrel{ \pm}{ \pm}\end{array}$ & $\begin{array}{l}\text { 登 } \\
\underline{2}\end{array}$ & है & $\frac{8}{5}$ & 吾 & 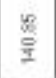 & $\begin{array}{l}9 \\
\text { D } \\
\text { है }\end{array}$ & 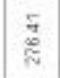 & 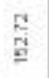 & $\begin{array}{l}E \\
\text { E }\end{array}$ \\
\hline$\frac{\overline{0}}{\tilde{0}}$ & $\frac{z}{4}$ & gू & $\begin{array}{l}\overline{0} \\
\overline{2}\end{array}$ & $\frac{\mathrm{g}}{\mathrm{g}}$ & $\overline{\bar{z}}$ & $\stackrel{8}{d}$ & $\frac{\pi}{2}$ & 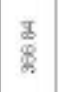 & $\frac{\frac{9}{8}}{8}$ & 굴 & 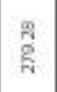 & $\begin{array}{l}\text { d } \\
\underline{b} \\
\underline{a}\end{array}$ & $\dddot{\Xi}$ & สี & 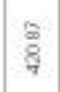 & $\begin{array}{l}\text { A } \\
\frac{1}{6}\end{array}$ & 管 \\
\hline$\underset{\mathbb{\alpha}}{\mathbb{\pi}}$ & $\widehat{\oplus}$ & $\frac{7}{8}$ & $\frac{m}{8}$ & $\stackrel{\Phi}{\equiv}$ & 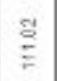 & ì & $\begin{array}{l}\bar{\Xi} \\
\text { s }\end{array}$ & $\begin{array}{l}\stackrel{\infty}{\circ} \\
\&\end{array}$ & $\begin{array}{l}\text { : } \\
\text { 总 }\end{array}$ & 费 & $\begin{array}{l}n \\
0 \\
0\end{array}$ & 홈 & $\frac{\mathrm{m}}{8}$ & $\begin{array}{l}8 \\
\text { 密 }\end{array}$ & $\begin{array}{l}\text { कृ } \\
\text { है }\end{array}$ & $\frac{8}{8}$ & 疋 \\
\hline $\begin{array}{l}\frac{0}{0} \\
\frac{0}{9} \\
\frac{1}{3}\end{array}$ & : & $\frac{E}{5}$ & $\frac{n}{8}$ & $\overline{\bar{y}}$ & בี & $\frac{\bar{T}}{\bar{T}}$ & $\frac{\text { के }}{\sigma}$ & 莺 & $\frac{\frac{.0}{5}}{\frac{E}{5}}$ & $\frac{8}{4}$ & $\overline{5}$ & $\frac{8}{8}$ & है & E & 密 & : & ํㅗㅁ \\
\hline \& & $\frac{0}{8}$ & $\stackrel{8}{2}$ & $\begin{array}{l}7 \\
9 \\
9\end{array}$ & $\frac{\infty}{\infty}$ & 鄫 & $\frac{\vec{t}}{\underline{G}}$ & $\stackrel{9}{6}$ & $\frac{7}{8}$ & 焉 & $\frac{E}{5}$ & $\frac{2}{6}$ & है & 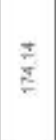 & $\begin{array}{l}\text { 蛋 } \\
\frac{2}{5}\end{array}$ & 敢 & $\begin{array}{l}8 \\
5 \\
5\end{array}$ & कू \\
\hline 잉 & $x$ & ח. & 墨 & $\begin{array}{l}\text { 营 } \\
\frac{0}{n}\end{array}$ & $\stackrel{ \pm}{=}$ & 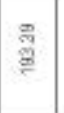 & g & స్ & 矢 & $\$$ & 苔 & $E$ & 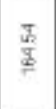 & $\begin{array}{l}\text { 勇 } \\
\text { 甪 }\end{array}$ & 苞 & 㺃 & 总 \\
\hline ס & $a^{2}$ & & & & \multicolumn{2}{|c|}{$\stackrel{8}{9}$} & & \multicolumn{2}{|c|}{ I } & \multicolumn{2}{|l|}{ 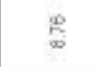 } & \multicolumn{2}{|c|}{$\stackrel{8}{*}$} \\
\hline$\stackrel{\frac{5}{n}}{s}$ & 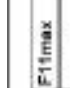 & \multicolumn{2}{|c|}{ 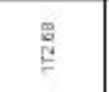 } & & & \multicolumn{2}{|c|}{ 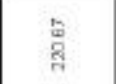 } & \multicolumn{2}{|c|}{ 藏 } & & \multicolumn{2}{|l|}{$\begin{array}{l}\frac{7}{7} \\
\frac{\phi}{2}\end{array}$} & \multicolumn{2}{|c|}{$\stackrel{b}{\bar{c}}$} \\
\hline$\frac{\pi}{0}$ & 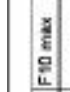 & \multicolumn{2}{|c|}{ 总 } & \multicolumn{2}{|c|}{$\frac{8}{2}$} & & \multicolumn{2}{|c|}{$\frac{\mathrm{q}}{\mathrm{m}}$} & \multicolumn{2}{|c|}{ 㞼 } & \multicolumn{2}{|c|}{ 高 } & & \multicolumn{2}{|c|}{$\underline{\frac{t}{3}}$} \\
\hline $\mathbb{L}_{0}$ & $\frac{6}{2}$ & \multicolumn{2}{|c|}{ 思 } & \multicolumn{2}{|c|}{ 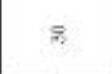 } & \multicolumn{2}{|c|}{$\bar{n}$} & \multicolumn{2}{|c|}{$m$} & \multicolumn{2}{|l|}{$\$$} & \multicolumn{2}{|c|}{$\therefore$} & \multicolumn{2}{|l|}{$\mp$} & : & 4 \\
\hline 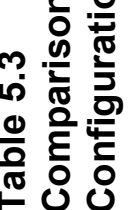 & & 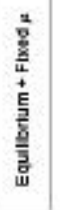 & 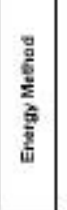 & 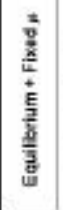 & 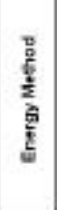 & 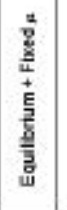 & 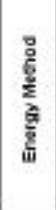 & 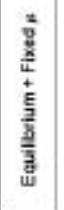 & 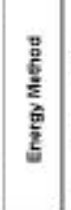 & 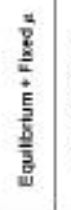 & 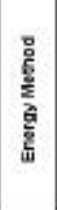 & 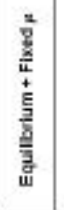 & 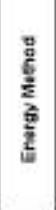 & 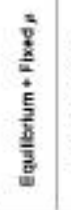 & 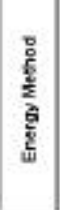 & 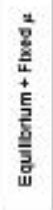 & 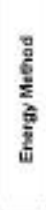 \\
\hline
\end{tabular}



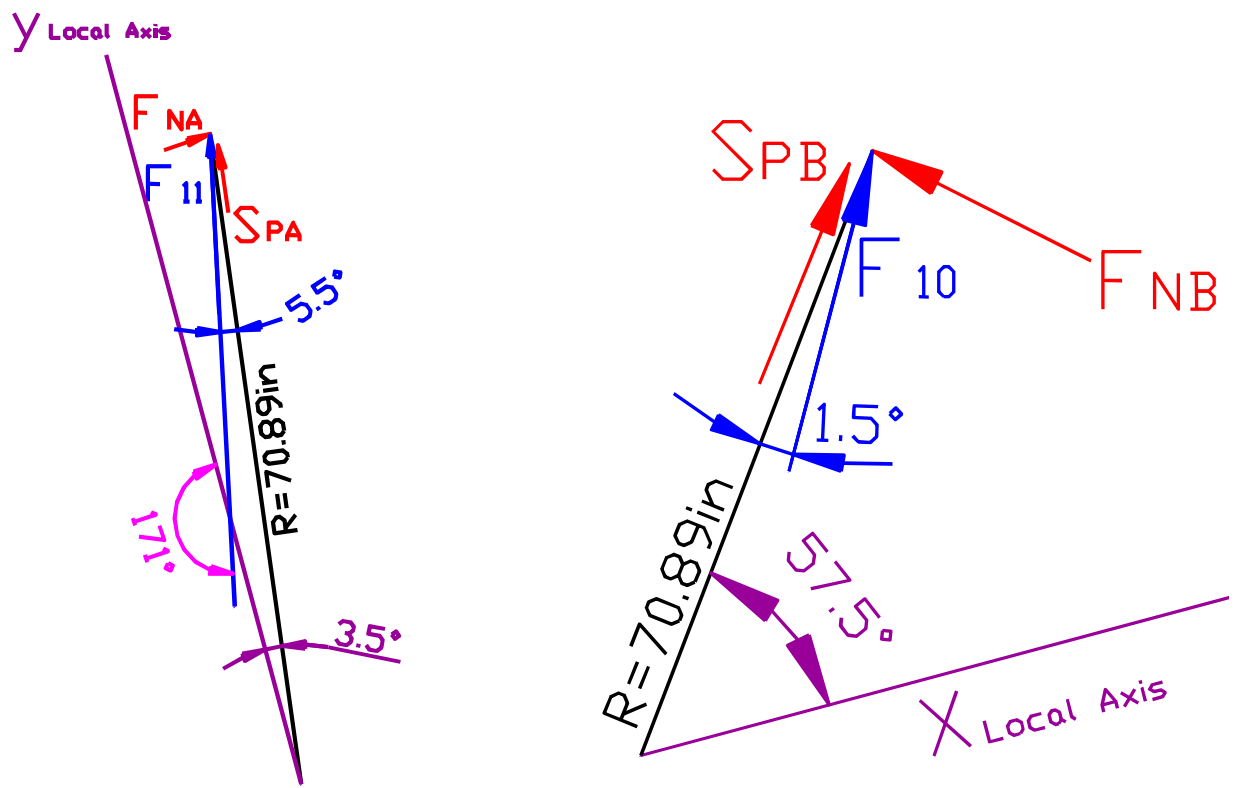

Figure 5.5. Support reaction geometry layout of proposed model: (left) support $A, F_{11}$, and (right) support $B, F_{10}$

In terms of the resulting coefficient of friction, with the exception of one impact experiment (No. 42), the obtained values for this third model are within the 0.43 to 0.6 range. These values are consistent within the Baltay and Gjelsvik (1990) data. Using this third configuration, the arc is in compression for all the impact experiments. It can be observed in column $B_{x}$ in Table 5.3. As mentioned, the horizontal reaction $B_{x}$ has to be negative (as shown in Figure 3.3c) for the arc to be in compression. This condition is also satisfied with this third configuration.

One additional column is introduced in Table 5.3, which is the normal stress developed at the instant of maximum normal force. These stresses are calculated by dividing the normal force to the wall $F_{w}$ by the contact area $(5 \times 7.25 \mathrm{in}$. $=36.25 \mathrm{sq}$ in.). As shown in Table 5.3, the range of maximum normal stresses developed for all the experiments is 6.35 to $15.93 \mathrm{ksi}$. For example, for Experiment 38, the value of $F_{w}$ is 230.31 kips, resulting in a maximum normal stress of $\sigma=F_{w} /$ Area $=230.31 / 36.25=6.35 \mathrm{ksi}$. These stresses are consistent with the range presented by the Baltay and Gjelsvik (1990) data shown in Table 3.4. As a result of these careful evaluations of the data, the third configuration is deemed to be an accurate model for this indeterminate bumper system. Key factors leading to this conclusion include the fact that this third configuration results in the arc bumper being in compression for all impact experiments as well as the consistency between the resulting coefficients of friction and the stresses developed with those values measured in the Baltay and Gjelsvik (1990) experiments.

The maximum normal force $\left(F_{w}\right)_{\max }$ is equal to the reaction force provided by the lock wall on the barge flotilla during the impact. Neither the forces $F_{\text {tow }}, F_{\text {drag }}$, and $F_{\text {helper }}$ acting on the barge flotilla (and depicted in Figure 2.3) nor the 
hydrodynamic forces (corresponding to the hydrodynamic added masses) were measured during the impact tests. However, the Table 5.3 computed values of $\left(F_{w}\right)_{\max }$ reflect the effects of all external forces identified in Figure 2.3 acting on the barge flotilla, as well as the effects of the hydrodynamic masses and the inertia of the barge flotilla mass decelerating during impact.

\subsection{ETL 1110-2-338 Engineering Procedure}

ETL 1110-2-338 provides an engineering procedure for the collision of a barge flotilla with a rigid structure. According to the ETL 1110-2-338 engineering procedure, the magnitude of the impact forces generated by a particular collision event is dependent on the mass (including hydrodynamic added mass of the barge flotilla), the approach velocity, the approach angle, the barge flotilla moment of inertia, damage sustained by the barge structure, and friction between the barge and the wall. A major distinction between this procedure and the traditional Navy method for determining berthing forces is the estimation of collision energy dissipated in deformation of the barge structure and transferred to the rotation of the barge flotilla. The analytical method uses the structural interaction mechanism of Minorsky, which provides an empirical relationship between the (nonrecoverable) hull deformation and the energy absorbed in a collision. The relationship between kinetic energy lost in a collision and the volume of in-plane (barge) material damaged is used to determine impact force as a relationship to instantaneous contact area of damaged structure.

Minorsky used the conservation laws of momentum and energy and the principles of rigid body mechanics to estimate the kinetic energy lost during a collision between two vessels. He then calculated a resistance factor that is essentially the volume of material damaged in the bow of the striking ship and in the side of the struck ship. Minorsky reasoned that the principal resistance to collision penetration is provided by deep structure that suffers in-plane damage. For the case of a barge striking a fixed wall, the main deck, the bottom plate, the head $\log$, and the transverse frames would offer resistance to damage.

Minorsky selected and analyzed 26 actual ship collisions and correlated the energy absorbed in the collision with the Minorsky resistance factor. Using the equivalency between energy absorbed and the work performed in deforming the structure, a constant described as the force per unit of damaged surface area was defined (=13.7 ksi). The Minorsky structural interaction mechanism is a constant pressure process operating with a pressure of $13.7 \mathrm{ksi}$ over the instantaneous face area of the damaged element. This allows for the definition of an equivalent, linear spring constant representing the crushing of the barge structure in the ETL 1110-2-338 analytical formulation. It is important to note that the entire structural interaction mechanism is modeled as a linear spring in the direction of collision corresponding to the energy absorption in the crushed barge structure. The formulation becomes one of an initial value problem for a barge flotilla collision with a rigid wall, representing a lock wall in this case, and leads to the solution given in ETL 1110-2-338. 
When computing values of maximum impact force normal to the wall, $\left(F_{w}\right)_{\max }$, following the engineering procedure outlined in ETL-1110-2-338, the mass, $M$, and moment of inertia, $I$, of the barge flotilla are increased to account for hydrodynamic effects by means of hydrodynamic added-mass terms. Different values for these hydrodynamic added masses are used in different barge flotilla directions. In the longitudinal direction of the barge flotilla, $M_{x}$ is set equal to $1.05^{\circ} \mathrm{M}$; in the transverse direction $M_{y}$ is set equal to $1.4 \mathrm{M}$, and $I_{\theta}$ is set equal to $1.4 I$.

The ETL 1110-2-338 engineering procedure was used to compute values of maximum impact force normal to the wall, $\left(F_{w}\right)_{\max }$, for the eight full-scale, controlled barge impact experiments listed in Table 5.3. The coefficients of friction used in these computations were the same as those derived from field-test data summarized in Table 5.3. The results of these ETL-based computations are given in Table 5.4. Values of $\left(F_{w}\right)_{\max }$ are between 263.8 and 423.8 kips for these computations.

\section{Table 5.4}

Values of $\left(F_{w}\right)_{\max }$, Time of End of Collision, and Deformation of Barge at Contact Point at End of Collision by the ETL 1110-2-338 Engineering Procedure

\begin{tabular}{|l|l|l|l|l|l|l|l||}
\hline \hline $\begin{array}{l}\text { Experiment } \\
\text { Number }\end{array}$ & $\begin{array}{l}\text { Approach } \\
\text { Velocity } \\
\text { fps }\end{array}$ & $\begin{array}{l}\text { Approach } \\
\text { Angle } \\
\text { deg }\end{array}$ & $\begin{array}{l}\text { Velocity } \\
\text { Normal } \\
\text { to Wall } \\
\text { fps }\end{array}$ & $\begin{array}{l}\text { Coefficient of } \\
\text { Friction - } \\
\text { Table 5.3 }\end{array}$ & $\begin{array}{l}\text { Time of End } \\
\text { of Collision } \\
\text { sec }\end{array}$ & $\begin{array}{l}\text { Deformation of } \\
\text { Barge at Contact } \\
\text { Point at End of } \\
\text { Collision } \\
\text { ft }\end{array}$ & $\begin{array}{l}\left(\boldsymbol{F}_{\mathbf{w}}\right)_{\text {max }} \\
\begin{array}{l}\text { (110-2-338* } \\
\text { kips }\end{array}\end{array}$ \\
\hline \hline 29 & 2.2 & 12.63 & 0.48 & 0.6 & 1.464 & 0.619 & 409.5 \\
\hline 30 & 2.35 & 12.19 & 0.50 & 0.48 & 1.412 & 0.619 & 420.9 \\
\hline 31 & 1.61 & 10.6 & 0.30 & 0.43 & 1.299 & 0.342 & 263.8 \\
\hline 37 & 1.95 & 10.29 & 0.35 & 0.52 & 1.292 & 0.399 & 317.4 \\
\hline 38 & 1.83 & 11.94 & 0.38 & 0.57 & 1.412 & 0.472 & 327.6 \\
\hline 39 & 1.61 & 14.12 & 0.39 & 0.51 & 1.54 & 0.532 & 317.2 \\
\hline 41 & 2.86 & 8.76 & 0.44 & 0.51 & 1.182 & 0.458 & 423.8 \\
\hline 42 & 1.83 & 17.48 & 0.55 & 0.09 & 1.625 & 386.5 \\
\hline \hline
\end{tabular}

The values of $\left(F_{w}\right)_{\max }$ given in Table 5.4 for the eight controlled-impact experiments occur at the times denoted as "time of end of collision." Note that computed values for the time of end of collision are between 1.182 and $1.625 \mathrm{sec}$ by the ETL 1110-2-338 engineering procedure, while the actual times to maximum force recorded for these eight controlled-impact experiments were between 0.1282 and $0.2352 \mathrm{sec}$ (Table A.2). The ETL 1110-2-338 procedure overestimates the time to maximum force by about a factor of 8 .

Table 5.4 also lists the computed deformation of barge at contact point (i.e., impact point) at end of collision by the ETL-1110-2-338 engineering procedure. Values range from 0.342 to $0.793 \mathrm{ft}$ in these eight computations. This computed deformation is the deformation of the linear spring in the direction of collision corresponding to the energy absorption in the crushed barge structure. Because 
the ETL 1110-2-338 analytical method uses the structural interaction mechanism of Minorsky, which provides an empirical relationship between the (nonrecoverable) hull deformation and the energy absorbed in a collision, this deformation may be viewed as an indicator of the nonrecoverable damage to the barge corner as a result of the barge flotilla impacting the lock wall. Note that no damage was observed to the barge corner during any of these low-velocity, controlled-impact experiments at Robert C. Byrd Lock.

The results of these eight ETL 1110-2-338 computations are repeated in Table 5.5, along with the Table 5.3 values for $\left(F_{w}\right)_{\max }$. For example, for Experiment 29, the ETL 1110-2-338 engineering procedure produces an $\left(F_{w}\right)_{\max }$ value of $409.5 \mathrm{kips}$, and the Table 5.3 energy method or the equilibrium with a fixed coefficient of friction value produces an $\left(F_{w}\right)_{\max }$ value of $287.53 \mathrm{kips}$. This corresponds to a 42-percent overprediction by the ETL 1110-2-338 approach. The maximum force normal to the wall, $\left(F_{w}\right)_{\max }$, computed using the ETL 11102-338 engineering procedure differs from the maximum force $\left(F_{w}\right)_{\max }$ values presented in Table 5.3 by a 33-percent underprediction to a 42 -percent overestimate for these eight impact tests.

\begin{tabular}{|c|c|c|c|c|c|c|c|}
\hline $\begin{array}{l}\text { Experiment } \\
\text { Number }\end{array}$ & $\begin{array}{l}\text { Approach } \\
\text { Velocity } \\
\text { fps }\end{array}$ & $\begin{array}{l}\text { Approach } \\
\text { Angle } \\
\text { deg }\end{array}$ & $\begin{array}{l}\text { Velocity } \\
\text { Normal } \\
\text { to Wall } \\
\text { fps }\end{array}$ & $\begin{array}{l}\text { Coefficient } \\
\text { of Friction - } \\
\text { Table 5.3 }\end{array}$ & $\begin{array}{l}\left(F_{w}\right)_{\max } \\
\text { Table } 5.3 \\
\text { kips }\end{array}$ & $\begin{array}{l}\left(F_{w}\right)_{\max } \text { ETL } \\
1110-2-338^{*} \\
\text { kips }\end{array}$ & $\begin{array}{l}\text { Percent } \\
\text { Difference }\end{array}$ \\
\hline 29 & 2.2 & 12.63 & 0.48 & 0.6 & 287.53 & 409.5 & 42 \\
\hline 30 & 2.35 & 12.19 & 0.50 & 0.48 & 371.16 & 420.9 & 13 \\
\hline 31 & 1.61 & 10.6 & 0.30 & 0.43 & 235.30 & 263.8 & 12 \\
\hline 37 & 1.95 & 10.29 & 0.35 & 0.52 & 327.49 & 317.4 & -3 \\
\hline 38 & 1.83 & 11.94 & 0.38 & 0.57 & 230.56 & 327.6 & 42 \\
\hline 39 & 1.61 & 14.12 & 0.39 & 0.51 & 272.06 & 317.2 & 17 \\
\hline 41 & 2.86 & 8.76 & 0.44 & 0.51 & 419.35 & 423.8 & 1 \\
\hline 42 & 1.83 & 17.48 & 0.55 & 0.09 & 577.46 & 386.5 & -33 \\
\hline
\end{tabular}

\section{5 $F_{w}$ Time-Histories}

Using the third model configuration that was described in Section 5.3, a complete time-history of force normal to the wall, $F_{w}$, during the approximately $9 \mathrm{sec}$ of impact was developed for eight of the impact experiments. The value of the coefficient of friction used in this calculation was obtained in Chapter 5 with the energy method for the last configuration studied. Using a computer program presented in Appendix B, the time-histories for eight experiments were calculated. It is important to mention that three of the experiments had some discrepancies in the recorded $F_{10}$ and $F_{11}$. 
These experiments are Nos. 40, 43, and 44. The reason for neglecting these experiments is that, for some unknown reason, the time-histories for $F_{10}$ and $F_{11}$ cross over several times, or at some instant of time they have the same value and in another instant they have very different values during the $9 \mathrm{sec}$ of the impact process. For example, Figure A.15 presents the force time-history for Experiment 40. From this, it easy to see that the maximum force was recorded at the front cell (cell 10) and then, from the third peak, the maximum load was recorded at the rear cell (cell 11).

For Experiments 43 and 44, the story is different. We can easily notice from Figures A.18 and A.19 that, at the beginning of the time-history, the recorded force at both load cells is the same (that is, they have the same slope for approximately the first $0.04 \mathrm{sec}$ ), and then they have a great difference in magnitude. This is a situation that can be explained if different barge-to-wall angles are adopted during the $9 \mathrm{sec}$ of impact, which was checked with the GPS data recorded during the entire $9 \mathrm{sec}$ of the impact process. We concluded that these angles remain constant during the impact process after a detailed analysis of the GPS data of these experiments. Experiments 40, 43, and 44 were the last experiments performed during the full-scale, low-velocity, controlled barge impact experiments at Robert C. Byrd Lock in December 1998. Of all the experiments, they are associated with the highest impact angles (17.52, 21.16, and 20.92, respectively).

We can observe from Table 5.3 that the only experiment for which the coefficient of friction did not agree with the values reported by Baltay and Gjelsvik (1990) is Experiment 42, which produced a coefficient of friction of 0.09 . The approach angle of Experiment 42 was $17.48 \mathrm{deg}$, which is very close to the approach angle of Experiment 40. In addition, it is possible that the concrete wall surface had more irregularities (damage) than in the previous experiments due to the repeated impacts at the same unarmored concrete wall location by the flotilla. It is important to notice that the experiments with high approach angles produced, in some way, unreasonable values (that is, unreasonable coefficient of friction, crossover of the recorded forces, or a variable value (not constant) of the difference between the $F_{10}$ and $F_{11}$ forces during the time-history). The high approach angles associated with these experiments and the fact that they were the last experiments conducted (and probably were impacting a damage zone in the concrete wall resulting from the previous impact experiments) could explain the unreasonable coefficient of friction or the crossover of the recorded forces in the time-history.

As shown in Table 5.6, it can be observed that, from the calculation of the time-histories for the acceptable eight experiments (Figures 5.6-5.13), the resulting maximum force normal to the wall $F_{w}$ is not equal to the sum of the maximum recorded forces $F_{10}$ and $F_{11}$. It is not true that the $F_{w}$ has to be equal to $F_{10}+F_{11}$, because the forces are not oriented in the same direction. Force $F_{w}$ is oriented in the vertical global direction, and $F_{10}$ and $F_{11}$ are oriented with some angle from the vertical global direction. In addition, the shear term affects the distribution of forces in the arc. 


\begin{tabular}{|c|c|c|c|c|c|}
\hline \multicolumn{6}{|c|}{$\begin{array}{l}\text { Table } 5.6 \\
\text { Comparison of the Maximum Recorded Load Cells and Maximum } \\
\text { Force Normal to the Wall }\end{array}$} \\
\hline Exp No. & $\begin{array}{l}\begin{array}{l}\text { F10max } \\
\text { (kips) }\end{array} \\
\end{array}$ & $\begin{array}{l}\begin{array}{l}\text { F11max } \\
\text { (kips) }\end{array} \\
\end{array}$ & $\begin{array}{l}\text { Approach } \\
\text { Angle, deg } \\
\end{array}$ & $\begin{array}{l}\text { F10max + F11max } \\
\text { (kips) }\end{array}$ & $\begin{array}{l}\text { Fw } \\
\text { (kips) } \\
\end{array}$ \\
\hline 29 & 59.62 & 172.68 & 12.63 & 232.30 & 286.78 \\
\hline 30 & 94.39 & 245.95 & 12.19 & 340.34 & 369.82 \\
\hline 31 & 32.86 & 161.68 & 10.6 & 194.54 & 236.32 \\
\hline 37 & 31.66 & 220.67 & 10.29 & 252.33 & 327.32 \\
\hline 38 & 32.59 & 138.24 & 11.94 & 170.83 & 230.31 \\
\hline 30 & 84.91 & 158.77 & 14.12 & 243.69 & 271.98 \\
\hline 41 & 28.92 & 315.49 & 8.76 & 344.41 & 419.38 \\
\hline 42 & 153.14 & 211.17 & 17.48 & 364.31 & 577.44 \\
\hline
\end{tabular}

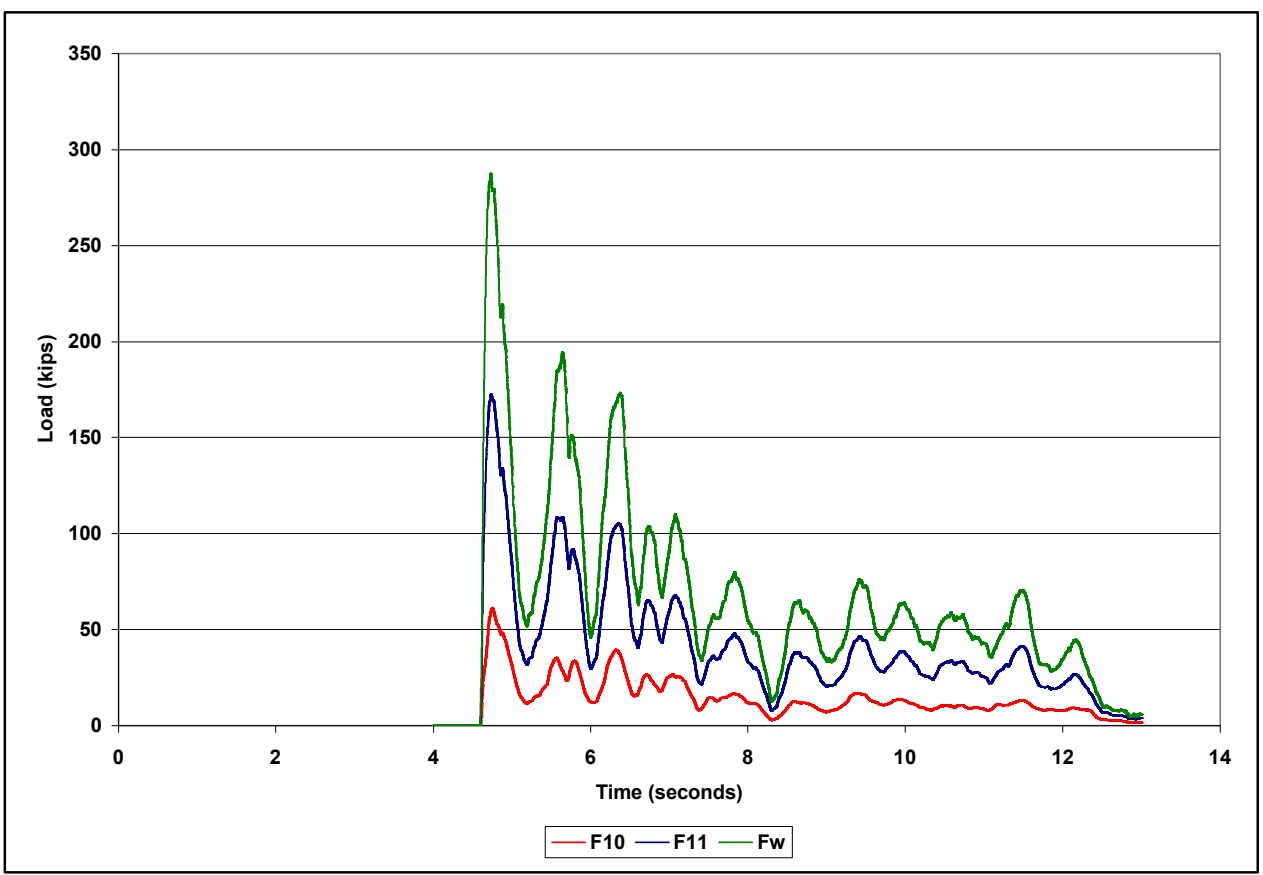

Figure 5.6. $\quad F_{10}, F_{11}$, and $F_{w}$ time-histories for Experiment 29 


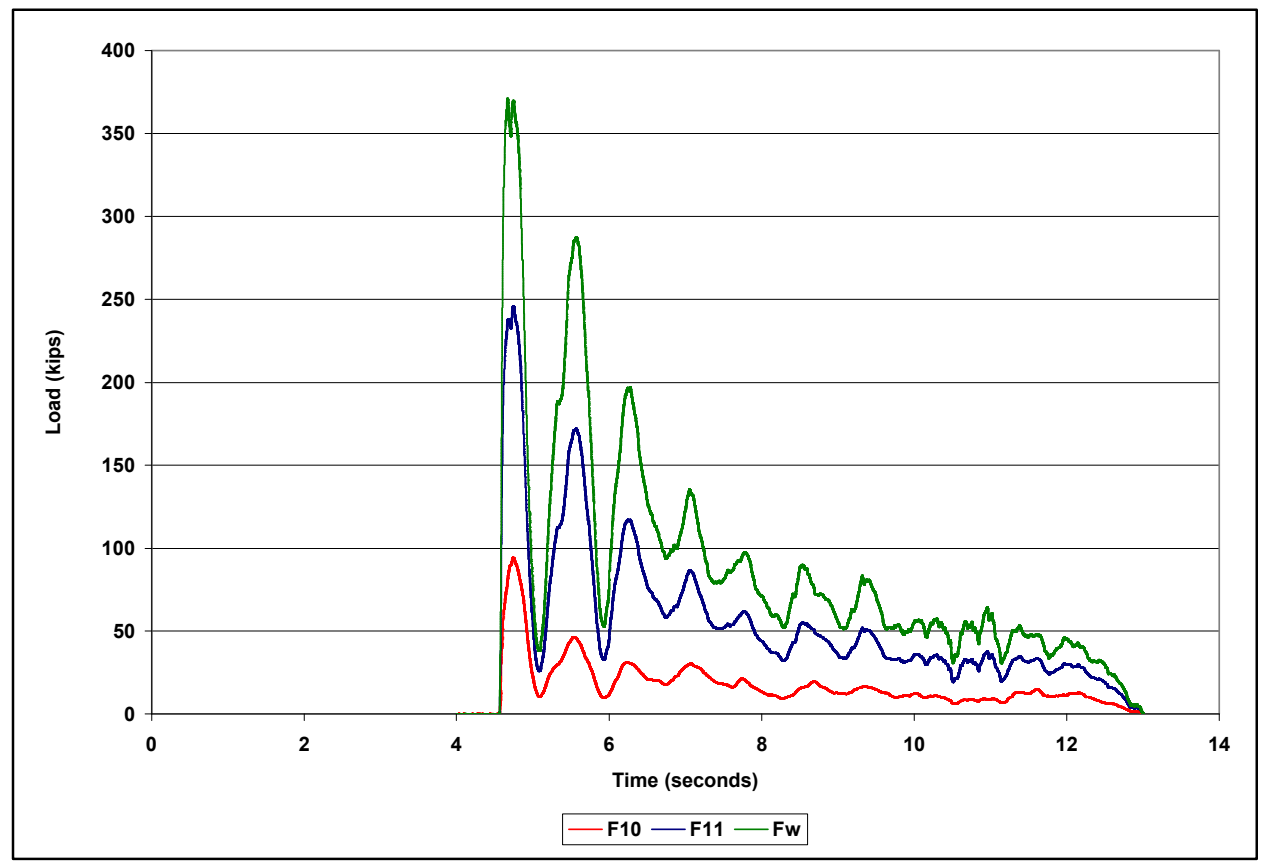

Figure 5.7. $F_{10}, F_{11}$, and $F_{w}$ time-histories for Experiment 30

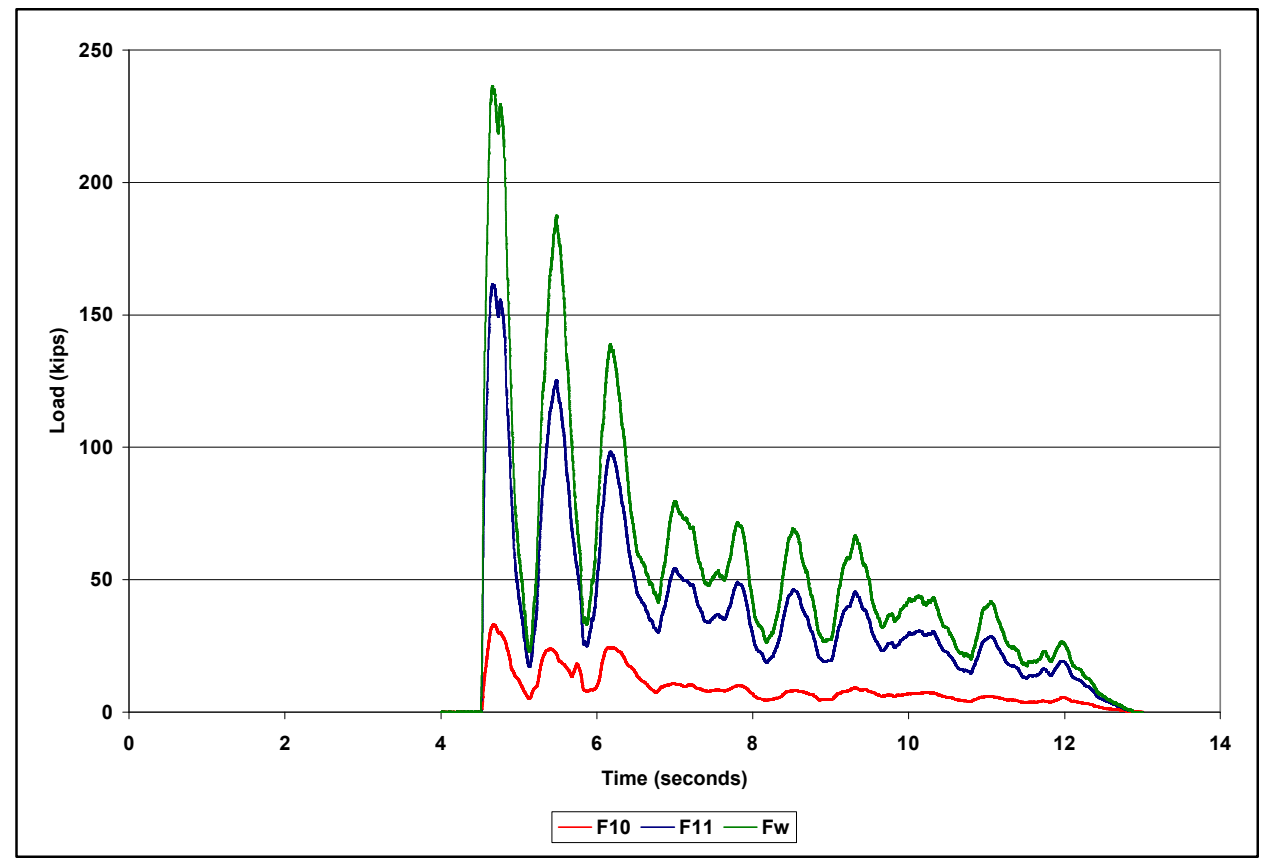

Figure 5.8. $\quad F_{10}, F_{11}$, and $F_{w}$ time-histories for Experiment 31 


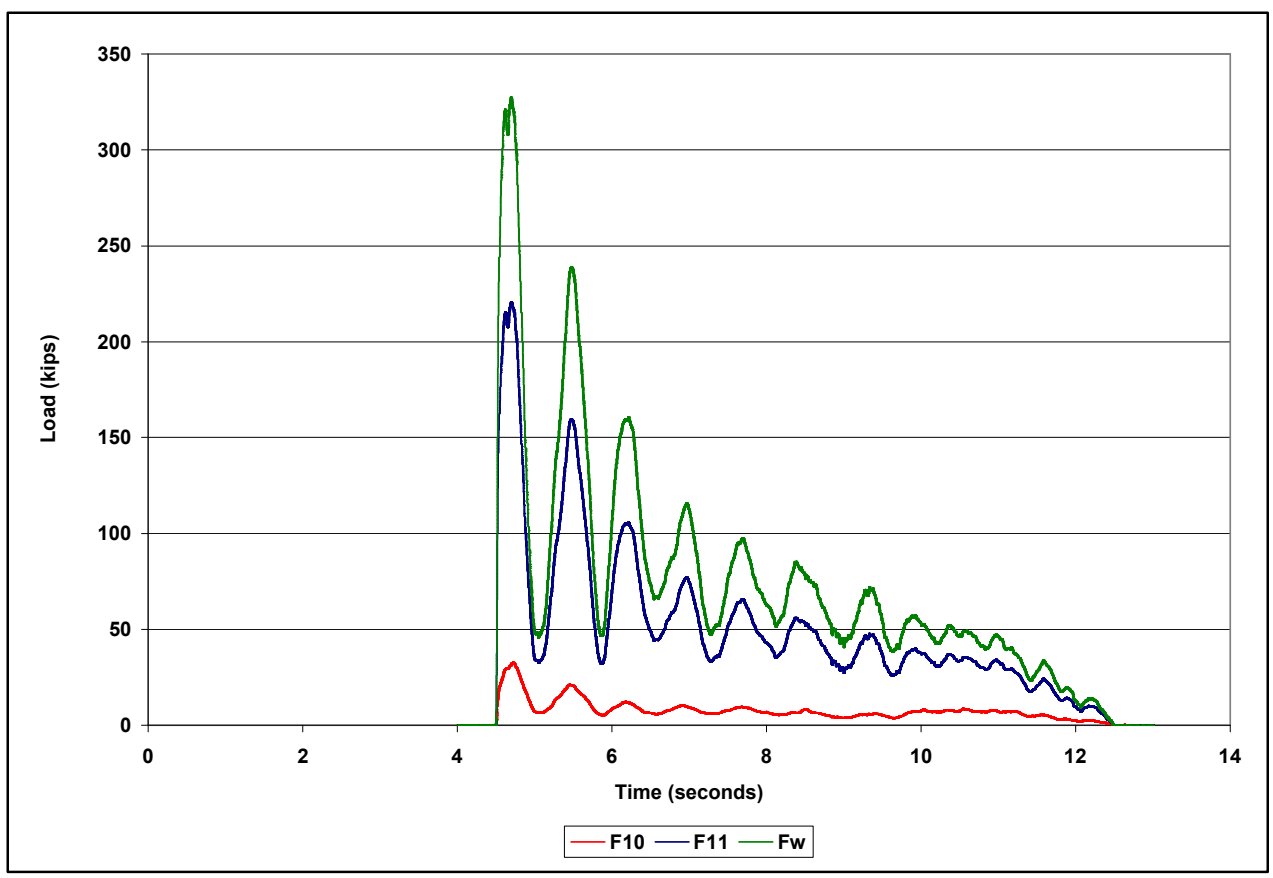

Figure 5.9. $F_{10}, F_{11}$, and $F_{w}$ time-histories for Experiment 37

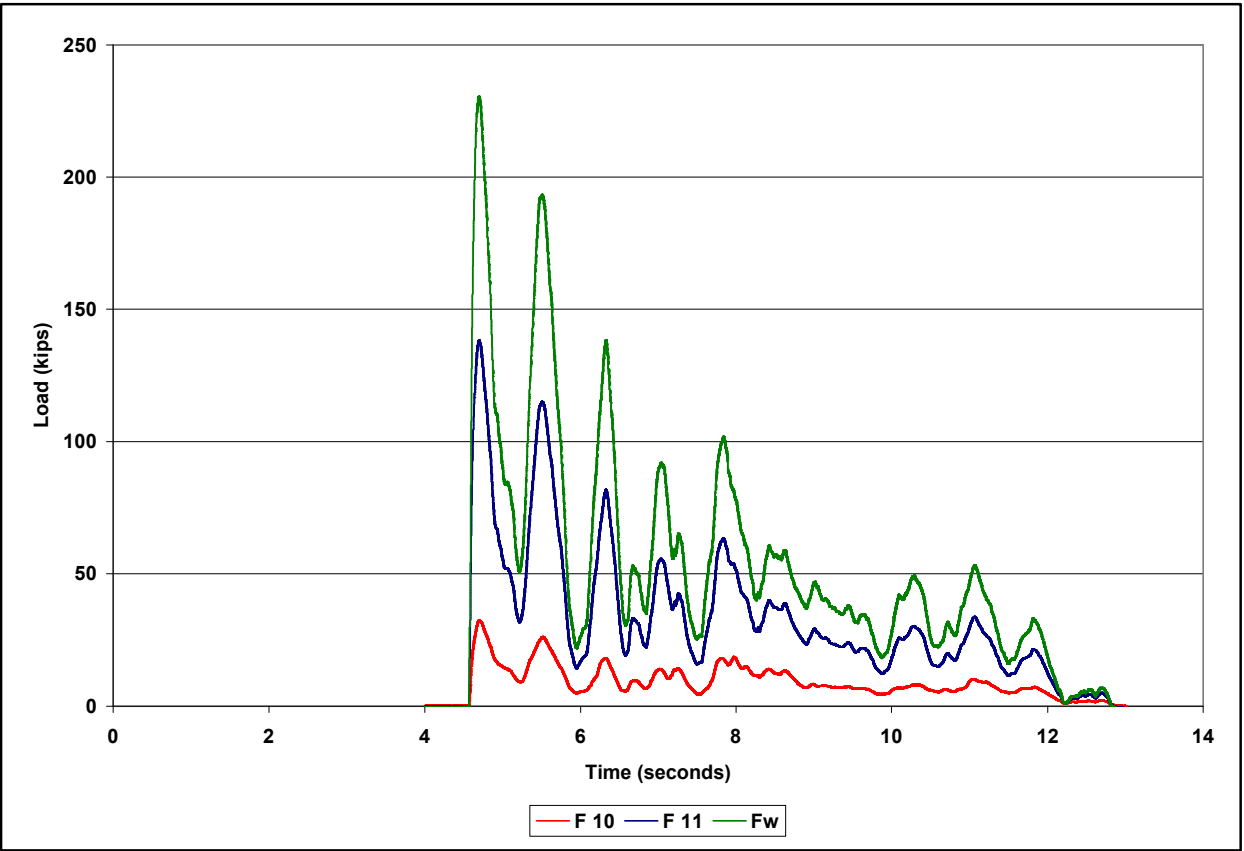

Figure 5.10. $F_{10}, F_{11}$, and $F_{w}$ time-histories for Experiment 38 


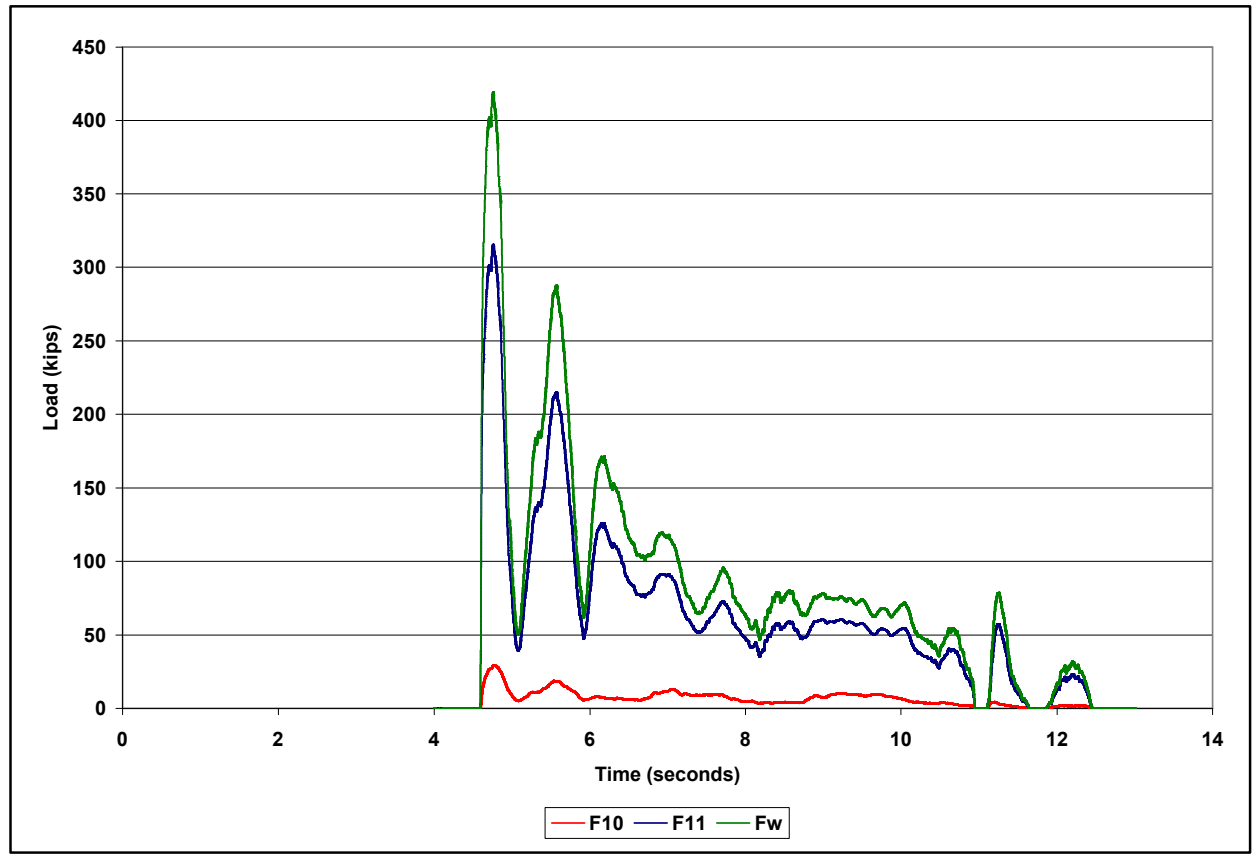

Figure 5.11. $F_{10}, F_{11}$, and $F_{w}$ time-histories for Experiment 39

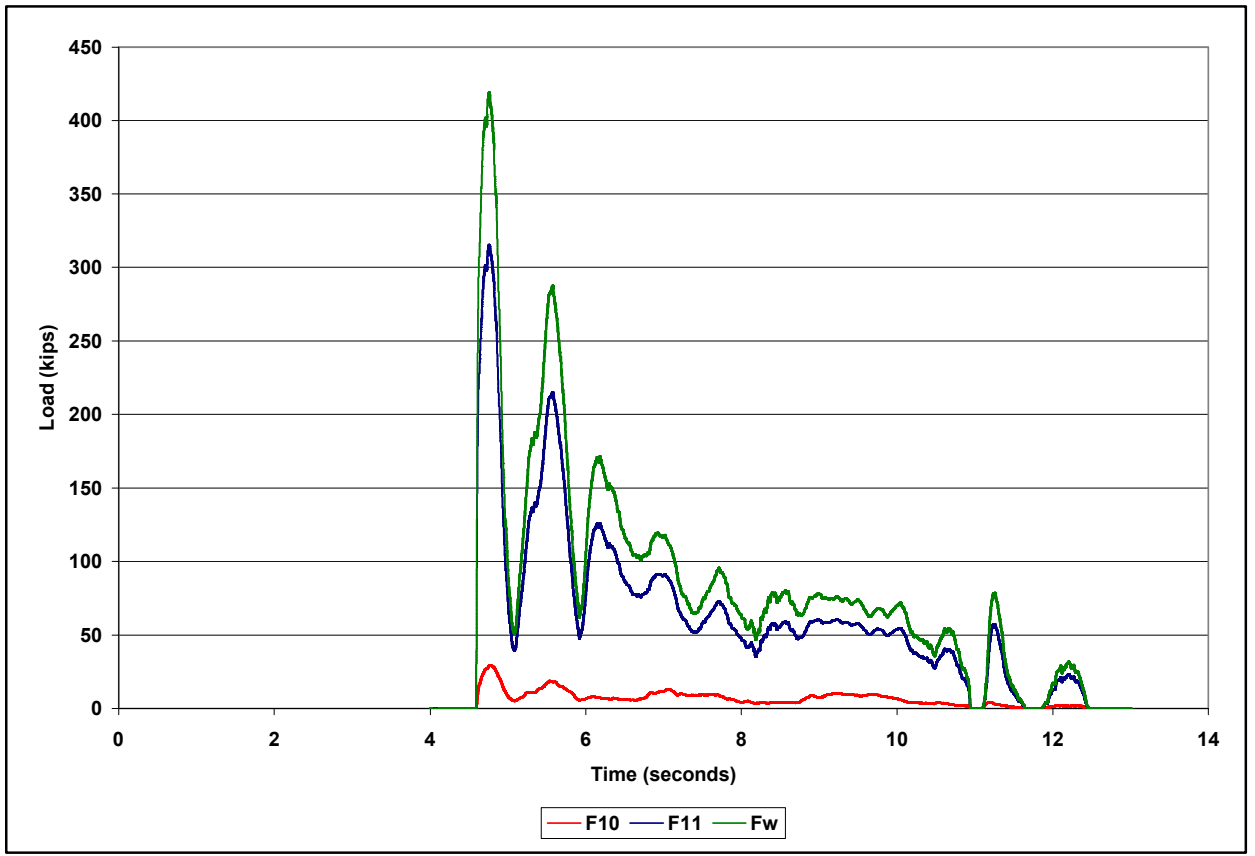

Figure 5.12. $F_{10}, F_{11}$, and $F_{w}$ time-histories for Experiment 41 


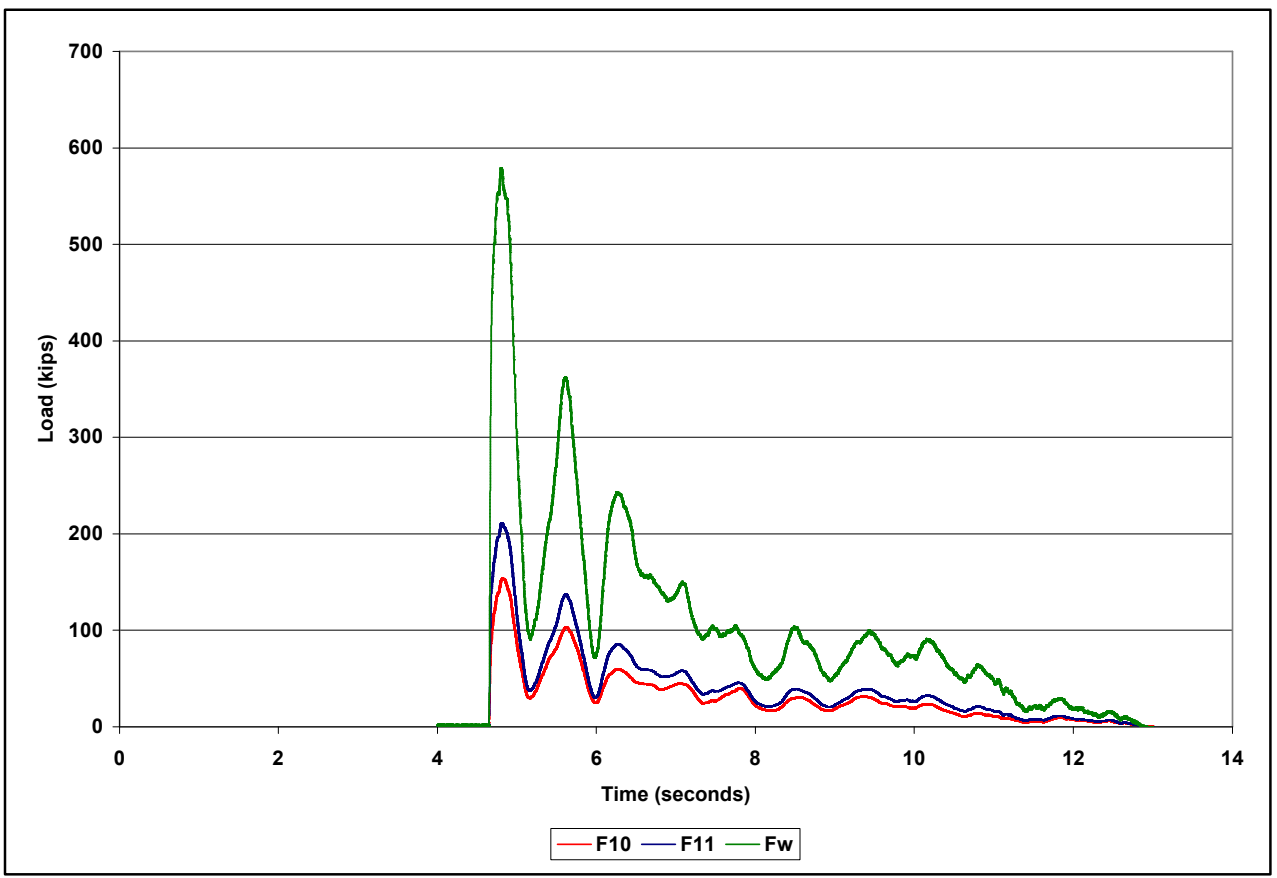

Figure 5.13. $F_{10}, F_{11}$, and $F_{w}$ time-histories for Experiment 42 


\section{Scaled Impulsive Force Formulation and Empirical Correlation}

\subsection{Scaled Impulsive Force Formulation}

The impulse and linear momentum equation normal to the wall can be expressed as

$$
\left(m_{\text {flotilla }}-m_{\text {water }}\right) v_{1} \sin \theta+\int_{t_{1}}^{t_{2}} F_{\text {tow }} \sin \theta d t+\int_{t_{1}}^{t_{2}} F_{\text {helper }} \cos \theta d t-\int_{t_{1}}^{t_{2}} F_{\text {drag }} \sin \theta d t=\int_{t_{1}}^{t_{2}} F_{w} d t
$$

where $\int_{t_{1}}^{t_{2}} F_{w} d t$ is the total impulse due to the force normal to the wall or, in other words, the total area under the $F_{w}$ versus time of impact curve. Recall that the velocity normal to the wall, $v \sin \theta$, is assumed to be zero during impact. The maximum normal force occurs at a $t_{l}$ from the beginning of the impact timehistory. The total impulse of the force normal to the wall can be divided into two impulses, one up to the maximum $F_{w}$, and a second calculated to the end of the time-history of impact at time $t_{2}$, as shown in Figure 6.1. These two impulses are designated, as shown in Figure 6.1, as areas $A_{1}$ and $A_{2}$, respectively.

The experimental total impulse equals $\left(A_{1}+A_{2}\right)$. Now, Equation 6.1 becomes

$$
\begin{aligned}
\int_{t_{1}}^{t_{2}} F_{w} d t=A_{1}+A_{2}= & \left(m_{\text {flotilla }}-m_{\text {water }}\right) v_{1} \sin \theta+\int_{t_{1}}^{t_{2}} F_{\text {tow }} \sin \theta d t \\
& +\int_{t_{1}}^{t_{2}} F_{\text {helper }} \cos \theta d t-\int_{t_{1}}^{t_{2}} F_{\text {drag }} \sin \theta d t
\end{aligned}
$$

where

$$
A_{1}=\int_{t_{1}}^{t_{1}+\Delta t_{1}} F_{\text {wall }} d t=\beta\left(F_{\text {wall }}\right)_{\text {max }} \Delta t_{1}
$$

and $\beta$ is a constant. By definition, $A_{2}$ is equal to $\left(A_{1}+A_{2}\right)$ minus $A_{1}$, or 


$$
A_{2}=\int_{t_{1}}^{t_{2}} F_{\text {wall }} d t-\beta\left(F_{\text {wall }}\right)_{\max } \Delta t_{1}
$$

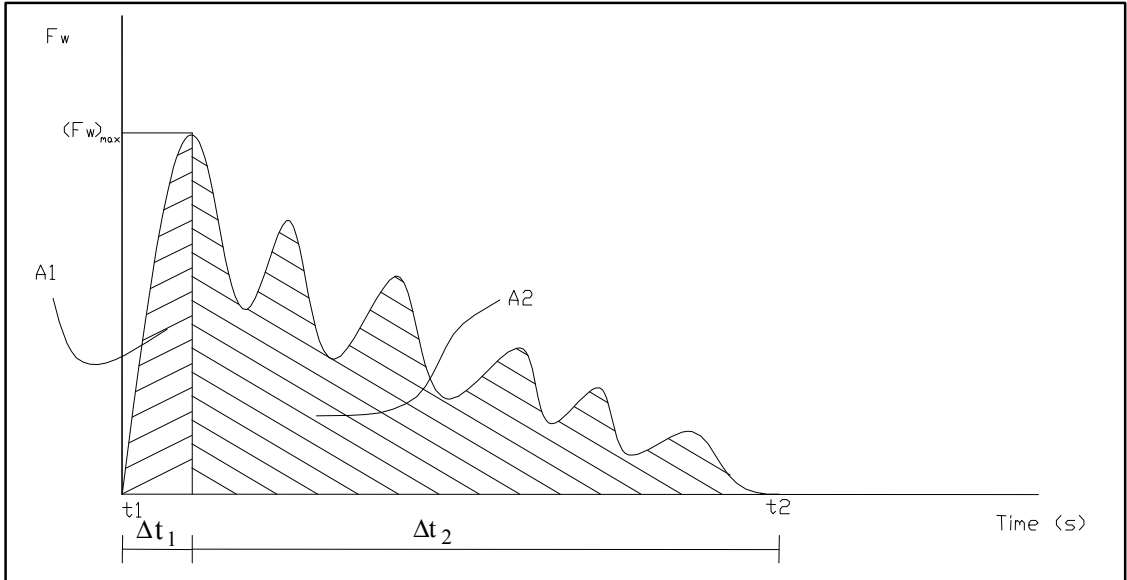

Figure 6.1. Typical experimental load time-history

A constant, $\gamma$, is introduced, which is defined as the ratio of the impulse up to the maximum normal force $F_{w}\left(A_{1}\right)$, divided by the experimental total impulse $\left(A_{1}+A_{2}\right)$, written as

$$
\gamma=\frac{A_{1}}{A_{1}+A_{2}}
$$

Then, Equation 6.3 can be written in the form

$$
A_{1}=\gamma *\left(A_{1}+A_{2}\right)
$$

and Equation 6.4 results in

$$
A_{2}=(1-\gamma) *\left(A_{1}+A_{2}\right)
$$

Substituting Equation 6.6 into Equation 6.3, we obtain

$$
\beta\left(F_{\text {wall }}\right)_{\max } \Delta t_{1}=\gamma\left(A_{1}+A_{2}\right)
$$

Finally, the maximum force normal to the wall can be determined from the following expression:

$$
\left(F_{\text {wall }}\right)_{\max }=\frac{\gamma\left(A_{1}+A_{2}\right)}{\beta \Delta t_{1}}
$$

Note that the last three terms on the right-hand side of Equation 6.2 were not measured during the experiments. However, we can associate the linear 
momentum with the total impulse at the left side of the same equation. The linear momentum can be calculated for each of the experiments and also the total impulse normal to the wall, which is the summation of $A_{1}$ and $A_{2}$. A new factor, which is the ratio of the total impulse due to the normal force divided by the linear momentum, is now introduced as

$$
F R A C=\frac{A_{1}+A_{2}}{m v \sin \theta}
$$

then, Equation 6.9 transforms to

$$
\left(F_{w}\right)_{\max }=\frac{\gamma^{*} F R A C^{*} m v \sin \theta}{\beta \Delta t_{1}}
$$

This approach was used to calculate the maximum normal force in the wall using the relation between the $F_{w}$ and the linear momentum. For all the experiments presented in Table 6.1, a statistical evaluation of all these factors ( $\beta$, $\gamma, F R A C$, etc.) was done. These factors, $\beta, \gamma, F R A C$, and $\Delta t_{1}$, are dependent variables of the independent variable $\left(F_{w}\right)_{\max }$. Then using the average values of these factors, an estimate of the force normal to the wall was calculated. These average values are presented in Table 6.1a.

As an example, Experiment 31 was selected. Recall that the total mass of the flotilla equals $1,865.59 \mathrm{k}-\mathrm{sec}^{2} / \mathrm{ft}$ (see Appendix A). Note that the masses used to develop the linear momentum normal to the wall correlation with values of $\left(F_{w}\right)_{\max }$ in this chapter do not include the calculation of hydrodynamic added masses. For these experiments, the following values were obtained, as shown in Table 6.1a.

Average values:

$$
\begin{aligned}
& \Delta t_{1}=0.16 \quad \mathrm{sec} \\
& \gamma=0.06279 \\
& \beta=0.72224 \\
& F R A C=0.8
\end{aligned}
$$

For Experiment 31: [The area under the force time-history $A_{1}+A_{2}$ was calculated using the numerical integration scheme presented in Appendix C.]

$$
\begin{aligned}
& v=1.61 \quad f t / \mathrm{sec} \\
& \theta=10.6^{\circ} \\
& A_{1}+A_{2}=466.83 \quad k-\sec \text { (see center shaded column in Table 6.1a) }
\end{aligned}
$$




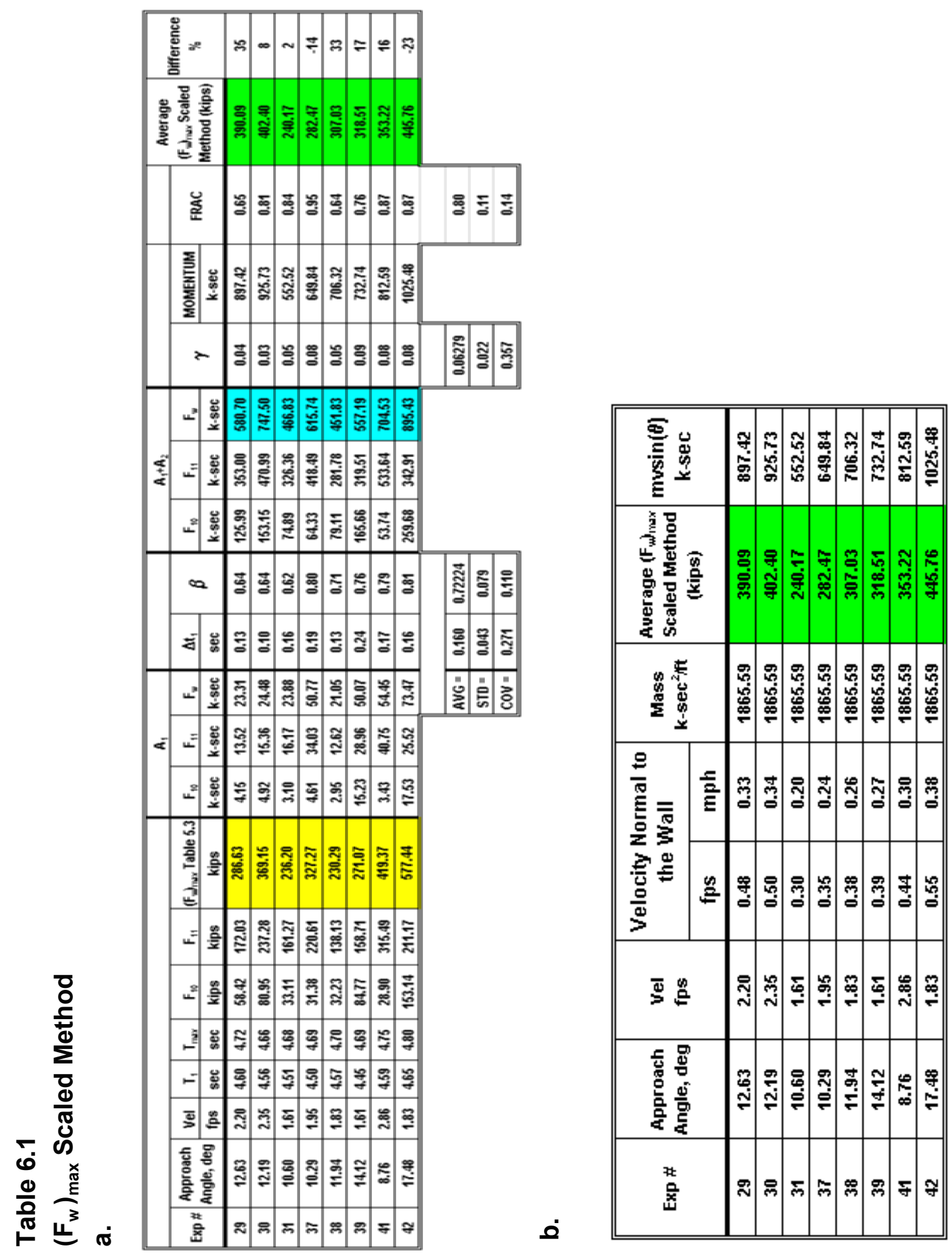




\section{Computation:}

$m v \sin \theta=\left(1,865.59 \frac{k-\mathrm{sec}^{2}}{f t}\right) *\left(1.61 \frac{f t}{\mathrm{sec}}\right) * \sin (10.60 \mathrm{deg})=552.5162 \quad k-s$

The total impulse normal to the wall, the $\left(A_{1}+A_{2}\right)$ shaded column in Table 6.1a, due to the force normal to the wall is less than the linear momentum normal to the wall.

For Experiment 31, the total impulse normal to the wall is computed to be 84 percent of the linear momentum normal to the wall $(=466.83 / 552.5162$ in decimal fraction). This ratio is identified as FRAC in Table 6.1a. The remaining 16 percent of the linear momentum is provided to the system by the drag force, the helper boat, and the tow boat, as shown in Figure 2.3. For all eight experiments, the Table 6.1 a ratio FRAC establishes that the total impulse normal to the wall is between 65 and 85 percent of the linear momentum normal to the wall.

\section{Computation:}

$\left(F_{w}\right)_{\max }=\frac{\gamma^{*} F R A C * m v \sin \theta}{\beta \Delta t_{1}}=\frac{(0.06279)(0.8)(552.5162)}{(0.72224)(0.16)}=240.17 \quad$ kips

Table 6.1a reports the average values of the $\Delta t_{l}, \gamma, \beta, F R A C$, and impact experiment-specific value $\left(A_{1}+A_{2}\right)$ used to calculate the maximum $F_{w}$ value by the scaled method, using Equation 6.11. Applying Equation 6.11 using the average values for $\Delta t_{l}, \gamma, \beta$, and $F R A C$ given in Table 6.1a, the estimate of $\left(F_{w}\right)_{\max }$ for Experiment 31 is computed equal to $240.17 \mathrm{kips}$. This value can be compared with the value found using the assumed coefficient of friction model or the energy model presented in Table 5.3 and repeated in the eighth column in Table 6.1a, equal to 236.20 kips. The approximation of the maximum force normal to the wall for this experiment is within 2 percent of the Table 5.3 value. It is important to mention that if the actual values of $\Delta t_{1}, \gamma, \beta$, and $F R A C$ are used to calculate the maximum force normal to the wall, the values obtained for the maximum $F_{w}$ are equal to the maximum $F_{w}$ reported in Table 5.3. This is because the maximum $F_{w}$ reported in Table 5.3 is used as the independent variable to determine the factors $\Delta t_{1}, \gamma, \beta$, and $F R A C$, making these factors dependent variables.

The resulting values of the maximum force normal to the wall using the average factors $\left(\Delta t_{1}, \gamma, \beta, F R A C\right)$, appear in Table $6.1 \mathrm{~b}$, and the trend of the scaled method is presented in Figure 6.2. It can be observed that the trend of the data points is to an increase in the magnitude of the force normal to the wall with an increase in the linear momentum normal to the wall. This trend can be observed from Equation 6.11 (middle line in Figure 6.2), which was used to relate the linear momentum of the flotilla and the maximum force normal to the wall. In addition, a least squares regression procedure applied to the four variables $\left(\Delta t_{l}, \gamma\right.$, $\beta, F R A C$ ) was used to develop the best-fit straight line through the eight data points (for the eight impact experiments). The line was assumed to start at the 
origin (i.e., no intercept term was used for the linear regression). The average minus one standard error and average plus one standard error lines are also shown in Figure 6.2. The eight data points shown in Figure 6.2 are the maximum force normal to the wall obtained from Table 5.3 for each experiment. These data points are presented only for comparison purposes, and because they are the independent variables from which the factors $\Delta t_{l}, \gamma, \beta$, and $F R A C$ were obtained and then used in Equation 6.11. The statistical evaluation applied to the four variables $\left(\Delta t_{1}, \gamma, \beta, F R A C\right)$ was done using the computer program presented in Appendix $\mathrm{B}$ and verified using the standard Excel statistical package.

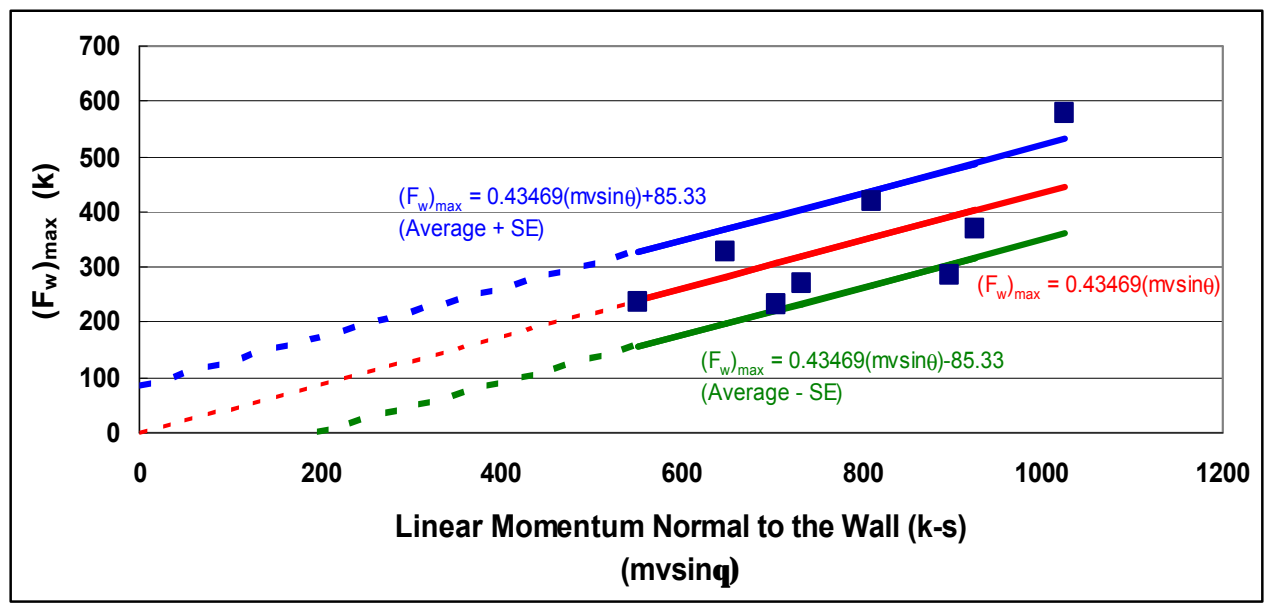

Figure 6.2. Scaled impulsive relationship

Figure 6.2 is a correlation based on low-velocity, shallow-impact (up to $21.1 \mathrm{deg}$ ) experiments that, by definition, do not account for factors that manifest themselves at higher velocities. Additionally, no damage occurred to the flotilla of barges, and no lashings broke during these eight impact experiments.

Therefore, at this time and pending the results of additional research, Figure 6.2 is deemed applicable to a barge flotilla that has a velocity normal to the wall up to and not exceeding $0.57 \mathrm{fps}(0.39 \mathrm{mph})$ with no damage occurring during impact events, and for impact angles up to $21.1 \mathrm{deg}$, for a barge flotilla with a linear momentum normal to the wall between 649.84 and 1,025.48 k-sec. Finally, Equation 6.11 transforms to

$$
\left(F_{w}\right)_{\max }=0.43469 *(m v \sin \theta)
$$

using the average $\Delta t_{l}, \gamma, \beta$, and $F R A C$ (given in Table 6.1a and shown in Figure 6.2 ), where the units for the mass, velocity, and maximum $F_{w}$ are $\mathrm{k}-\mathrm{sec}^{2} / \mathrm{ft}, \mathrm{ft} / \mathrm{sec}$, and kips, respectively.

The maximum normal force $\left(F_{w}\right)_{\max }$ by the scaled method is equal to the reaction force provided by the lock wall on the barge flotilla during the impact. Note in Table $6.1 \mathrm{~b}$ that the mass used to develop Figure 6.2 correlation of linear momentum normal to the wall with values of $\left(F_{w}\right)_{\max }$ is the mass of the barge flotilla (given in Appendix A) and does not include the computation of any hydrodynamic added masses. However, the Table 6.1a values of $\left(F_{w}\right)_{\max }$ 
(computed using Equation 6.11) that are used in the Figure 6.2 correlation reflect the effects of the Figure 2.3 external forces of $F_{\text {tow }}, F_{\text {drag }}$, and $F_{\text {helper }}$ acting on the barge flotilla, as well as the effects of the hydrodynamic masses and the inertia of the barge flotilla mass decelerating during impact.

A summary of the values of the Table 5.3 maximum impact force normal to the wall, $\left(F_{w}\right)_{\max }$, for the energy method or the equilibrium with a fixed coefficient of friction values for the eight full-scale, controlled barge impact experiments and of the Figure 6.2 best-fit straight-line $\left(F_{w}\right)_{\max }$ values is given in Table 6.2. For example, the energy method or the equilibrium with a fixed coefficient of friction value $(=0.6)$ for the full-scale, controlled barge impact experiment (No. 29) produces an $\left(F_{w}\right)_{\max }$ value of $286.63 \mathrm{kips}$, and the best-fit straight line of the scaled impulsive relationship produces an $\left(F_{w}\right)_{\max }$ value of 390.09 kips. This corresponds to a 35 -percent overprediction by the best-fit straight line of the scaled impulsive relationship approach. The maximum force normal to the wall $\left(F_{w}\right)_{\max }$ computed using the best-fit straight line of the scaled impulsive relationship differs from the maximum force $\left(F_{w}\right)_{\max }$ values presented in Table 5.3 by a 23 -percent underprediction to a 36-percent overestimate for these eight impact tests.

\begin{tabular}{|c|c|c|c|c|c|c|c|}
\hline \multicolumn{8}{|c|}{$\begin{array}{l}\text { Table } 6.2 \\
\text { Comparison Between Table } 5.3\left(F_{w}\right)_{\max } \text { Values and the Figure } 6.2 \text { Best-Fit } \\
\text { Straight-Line }\left(F_{w}\right)_{\max } \text { Values of the Scaled Impulsive Relationship }\end{array}$} \\
\hline $\begin{array}{l}\text { Experiment } \\
\text { Number }\end{array}$ & $\begin{array}{l}\text { Approach } \\
\text { Velocity } \\
\text { fps }\end{array}$ & $\begin{array}{l}\text { Approach } \\
\text { Angle } \\
\text { deg }\end{array}$ & $\begin{array}{l}\text { Velocity } \\
\text { Normal } \\
\text { to Wall } \\
\text { fps }\end{array}$ & $\begin{array}{l}\text { Coefficient } \\
\text { of Friction } \\
\text { Table } 5.3\end{array}$ & $\begin{array}{l}\left(F_{w}\right)_{\max } \\
\text { Table } 5.3 \\
\text { kips }\end{array}$ & $\begin{array}{l}\left(F_{w}\right)_{\max } \\
\text { Figure } 6.2 \\
\text { Average } \\
\text { kips }\end{array}$ & $\begin{array}{l}\text { Percent } \\
\text { Difference }\end{array}$ \\
\hline 29 & 2.2 & 12.63 & 0.48 & 0.6 & 286.63 & 390.09 & 36 \\
\hline 30 & 2.35 & 12.19 & 0.50 & 0.48 & 369.15 & 402.40 & 8 \\
\hline 31 & 1.61 & 10.6 & 0.30 & 0.43 & 236.20 & 240.17 & 2 \\
\hline 37 & 1.95 & 10.29 & 0.35 & 0.52 & 327.27 & 282.47 & -14 \\
\hline 38 & 1.83 & 11.94 & 0.38 & 0.57 & 230.29 & 307.03 & 33 \\
\hline 39 & 1.61 & 14.12 & 0.39 & 0.51 & 271.07 & 318.51 & 17 \\
\hline 41 & 2.86 & 8.76 & 0.44 & 0.51 & 419.37 & 353.22 & -16 \\
\hline 42 & 1.83 & 17.48 & 0.55 & 0.09 & 577.44 & 445.76 & -23 \\
\hline
\end{tabular}

\subsection{ETL 1110-2-338 Engineering Procedure Comparison with Scaled Impulsive Force Formulation Results}

ETL 1110-2-338 provides an engineering procedure for the collision of a barge flotilla with a rigid structure. According to the ETL 1110-2-338 engineering procedure, the magnitude of the impact forces generated by a particular collision event is dependent on the mass (including hydrodynamic added mass of the barge flotilla), the approach velocity, the approach angle, the barge flotilla moment of inertia, damage sustained by the barge structure, and friction between the barge and the wall. A major distinction between this procedure and the traditional Navy method for determining berthing forces is the estimation of collision energy dissipated in deformation of the barge structure and transferred to the rotation of the barge flotilla. The analytical method uses the 
structural interaction mechanism of Minorsky, which provides an empirical relationship between the (nonrecoverable) hull deformation and the energy absorbed in a collision. The relationship between kinetic energy lost in a collision and the volume of in-plane (barge) material damaged is used to determine impact force as a relationship to instantaneous contact area of damaged structure. Additional details regarding this approach are discussed in Section 5.4 of Chapter 5.

The ETL 1110-2-338 engineering procedure was used to compute values of maximum impact force normal to the wall, $\left(F_{w}\right)_{\max }$, for the eight full-scale, controlled barge impact experiments listed in Table 5.3. The coefficients of friction used in these computations were the same as those derived from field-test data summarized in Table 5.3. The results of these ETL-based computations are given in Table 6.3 along with the results from the Figure 6.2 scaled impulsive relationship best-fit straight line. For example, the best-fit scaled impulsive relationship for barge impact Experiment 29 produces an $\left(F_{w}\right)_{\max }$ value of 390.09 kips, and the ETL 1110-2-338 engineering procedure produces an $\left(F_{w}\right)_{\max }$ value of 409.5 kips. This corresponds to a 5-percent overprediction by the ETL 1110-2-338 approach. The maximum force normal to the wall $\left(F_{w}\right)_{\max }$ computed using the ETL 1110-2-338 engineering procedure differs from the best-fit straight line of the scaled impulsive Figure 6.2 relationship by a 13 -percent underprediction to a 20 -percent overestimate for these eight impact tests.

\begin{tabular}{|c|c|c|c|c|c|c|c|}
\hline \multicolumn{8}{|c|}{$\begin{array}{l}\text { Table } 6.3 \\
\text { Comparison Between the Figure } 6.2 \text { Best-Fit Straight-Line }\left(F_{w}\right)_{\max } \text { Values of the } \\
\text { Scaled Impulsive Relationship and }\left(F_{w}\right)_{\max } \text { by the ETL 1110-2-338 Engineering } \\
\text { Procedure }\end{array}$} \\
\hline $\begin{array}{l}\text { Experiment } \\
\text { Number }\end{array}$ & $\begin{array}{l}\text { Approach } \\
\text { Velocity } \\
\text { fps }\end{array}$ & $\begin{array}{l}\text { Approach } \\
\text { Angle } \\
\text { deg }\end{array}$ & $\begin{array}{l}\text { Velocity } \\
\text { Normal } \\
\text { to Wall } \\
\text { fps }\end{array}$ & $\begin{array}{l}\text { Coefficient } \\
\text { of Friction } \\
\text { Table } 5.3 \\
\end{array}$ & $\begin{array}{l}\left(F_{w}\right)_{\max } \\
\text { Figure } 6.2 \\
\text { Average } \\
\text { kips }\end{array}$ & $\begin{array}{l}\left(F_{w}\right)_{\max } \\
\text { ETL 1110- } \\
2-338^{*} \\
\text { kips }\end{array}$ & $\begin{array}{l}\text { Percent } \\
\text { Difference }\end{array}$ \\
\hline 29 & 2.2 & 12.63 & 0.48 & 0.6 & 390.09 & 409.5 & 5 \\
\hline 30 & 2.35 & 12.19 & 0.50 & 0.48 & 402.40 & 420.9 & 5 \\
\hline 31 & 1.61 & 10.6 & 0.30 & 0.43 & 240.17 & 263.8 & 10 \\
\hline 37 & 1.95 & 10.29 & 0.35 & 0.52 & 282.47 & 317.4 & 12 \\
\hline 38 & 1.83 & 11.94 & 0.38 & 0.57 & 307.03 & 327.6 & 7 \\
\hline 39 & 1.61 & 14.12 & 0.39 & 0.51 & 318.51 & 317.2 & 0 \\
\hline 41 & 2.86 & 8.76 & 0.44 & 0.51 & 353.22 & 423.8 & 20 \\
\hline 42 & 1.83 & 17.48 & 0.55 & 0.09 & 445.76 & 386.5 & -13 \\
\hline
\end{tabular}

Table 6.4 compares the values of maximum impact force normal to the wall, $\left(F_{w}\right)_{\max }$, for the eight full-scale, controlled barge impact experiments computed using the ETL 1110-2-338 engineering procedure with the range in values from the Figure 6.2 scaled impulsive relationship. The results given in Table 6.4 show that the maximum impact force normal to the wall, $\left(F_{w}\right)_{\max }$, for the eight full-scale experiments computed using the ETL 1110-2-338 approach are within one standard error of the Figure 6.2 best-fit straight line of the scaled impulsive relationship. 


\begin{tabular}{|c|c|c|c|c|c|c|c|}
\hline \multicolumn{8}{|c|}{$\begin{array}{l}\text { Table } 6.4 \\
\text { Comparison Between the Figure } 6.2 \text { Scaled Impulsive Relationship for }\left(F_{w}\right)_{\max } \\
\text { and }\left(F_{w}\right)_{\max } \text { by the ETL 1110-2-338 Engineering Procedure }\end{array}$} \\
\hline $\begin{array}{l}\text { Experiment } \\
\text { Number }\end{array}$ & $\begin{array}{l}\text { Approach } \\
\text { Velocity } \\
\text { fps }\end{array}$ & $\begin{array}{l}\text { Approach } \\
\text { Angle } \\
\text { deg }\end{array}$ & $\begin{array}{l}\text { Velocity } \\
\text { Normal } \\
\text { to Wall } \\
\text { fps }\end{array}$ & $\begin{array}{l}\left(F_{w}\right)_{\max } \\
\text { Figure } 6.2 \\
\text { Ave-SE } \\
\text { kips }\end{array}$ & $\begin{array}{l}\left(F_{w}\right)_{\max } \\
\text { Figure } 6.2 \\
\text { Average } \\
\text { kips }\end{array}$ & $\begin{array}{l}\left(F_{\mathrm{w}}\right)_{\max } \\
\text { Figure } 6.2 \\
\text { Ave+SE } \\
\text { kips }\end{array}$ & $\begin{array}{l}\left(F_{w}\right)_{\max } \text { ETL } \\
1110-2-338^{*} \\
\text { kips }\end{array}$ \\
\hline 29 & 2.2 & 1212.63 & 0.48 & 304.77 & 39390.09 & 40 & $\begin{array}{l}409.5 \\
\end{array}$ \\
\hline 30 & 2.35 & 12.19 & 0.50 & 317.07 & 402.40 & 487.73 & 420.9 \\
\hline 31 & 1.61 & 10.6 & 0.30 & 154.84 & 240.17 & 325.50 & 263.8 \\
\hline 37 & 1.95 & 10.29 & 0.35 & 197.15 & 282.47 & 367.81 & 317.4 \\
\hline 38 & 1.83 & 11.94 & 0.38 & 221.70 & 307.03 & 392.36 & 327.6 \\
\hline 39 & 1.61 & 14.12 & 0.39 & 233.18 & 318.51 & 403.84 & 317.2 \\
\hline 41 & 2.86 & 8.76 & 0.44 & 267.89 & 353.22 & 438.55 & 423.8 \\
\hline 42 & 1.83 & 17.48 & 0.55 & 360.44 & 445.76 & 531.10 & 386.5 \\
\hline
\end{tabular}

\subsection{Empirical Correlation Between (Fw) $)_{\max }$ and Linear Momentum Normal to the Wall}

In this section, an empirical correlation between the maximum force normal to the wall and the linear momentum normal to the wall is presented. The maximum force, $F_{w}$, used in this correlation was obtained from the models presented in Chapter 5. Using values for the maximum normal force, $F_{w}$, and the linear momentum normal to the wall given in Table 6.5 (values from Chapter 5), a best-fit straight line was calculated for the eight experiments. This approach relates the $F_{w}$ obtained from the energy method directly to the linear momentum. These results can be compared to the results from the scaled impulsive relationship. It is important to mention that only one data point of the whole $F_{w}$ time-history for each of the eight experiments was used to develop this empirical correlation. However, in the scaled method, the whole $F_{w}$ time-history was used because the total impulse $\left(A_{1}+A_{2}\right)$ for each experiment was used to determine Equation 6.11.

The least squares regression procedure was used to develop the best-fit straight line through the eight data points (for the eight impact experiments) for the empirical correlation. The line was assumed to start at the origin (i.e., no intercept term was used for the linear equation). The resulting best-fit straight line and the average minus one standard error and average plus one standard error lines are shown in Figure 6.3.

The statistical evaluation was done using the computer program presented in Appendix B and verified using the standard Excel statistical package. The concepts that apply to the statistical theory are presented in Appendix D. 


\begin{tabular}{|c|c|c|c|c|c|}
\hline \multicolumn{6}{|c|}{$\begin{array}{l}\text { Table } 6.5 \\
\left(F_{w}\right)_{\max } \text { Empirical Correlation }\end{array}$} \\
\hline Exp \# & $\begin{array}{l}\text { Approach } \\
\text { Angle, deg }\end{array}$ & $\begin{array}{l}\text { Vel } \\
\text { fps }\end{array}$ & $\begin{array}{l}\text { Mass } \\
\text { k-sec } / \mathrm{ft}\end{array}$ & $\begin{array}{l}\text { Fw(max) } \\
\text { Table } 5.3 \\
\text { kips }\end{array}$ & $\begin{array}{l}\operatorname{mvsin}(\theta) \\
\text { k-sec }\end{array}$ \\
\hline 29 & 12.63 & 2.20 & 1865.59 & 286.63 & 897.42 \\
\hline 30 & 12.19 & 2.35 & 1865.59 & 369.15 & 925.73 \\
\hline 31 & 10.60 & 1.61 & 1865.59 & 236.2 & 552.52 \\
\hline 37 & 10.29 & 1.95 & 1865.59 & 327.27 & 649.84 \\
\hline 38 & 11.94 & 1.83 & 1865.59 & 230.29 & 706.32 \\
\hline 39 & 14.12 & 1.61 & 1865.59 & 271.07 & 732.74 \\
\hline 41 & 8.76 & 2.86 & 1865.59 & 419.37 & 812.59 \\
\hline 42 & 17.48 & 1.83 & 1865.59 & 577.44 & 1025.48 \\
\hline
\end{tabular}

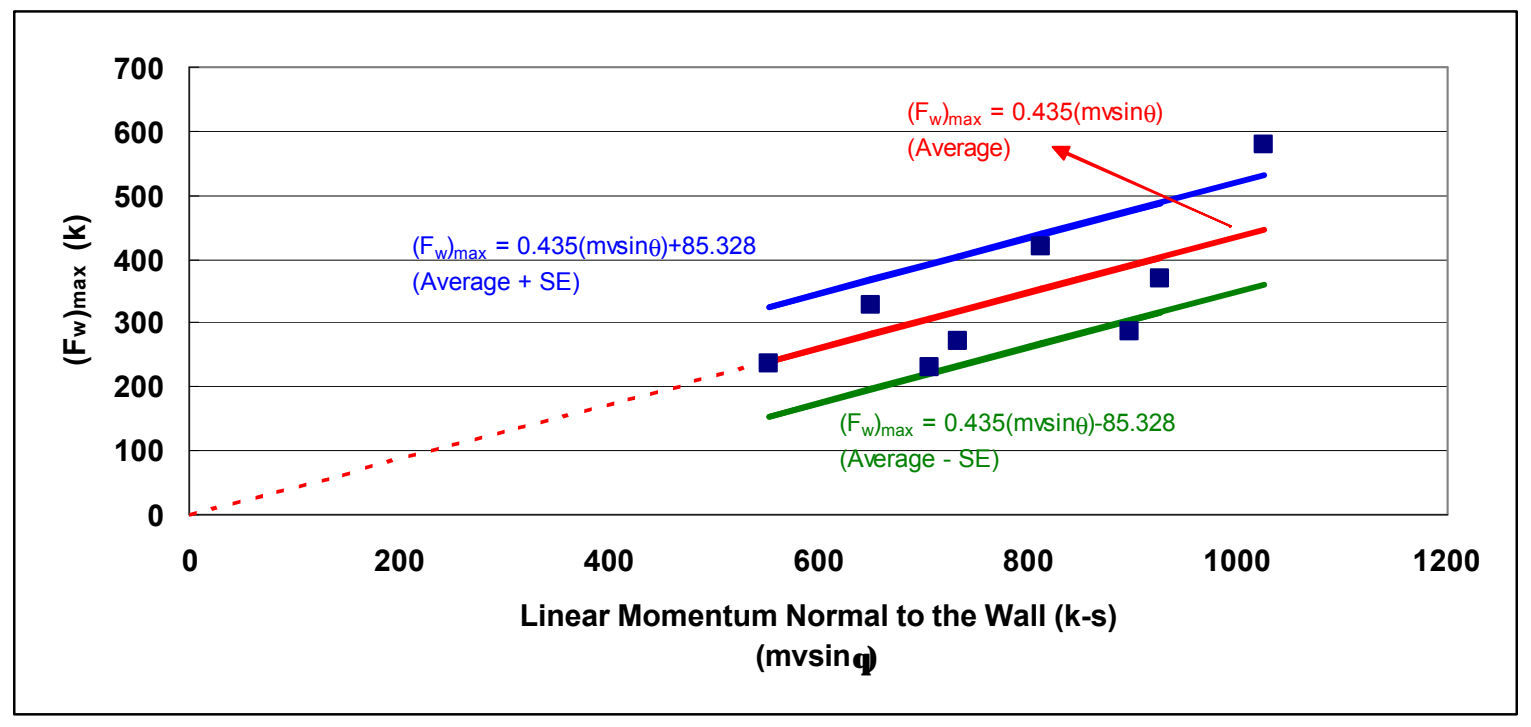

Figure 6.3. Empirical correlation between $\left(F_{w}\right)_{\max }$ and linear momentum normal to the wall

The resulting best-fit equation for this set of eight data values is $\left(F_{w}\right)_{\max }=0.435 \mathrm{mv} \sin$ ? . That is, a coefficient times the linear momentum normal to the wall determines the maximum force normal to the wall. It is interesting to note that the Equation 6.11 scaled impulsive relationship has the same form as this new empirical equation. Using the average of the $\gamma, \beta, \Delta t_{l}$, and FRAC coefficients presented in Table 6.1a, Equation 6.11 transforms to

$$
\left(F_{w}\right)_{\max }=\frac{\gamma F R A C}{\beta \Delta t_{1}} m v \sin \theta=\frac{0.06279 * 0.8}{0.72224 * 0.16} m v \sin \theta=0.43469 m v \sin \theta
$$

Note that the coefficients are nearly the same value for the two approaches. 
We can observe that the greater the magnitude for the linear momentum, the larger will be the maximum value for the impact force normal to the wall, as shown in Figure 6.3. Figure 6.3 is a correlation based on low-velocity, shallowimpact (up to $21.1 \mathrm{deg}$ ) experiments that, by definition, do not account for factors that manifest themselves at higher velocities. Additionally, no damage occurred to the flotilla of barges, and no lashings broke during these eight impact experiments. Therefore, at this time and pending the results of additional research, Figure 6.3 is deemed applicable to a barge flotilla that has a velocity normal to the wall up to and not exceeding $0.57 \mathrm{fps}(0.39 \mathrm{mph})$ with no damage occurring during impact events, for impact angles up to $21.1 \mathrm{deg}$, for a barge flotilla with a linear momentum normal to the wall between 649.84 and $1,025.48 \mathrm{k}$-sec. The equation to determine the maximum force normal to the wall using the empirical correlation is

$$
\left(F_{w}\right)_{\max }=0.435(m v \sin \theta)
$$

where the units for the mass, velocity and maximum $F_{w}$ are $\mathrm{k}-\mathrm{sec}^{2} / \mathrm{ft}$, $\mathrm{ft} / \mathrm{sec}$, and kips, respectively.

The maximum normal force $\left(F_{w}\right)_{\max }$ by the empirical correlation is equal to the reaction force provided by the lock wall on the barge flotilla during the impact. Note that, in Table 6.5, the mass used to develop the Figure 6.3 correlation of linear momentum normal to the wall with values of $\left(F_{w}\right)_{\max }$ is the mass of the barge flotilla (given in Appendix A) and does not include the computation of any hydrodynamic added masses. However, the values of $\left(F_{w}\right)_{\max }$ in Table 6.5 (which are derived from the field-test data and originally reported in Table 5.3) that are used in the Figure 6.3 correlation reflect the effects of the Figure 2.3 external forces of $F_{\text {tow }}, F_{\text {drag }}$, and $F_{\text {helper }}$ acting on the barge flotilla, as well as the effects of the hydrodynamic masses and the inertia of the barge flotilla mass decelerating during impact.

A summary of the values of the Table 5.3 maximum impact force normal to the wall, $\left(F_{w}\right)_{\max }$, for the energy method or the equilibrium with a fixed coefficient of friction values for the eight full-scale, controlled barge impact experiments and the values from the Figure 6.3 best-fit straight-line $\left(F_{w}\right)_{\max }$ values is given in Table 6.6. For example, the energy method or the equilibrium with a fixed coefficient of friction value $(=0.6)$ for the full-scale, controlled barge impact experiment (No. 29) produces an $\left(F_{w}\right)_{\max }$ value of $286.63 \mathrm{kips}$, and the best-fit straight line of the empirical correlation produces an $\left(F_{w}\right)_{\max }$ value of 390.38 kips. This corresponds to a 36-percent overprediction by the best-fit straight line of the empirical correlation approach. The maximum force normal to the wall $\left(F_{w}\right)_{\max }$ computed using the best-fit straight line of the empirical correlation differs from the maximum force $\left(F_{w}\right)_{\max }$ values presented in Table 5.3 by a 23 -percent underprediction to a 36-percent overestimate for these eight impact tests. 


\begin{tabular}{|c|c|c|c|c|c|c|c|}
\hline \multicolumn{8}{|c|}{$\begin{array}{l}\text { Table } 6.6 \\
\text { Comparison Between Table } 5.3\left(F_{w}\right)_{\max } \text { Values and the Figure } 6.3 \text { Best-Fit } \\
\text { Straight-Line }\left(F_{w}\right)_{\max } \text { Values of the Empirical Correlation }\end{array}$} \\
\hline $\begin{array}{l}\text { Experiment } \\
\text { Number }\end{array}$ & $\begin{array}{l}\text { Approach } \\
\text { Velocity } \\
\text { fps }\end{array}$ & $\begin{array}{l}\text { Approach } \\
\text { Angle } \\
\text { deg }\end{array}$ & $\begin{array}{l}\text { Velocity } \\
\text { Normal } \\
\text { to Wall } \\
\text { fps }\end{array}$ & $\begin{array}{l}\text { Coefficient } \\
\text { of Friction } \\
\text { Table } 5.3 \\
\end{array}$ & $\begin{array}{l}\left(\mathbf{F}_{\mathrm{w}}\right)_{\max } \\
\text { Table } 5.3 \\
\text { kips }\end{array}$ & $\begin{array}{l}\left(F_{w}\right)_{\max } \\
\text { Figure } 6.3 \\
\text { Average } \\
\text { kips } \\
\end{array}$ & $\begin{array}{l}\text { Percent } \\
\text { Difference }\end{array}$ \\
\hline 29 & 2.2 & 12.63 & 0.48 & 0.6 & 286.63 & 390.38 & 36 \\
\hline 30 & 2.35 & 12.19 & 0.50 & 0.48 & 369.15 & 402.69 & 9 \\
\hline 31 & 1.61 & 10.6 & 0.30 & 0.43 & 236.20 & 240.35 & 2 \\
\hline 37 & 1.95 & 10.29 & 0.35 & 0.52 & 327.27 & 282.68 & -14 \\
\hline 38 & 1.83 & 11.94 & 0.38 & 0.57 & 230.29 & 307.25 & 33 \\
\hline 39 & 1.61 & 14.12 & 0.39 & 0.51 & 271.07 & 318.74 & 18 \\
\hline 41 & 2.86 & 8.76 & 0.44 & 0.51 & 419.37 & 353.48 & -16 \\
\hline 42 & 1.83 & 17.48 & 0.55 & 0.09 & 577.44 & 446.08 & -23 \\
\hline
\end{tabular}

\subsection{ETL 1110-2-338 Engineering Procedure Comparison With Empirical Correlation Results}

The ETL 1110-2-338 engineering procedure was used to compute values of maximum impact force normal to the wall, $\left(F_{w}\right)_{\max }$, for the eight full-scale, controlled barge impact experiments listed in Table 5.3. The coefficients of friction used in these computations were the same as those derived from field-test data summarized in Table 5.3. The results of these ETL-based computations are given in Table 6.7 along with the results from the Figure 6.3 empirical correlation best-fit straight line. For example, the best-fit empirical correlation for barge impact Experiment 29 produces an $\left(F_{w}\right)_{\max }$ value of $390.38 \mathrm{kips}$, and the ETL 1110-2-338 engineering procedure produces an $\left(F_{w}\right)_{\max }$ value of 409.5 kips. This corresponds to a 5-percent overprediction by the ETL 1110-2-338 approach. The maximum force normal to the wall $\left(F_{w}\right)_{\max }$ computed using the ETL 1110-2338 engineering procedure differs from the best-fit straight line of the empirical correlation Figure 6.3 relationship by a 13-percent underprediction to a 20 percent overestimate for these eight impact tests.

Table 6.8 compares the values of maximum impact force normal to the wall, $\left(F_{w}\right)_{\max }$, for the eight full-scale, controlled barge impact experiments computed using the ETL 1110-2-338 engineering procedure with the range in values from the Figure 6.3 empirical correlation. The results given in Table 6.8 show that the maximum impact force normal to the wall, $\left(F_{w}\right)_{\max }$, for the eight full-scale, computed using the ETL 1110-2-338 approach are within one standard error of the Figure 6.3 best-fit straight line of the empirical correlation. 


\begin{tabular}{|c|c|c|c|c|c|c|c|}
\hline \multicolumn{8}{|c|}{$\begin{array}{l}\text { Table } 6.7 \\
\text { Comparison Between the Figure } 6.3 \text { Best-Fit Straight-Line }\left(F_{w}\right)_{\max } \text { Values of the } \\
\text { Empirical Correlation and }\left(F_{w}\right)_{\max } \text { by the ETL 1110-2-338 Engineering Procedure }\end{array}$} \\
\hline $\begin{array}{l}\text { Experiment } \\
\text { Number }\end{array}$ & $\begin{array}{l}\text { Approach } \\
\text { Velocity } \\
\text { fps }\end{array}$ & $\begin{array}{l}\text { Approach } \\
\text { Angle } \\
\text { deg }\end{array}$ & $\begin{array}{l}\text { Velocity } \\
\text { Normal to } \\
\text { the Wall } \\
\text { fps }\end{array}$ & $\begin{array}{l}\text { Coefficient } \\
\text { of Friction } \\
\text { Table } 5.3\end{array}$ & \begin{tabular}{l|}
$\left(F_{w}\right)_{\max }$ \\
Figure 6.3 \\
Average \\
Kips
\end{tabular} & $\begin{array}{l}\left(F_{w}\right)_{\max } \mathrm{ETL} \\
1110-2-338^{*} \\
\text { kips }\end{array}$ & $\begin{array}{l}\text { Percent } \\
\text { Difference }\end{array}$ \\
\hline 29 & 2.2 & 12.63 & 0.48 & 0.60 & 390.38 & 409.5 & 5 \\
\hline 30 & 2.35 & 12.19 & 0.50 & 0.48 & 402.69 & 420.9 & 5 \\
\hline 31 & 1.61 & 10.6 & 0.30 & 0.43 & 240.35 & 263.8 & 10 \\
\hline 37 & 1.95 & 10.29 & 0.35 & 0.52 & 282.68 & 317.4 & 12 \\
\hline 38 & 1.83 & 11.94 & 0.38 & 0.57 & 307.25 & 327.6 & 7 \\
\hline 39 & 1.61 & 14.12 & 0.39 & 0.51 & 318.74 & 317.2 & -1 \\
\hline 41 & 2.86 & 8.76 & 0.44 & 0.51 & 353.48 & 423.8 & 20 \\
\hline 42 & 1.83 & 17.48 & 0.55 & 0.09 & 446.08 & 386.5 & -13 \\
\hline
\end{tabular}

\begin{tabular}{|c|c|c|c|c|c|c|c|}
\hline \multicolumn{8}{|c|}{$\begin{array}{l}\text { Table } 6.8 \\
\text { Comparison Between the Figure } 6.3 \text { Empirical Correlation for }\left(F_{w}\right)_{\max } \text { and }\left(F_{w}\right)_{\max } \\
\text { by the ETL 1110-2-338 Engineering Procedure }\end{array}$} \\
\hline $\begin{array}{l}\text { Experiment } \\
\text { Number }\end{array}$ & $\begin{array}{l}\text { Approach } \\
\text { Velocity } \\
\text { fps }\end{array}$ & $\begin{array}{l}\text { Approach } \\
\text { Angle } \\
\text { deg }\end{array}$ & $\begin{array}{l}\text { Velocity } \\
\text { Normal to } \\
\text { the Wall } \\
\text { fps }\end{array}$ & $\begin{array}{l}\left(F_{w}\right)_{\max } \\
\text { Figure } 6.3 \\
\text { Ave-SE } \\
\text { kips }\end{array}$ & $\begin{array}{l}\left(F_{w}\right)_{\max } \\
\text { Figure } 6.3 \\
\text { Average } \\
\text { kips }\end{array}$ & $\begin{array}{l}\left(F_{w}\right)_{\max } \\
\text { Figure } 6.3 \\
\text { Ave+SE } \\
\text { Kips }\end{array}$ & $\begin{array}{l}\left(F_{w}\right)_{\max } \text { ETL } \\
1110-2-338^{*} \\
\text { kips }\end{array}$ \\
\hline 29 & 2.2 & 12.63 & 0.48 & 305.05 & 390.38 & 4775.71 & "409.5 \\
\hline 30 & 2.35 & 12.19 & 0.50 & 317.36 & 402.69 & 488.02 & 420.9 \\
\hline 31 & 1.61 & 10.6 & 0.30 & 155.05 & 240.35 & 325.67 & 263.8 \\
\hline 37 & 1.95 & 10.29 & 0.35 & 197.35 & 282.68 & 368.01 & 317.4 \\
\hline 38 & 1.83 & 11.94 & 0.38 & 221.92 & 307.25 & 392.58 & 327.6 \\
\hline 39 & 1.61 & 14.12 & 0.39 & 233.41 & 318.74 & 404.07 & 317.2 \\
\hline 41 & 2.86 & 8.76 & 0.44 & 268.15 & 353.48 & 438.80 & 423.8 \\
\hline 42 & 1.83 & 17.48 & 0.55 & 360.76 & 446.08 & 531.41 & 386.5 \\
\hline
\end{tabular}

\subsection{Empirical Correlation Between $\left(F_{w}\right)_{\max }$ and Kinetic Energy Normal to the Wall}

In this section an empirical correlation between the maximum force normal to the wall and the kinetic energy normal to the wall of the barge flotilla is presented.

The kinetic energy is defined as $T=\frac{1}{2} m v^{2}$, where $m$ is the mass of the object and $v$ is the speed the object. This is a positive scalar quantity since it does not depend on the direction of the particle's velocity. Furthermore, the kinetic energy has the same units as work, e.g., joules (J) or foot-pounds, force (ft-lb). 
The force $F_{w}$ used in this correlation was obtained from the models presented in Section 5.3 of Chapter 5 . Using the values of maximum normal force $\left(F_{w}\right)_{\max }$ from eight of the impact experiments and the kinetic energy concept shown in Table 6.9 (values from Chapter 5), a best-fit straight line was calculated. This approach relates the $\left(F_{w}\right)_{\max }$ values obtained from the energy method (see Section 5.3) interpretation of the bumper instrumentation data directly with the kinetic energy. A least squares regression procedure was used to develop the best-fit straight line through the eight data points (for the eight impact experiments). The line was assumed to start at the origin (i.e., no intercept term was used for the linear equation). The resulting best-fit straight line and the average minus one standard error and average plus one standard error lines are shown in Figure 6.4.

\section{Table 6.9 \\ Comparison Between Table $5.3\left(F_{w}\right)_{\max }$ Values and the Figure 6.4 Best-Fit Straight-Line $\left(F_{w}\right)_{\max }$ Values of the Empirical Correlation Using the Kinetic Energy Concept}

\begin{tabular}{||l|l|l|l|l|l|l|l||}
\hline \hline $\begin{array}{l}\text { Experiment } \\
\text { Number }\end{array}$ & $\begin{array}{l}\text { Approach } \\
\text { Velocity } \\
\text { fps }\end{array}$ & $\begin{array}{l}\text { Approach } \\
\text { Angle } \\
\text { Deg }\end{array}$ & $\begin{array}{l}\text { Velocity } \\
\text { Normal } \\
\text { to Wall } \\
\text { fps }\end{array}$ & $\begin{array}{l}\text { Coefficient } \\
\text { of Friction } \\
\text { Table 5.3 }\end{array}$ & $\begin{array}{l}\left(F_{\mathrm{w}}\right)_{\max } \\
\left(\begin{array}{l}\left.F_{\text {wax }}\right)_{\max } \\
\text { kips }\end{array}\right.\end{array}$ & $\begin{array}{l}\text { Figure 6.4 } \\
\text { Average } \\
\text { kips }\end{array}$ & $\begin{array}{l}\text { Percent } \\
\text { Difference }\end{array}$ \\
\hline \hline 29 & 2.2 & 12.63 & 0.48 & 0.60 & 286.63 & 406.62 & 42 \\
\hline 30 & 2.35 & 12.19 & 0.50 & 0.48 & 369.15 & 441.21 & 20 \\
\hline 31 & 1.61 & 10.6 & 0.30 & 0.43 & 236.20 & 158.84 & -33 \\
\hline 37 & 1.95 & 10.29 & 0.35 & 0.52 & 327.27 & 216.19 & -34 \\
\hline 38 & 1.83 & 11.94 & 0.38 & 0.57 & 230.29 & 254.84 & 11 \\
\hline 39 & 1.61 & 14.12 & 0.39 & 0.51 & 271.07 & 268.43 & -1 \\
\hline 41 & 2.86 & 8.76 & 0.44 & 0.51 & 419.37 & 341.67 & -19 \\
\hline 42 & 1.83 & 17.48 & 0.55 & 0.09 & 577.44 & 533.87 & -8 \\
\hline
\end{tabular}

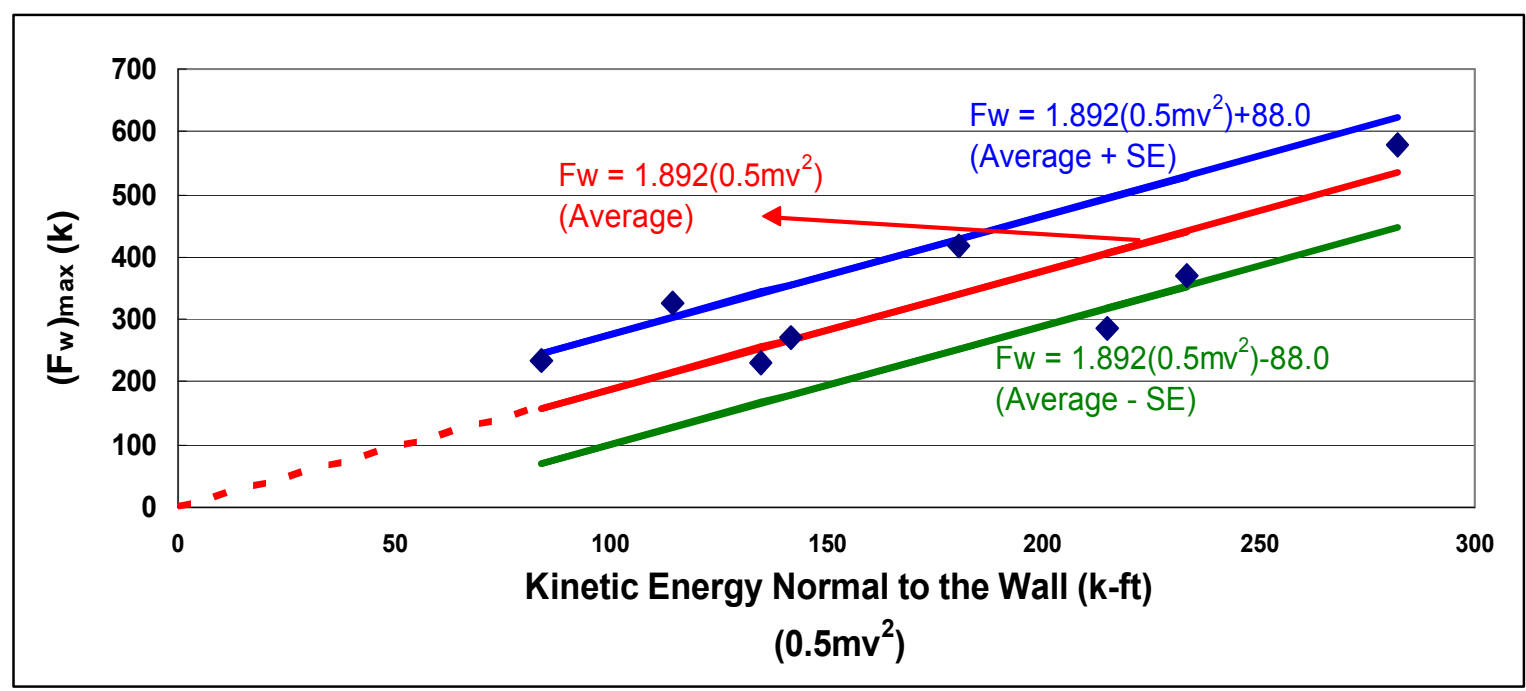

Figure 6.4. Empirical correlation using the kinetic energy concept 
The statistical evaluation was done using the computer program presented in Appendix B and verified using the standard Excel statistical package. The concepts that apply to the statistical theory are presented in Appendix D. It can be observed that, the greater the magnitude for the kinetic energy, the larger will be the maximum value for the impact force normal to the wall, as shown in Figure 6.4. Figure 6.4 is a correlation based on low-velocity, shallow-impact (up to $21.1 \mathrm{deg}$ ) experiments that, by definition, do not account for factors that manifest themselves at higher velocities. Additionally, no damage occurred to the flotilla of barges, and no lashings broke during these eight impact experiments. At this time and pending the results of additional research, Figure 6.4 is deemed applicable to a barge flotilla that has a velocity normal to the wall up to and not exceeding $0.57 \mathrm{fps}(0.39 \mathrm{mph})$ with no damage occurring during impact events, for impact angles up to 21.1 degrees, and for a barge flotilla with kinetic energy normal to the wall between 83.95 and $282.17 \mathrm{k}-\mathrm{ft}$.

Note that $v$ is the velocity normal to the wall in the equations given in Figure 6.4. We can observe that, the greater the magnitude for the kinetic energy normal to the wall, the larger will be the maximum value for the impact force normal to the wall, as shown in Figure 6.4. In these expressions, the units for the mass, velocity and maximum $F_{w}$ are $\mathrm{k}-\mathrm{sec}^{2} / \mathrm{ft}, \mathrm{ft} / \mathrm{sec}$, and kips, respectively.

The maximum normal force $\left(F_{w}\right)_{\max }$ by the empirical correlation is equal to the reaction force provided by the lock wall on the barge flotilla during the impact. Note that, in Table 6.9, the mass used to develop the Figure 6.4 correlation of kinetic energy normal to the wall with values of $\left(F_{w}\right)_{\max }$ is the mass of the barge flotilla (given in Appendix A) and does not include the computation of any hydrodynamic added masses. However, in Table 6.9, the values of $\left(F_{w}\right)_{\max }$ (which are derived from the field-test data and originally reported in Table 5.3) that are used in the Figure 6.4 correlation reflect the effects of the Figure 2.3 external forces of $F_{\text {tow }}, F_{\text {drag }}$, and $F_{\text {helper }}$ acting on the barge flotilla acting, as well as the effects of the hydrodynamic masses and the inertia of the barge flotilla mass decelerating during impact.

A summary of the values of the Table 5.3 maximum impact force normal to the wall, $\left(F_{w}\right)_{\max }$, for the energy method or the equilibrium with a fixed coefficient of friction values for the eight full-scale, controlled barge impact experiments and of the Figure 6.4 best-fit straight-line $\left(F_{w}\right)_{\max }$ values is given in Table 6.9. For example, the energy method or the equilibrium with a fixed coefficient of friction value $(=0.6)$ for the full-scale, controlled barge impact Experiment 29 produces an $\left(F_{w}\right)_{\max }$ value of $286.63 \mathrm{kips}$, and the best-fit straight line of the empirical correlation using the kinetic energy concept produces an $\left(F_{w}\right)_{\max }$ value of $406.62 \mathrm{kips}$. This corresponds to a 42 -percent overprediction by the best-fit straight line of the empirical correlation approach. The maximum force normal to the wall $\left(F_{w}\right)_{\max }$ computed using the best-fit straight line of the empirical correlation differs from the maximum force $\left(F_{w}\right)_{\max }$ values presented in Table 5.3 by a 34-percent underprediction to a 42-percent overestimate for these eight impact tests. 


\subsection{Summary, Conclusions and Recommendation}

This chapter summarizes the research and development of three engineering procedures to predict the value for the maximum impact force, $\left(F_{w}\right)_{\max }$, acting normal to the lock wall during impact; the scaled method (Section 6.1); the empirical correlation using linear momentum normal to the wall (Section 6.3); and the empirical correlation using kinetic energy normal to the wall (Section 6.5). After a careful evaluation of all three formulations to calculate $\left(F_{w}\right)_{\max }$, the authors recommend that the empirical correlation using linear momentum normal to the wall (given in Figure 6.3) be used. Recall that Figure 6.3 is a correlation based on low-velocity, shallow-impact (up to $21.1 \mathrm{deg}$ ) experiments that, by definition, do not account for factors that manifest themselves at higher velocities. Additionally, no damage occurred to the flotilla of barges during these impact experiments. Therefore, at this time and pending the results of additional research, Figure 6.3 is deemed applicable to a barge flotilla that has a velocity normal to the wall up to and not exceeding $0.57 \mathrm{fps}(0.39 \mathrm{mph})$ with no damage occurring during impact events, for impact angles up to $21.1 \mathrm{deg}$, and for a barge flotilla with a linear momentum normal to the wall between 649.84 and $1,025.48 \mathrm{k}-\mathrm{sec}$.

The ETL 1110-2-338 engineering procedure was used to compute values of maximum impact force normal to the wall, $\left(F_{w}\right)_{\max }$, for the eight full-scale, controlled barge impact experiments. A key aspect of this engineering formulation is computation of collision energy dissipated in nonrecoverable, plastic hull deformation of (i.e., damage to) the corner of the barge where impact with the wall occurs. Note that no damage was observed to the barge corner during any of these low-velocity, controlled-impact experiments at Robert C. Byrd Lock. After a careful evaluation of the ETL 1110-2-338 formulation and results of the computations given in this chapter and in Chapter 5, the authors recommend that this engineering procedure not be used when damage to the barge will not occur during impact. 


\section{Possible Layout for Future Experiments}

The experiments that form the basis of this research contain many unknowns, producing a sensitive indeterminate system that complicates the interpretation of the measured results. The force exerted by the towboat and helper boat, the drag force, and the orientation of the measured forces at the load cells in the bumper are some examples of the variables affecting the problem formulation. Suggestions are made in the following list to avoid some of the problems encountered with using the results from the December 1998 experiments in the creation of the numerical models in this barge impact research project.

a. Measure four reactions and the exact orientation to avoid the approximation of the orientation of the forces $F_{10}$ and $F_{11}$. This involves the use of a pair of two-axis load cell pins.

$b$. Measure layout geometry of bumper on barge.

c. Take pictures directly vertical over the impact zone.

d. Do not use a helper boat.

e. Align a pair of GPS monitoring points parallel to the side of the lead impact barge.

f. Analyze the first experiments to adjust the system in the field prior to finishing the test.

Table 7.1 presents some suggested values for future experiments. These values consider a range for the number of barges in the flotilla, the approach velocity, and the approach angle to produce a linear momentum below the values reported in the experiments with a 15-barge flotilla. The mass per barge was calculated based on the mass of the 15-barge flotilla divided by 15 to obtain a unit mass value. 


\begin{tabular}{|c|c|c|c|c|}
\hline $\begin{array}{l}\text { Number of } \\
\text { Barges }\end{array}$ & $\begin{array}{l}\text { Mass per Barge } \\
\text { k-s }{ }^{2} / \mathrm{ft}\end{array}$ & $\begin{array}{l}\text { Approach } \\
\text { Velocity, ft/s }\end{array}$ & $\begin{array}{l}\text { Approach } \\
\text { Angle } \\
\text { deg }\end{array}$ & $\begin{array}{l}\text { Linear } \\
\text { Momentum, k-s } \\
\end{array}$ \\
\hline 1 & 130 & 6 & 30 & 390 \\
\hline 2 & 130 & 5 & 30 & 650 \\
\hline 4 & 130 & 4 & 20 & 711 \\
\hline 8 & 130 & 3 & 15 & 808 \\
\hline
\end{tabular}




\section{Conclusions and Recommendations}

In this research project, a complex dynamic problem was modeled using a single mass model to determine the force applied to the lock wall by a barge flotilla. The input data for the research were obtained from the experiments conducted in 1998 at the Robert C. Byrd Lock in West Virginia. The input data were the approach angle, the approach velocity, and the force time-histories recorded in the experiment. The approach velocity and angle were obtained using a global positioning system.

The load time-histories were obtained using an instrumented arc beam. This beam was made of A-36 structural steel and placed at the corner of the barge using a pin-pin connection. The loads were recorded in a direction other than the radial direction of the arc bumper. To determine the maximum force applied to the wall, the impulse and linear momentum principle was applied. However, the system of equations that this principle uses was not enough to solve the complete time-history of impact from time $t_{1}$ to time $t_{2}$. There were more unknown forces in the system than equations. Two sets of methodologies were used to interpret the barge impact data.

One of the methodologies used to determine the normal load applied to the lock wall by the barge flotilla involved the use of the equations of equilibrium combined with an assumed value for the coefficient of friction. Another methodology used to determine the normal load applied to the lock wall by the barge flotilla involved the relation between the linear momentum and the impulse normal to the wall produced by the force computed using the model referred to as the assumed coefficient of friction method, or the energy method. An empirical correlation was developed relating the maximum force on the bumper (normal to the wall) to the linear momentum $m \cdot v \cdot \sin \theta$ at time of initial impact.

Three possible bumper configurations were analyzed based on the location of the bumper in relation with the longitudinal axis of the barges and the load cell orientations. The first configuration was based on the configuration reported at the time of the experiments. The bumper was placed $54 \mathrm{deg}$ from the longitudinal axis of the barges, and the load cells were oriented in the radial direction. This configuration produced some unreasonable values of coefficient of friction and can produce tension in the arc, which is physically impossible. After a detailed study of drawings and photographs, a new configuration was estimated. In this second case, the arc was considered to be placed in the same position as the first 
configuration, but the load cells were oriented in a direction outside the radial direction. An unreasonable solution was again obtained in terms of the coefficient of friction (greater than 1, or negative values) and tension in the arc. Then, a final (third) configuration was obtained based on the values of coefficient of friction (between 0 and 1) and compression in the arc. With this final configuration, the force normal to the wall time-histories was calculated for eight experiments, and an empirical relationship using the impulse and linear momentum principle was obtained (Figure 6.3) to calculate the maximum normal force at the wall due to the flotilla impact.

Chapter 6 summarized the development of three engineering procedures to predict the value for the maximum impact force, $\left(F_{w}\right)_{\max }$, acting normal to the lock wall during impact: the scaled method (Section 6.1); the empirical correlation using linear momentum normal to the wall (Section 6.3); and the empirical correlation using kinetic energy normal to the wall (Section 6.5). After a careful evaluation of all three formulations to calculate $\left(F_{w}\right)_{\max }$, the authors recommend that the empirical correlation using linear momentum normal to the wall given in Figure 6.3 be used. Recall that Figure 6.3 is a correlation based on low-velocity, shallow-impact $(<21.1 \mathrm{deg})$ experiments that, by definition, do not account for factors that manifest themselves at higher velocities. Additionally, no damage occurred to the flotilla of barges during these impact experiments. Therefore, at this time and pending the results of additional research, Figure 6.3 is deemed applicable to a barge flotilla that has a velocity normal to the wall up to and not exceeding $0.57 \mathrm{fps}(0.39 \mathrm{mph})$ with no damage occurring during impact events, for impact angles up to $21.1 \mathrm{deg}$, and for a barge flotilla with a linear momentum normal to the wall between 649.84 and $1,025.48 \mathrm{k}-\mathrm{sec}$.

The ETL 1110-2-338 engineering procedure was also used to compute values of maximum impact force normal to the wall, $\left(F_{w}\right)_{\max }$, for the eight full-scale, controlled barge impact experiments. A key aspect of this engineering formulation is computation of collision energy dissipated in nonrecoverable, plastic hull deformation of (i.e., damage to) the corner of the barge where impact with the wall occurs. No damage was observed to the barge corner during any of these low-velocity, controlled-impact experiments at Robert C. Byrd Lock. After a careful evaluation of the ETL 1110-2-338 formulation and the results of the computations given in Chapters 5 and 6 , the authors recommend that this engineering procedure not be used when damage to the barge will not occur during impact.

The interpretation described in this report did not include an evaluation of how the presence of the bumper alters the barge-to-lock wall impacts or consideration of any flexibility actions of the lock wall (e.g., rocking on its foundation) during the impact event. The effect of wall/system flexibility during impact events as well as the response of a multi-degree-of-freedom system (to account for the lashings among the barges that comprise the flotilla during an impact event) are important issues that will be the subject of future research. This series of events will be interpreted using acceleration time-histories that were recorded during impact events using Newton's second law $(F=m a)$.

Finally, the suggestions made in Chapter 7 should be considered if future instrumented barge impact experiments are to be conducted. The use of simple 
geometric bumper configurations and the use of four load cells is recommended to address the problem of the measured nonradial forces at the pin-pin connections. 


\section{References}

Alder, H. L., and Roessler, E. B. (1977). Introduction to probability and statistics, 6th ed., University of California-Davis. Freeman and Co., New York.

American Concrete Institute. (1997). ACI 349-97, Appendix B, Section B.6.5.2.1.

Bangash, M. Y .H. (2000). Impact and explosion. CRC Press, Boca Raton, FL.

Baltay, P., and Gjelsvik, A. (1990). "Coefficient of friction for steel on concrete at high normal stress," Journal of Materials in Civil Engineering 2(1), 46-92.

Beyer, H. W. (1976). Standard mathematical tables, 24th ed. CRC Press, Cleveland, $\mathrm{OH}$.

Borg, S. F., and Genaro, J. J. (1960). Advanced structural analysis. Van Nostrand, Princeton, NJ.

Bowden, F. P., and Tabor, D. (1950). The friction and lubrication of solids. Clarendon Press, Oxford, England.

Chapra, S. C., and Canale, R. P. (1988). Numerical methods for engineers, $2 \mathrm{~d}$ ed. McGraw-Hill, New York.

Clifford, D. W. (1959). Statically indeterminate structure, 4th ed. International Text Book Company, Scranton, P A.

Computer \& Structures, Inc. (2000). "SAP2000 Computer structural program," University of California, Berkeley.

Dean, G. D. (1998). Advanced engineering mathematics. CRC Press, Boca Raton, FL.

Dean, R., and Dalrymple, R. (1984). Waterwave mechanics for engineers and scientists. Prentice-Hall, Englewood Cliffs, NJ.

Hancock, G. J., and Olsen, C. J. (1988). "Structural behavior of stressed arch structural system," Report No. R576, The University of Sydney, Australia. 
Headquarters, Department of the Army. (1993-rescinded). "Barge impact analysis," Engineer Technical Letter 1110-2-338, Washington, DC.

Idun, E. K. and Darwin, D. (1999). "Bond of epoxy-coated reinforcement: Coefficient of friction and rib face angle," ACI Structural Journal 96(4), 609-15.

Integrated Engineering Software. (1998). "VisualAnalysis-3D,” Bozeman, MT.

Karman, T. V., and Biot, M. A. (1940). Mathematics methods in engineering. McGraw Hill, New York.

Lopes, S. M. R., and Simoes, L. M. L. P. (1999). "Influence of corrosion on prestress strands," Canadian Journal of Civil Engineering 26(6), 782-88.

Martin, S. K. (1989). "Effects of geometry on the kinetic energy of a towboat and barges in a navigation lock," Technical Report REMR-HY-4, U.S. Army Engineer Waterways Experiment Station, Vicksburg, MS.

McCormick, M. E. (1973). Ocean engineering wave mechanics. John Wiley and Sons, New York.

Mort, R. (1994). Applied fluid mechanics, 4th ed. Merrill, Macmillan Publishing, New York.

Olofsson, U., and Holmgren, M. (1994). "Friction measurement at low sliding speed using a servohydraulic tension-torsion machine," Experimental Mechanics 34(3), 202-07.

Pytel, A., and Kiusalaas, J. (1994). Engineering mechanics. Harper Collins College Publishers, New York.

Rabbat, B. G., and Russell, H. G. (1985). "Friction coefficient of steel on concrete or grout," Journal of Structural Engineering 111(3), 505-15.

Roberson, J. A., and Crowe, C. T. ( 1985). Engineering fluid mechanics, $3 \mathrm{~d}$ ed. Houghton Mifflin, Boston, MA.

Sarpkaya, T., and Isaacson, M. (1981). Mechanics of wave forces on offshore structure. Van Nostrand Reinhold, New York.

Sayers, L. (1998). "Designing a material handling system for Ingersoll Rand Company, Design Project 2, Penn State University," University Park, PA.

Seely, F., and Smith, J. ( 1960). Advanced mechanics of material, 2d ed. John Wiley and Sons, New York.

Street, R., Watters, G., and Vennard, J. (1996). Elementary fluid mechanics, 7 th ed. John Wiley and Sons, New York.

Timoshenko, S., and Woinowsky-Krienger, S. (1959). Theory of plates and shells, 2d ed. McGraw Hill, New York. 
Tuma, J., and Munshi, R. K. (1971). Advanced structural analysis. McGraw Hill, New York.

Wang, Chu-Kia. (1953). Statically indeterminate structure. McGraw-Hill, New York.

Wilson, J. F. (1984). Dynamic of offshore structures. John Wiley and Sons, New York. 


\section{Appendix A Summary of Experimental Results}

The data and analysis presented in this appendix were generated from field data acquired during the full-scale barge impact experiments conducted at Robert C. Byrd Lock and Dam in December 1998. The data presented here represent only the portion relevant to this report, mainly the load bumper and global positioning system (GPS) data.

Figure A.1 shows the tow configuration and orientation for the barge impact experiments. The flotilla consisted of 15 jumbo open-hopper barges (35 by $195 \mathrm{ft}),{ }^{1}$ ballasted with anthracite coal to a draft of $9 \mathrm{ft}$, a typical configuration for commercial traffic on the Ohio River main stem. The front and rear rows were single-raked barges (approximately 23-deg rake at the front, flat at the back). The middle nine barges were double raked (rakes at both ends). The drawing below shows the two coordinate systems used in this analysis: the global axis represents the lock wall, and the local axis is on the tow. The impact angle $(\theta)$ is the angle of rotation between these axes. The impact angle, $\theta$, referenced throughout this report is the angle between the port side of the right-front barge and the lock wall, as measured with the GPS systems (see Table A.1).

Force time-histories for the load-bumper gages F10 (front) and F11 (rear) for Experiments 22-31 and 37-44 are presented in this appendix. Full-duration plots for all experiments are included, as well as expanded plots of most experiments showing the first load cycle. Table A.1 summarizes the significant aspects of these plots. In Table A.2, rise time (defined here as $\Delta \mathrm{T}$ between contact and peak load) is listed for each measurement along with the time of contact.

Figure A. 2 shows the force time-histories of the front load cell F10 and rear load cell F1 1 for Experiment 22 during the $9 \mathrm{sec}$ of impact. This experiment was conducted at a shallow approach angle of $10 \mathrm{deg}$ and prior to removal of the flatpack skid plate along the front face of the bumper. For this shallow approach angle, the rear load cell absorbed nearly all the load during the impact, compared with the near-zero loads recorded by the front load cell. Note that the initial

\footnotetext{
${ }^{1}$ A table of factors for converting non-SI units of measurement to SI units is presented on page xiii of the main text.
} 


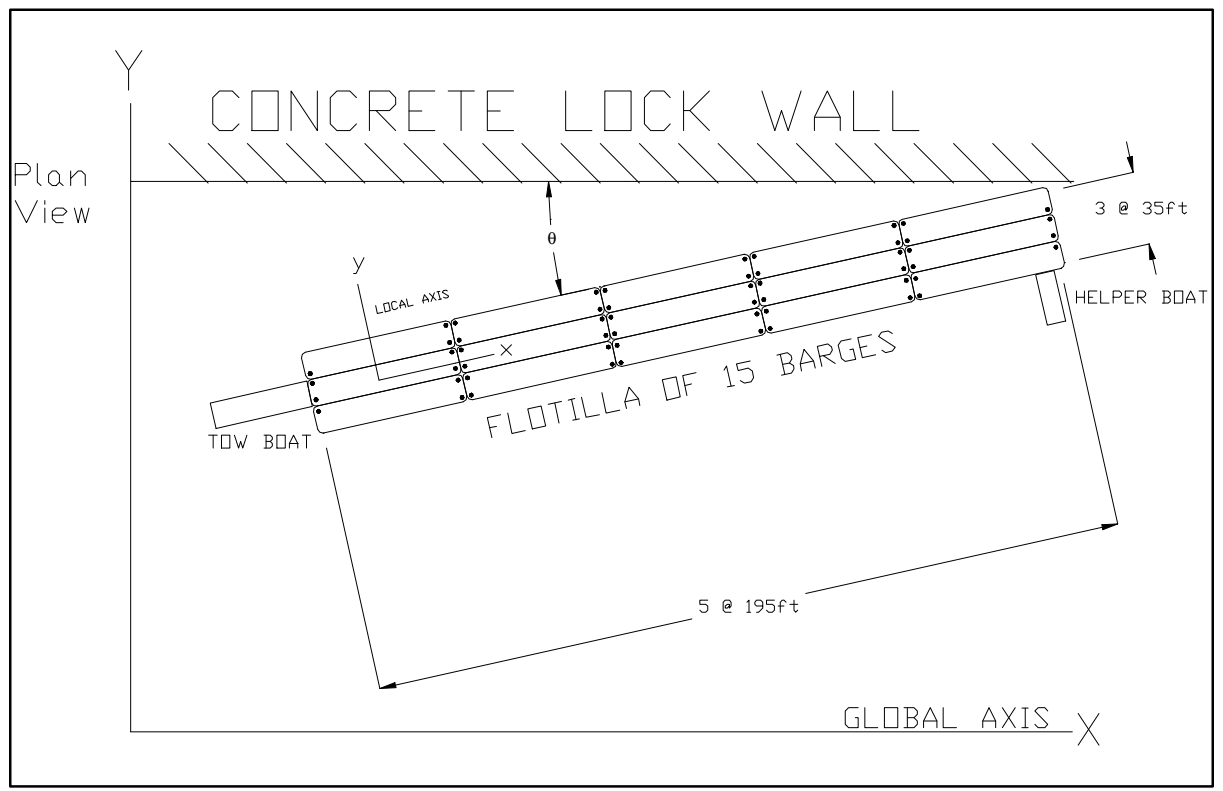

Figure A.1. Experiment configuration diagram

\section{Table A.1}

\section{$F_{11} \max , F_{10} \max , \Delta T$}

\begin{tabular}{|c|c|c|c|c|c|c|c|c|c|c|}
\hline \multirow{2}{*}{$\begin{array}{c}\text { Experiment } \\
\text { Number }\end{array}$} & \multicolumn{2}{|c|}{ Velocity } & \multirow{2}{*}{$\begin{array}{c}\text { Approach } \\
\text { Angle } \\
\text { (degrees) }\end{array}$} & \multicolumn{2}{|c|}{$F_{10}$} & \multicolumn{2}{|c|}{$F_{11}$} & \multirow{2}{*}{$\begin{array}{c}T_{1} \\
(\sec )\end{array}$} & \multirow[b]{2}{*}{$\begin{array}{c}\Delta \mathbf{T}^{*} \\
(\mathrm{sec})\end{array}$} & \multirow{2}{*}{$\begin{array}{c}\text { Difference } \\
\text { in times } \\
(\%)\end{array}$} \\
\hline & fps & $\mathrm{mph}$ & & $\begin{array}{c}\text { Max } \\
\text { (kips) }\end{array}$ & $\begin{array}{l}\text { Time } \\
\text { (sec) }\end{array}$ & $\begin{array}{c}\text { Max } \\
\text { (kips) }\end{array}$ & $\begin{array}{l}\text { Time } \\
\text { (sec) }\end{array}$ & & & \\
\hline 29 & 2.20 & 1.500 & 12.63 & 61.41280 & 4.74560 & 172.68090 & 4.72820 & 4.72820 & 0.01740 & 0.36800 \\
\hline 30 & 2.35 & 1.602 & 12.19 & 94.45936 & 4.73440 & 245.95400 & 4.73960 & 4.73960 & 0.00520 & 0.10971 \\
\hline 31 & 1.61 & 1.098 & 10.60 & 33.49701 & 4.67420 & 161.68200 & 4.65740 & 4.65740 & 0.01680 & 0.36072 \\
\hline 37 & 1.95 & 1.330 & 10.29 & 32.78601 & 4.71740 & 220.67440 & 4.69300 & 4.69300 & 0.02440 & 0.51992 \\
\hline 38 & 1.83 & 1.248 & 11.94 & 32.60806 & 4.69680 & 138.24350 & 4.69720 & 4.69720 & 0.00040 & 0.00852 \\
\hline 39 & 1.61 & 1.098 & 14.12 & 85.97357 & 4.66300 & 158.77290 & 4.68520 & 4.68520 & 0.02220 & 0.47383 \\
\hline 40 & 1.91 & 1.302 & 17.52 & 144.51930 & 4.81440 & 136.29760 & 4.80720 & 4.81440 & 0.00720 & 0.14955 \\
\hline 41 & 2.86 & 1.950 & 8.76 & 29.46939 & 4.76580 & 315.49250 & 4.75480 & 4.75480 & 0.01100 & 0.23135 \\
\hline 42 & 1.83 & 1.248 & 17.48 & 153.72340 & 4.81500 & 211.17280 & 4.80460 & 4.80460 & 0.01040 & 0.21646 \\
\hline 43 & 0.88 & 0.600 & 21.16 & 98.70299 & 4.53720 & 80.74776 & 4.52260 & 4.53720 & 0.01460 & 0.32178 \\
\hline 44 & 1.22 & 0.832 & 20.92 & 172.67910 & 4.79500 & 109.07760 & 4.80380 & 4.79500 & 0.00880 & 0.18352 \\
\hline
\end{tabular}

impact force pulse contains the maximum magnitude force that is recorded during the experiment for both load cells. This observation is valid for all experiments.

Figure A. 3 shows the force time-histories of the front load cell F10 and rear load cell F11 for Experiment 27. This experiment was conducted at a shallow approach angle of $8 \mathrm{deg}$ at a location farther up the wall from the primary target site, for the purpose of "shearing off" the damaged flat-pack bracket hardware. This experiment should not be used for evaluation purposes. Only those experiments designated with numbers above 27 were used in the data reduction that is discussed in this appendix. 


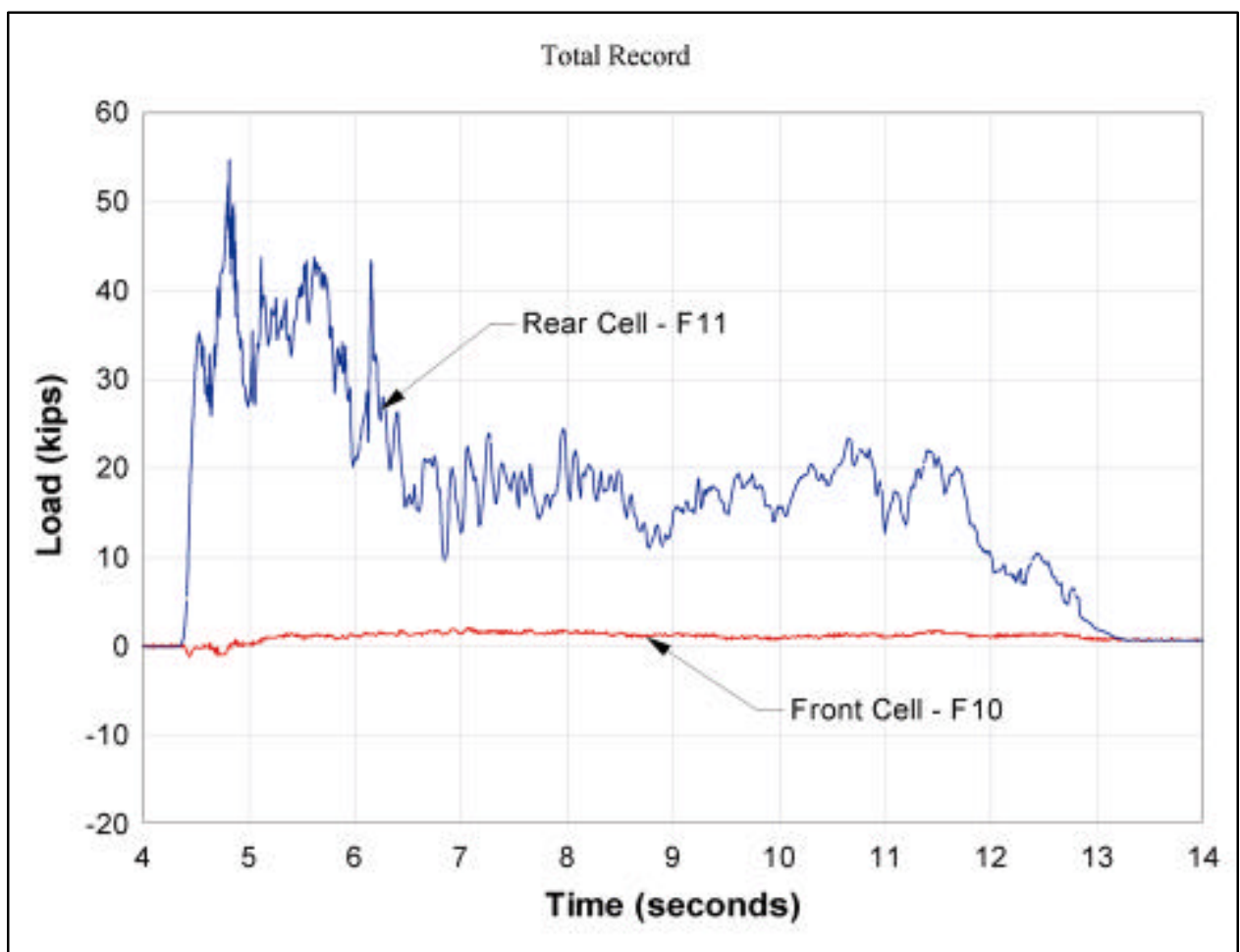

Figure A.2. Experiment 22-Time variation of recorded bumper forces F10 and F11 during barge impact with an approach velocity of $0.88 \mathrm{fps}$ and a 10-deg impact angle

\begin{tabular}{|c|c|c|}
\hline \multicolumn{3}{|c|}{$\begin{array}{l}\text { Table A.2 } \\
\text { Time in Seconds to Maximum } \\
\text { Load and Time of Contact of } \\
\text { Experiment }\end{array}$} \\
\hline Experiment & $\Delta t_{i}$ & $\begin{array}{l}\text { Time of } \\
\text { Contact }\end{array}$ \\
\hline 29 & 0.1282 & 9 \\
\hline 30 & 0.1796 & 9 \\
\hline 31 & 0.1374 & 9 \\
\hline 37 & 0.193 & 9 \\
\hline 38 & 0.1272 & 9 \\
\hline 39 & 0.2352 & 9 \\
\hline 40 & 0.1344 & 9 \\
\hline 41 & 0.1648 & 9 \\
\hline 42 & 0.1596 & 9 \\
\hline 43 & 0.1422 & 9 \\
\hline 44 & 0.25 & 9 \\
\hline Avg & 0.168327 & \\
\hline Std & 0.042495 & \\
\hline COV & 0.252458 & \\
\hline
\end{tabular}




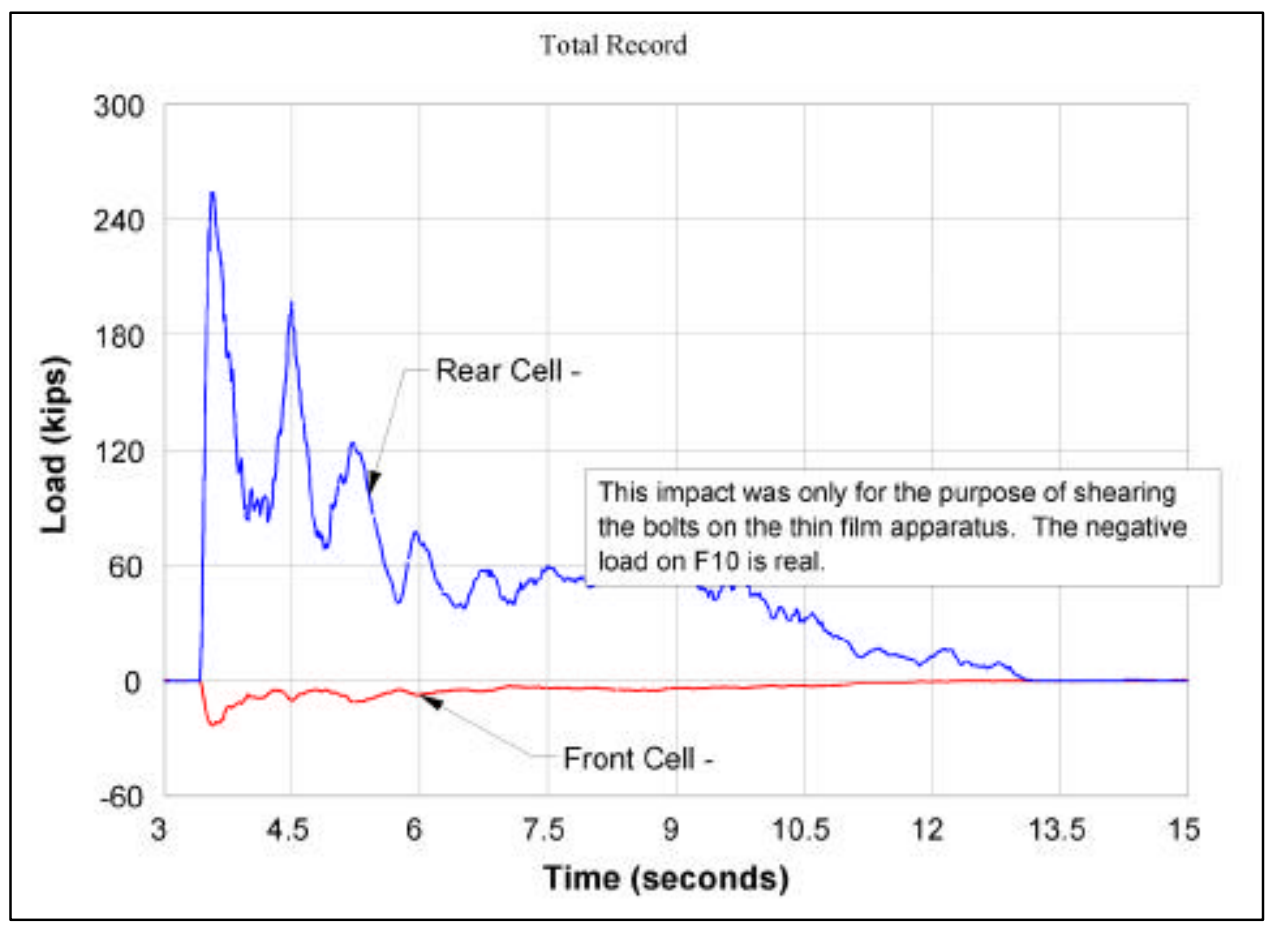

Figure A.3. Experiment 27-Time variation of recorded bumper forces F10 and F11 during barge impact with an approach velocity of $2.2 \mathrm{fps}$ and an 8-deg impact angle

Figures A.4-A.6 show the force time-histories of the front load cell F10 and rear load cell F11 for Experiments 23-25, respectively. These experiments were conducted at shallow approach angles ranging from 15.5 to $18 \mathrm{deg}$. Note that the maximum forces were recorded by the rear load cell (F11) during these experiments.

Figure A.7 shows the force time-histories of the front load cell F10 and rear load cell F11 for Experiment 26. This experiment was conducted at a steep approach angle of $23.75 \mathrm{deg}$. Note that the magnitude of the forces recorded by the front load cell (F10) during impact exceeds the forces recorded by the rear load cell (F11). The authors believe that the front load cell recorded the largest force, as compared to that recorded by the rear load cell, due to the proximity of the approach angle of the flotilla in comparison with the midpoint of the arc of the bumper. Midpoint of the arc geometry of the bumper is equal to $21.5 \mathrm{deg}$ (the average of 7 and $36 \mathrm{deg}$ ). The point of impact is a function of the approach angle and the mounting coordinates (in terms of angles for the bumper connection/reaction points on the barge), and the approach angle of the flotilla and barge on which the bumper is mounted. The approach angle of $23.75 \mathrm{deg}$ is in excess of the midpoint angle of $21.5 \mathrm{deg}$ along the arc of the bumper; thus, the front bumper load cell F10 will record the maximum force. 


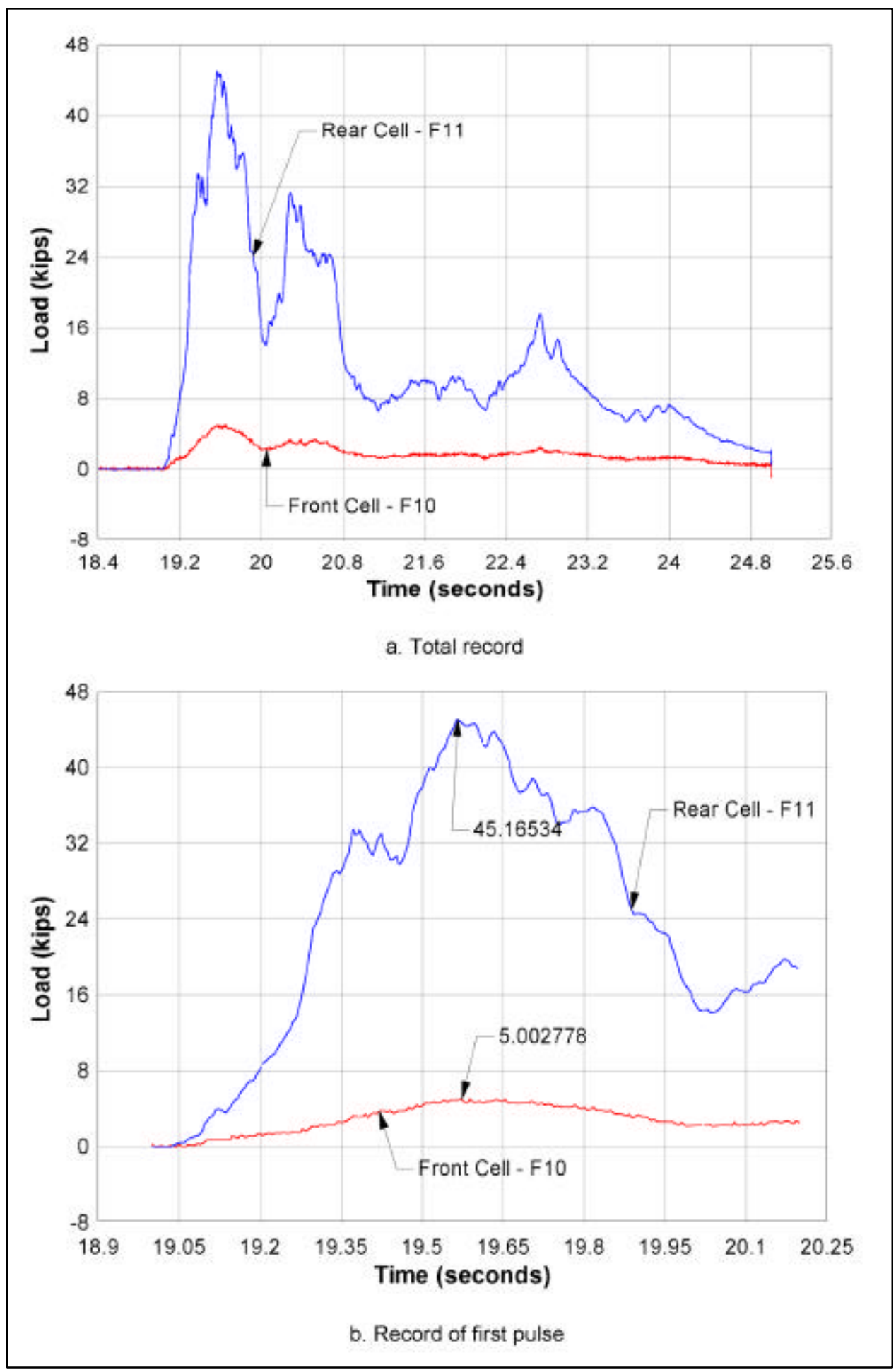

Figure A.4. Experiment 23-Time variation of recorded bumper forces F10 and F11 during barge impact with an approach velocity of $0.81 \mathrm{fps}$ and a 15.5-deg impact angle 


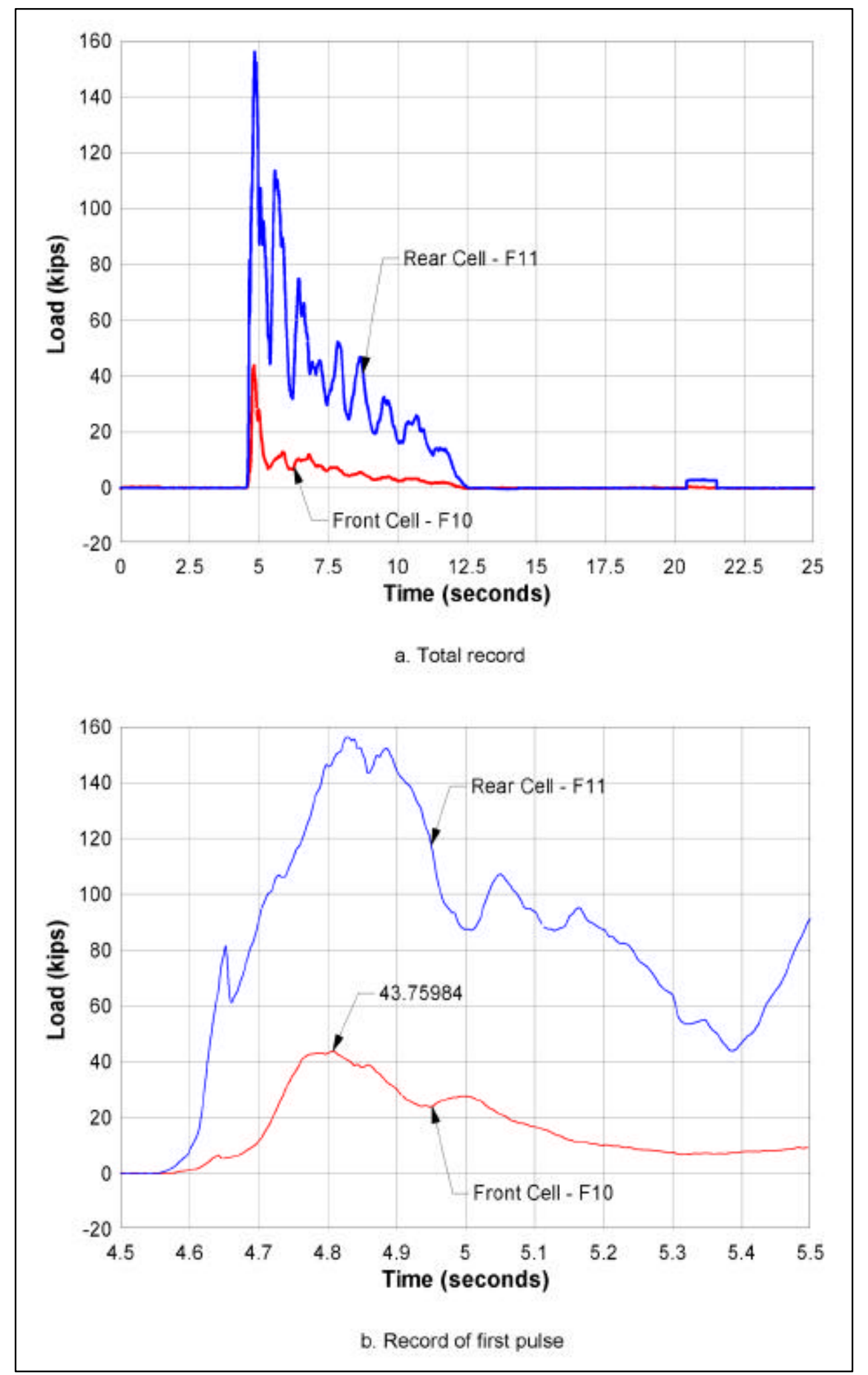

Figure A.5. Experiment 24-Time variation of recorded bumper forces F10 and F11 during barge impact with an approach velocity of $1.1 \mathrm{fps}$ and an 18-deg impact angle 


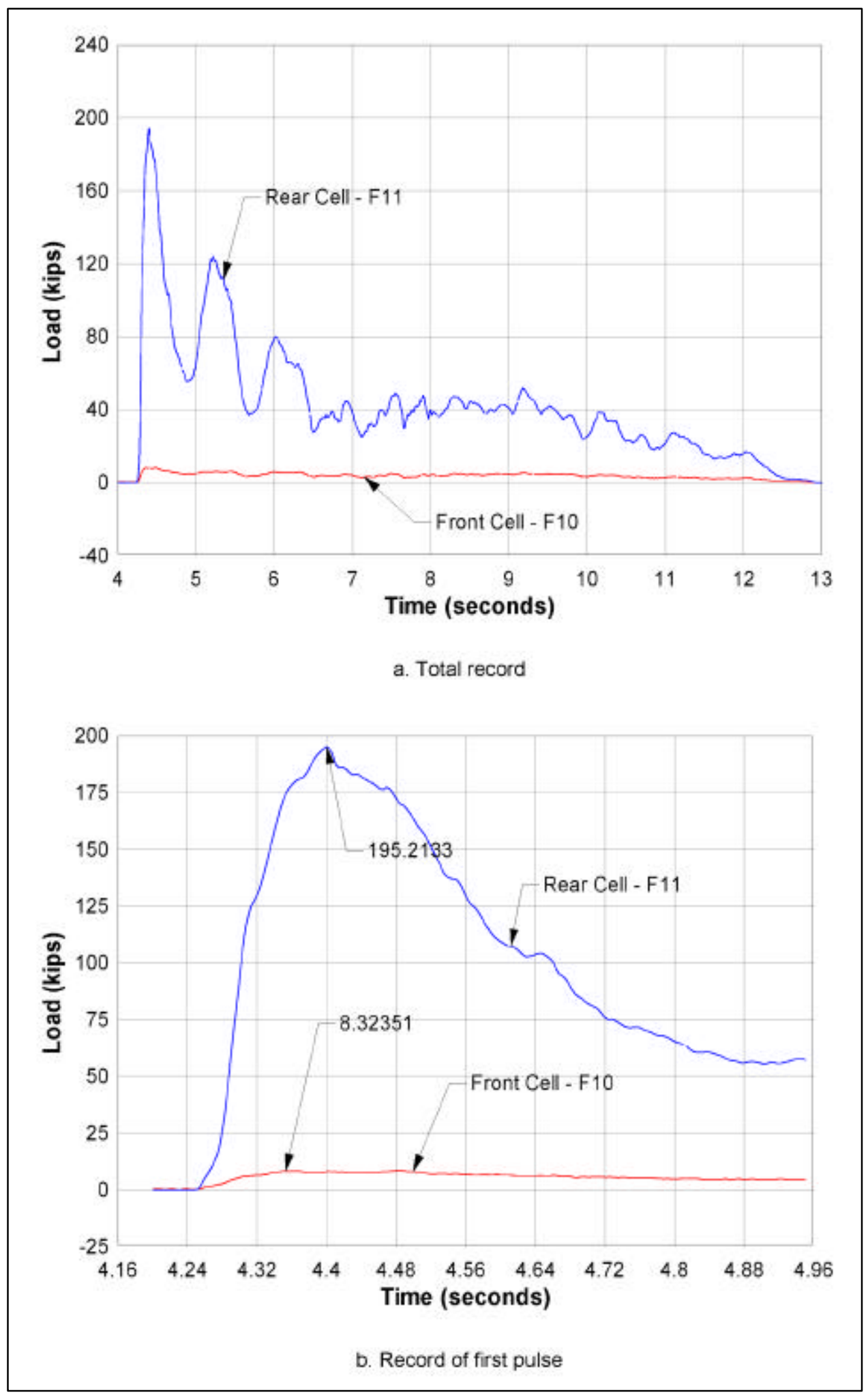

Figure A.6. Experiment 25-Time variation of recorded bumper forces F10 and F11 during barge impact with an approach velocity of $2.2 \mathrm{fps}$ and a 16.25-deg impact angle 


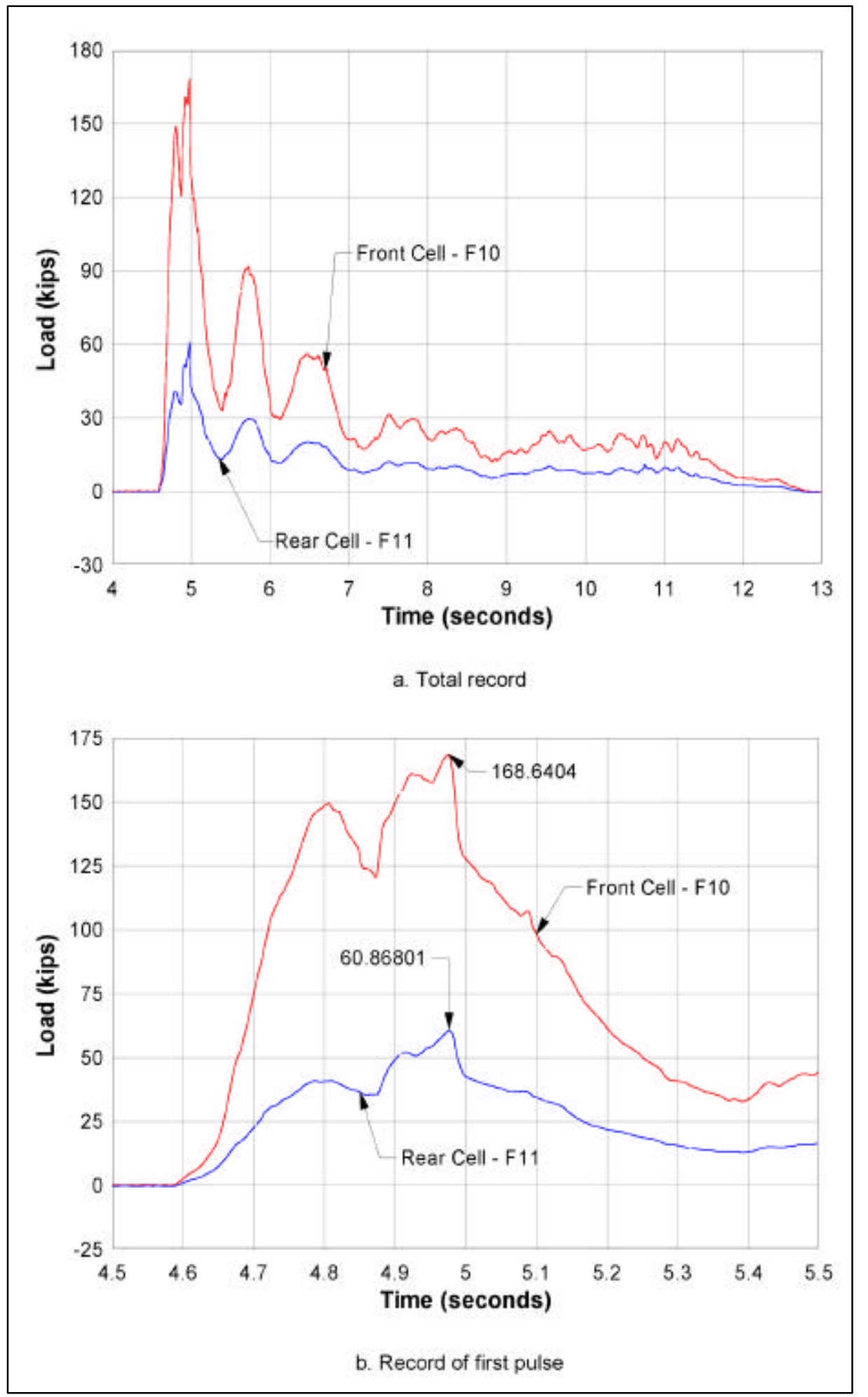

Figure A.7. Experiment 26-Time variation of recorded bumper forces F10 and F11 during barge impact with an approach velocity of $1.1 \mathrm{fps}$ and a 23.75-deg impact angle 
Figures A.8-A.13 show the force time-histories of the front load cell F10 and rear load cell F11 for Experiments 28-31 and Experiments 37 and 38, respectively. These experiments were conducted at shallow approach angles ranging from 12.5 to $15 \mathrm{deg}$. Note that the maximum forces were recorded by the rear load cell (F11) during these experiments.

Figure A.14 shows the force time-histories of the front load cell F10 and rear load cell F11 for Experiment 39. This experiment was conducted at a moderate approach angle of $17.25 \mathrm{deg}$. Note that the maximum forces were recorded by the rear load cell (F11) for this experiment. During the first force pulse, the rear load cell F11 records a maximum force that is nearly twice the magnitude of force recorded by the front load cell F10.

Figure A.15 shows the force time-histories of the front load cell F10 and rear load cell F11 for Experiment 40. This experiment was conducted at a moderate approach angle of $20.25 \mathrm{deg}$. Note that during the first two impact force pulses, the maximum forces were nearly the same for both load cells, with the front load cell (F10) recording slightly larger forces. This trend was reversed during the subsequent impact pulses. Recall that the midpoint along the arc of the bumper is $21.5 \mathrm{deg}$ and that the approach angle in this experiment is close to this value. The trend of the rear load cell recording slightly larger values than the front load cell a few seconds after impact commences implies that there was a change in angle of the flotilla (relative to the wall) during the $9 \mathrm{sec}$ of impact.

Figure A.16 shows the force time-histories of the front load cell F10 and rear load cell F11 for Experiment 41. This experiment was conducted at a shallow approach angle of $11.5 \mathrm{deg}$. Note that the maximum forces were recorded by the rear load cell (F11) during this experiment.

Figure A.17 shows the force time-histories of the front load cell F10 and rear load cell F11 for Experiment 42. This experiment was conducted at a moderate approach angle of $18.5 \mathrm{deg}$. Note that the maximum forces were recorded by the rear load cell (F11) for this experiment. During the first force pulse, the rear load cell F11 records a maximum force but, because of the moderate approach angle, the front load cell F10 records a maximum force that is only about 25 percent less than the maximum value recorded by the rear load cell.

Figures A.18 and A.19 show the force time-histories of the front load cell F10 and rear load cell F11 for Experiments 43 and 44, respectively. These experiments were conducted at steep approach angles (25 and $23 \mathrm{deg}$, respectively). Note that the maximum forces were recorded by the front load cell (F10) for these two experiments. During the first force pulse, the rear load cell F11 records a maximum force that is only about 10 percent less than the maximum value recorded by the front load cell in Experiment 43 and about 40 percent less for Experiment 44. 


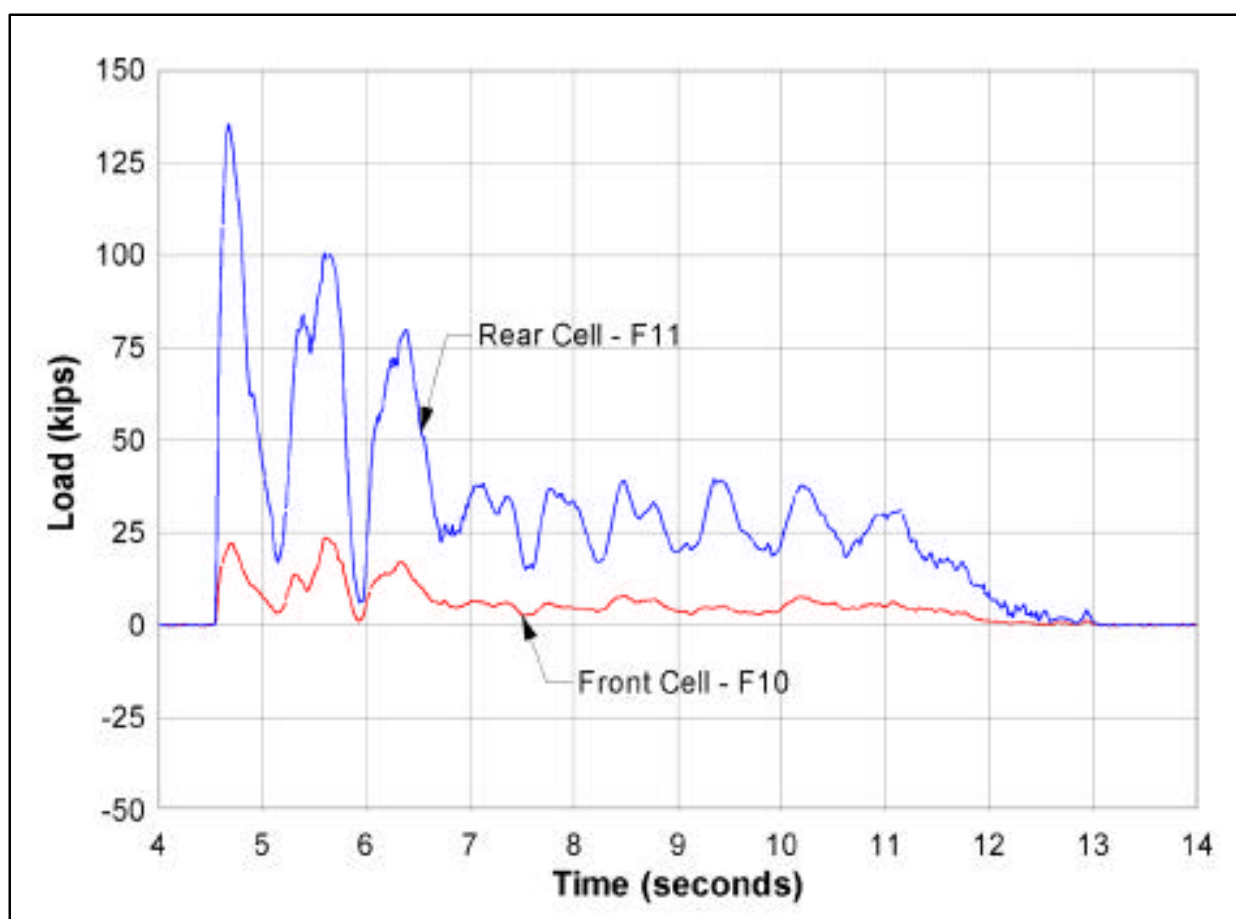

a. Total record

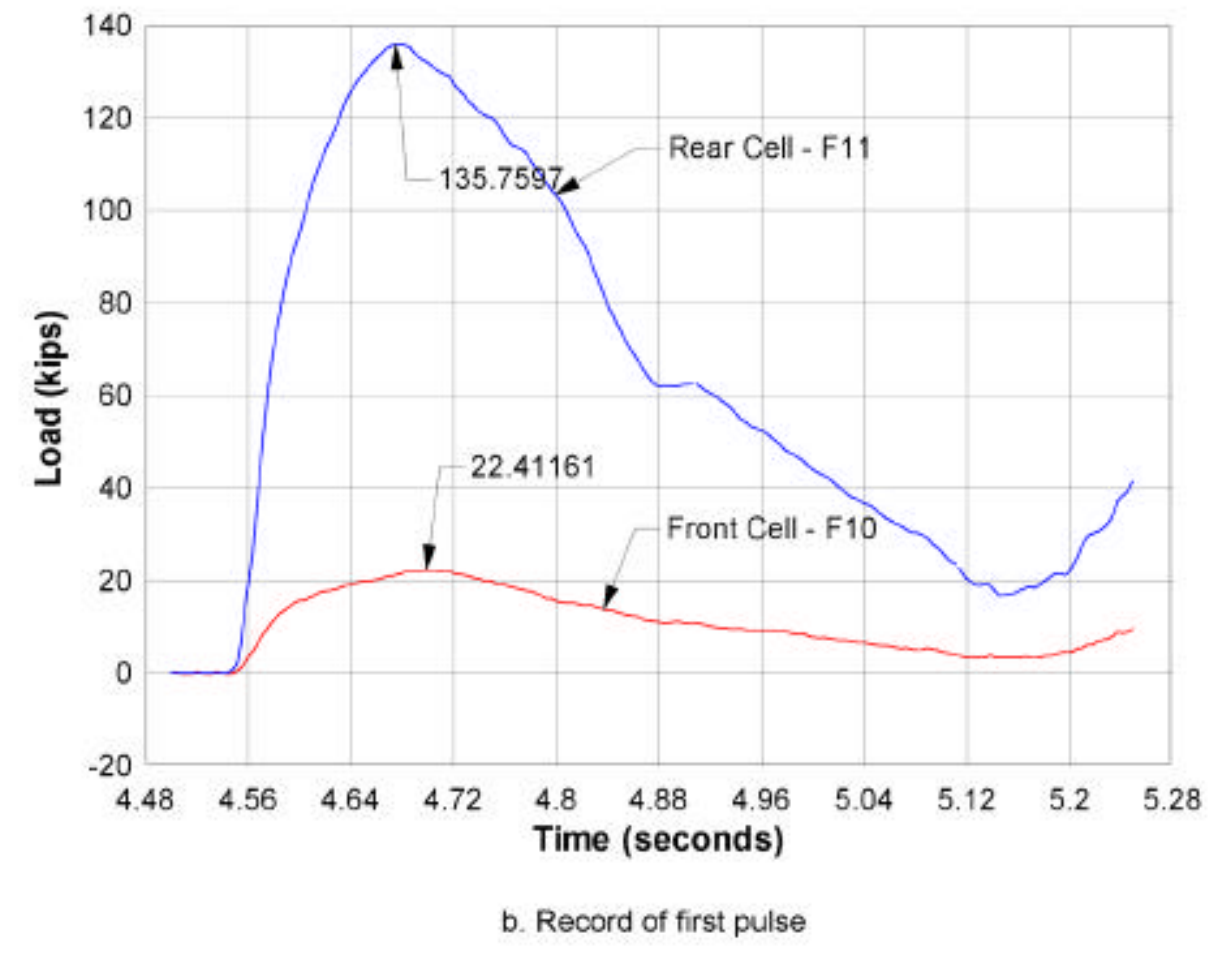

Figure A.8. Experiment 28-Time variation of recorded bumper forces F10 and F11 during barge impact with an approach velocity of $2.35 \mathrm{fps}$ and a 12.5-deg impact angle 


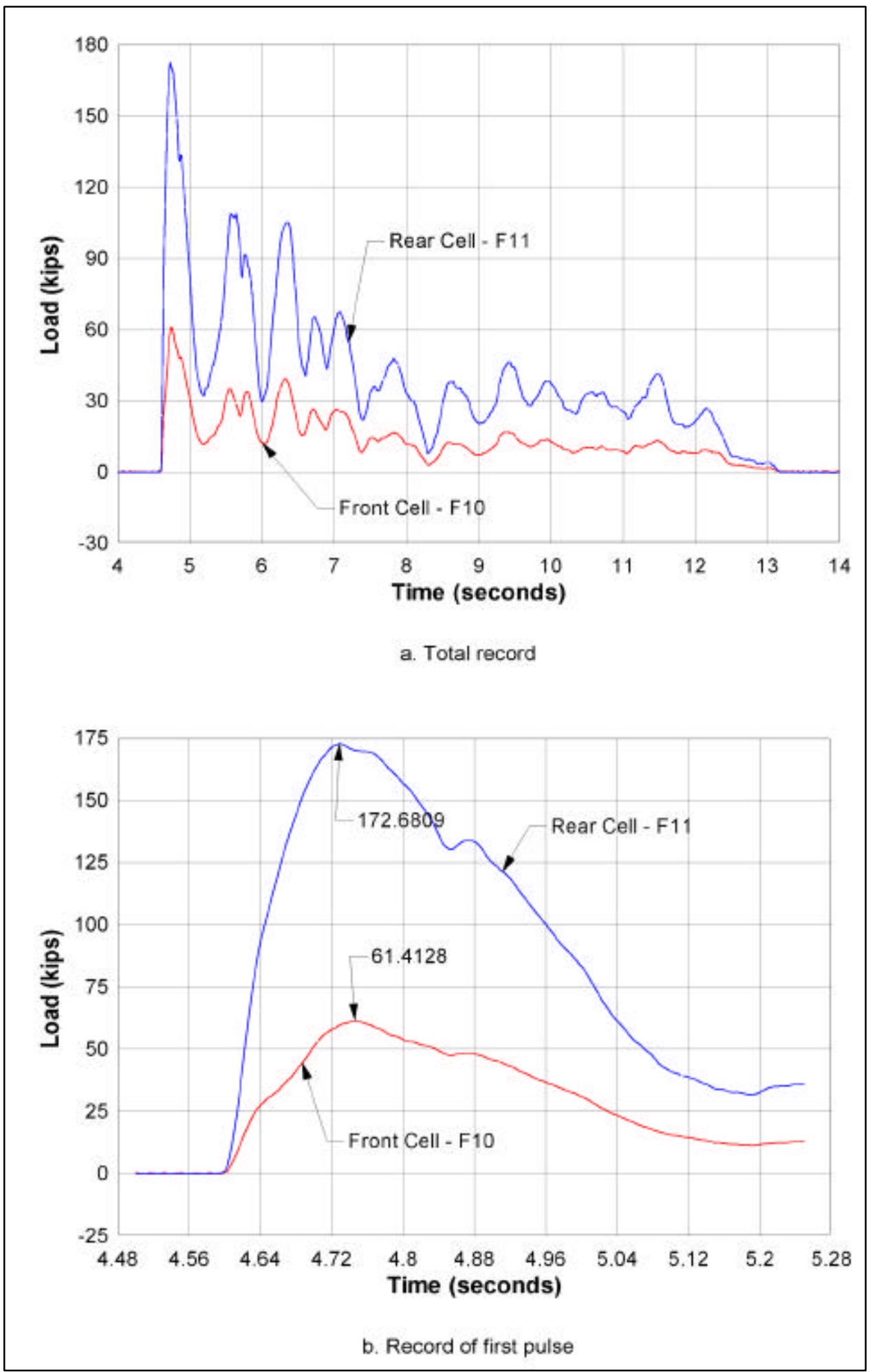

Figure A.9. Experiment 29-Time variation of recorded bumper forces F10 and F11 during barge impact with an approach velocity of $2.2 \mathrm{fps}$ and a 15-deg impact angle 


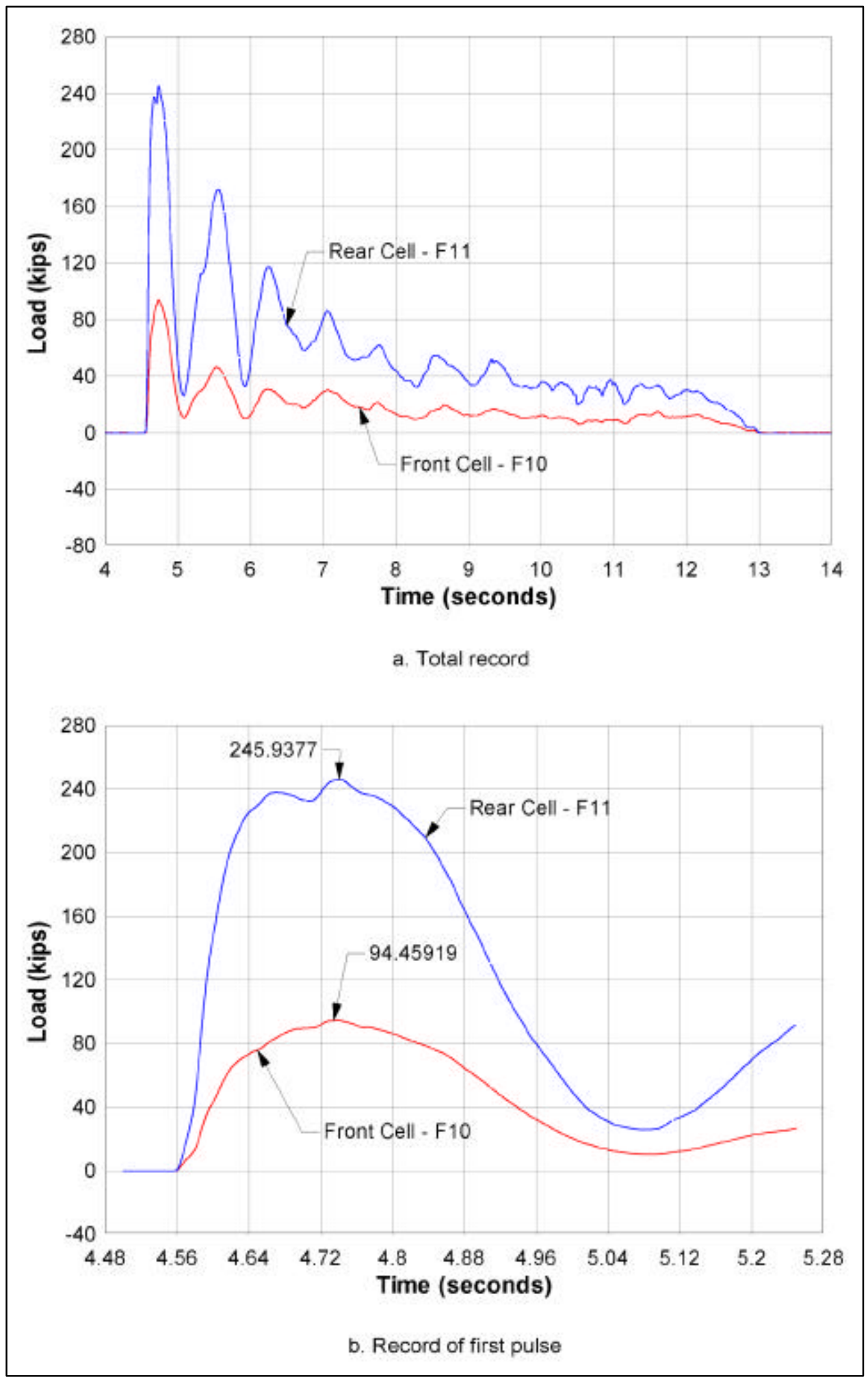

Figure A.10. Experiment 30-Time variation of recorded bumper forces F10 and F11 during barge impact with an approach velocity of $2.35 \mathrm{fps}$ and a 15-deg impact angle 


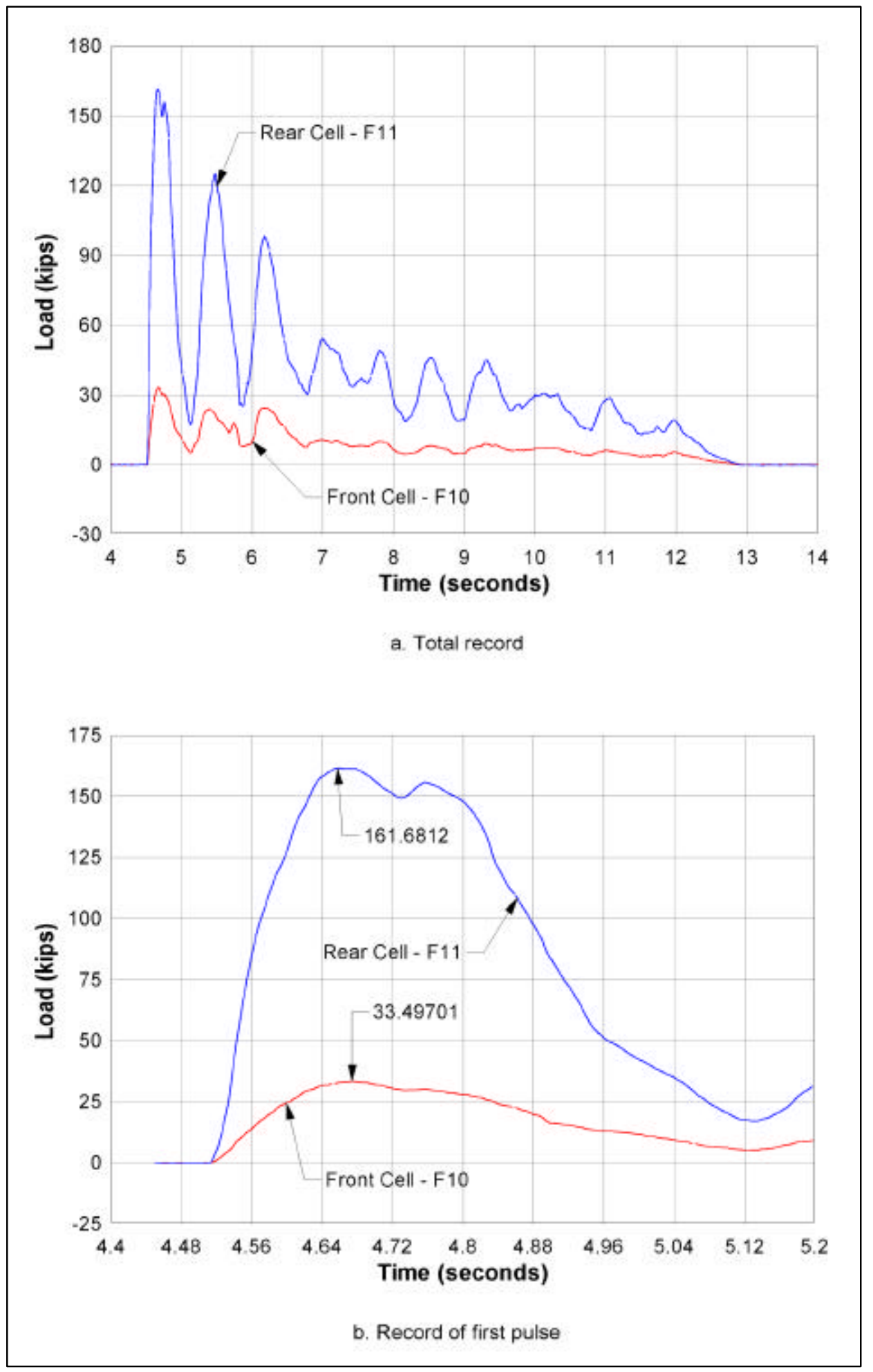

Figure A.11. Experiment 31-Time variation of recorded bumper forces F10 and F11 during barge impact with an approach velocity of $1.61 \mathrm{fps}$ and a 13.25-deg impact angle 


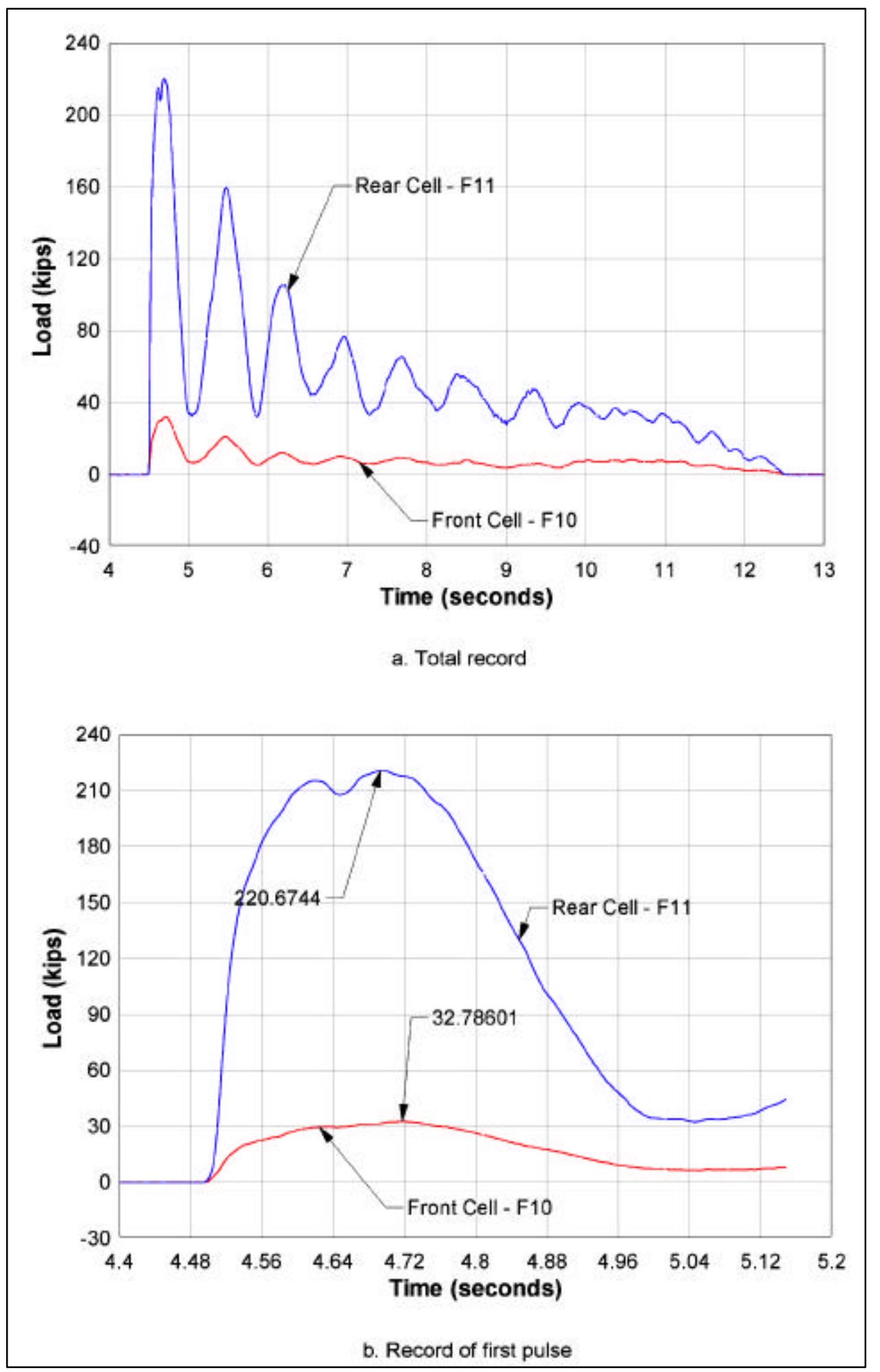

Figure A.12. Experiment 37-Time variation of recorded bumper forces F10 and F11 during barge impact with an approach velocity of $1.95 \mathrm{fps}$ and a 12.5-deg impact angle 


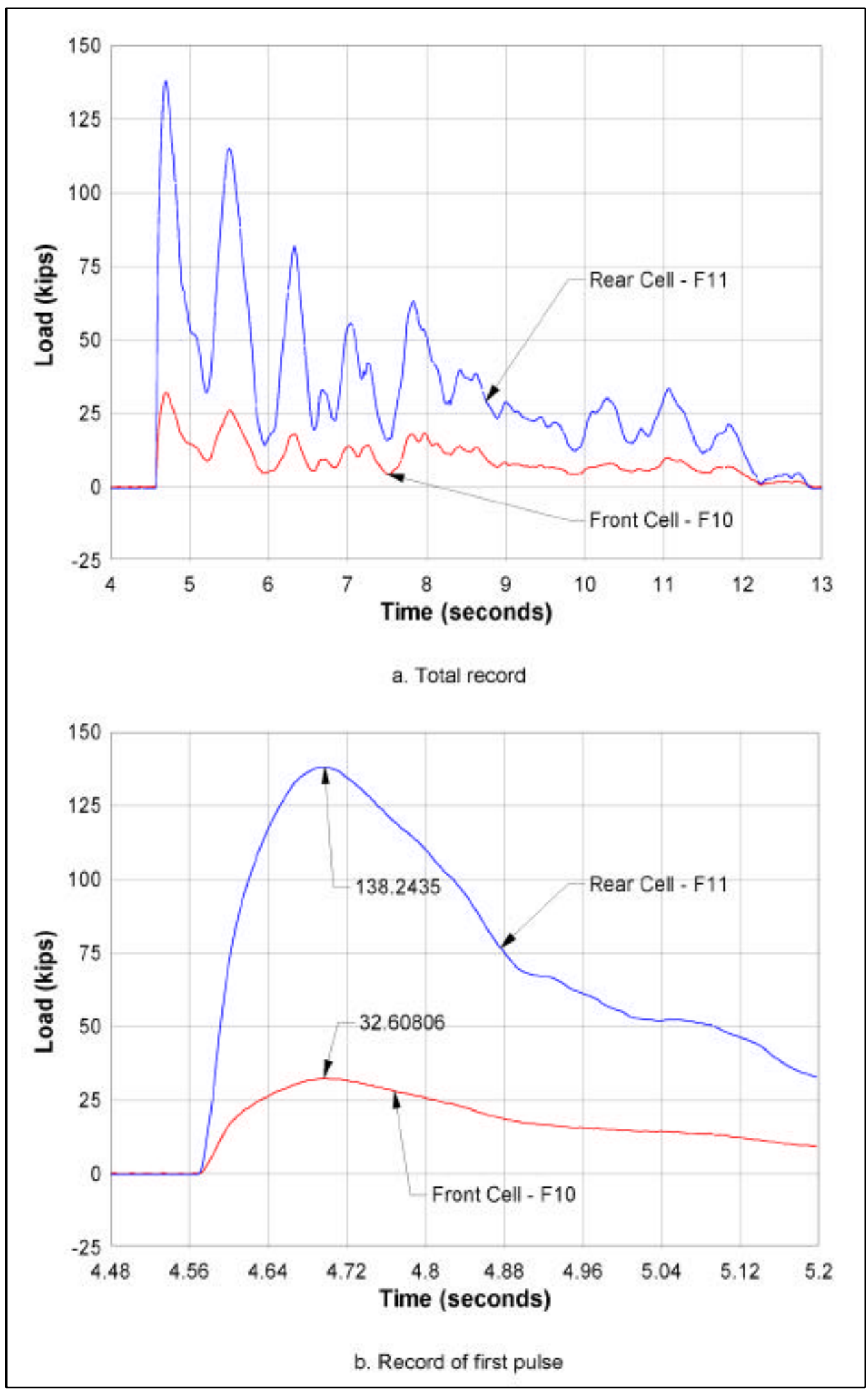

Figure A.13. Experiment 38-Time variation of recorded bumper forces $F 10$ and F11 during barge impact with an approach velocity of $1.83 \mathrm{fps}$ and a 14.25-deg impact angle 


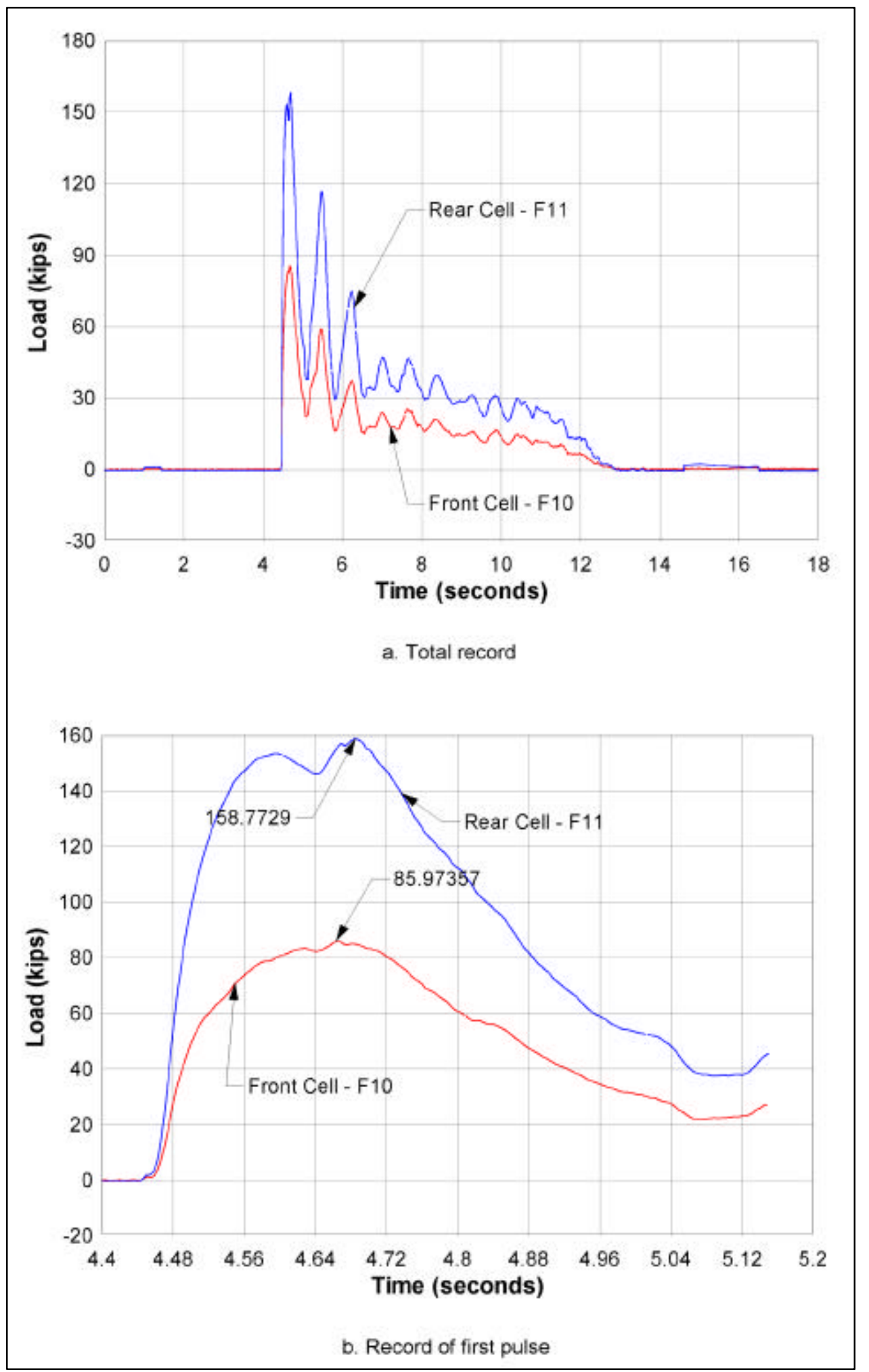

Figure A.14. Experiment 39-Time variation of recorded bumper forces F10 and F11 during barge impact with an approach velocity of $1.61 \mathrm{fps}$ and a 17.25-deg impact angle 


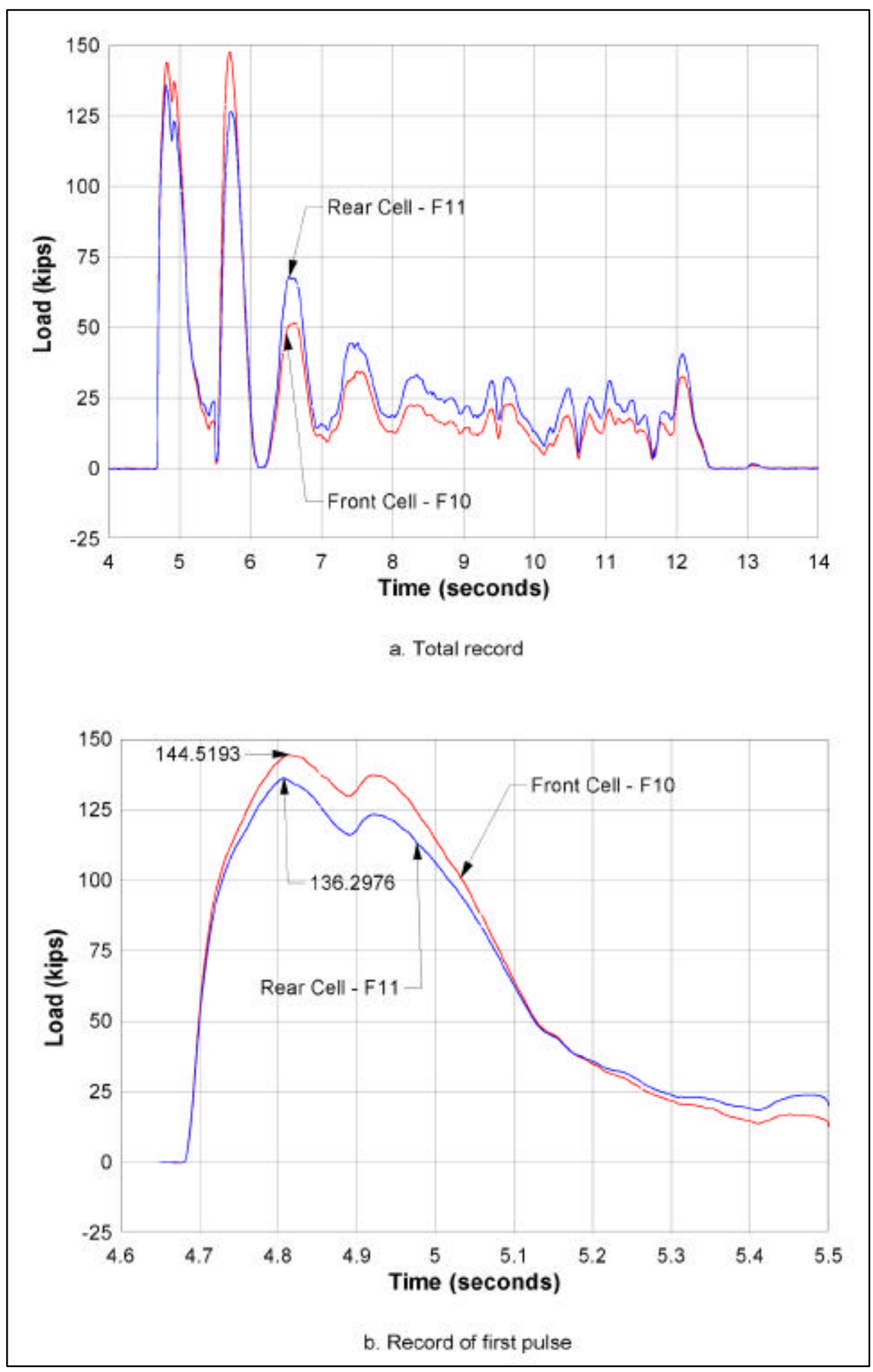

Figure A.15. Experiment 40-Time variation of recorded bumper forces F10 and F11 during barge impact with an approach velocity of $1.91 \mathrm{fps}$ and a 20.25-deg impact angle 


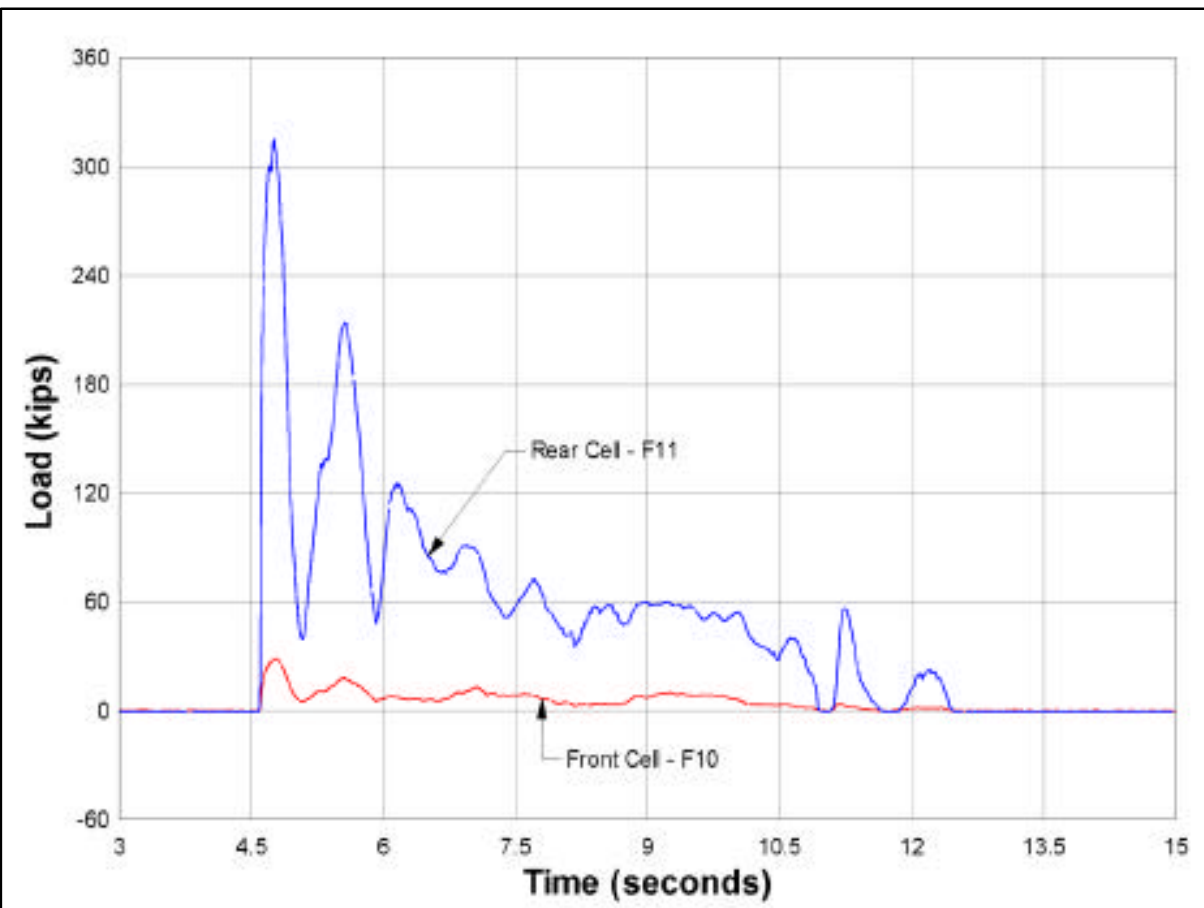

a. Total record

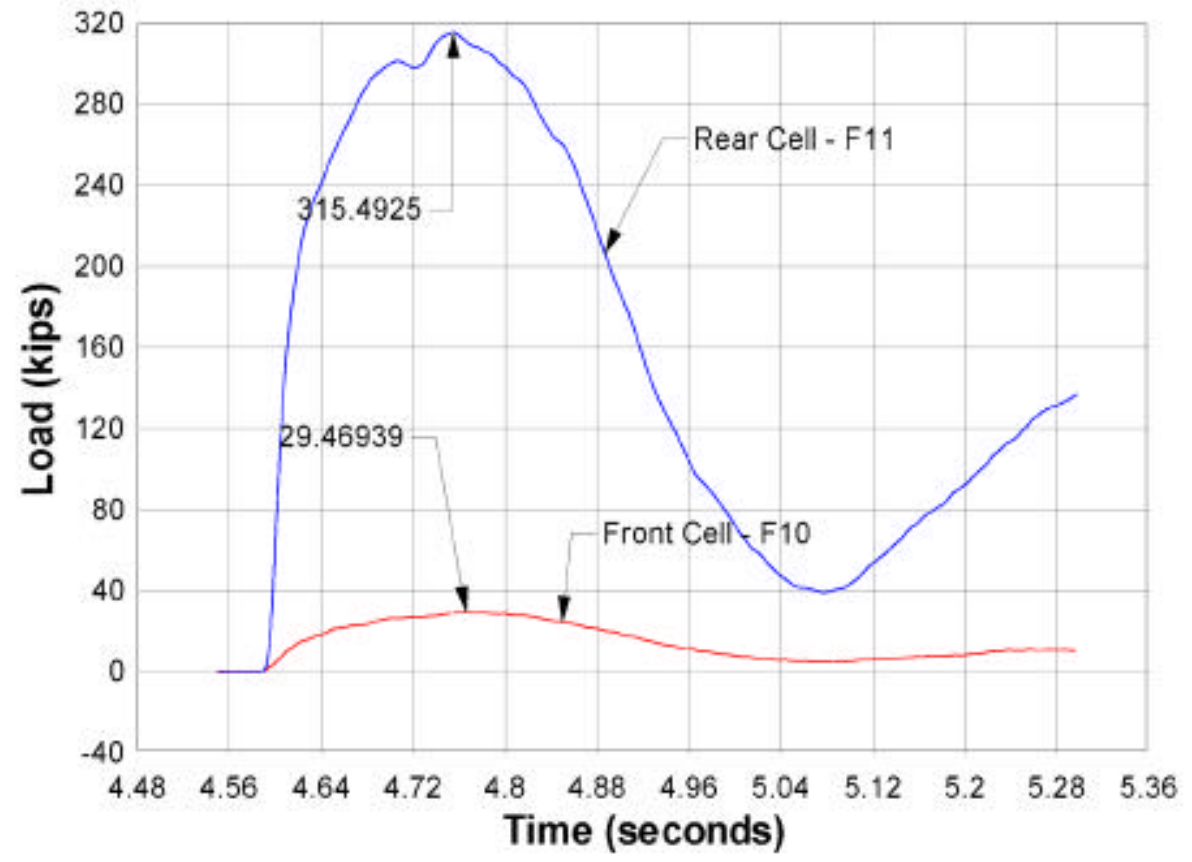

b. Record of first pulse

Figure A.16. Experiment 41-Time variation of recorded bumper forces F10 and F11 during barge impact with an approach velocity of $2.86 \mathrm{fps}$ and an 11.5-deg impact angle 


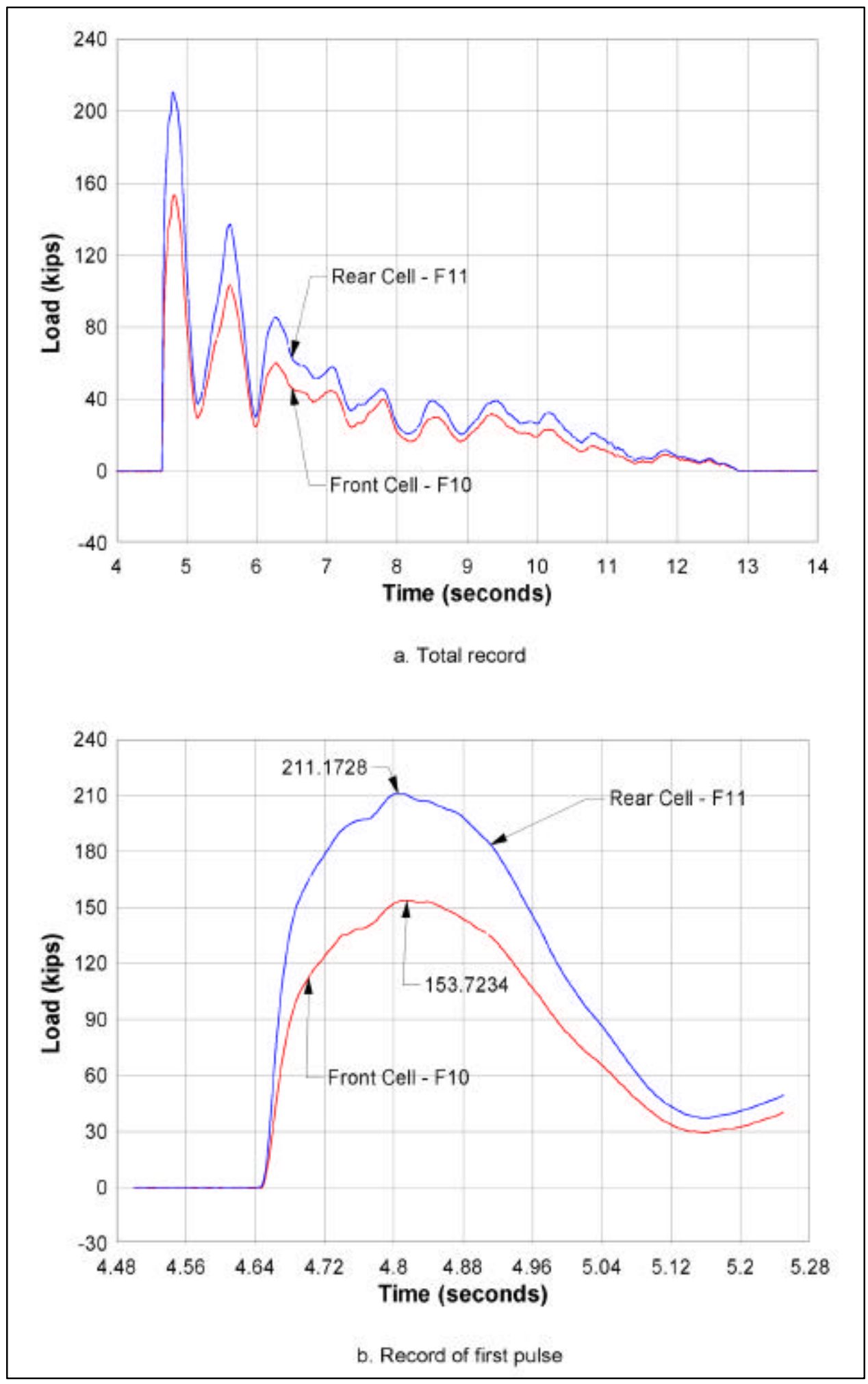

Figure A.17. Experiment 42-Time variation of recorded bumper forces F10 and F11 during barge impact with an approach velocity of $1.83 \mathrm{fps}$ and an 18.5-deg impact angle 


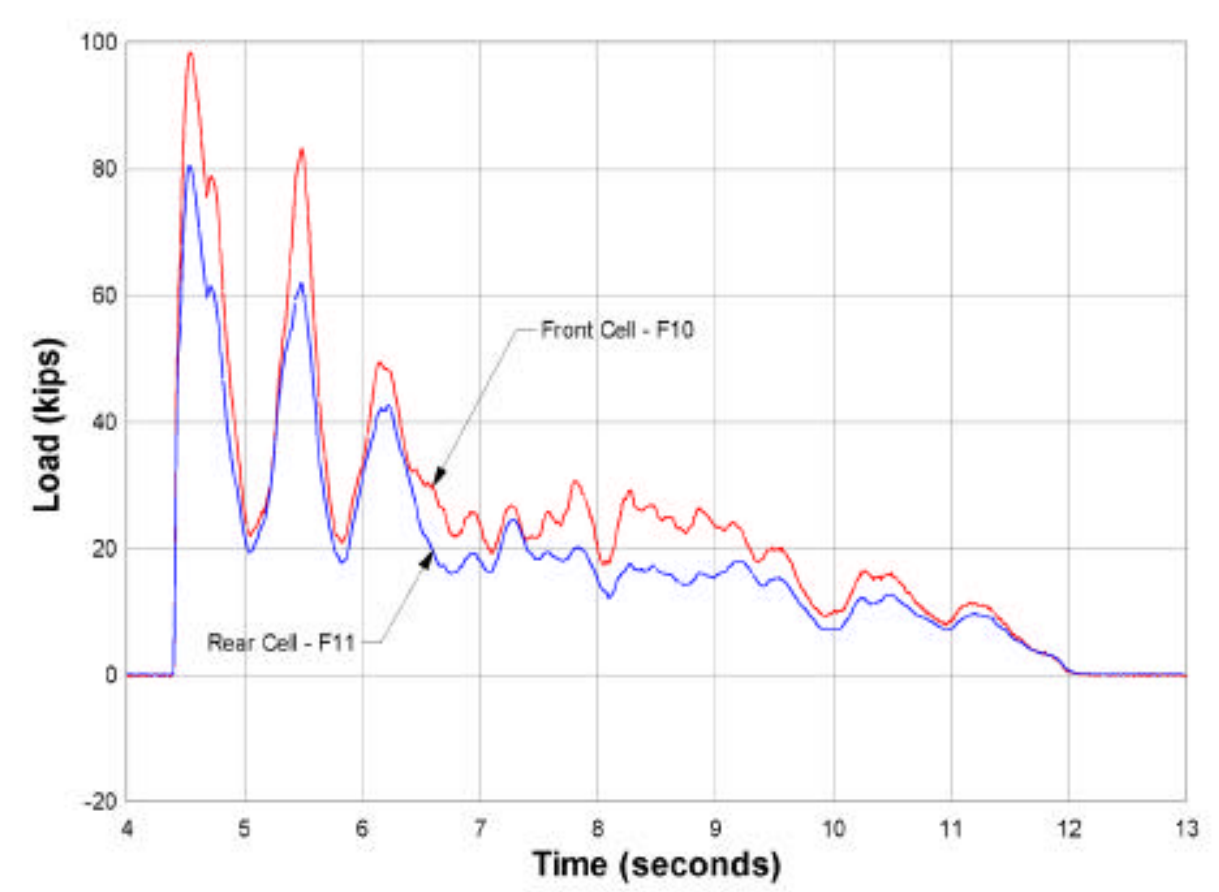

a. Total record

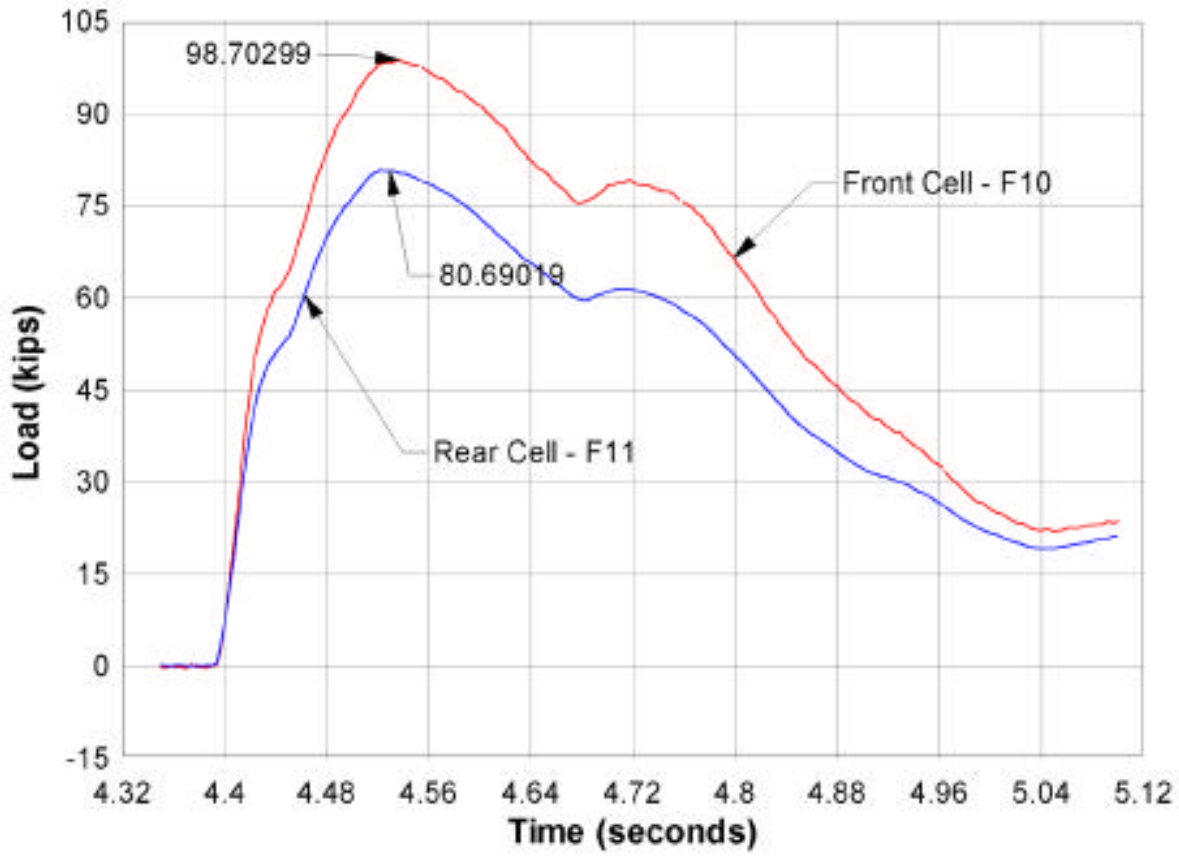

b. Record of first pulse

Figure A.18. Experiment 43-Time variation of recorded bumper forces F10 and F11 during barge impact with an approach velocity of $0.88 \mathrm{fps}$ and a 25-deg impact angle 


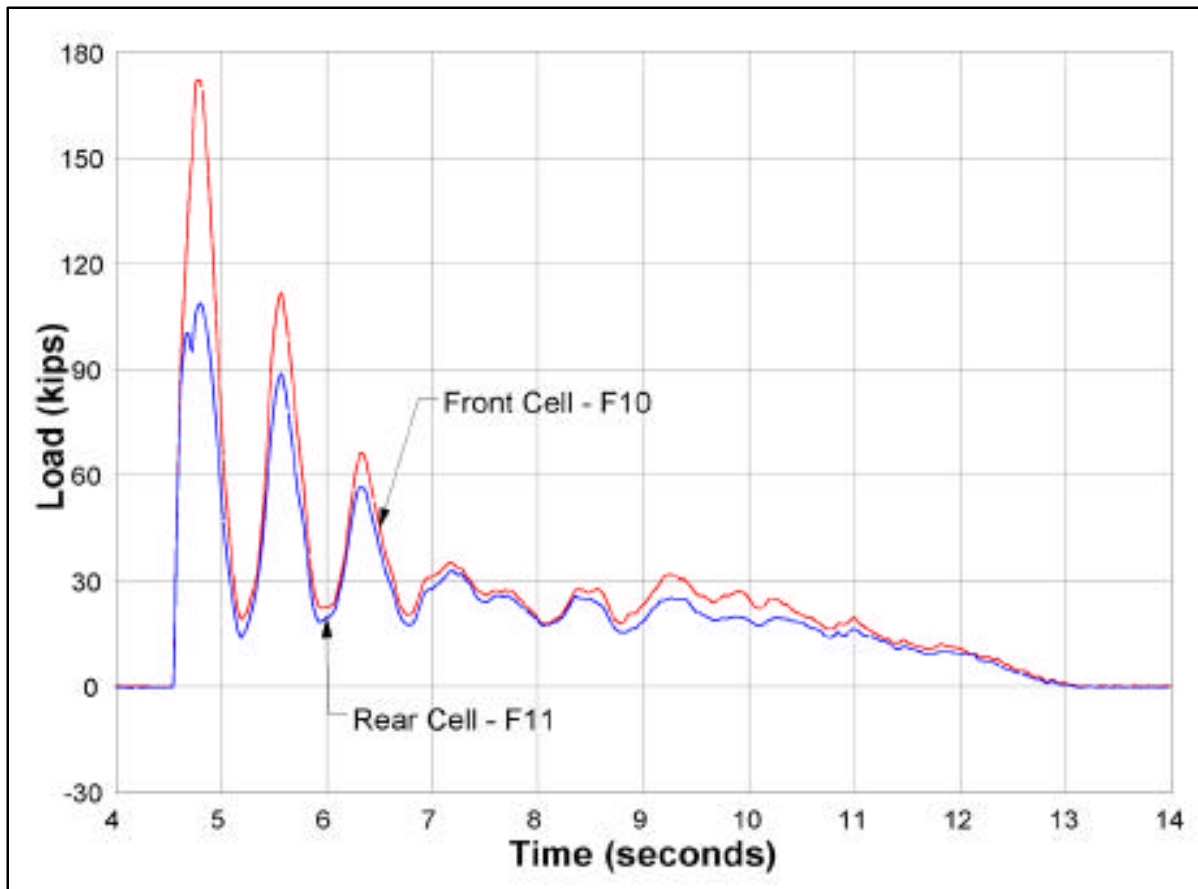

a. Total record

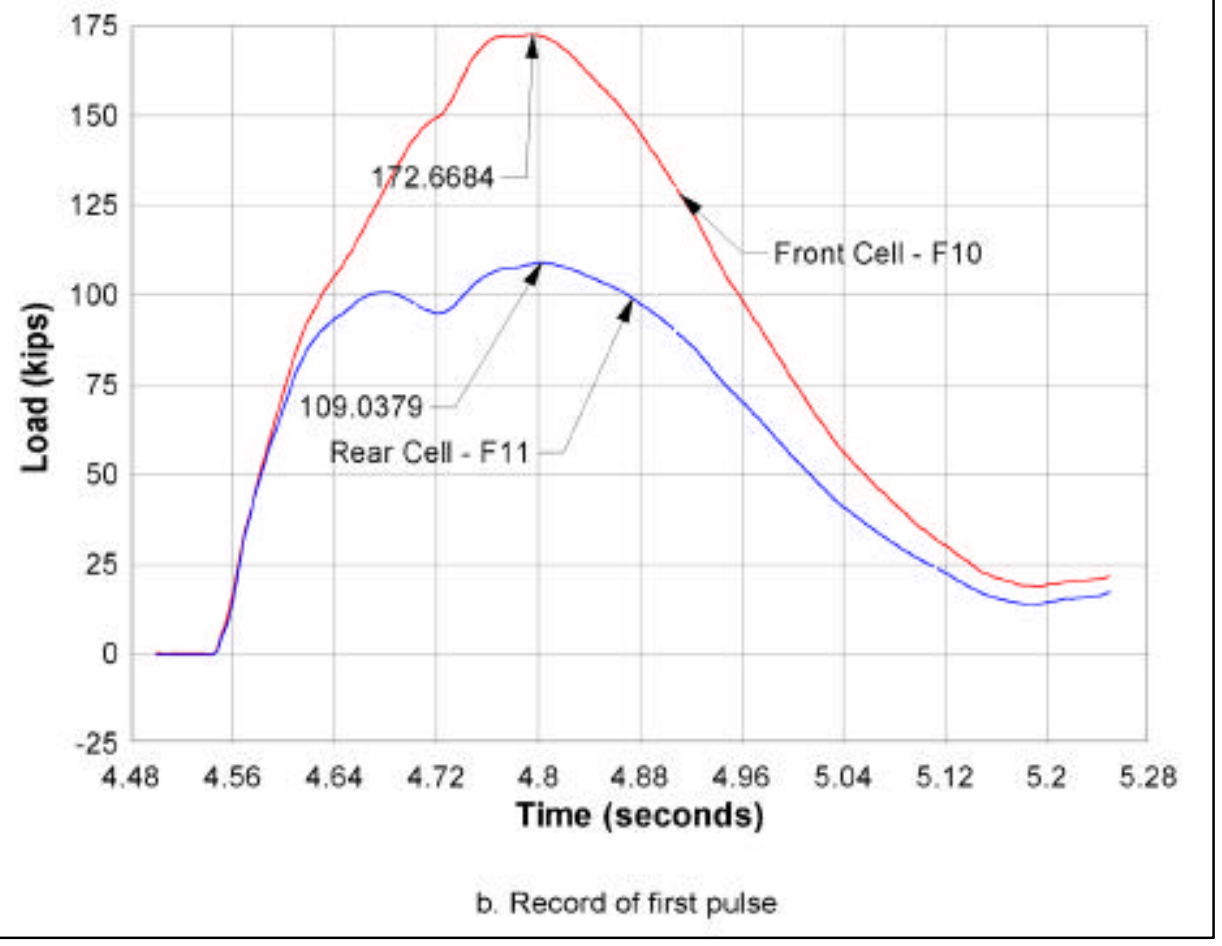

Figure A.19. Experiment 44-Time variation of recorded bumper forces F10 and F11 during barge impact with an approach velocity of $1.22 \mathrm{fps}$ and a 23-deg impact angle 
The bumper force data reduction and data assessment, summarized in Table A.1, demonstrate that, for Experiments 29-31 and 37-44, the maximum force values recorded by the front and rear load cells F10 and F11, respectively, occurred at approximately the same time.

This data reduction and data assessment also shows that the duration of impact between the flotilla and the wall was about $9 \mathrm{sec}$ (Table A.2). The time to maximum load was always observed to be recorded during the first impact force pulse for these experiments and occurred, on average, $0.186 \mathrm{sec}$ after initial contact was made with the wall, with a standard deviation of $0.042 \mathrm{sec}$ and a coefficient of variation of 0.25 (Table A.2).

Some comments regarding the development of Table A.3 should be noted. The exact angle of impact is critical in determining the reaction forces acting on the barge corner. To this end, the differential GPS data (DGPS) documenting the position of the corner barge have been carefully analyzed to identify the exact time that impact occurred, as well as the precise orientation of the barge at impact. This table presents the angle for the last $5 \mathrm{sec}$ (points) prior to impact. The column "Theta GPS " gives the angle formed by the line between GPS stations 1 and 2 and the lock wall. The correction value listed in the "Theta Corr" column is that needed to bring this line parallel to the barge's port side. "Theta AVE" is then found for the five points. Velocity is taken from Table A.1.

The data in Table A.4 summarize the individual barge weights of the 15 barges, towboat, and helper boat. The total mass is $1,865.59 \mathrm{k}-\mathrm{sec}^{2} / \mathrm{ft}$, equal to the total weight divided by the gravitational constant, $g$.

The precise tow position during the 44 impact experiments was determined using kinematic DGPS instruments. These instruments were located on the barge flotilla, as shown in Figure A.20. The two most significant units (GPS-1 and GPS-2) were deployed along the port side of the corner barge, with a third unit (GPS-3) on the stern area of the center barge. These units recorded tow position each second to an accuracy of $2 \mathrm{~cm}$. The time and point of impact were obtained through the positioning plots of the forwardmost DGPS station (Figures A.21A.30). This station followed the general course of the tow up to the time of impact. After impact, the front of the barge tracked parallel to the lock wall. Once the time of impact was identified, the impact angle (the angle formed by the port side of the corner barge with the lock wall) was determined from the GPS data and corrected for the relative positions of GPS stations 1 and 2 on the barge (see Table A.3). This angle is critical to the bumper geometry and the resulting force system. Velocity (actually, speed) was calculated from the displacement of the front corner GPS unit per unit time (1 sec). 
Table A.3

Angles and Velocity for Each Experiment

\begin{tabular}{|c|c|c|c|c|c|c|c|c|}
\hline \multirow{2}{*}{ Experiment } & \multirow{2}{*}{ Point } & \multirow{2}{*}{ ThetaGPS } & \multirow{2}{*}{ Theta Corr } & \multirow{2}{*}{ Thota } & \multicolumn{3}{|c|}{ Theda } & \multirow{2}{*}{ Vetocity fipe } \\
\hline & & & & & AME & STD & $\infty \mathrm{V}$ & \\
\hline \multirow{5}{*}{29} & 1 & 13.0004 & 04468 & 126516 & & & & \\
\hline & 2 & 13.1166 & 04488 & 12.068 & & & & \\
\hline & 3 & 131005 & 04468 & 126057 & 12699 & 0,009125 & 0,00204 & 22 \\
\hline & 4 & $13,0 / 28$ & 04468 & 12626 & & & & \\
\hline & 5 & 130422 & 04468 & 125964 & & & & \\
\hline \multirow{5}{*}{30} & 1 & 121738 & 04468 & 11.727 & & & & \\
\hline & 2 & 128002 & 04468 & 123614 & & & & \\
\hline & 3 & 127747 & 04468 & 123279 & 12.1931ब & 0.263734 & 00खा67 & 235 \\
\hline & 4 & 127419 & 04468 & 122961 & & & & \\
\hline & 5 & $12 \pi 012$ & 04468 & 122544 & & & & \\
\hline \multirow{5}{*}{31} & 1 & 11.0048 & 04468 & 10648 & & & & \\
\hline & 2 & $11.0 / 79$ & 04468 & 106311 & & & & \\
\hline & 3 & 11.0699 & 04468 & 106131 & 10.60474 & $0.0402 \sqrt{6}$ & 0,00379 & 1.61 \\
\hline & 4 & $11.0 \leq 27$ & 04468 & 10.5969 & & & & \\
\hline & 5 & 109924 & 04468 & 105456 & & & & \\
\hline 37 & 1 & NA & 04468 & 1029 & 1029 & & & 1.95 \\
\hline 38 & 1 & $\mathrm{NA}$ & 04468 & 11.94 & 11.94 & & & 1.83 \\
\hline \multirow{5}{*}{39} & 1 & 14.5044 & 04468 & $14.10 / 6$ & & & & \\
\hline & 2 & 14.5502 & 04468 & 14.1224 & & & & \\
\hline & 3 & 145736 & 04468 & 14.1267 & 14,12899 & 0.016307 & 000154 & 1.61 \\
\hline & 4 & 145538 & 04468 & 14.137 & & & & \\
\hline & 5 & 14598 & 04468 & 14.1512 & & & & \\
\hline \multirow{5}{*}{40} & 1 & 17.9614 & 04468 & 175046 & & & & \\
\hline & 2 & 17,9681 & 04468 & 175213 & & & & \\
\hline & 3 & 17.9763 & 04468 & 17,5296 & 175284 & 001672 & 0,000964 & 1,91 \\
\hline & 4 & 17.9648 & 04468 & 17.538 & & & & \\
\hline & 5 & 17.9054 & 04468 & 175406 & & & & \\
\hline \multirow{5}{*}{41} & 1 & 9.1506 & 04468 & 87118 & & & & \\
\hline & 2 & 9.2691 & 04468 & 8.8023 & & & & \\
\hline & 3 & 9.2361 & 04468 & 8.7003 & 8.70009 & 0.041860 & 0.004774 & 2.86 \\
\hline & 4 & 9.2135 & 04468 & 8.7667 & & & & \\
\hline & 5 & 9,1906 & 04468 & 87458 & & & & \\
\hline \multirow{5}{*}{42} & 1 & 17.9106 & 04468 & 17.4637 & & & & \\
\hline & 2 & 180082 & 04468 & 17.5614 & & & & \\
\hline & 3 & 17.954 & 04468 & 175006 & $17.481 \%$ & 0.05014 & 0.003147 & 1.83 \\
\hline & 4 & 17.9054 & 04468 & $17.45 \times 6$ & & & & \\
\hline & 5 & 17.8639 & 04468 & 17.4171 & & & & \\
\hline \multirow{5}{*}{43} & 1 & 21.5017 & 04463 & 21.1149 & & & & \\
\hline & 2 & 21.666 & 04468 & 21.1828 & & & & \\
\hline & 3 & 21.6314 & 04468 & 21.1846 & 21,16854 & 0,0008 & 0,001450 & 0.88 \\
\hline & 4 & 21.6246 & 04468 & 21.1778 & & & & \\
\hline & 5 & 21.6284 & 04468 & 21.1816 & & & & \\
\hline \multirow{5}{*}{44} & 1 & 21.3719 & 04468 & 209251 & & & & \\
\hline & 2 & 21.3756 & 04468 & 209088 & & & & \\
\hline & 3 & 21,3765 & 04468 & 20.9097 & 20.90816 & 0,001783 & $85 x-06$ & 1.22 \\
\hline & 4 & $21.3 \sqrt{51}$ & 04468 & 20.9283 & & & & \\
\hline & 5 & $21.3 / 57$ & 04468 & 20.9009 & & & & \\
\hline 1 Avalabe & & & & & & & & \\
\hline
\end{tabular}


Table A.4

Tonnage of Barge Flotilla-Barges, Coal, and Boats (Data in this table courtesy of American Electric Power Company)

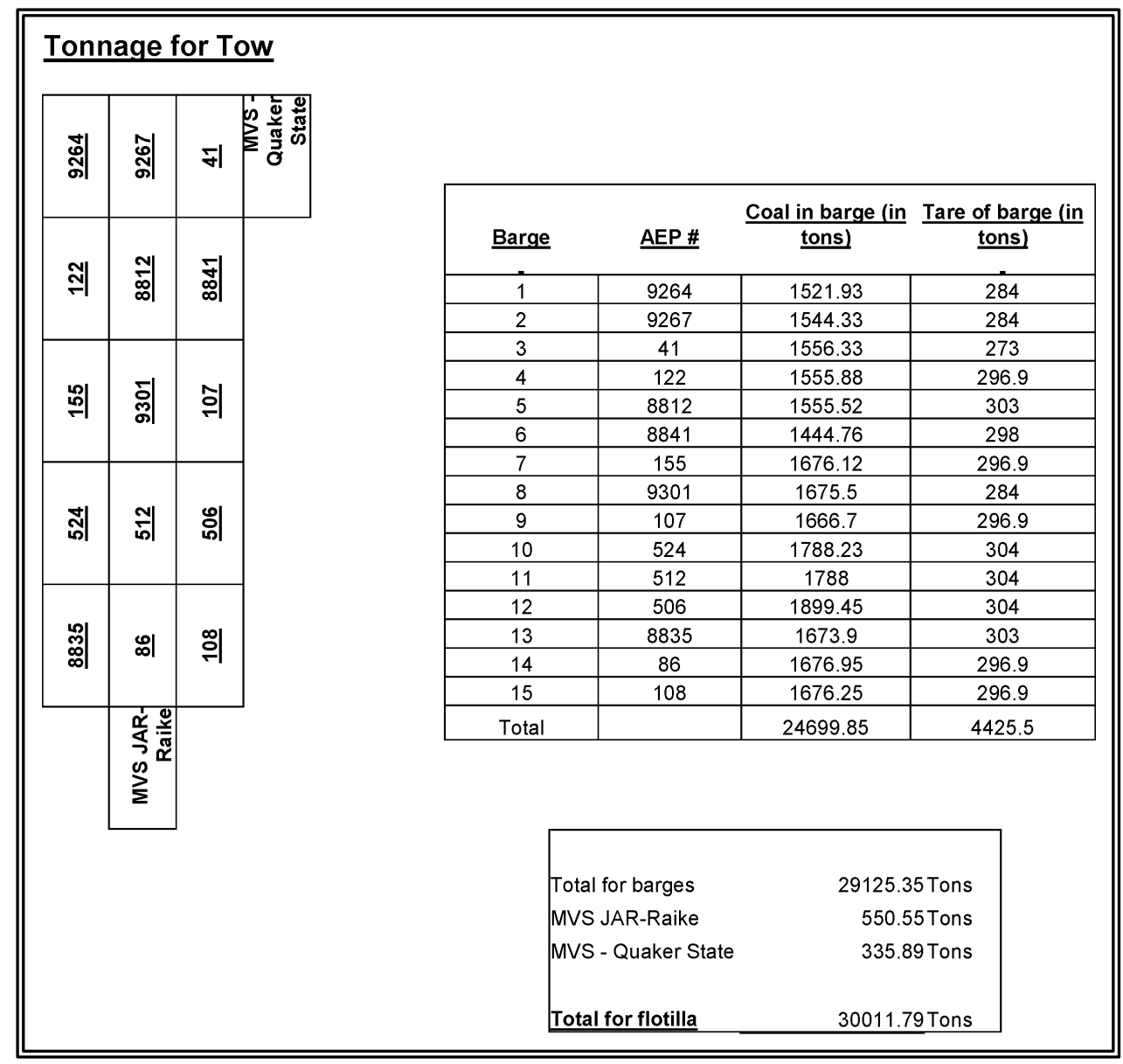




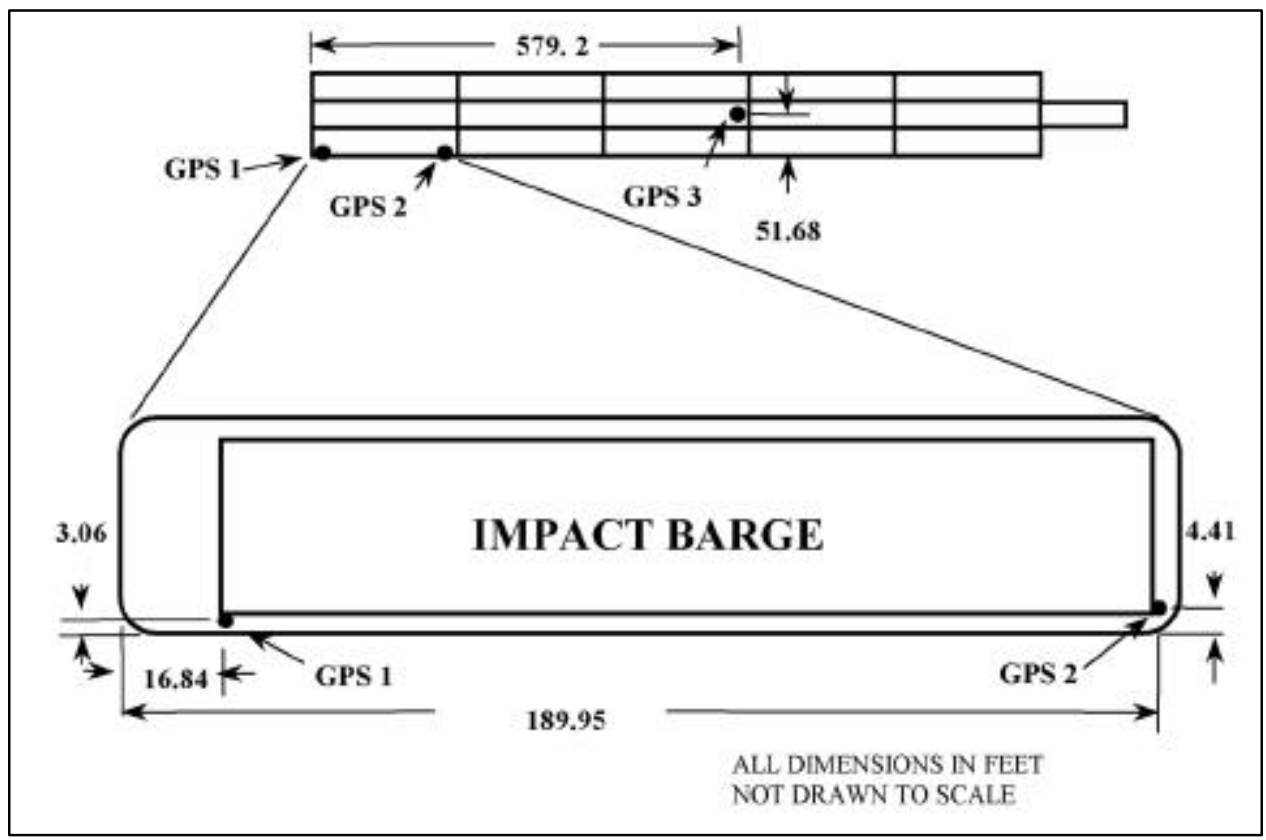

Figure A.20. Differential GPS instrument locations for Experiments 22-44

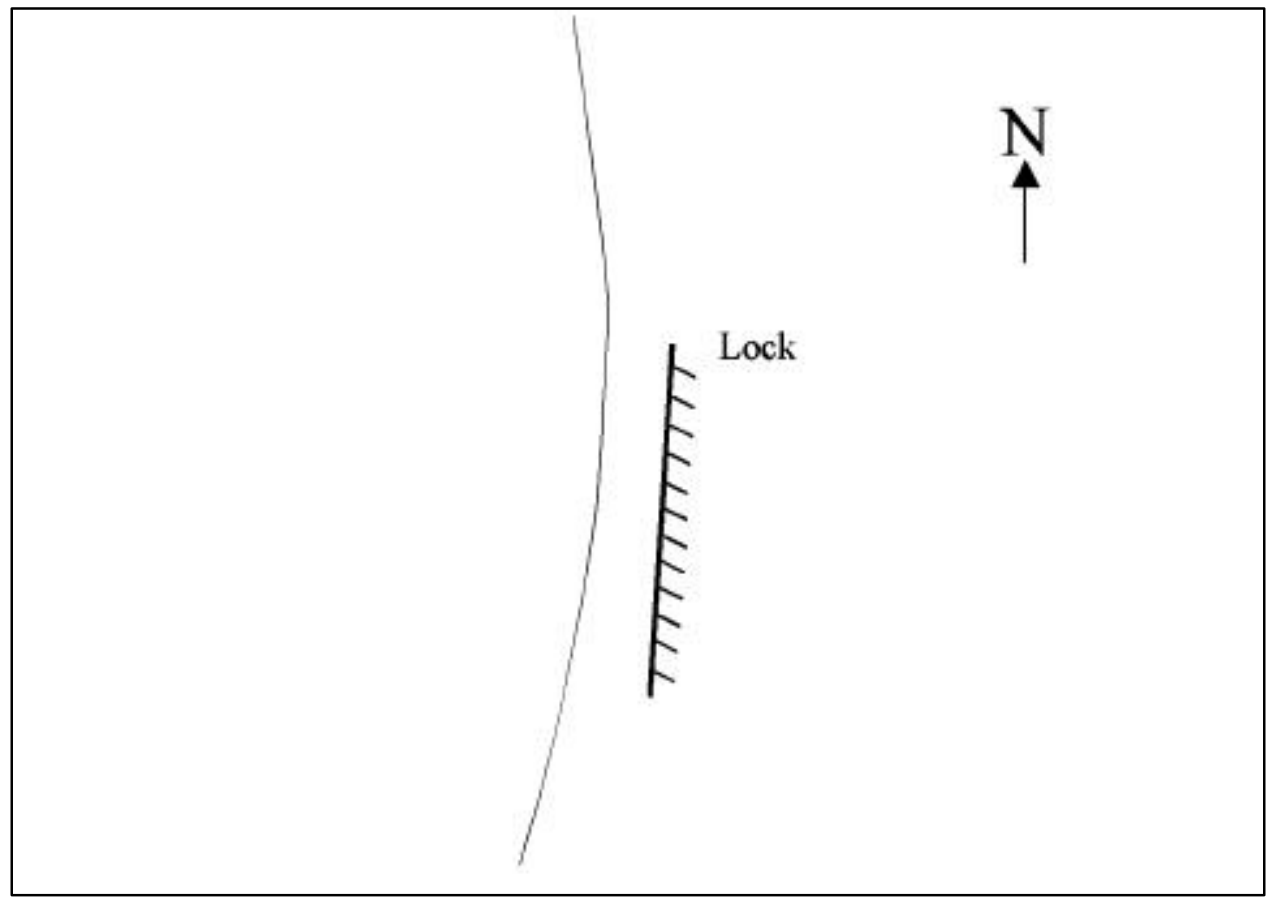

Figure A.21. Route of Experiment 29 and wall alignment 


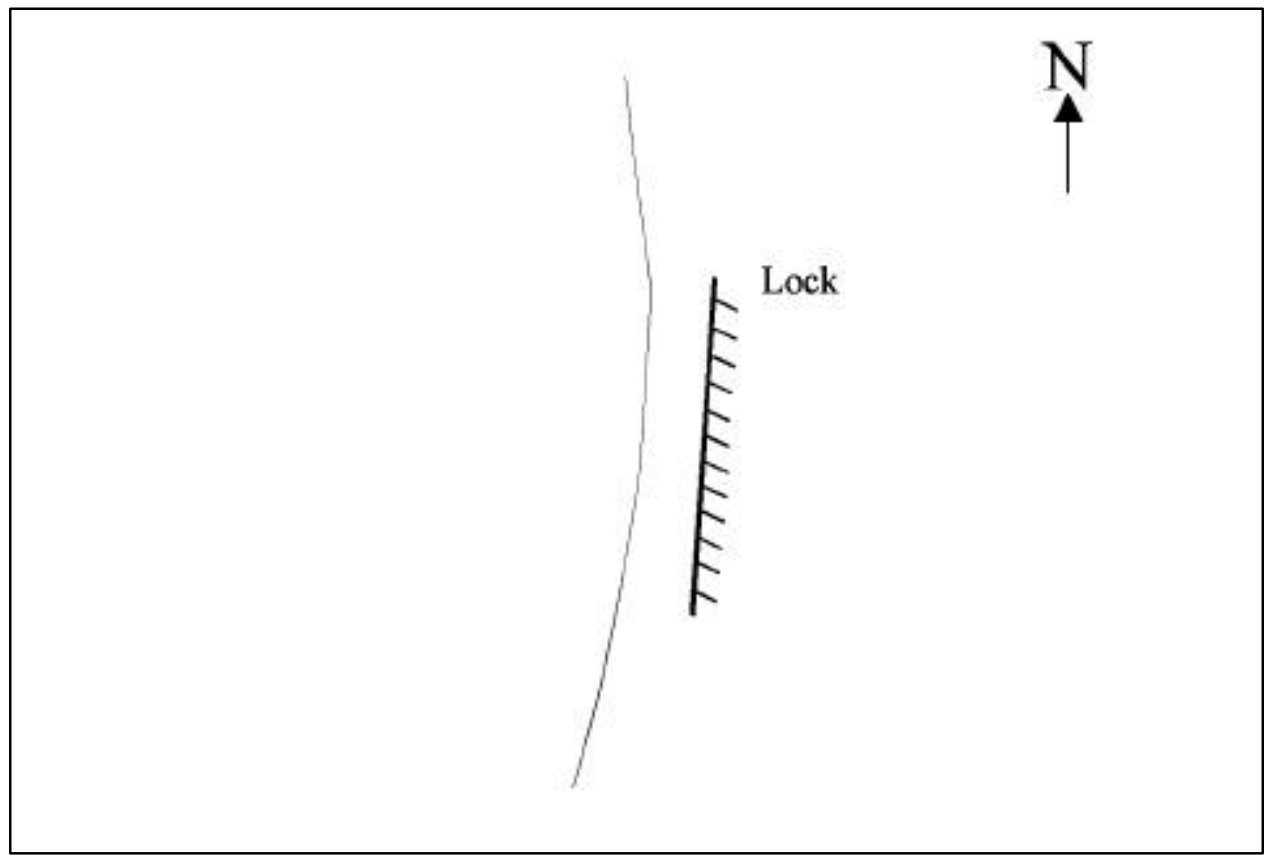

Figure A.22. Route of Experiment 30 and wall alignment

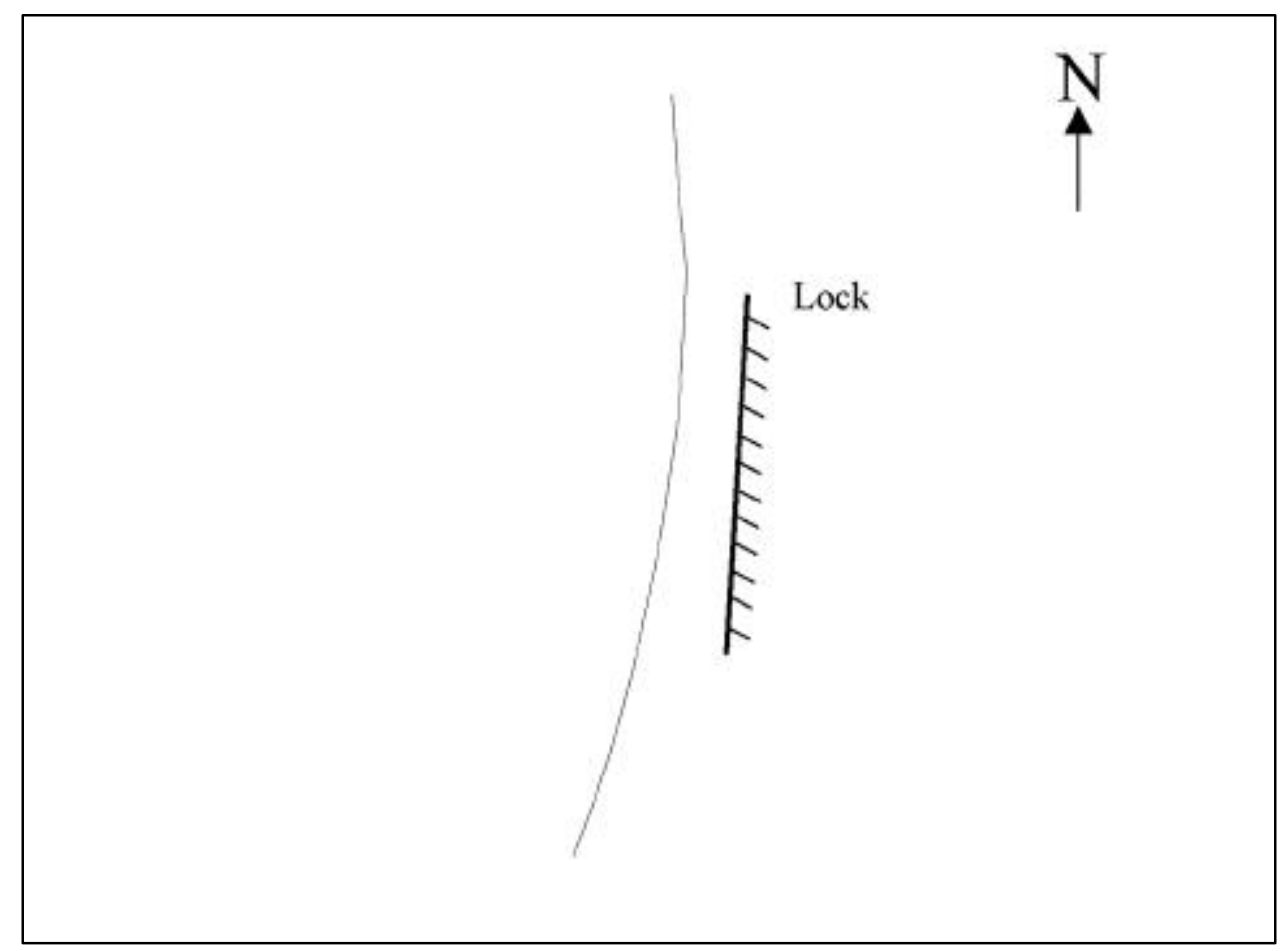

Figure A.23. Route of Experiment 31 and wall alignment 


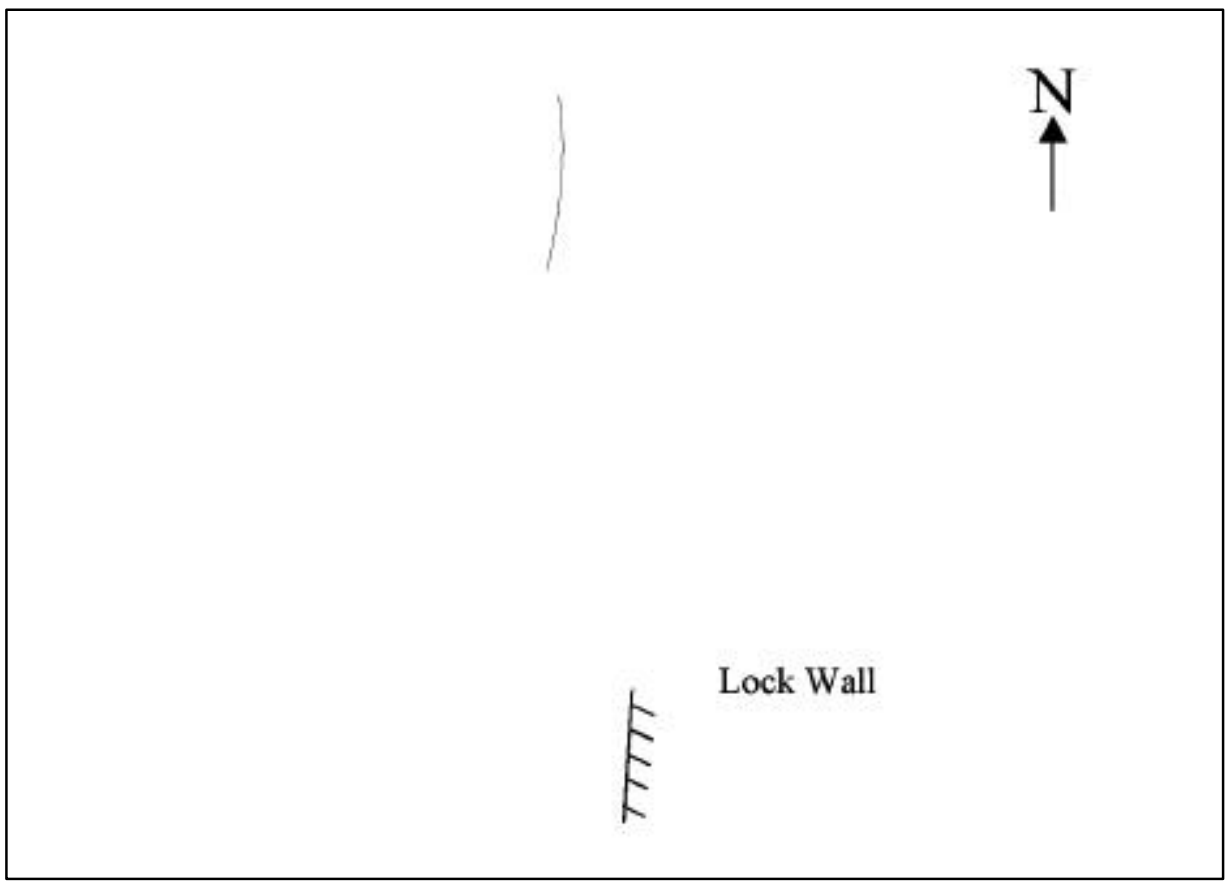

Figure A.24. Route of Experiment 37 GPS-2 and wall alignment (Note: GPS-1 data were not available for this impact)

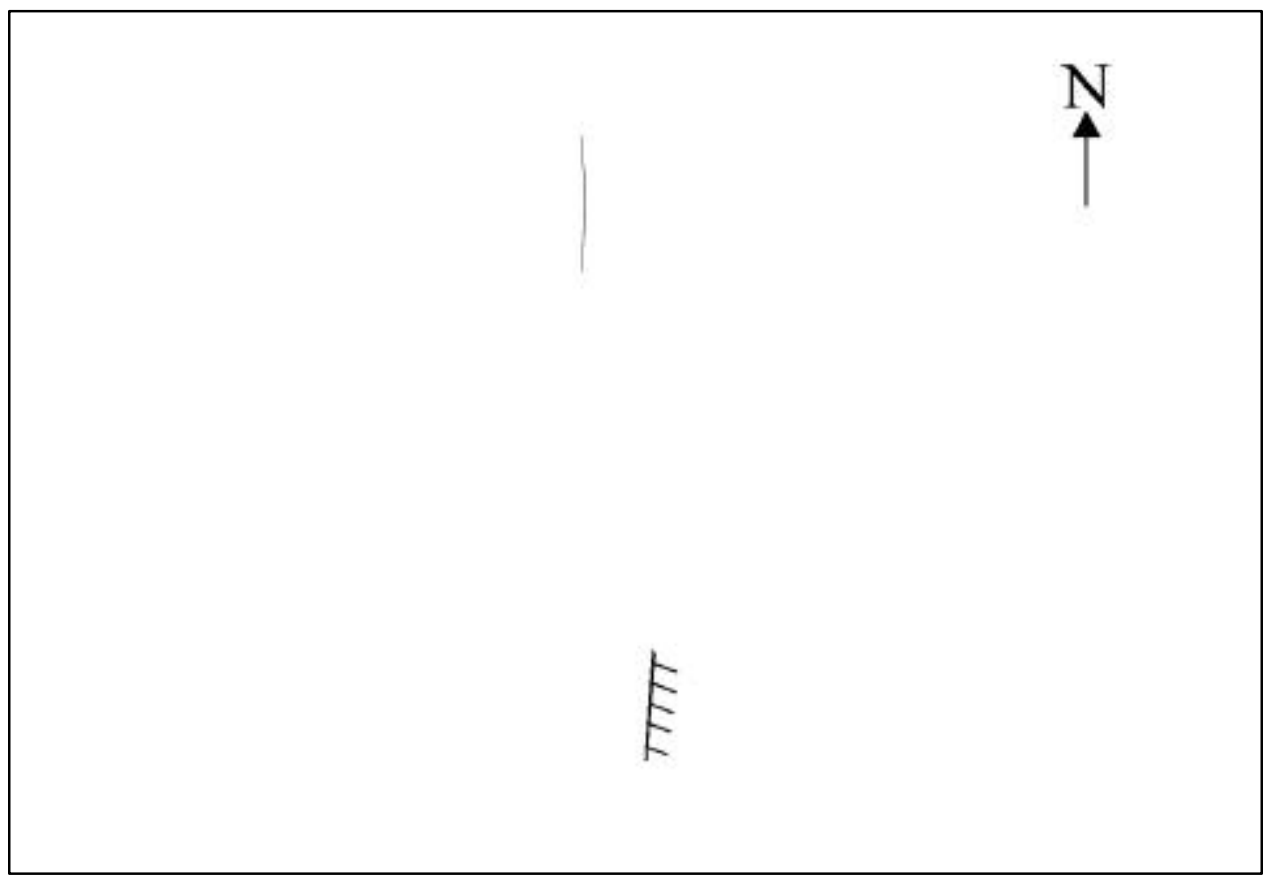

Figure A.25. Route of Experiment 38 GPS-2 and wall alignment (Note: GPSdata were not available for this impact) 


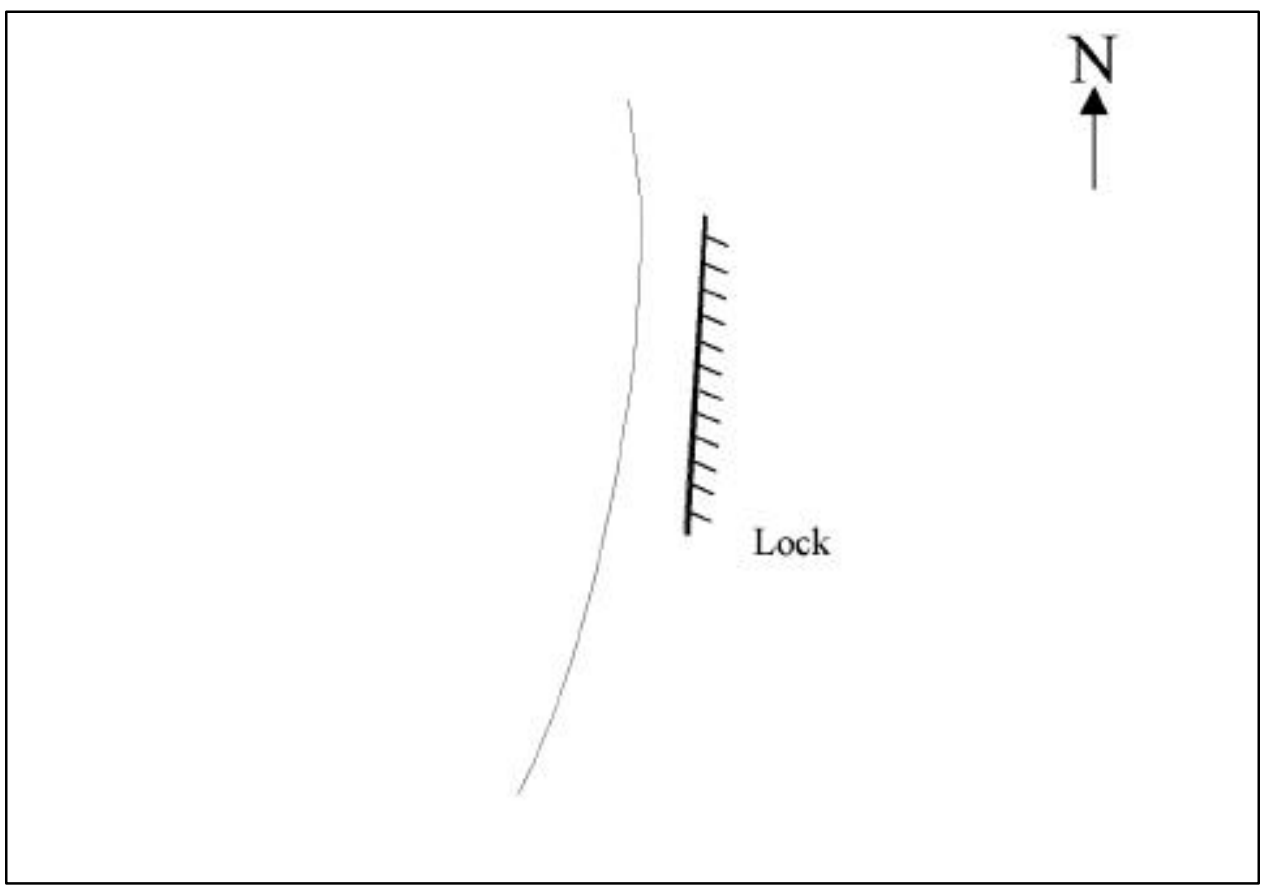

Figure A.26. Route of Experiment 39 and wall alignment

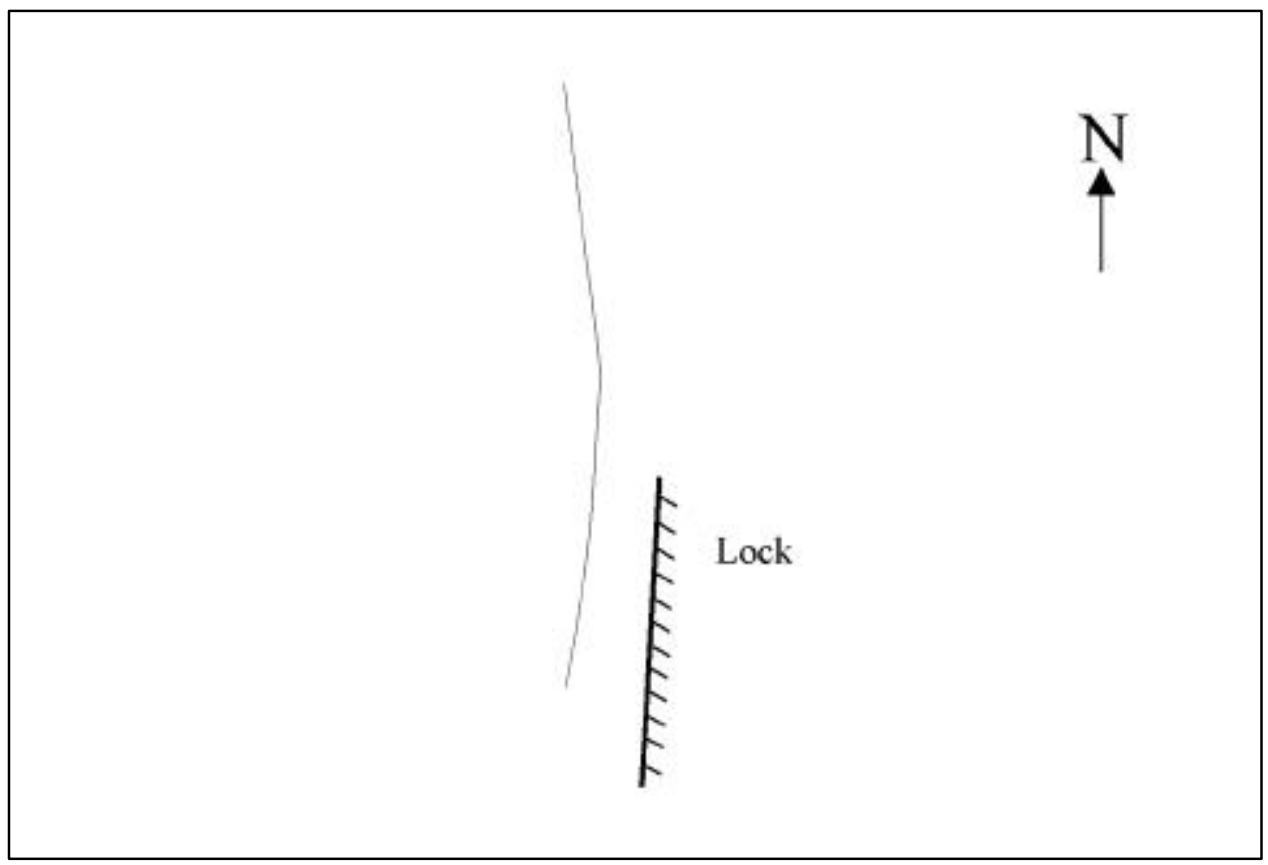

Figure A.27. Route of Experiment 40 and wall alignment 


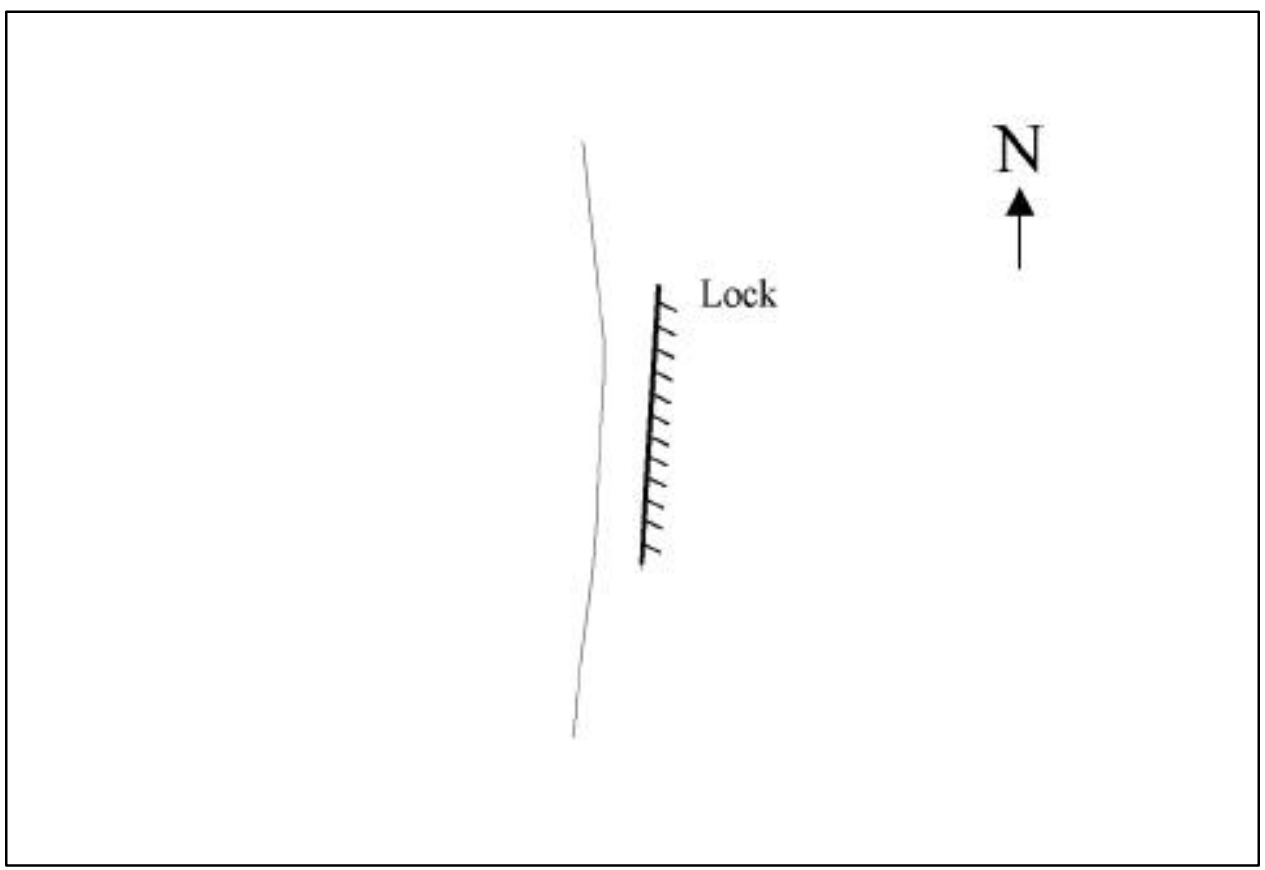

Figure A.28. Route of Experiment 41 and wall alignment

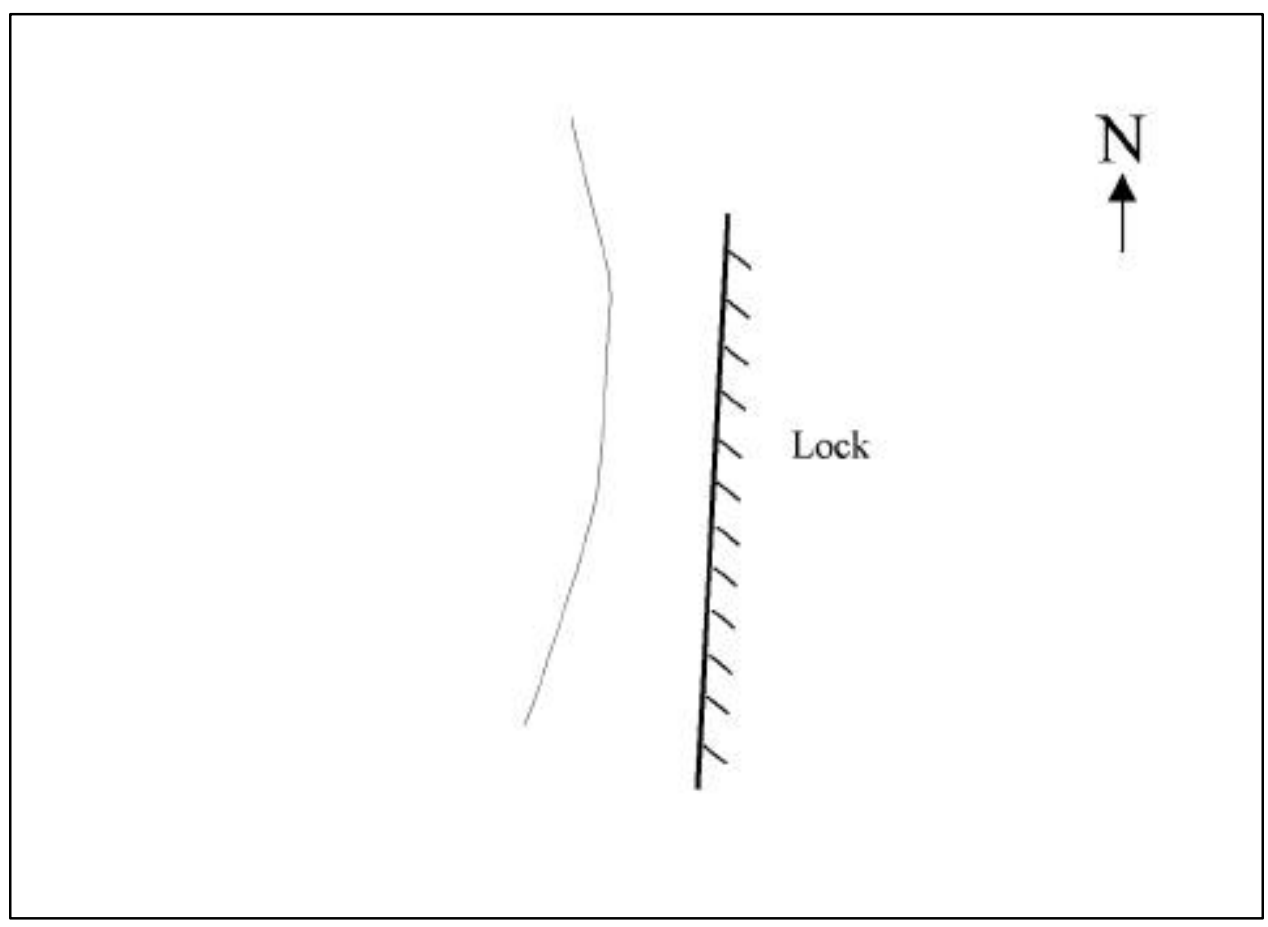

Figure A.29. Route of Experiment 42 and wall alignment 


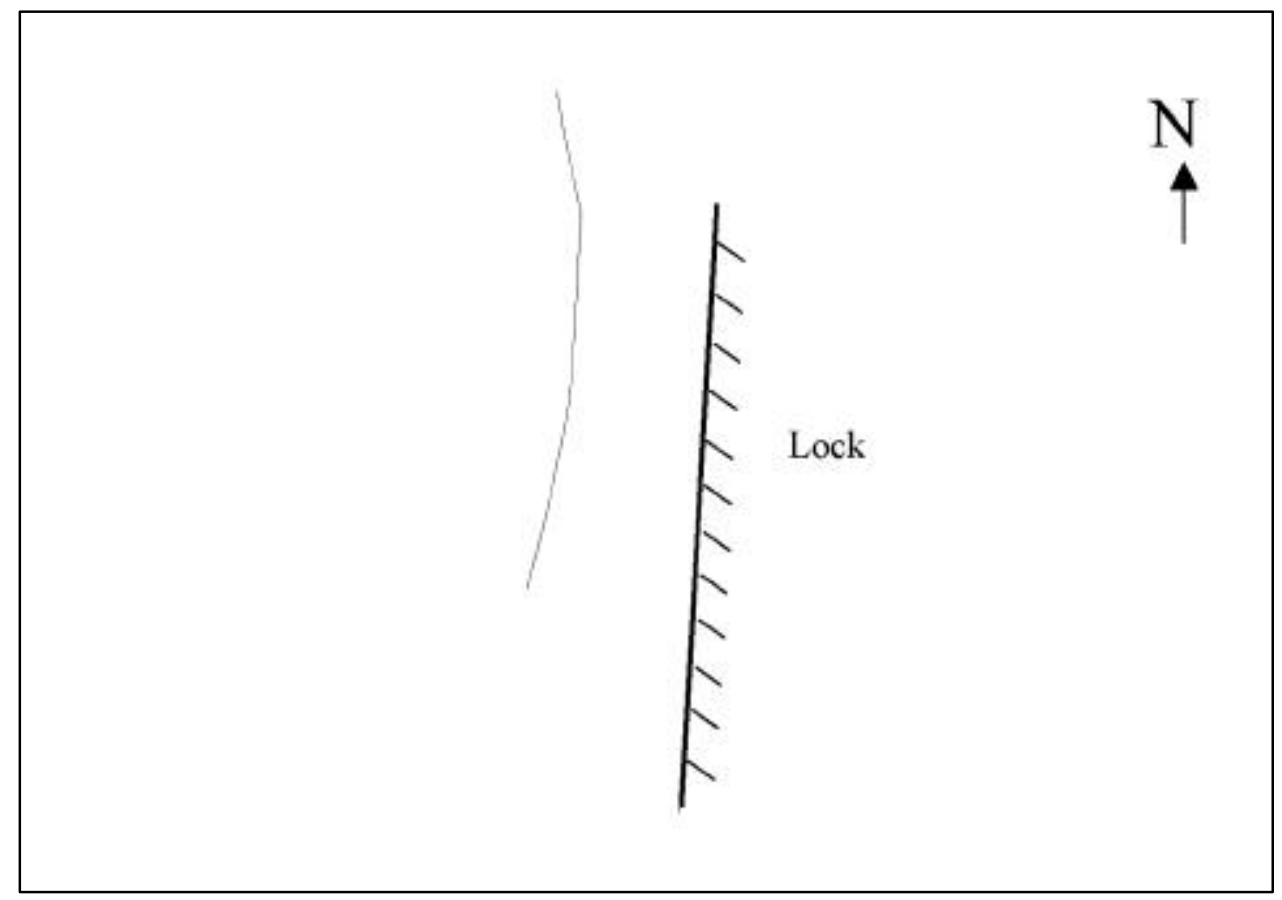

Figure A.30. Route of Experiment 43 and wall alignment

An additional assessment was performed to determine the variation, if any, of the impact angle during the $9 \mathrm{sec}$ of impact. In Figures A.31-A.36, the route recorded for GPS-1 and GPS-2 is presented. Three additional lines are also presented. The red line (on the right) is the reference line that joins the initial point of contact of both trajectories. The green line (on the left)is the reference line that joins the final point of contact of both trajectories. It is also indicated as the line that makes reference to the alignment of the concrete wall.

Figures A.31-A.36 present (in the upper portion) the trajectory of both GPS units for the corresponding experiment. At the lower portion of the figure, each trajectory is considered separately to observe that both angles (initial and final angle with respect to the concrete wall) are the same. The presented angles in each figure are very close to the angle used in the calculation in this technical report. It is important to mention that the route of GPS-2 was not provided for Experiments 37 and 38 and, for that reason, these routes were not included in these plots. 

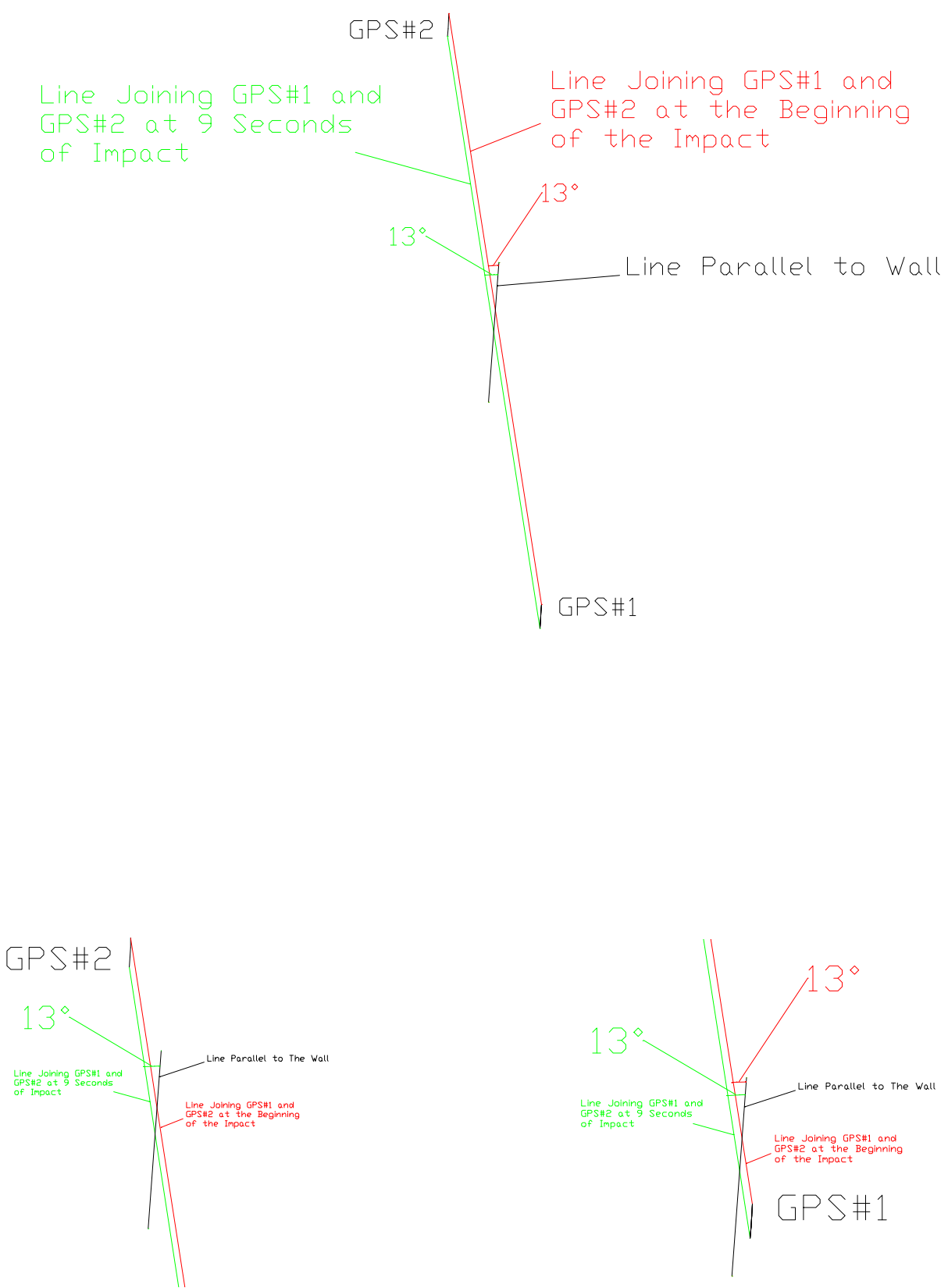

Figure A.31. GPS-1 and GPS-2 route of Experiment 29 and wall alignment during $9 \mathrm{sec}$ of impact 

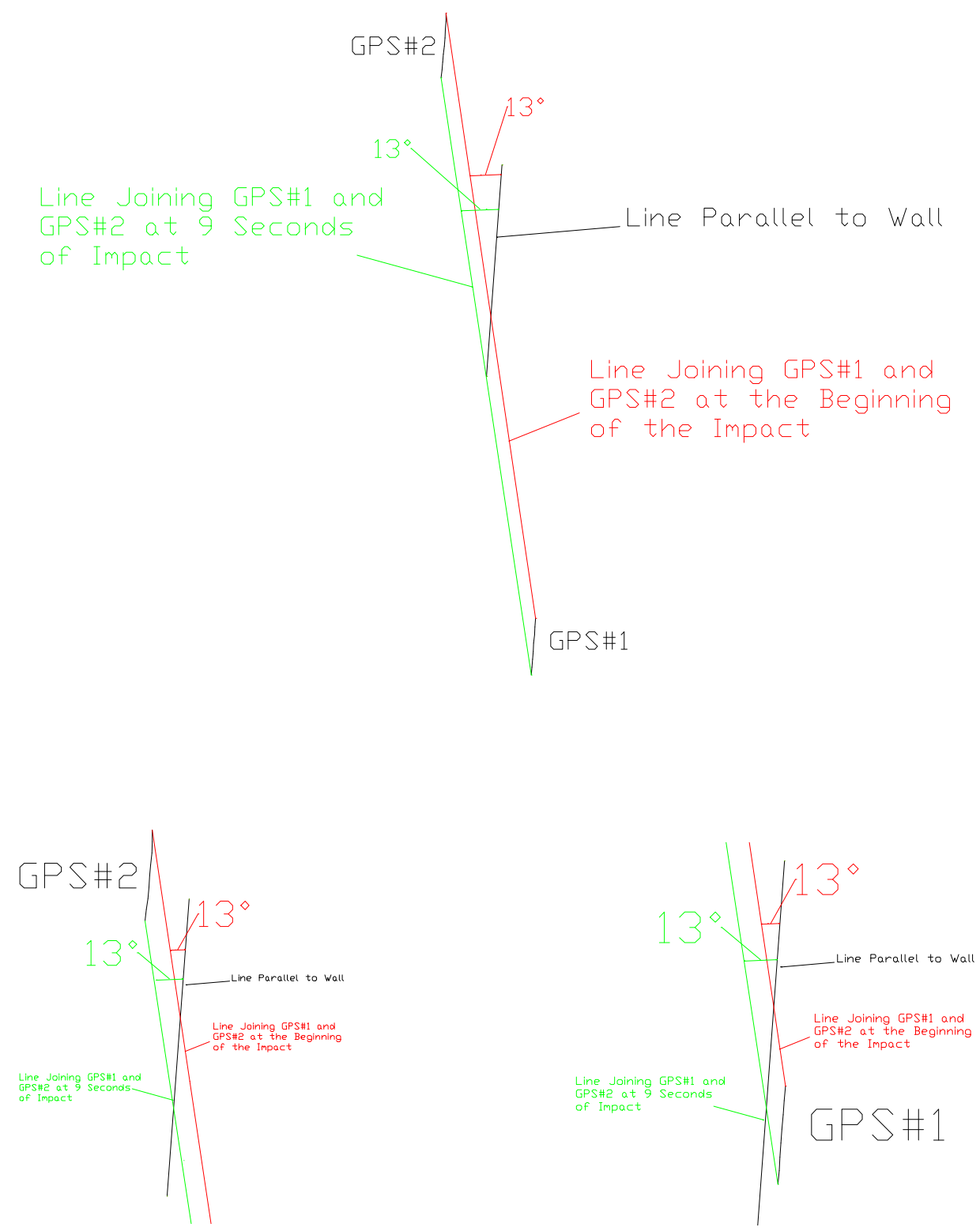

Figure A.32. GPS-1 and GPS-2 route of Experiment 30 and wall alignment during 9 sec of impact 

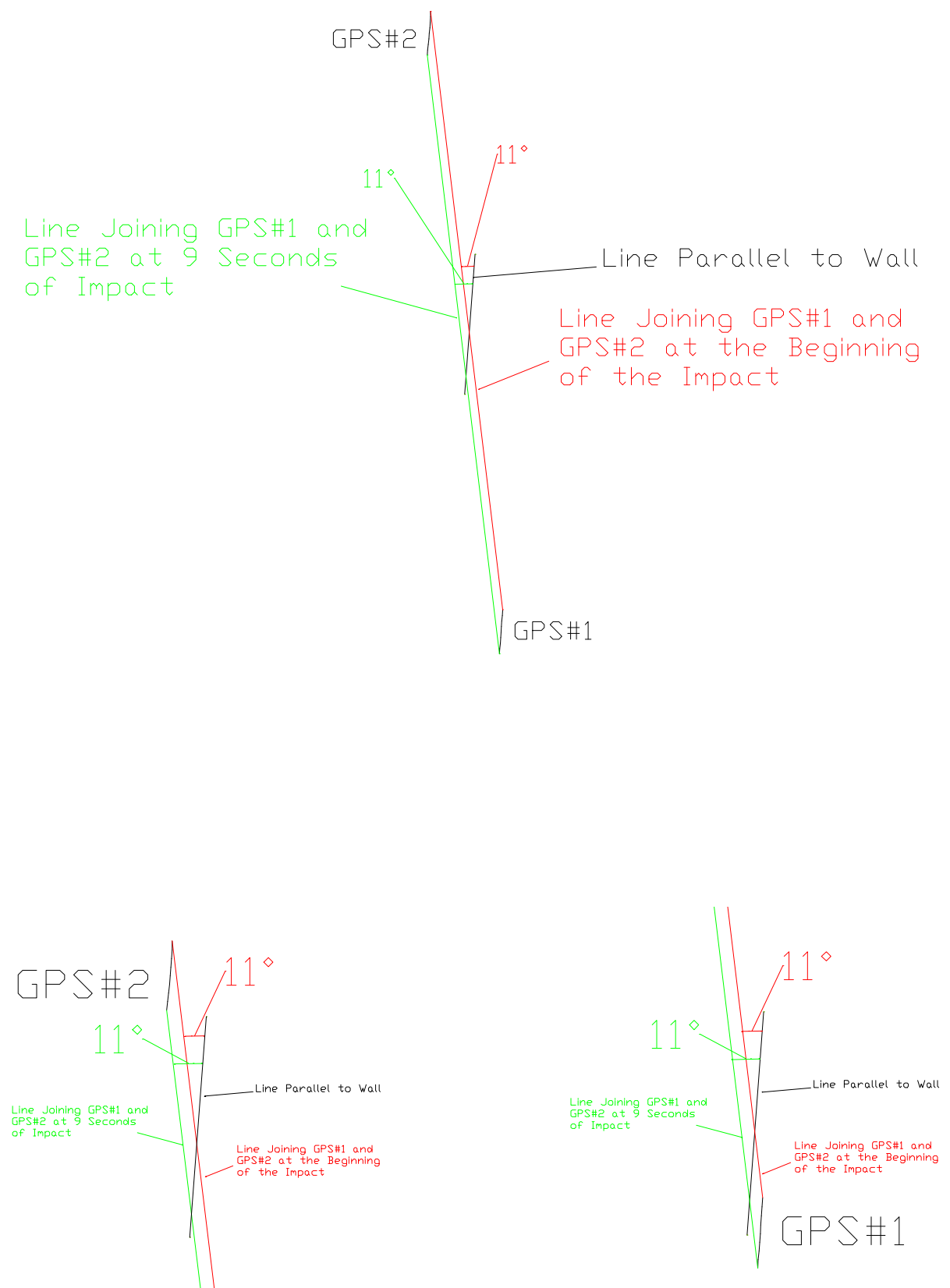

Figure A.33. GPS-1 and GPS-2 route of Experiment 31 and wall alignment during 9 sec of impact 

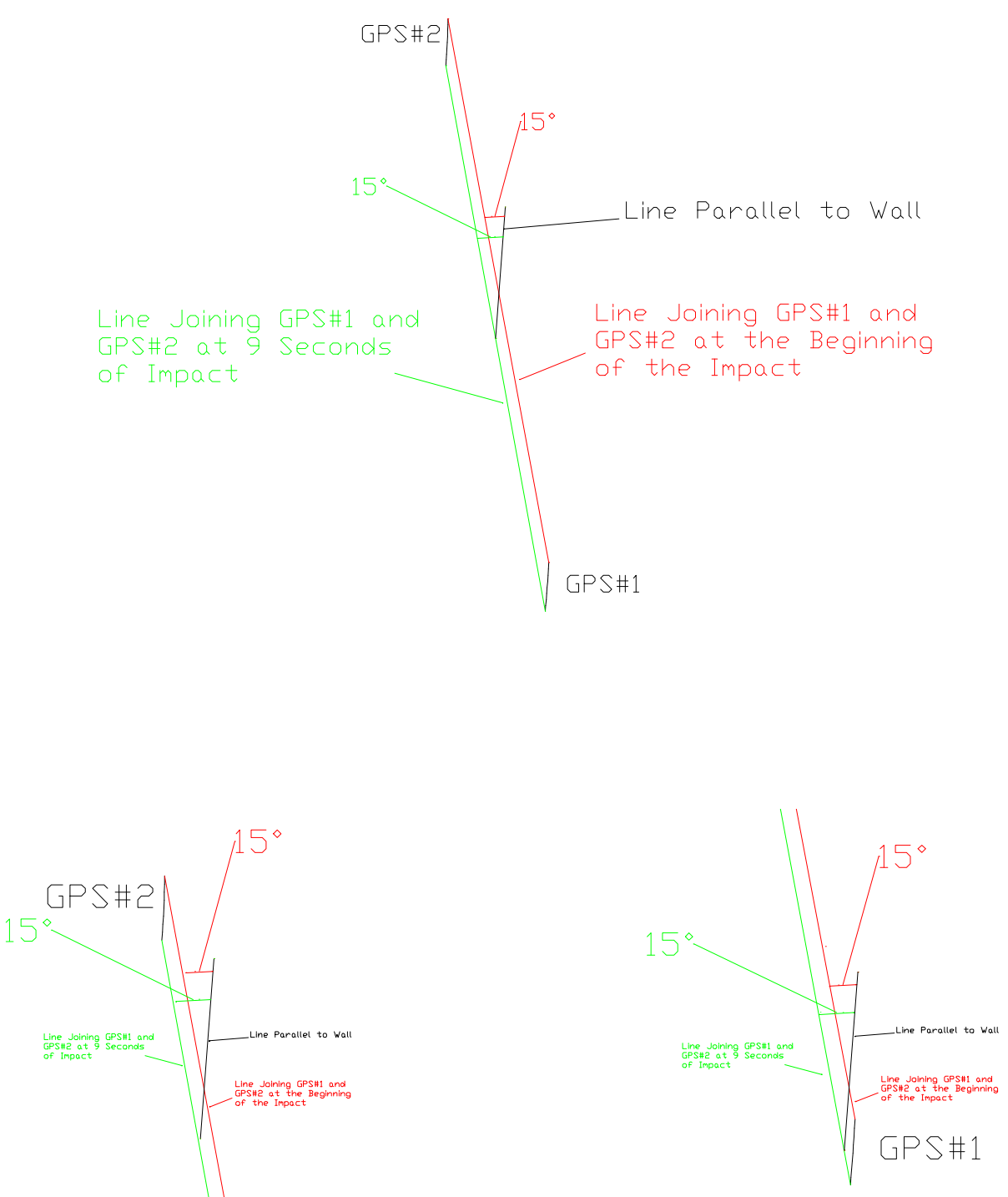

Figure A.34. GPS-1 and GPS-2 route of Experiment 39 and wall alignment during 9 sec of impact 

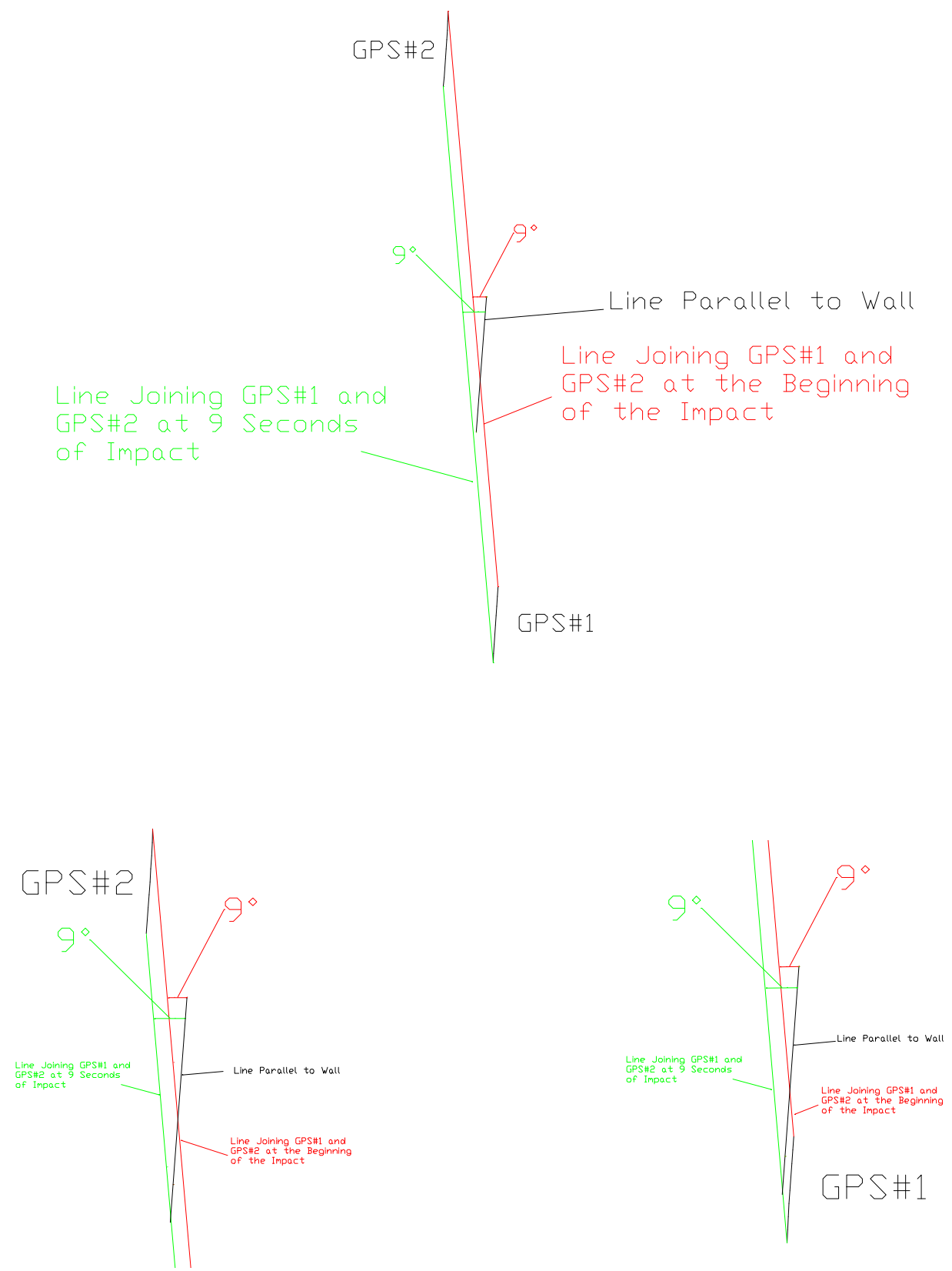

Figure A.35. GPS-1 and GPS-2 route of Experiment 41 and wall alignment during 9 sec of impact 

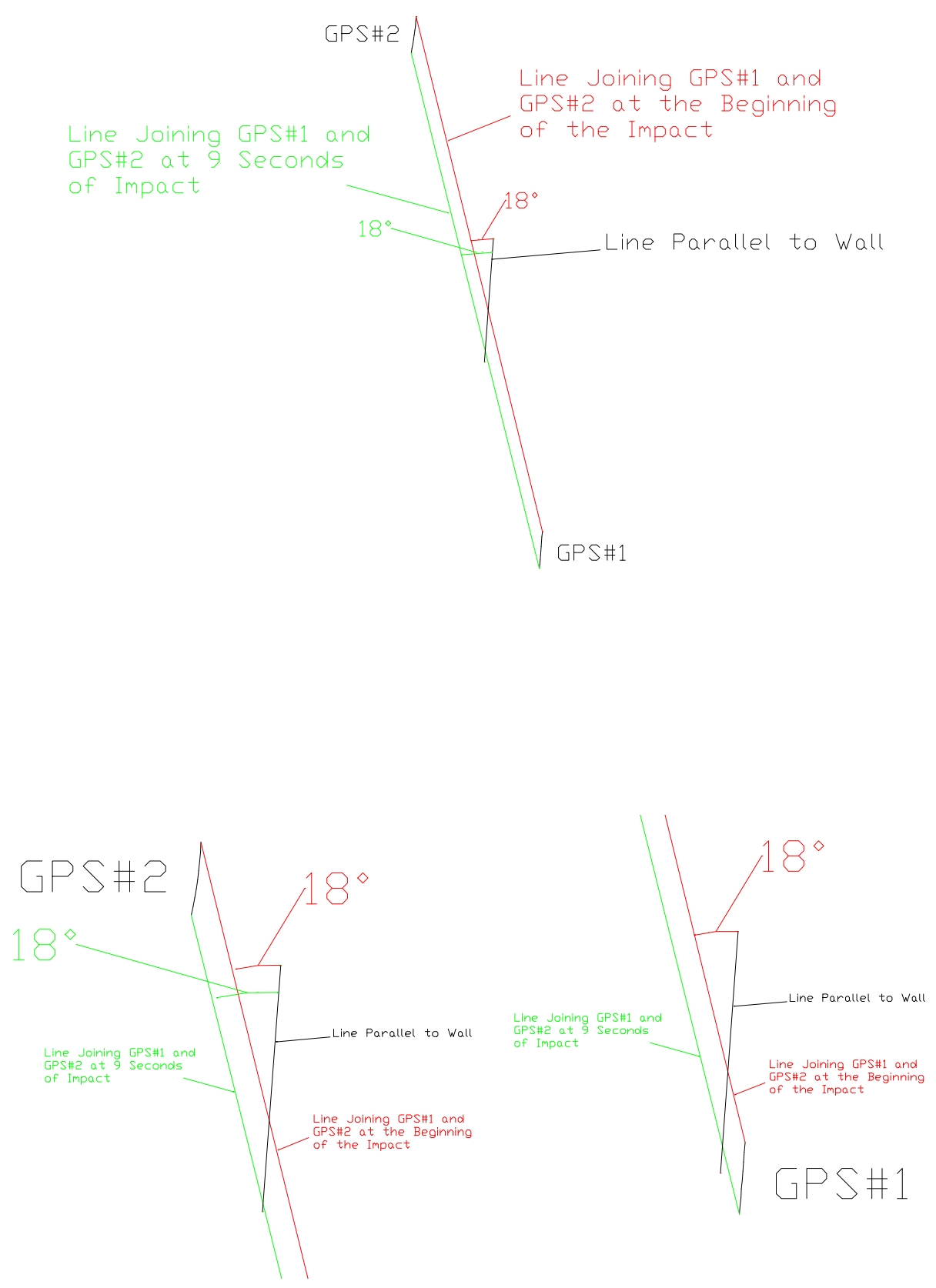

Figure A.36. GPS-1 and GPS-2 route of Experiment 42 and wall alignment during 9 sec of impact 


\section{Appendix B FORTRAN Source Programs and Maple Worksheets}

\section{B.1 Program to Calculate the Forces in the Arc Beam Using the Assumed Coefficient of Friction Model}

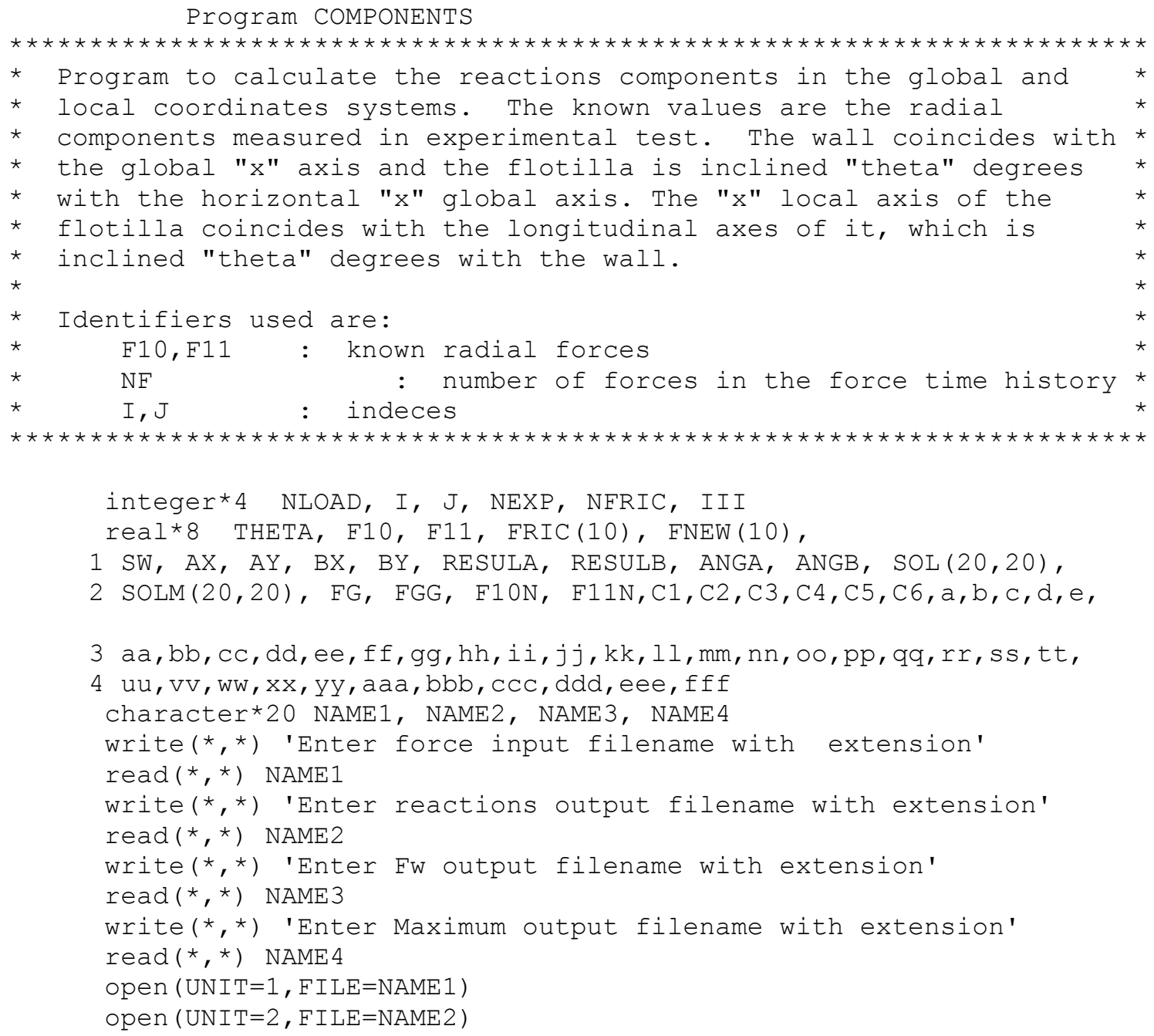




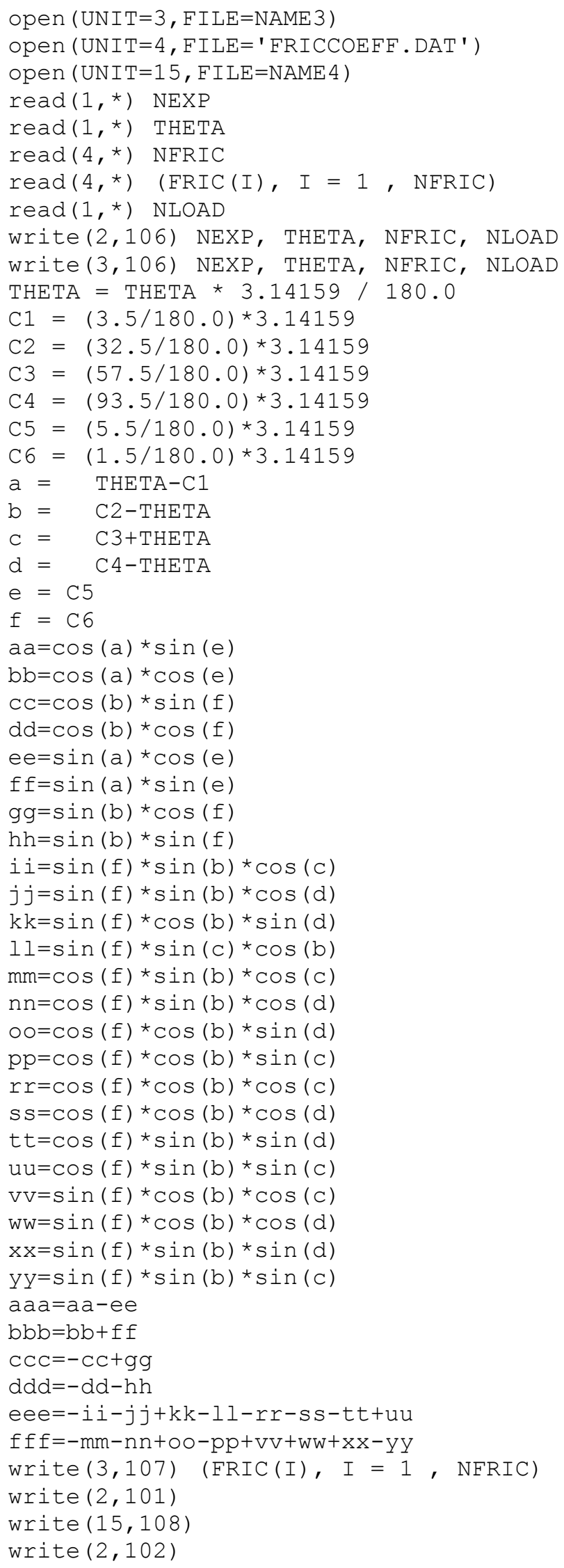




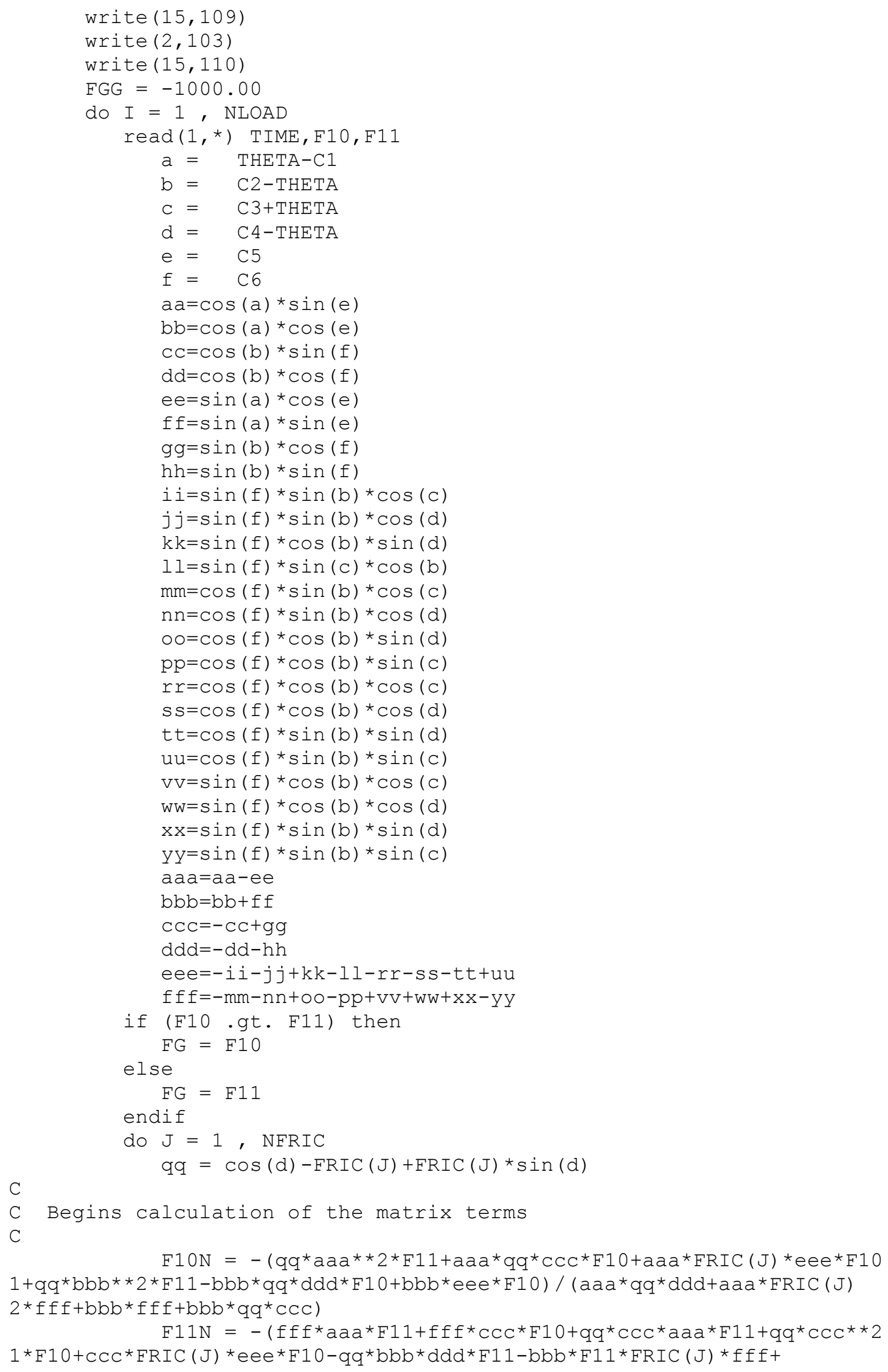




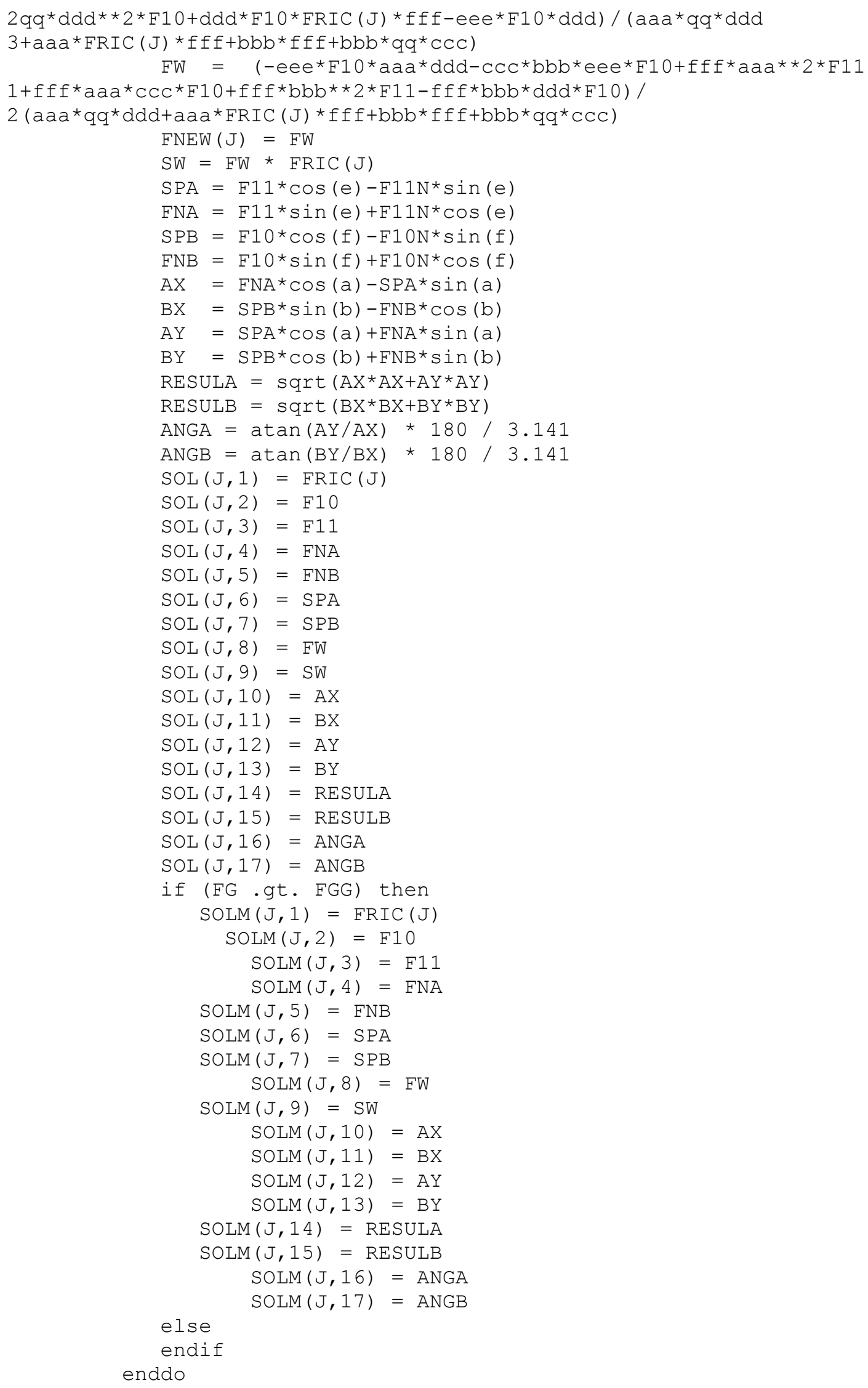




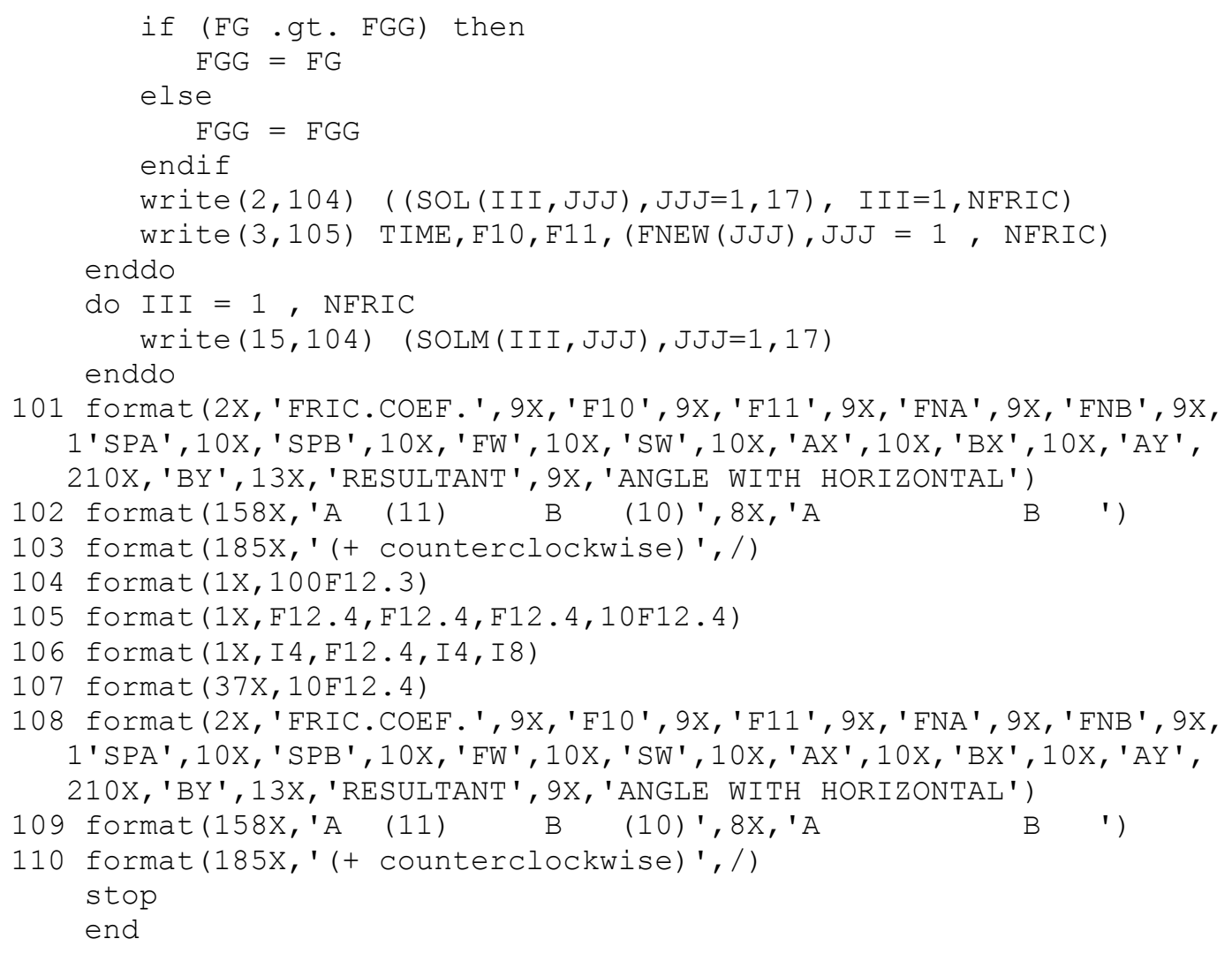

\section{B.2 Program to Calculate $F_{w}$ for Experimental Data Using the Scale Impulse Force Formulation}

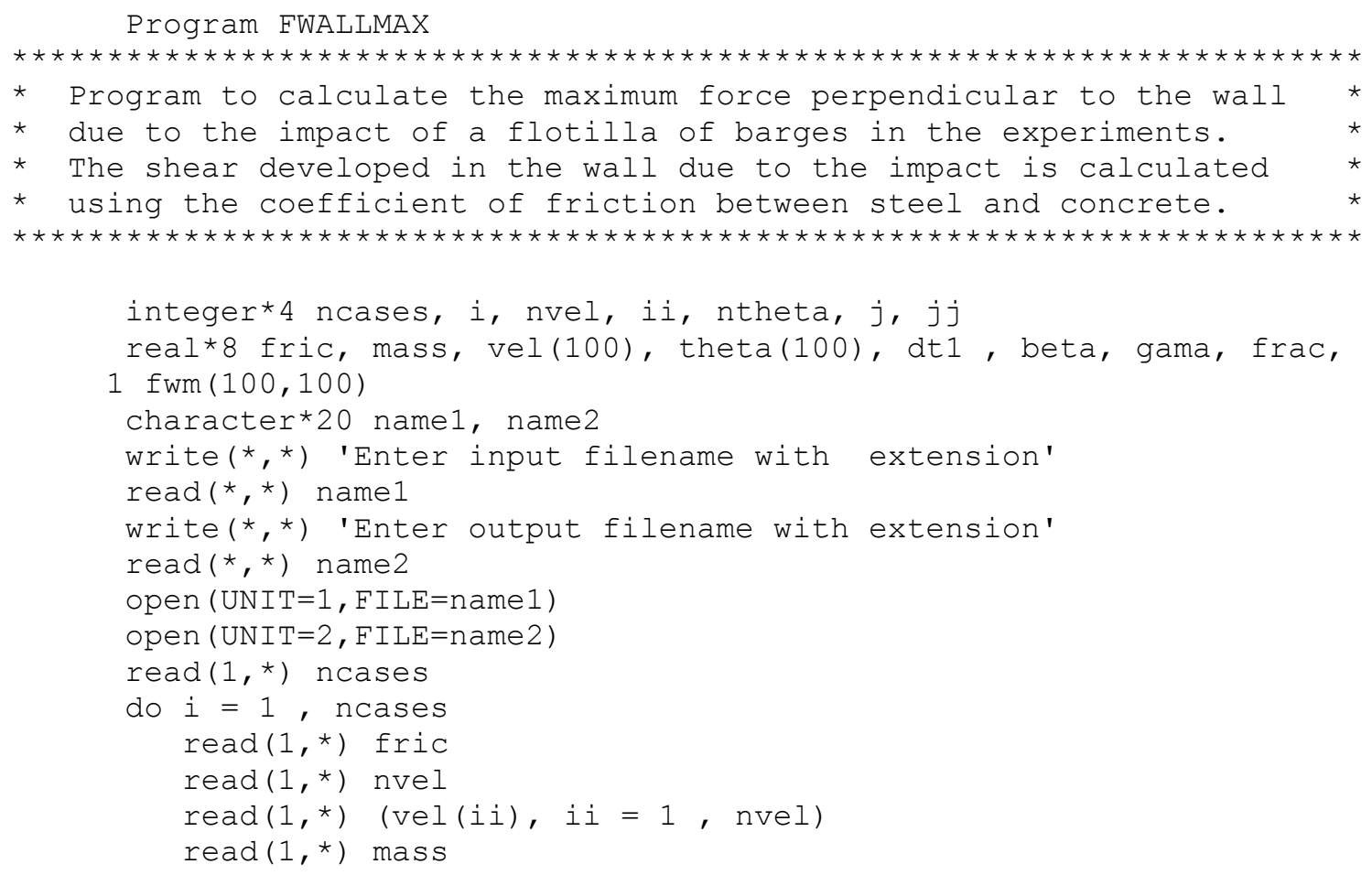




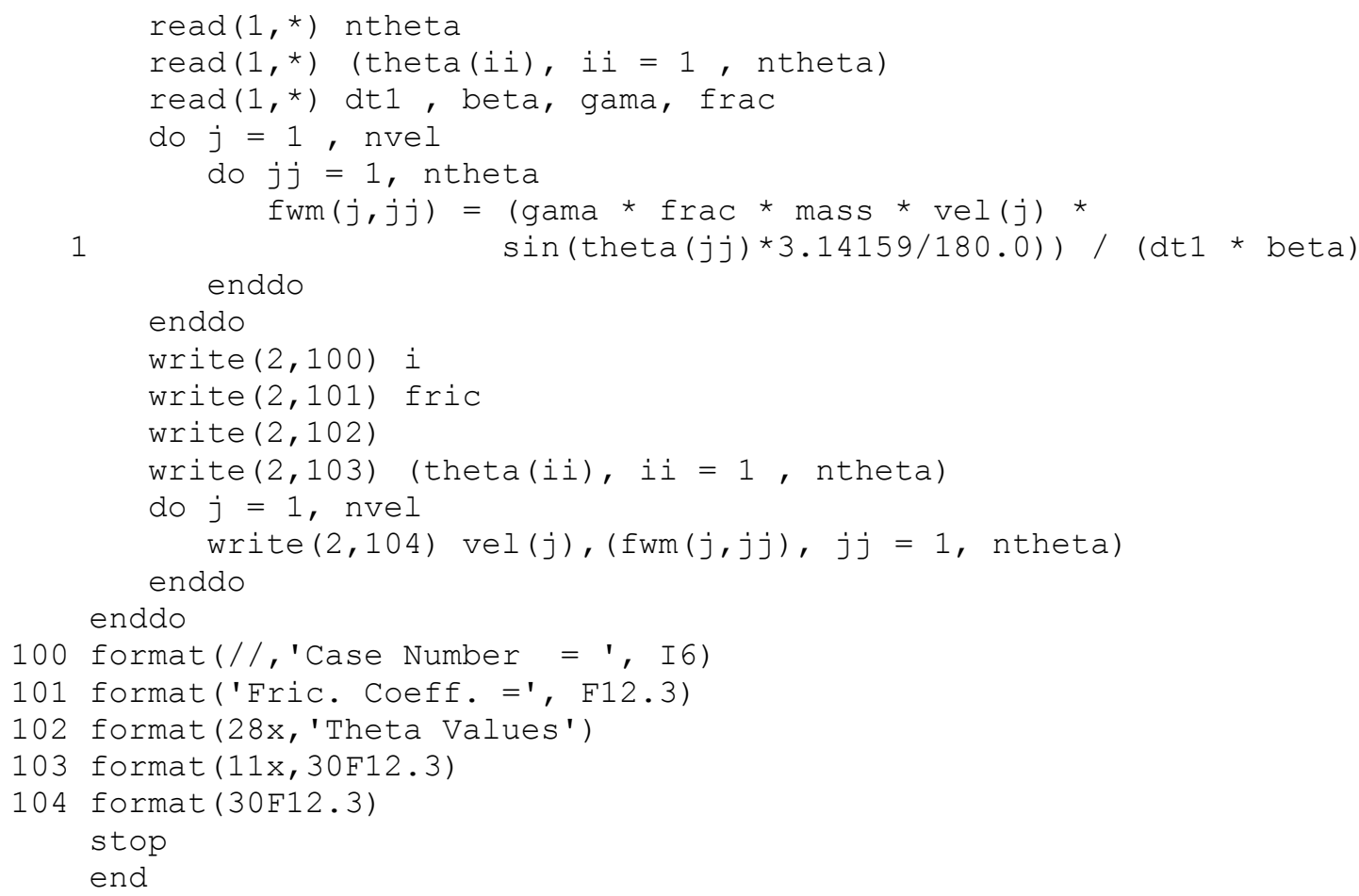

\section{B3. Program to Calculate the Numerical Integration of the Force Versus Time or Acceleration-Velocity- Displacement}

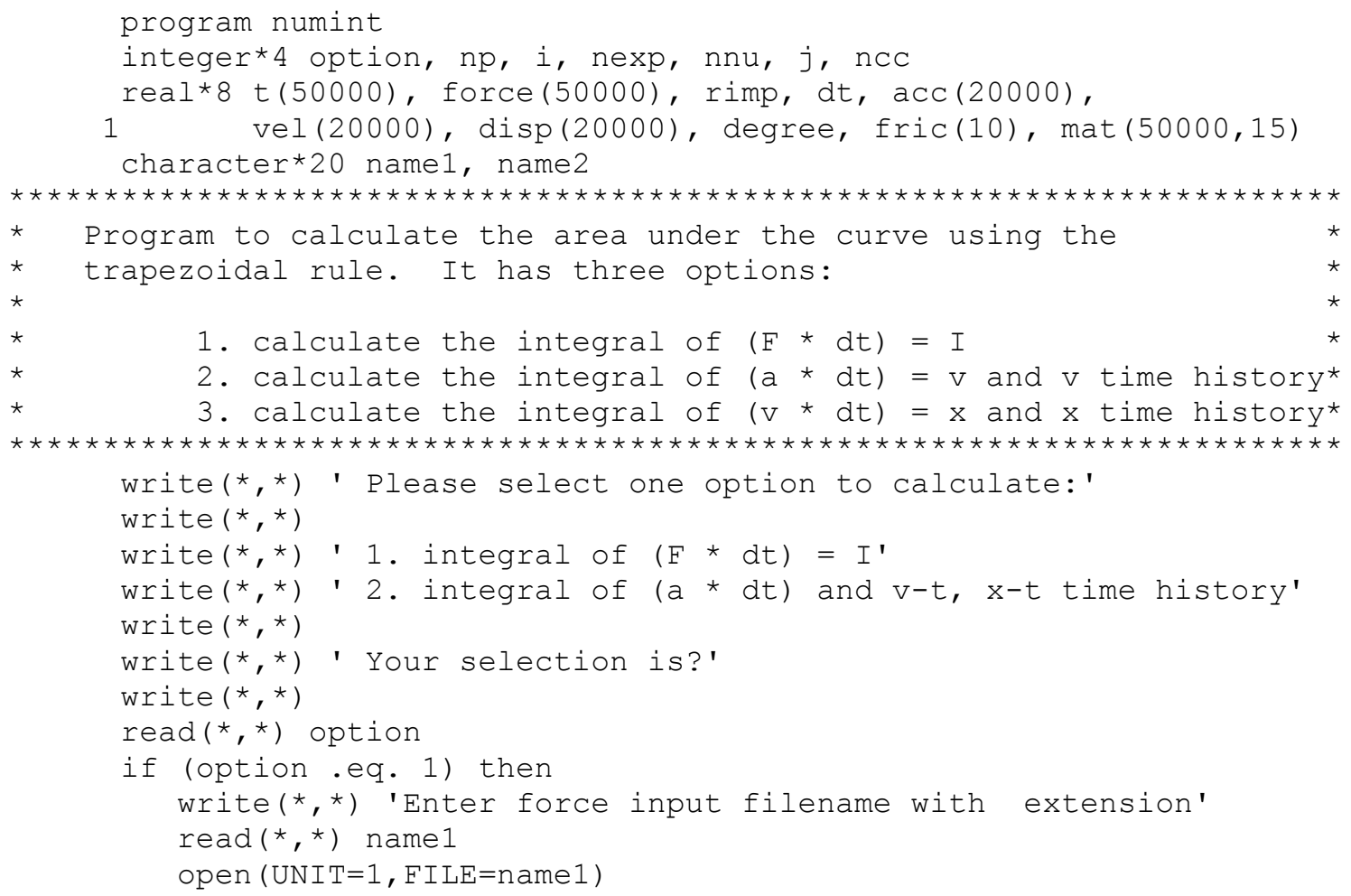




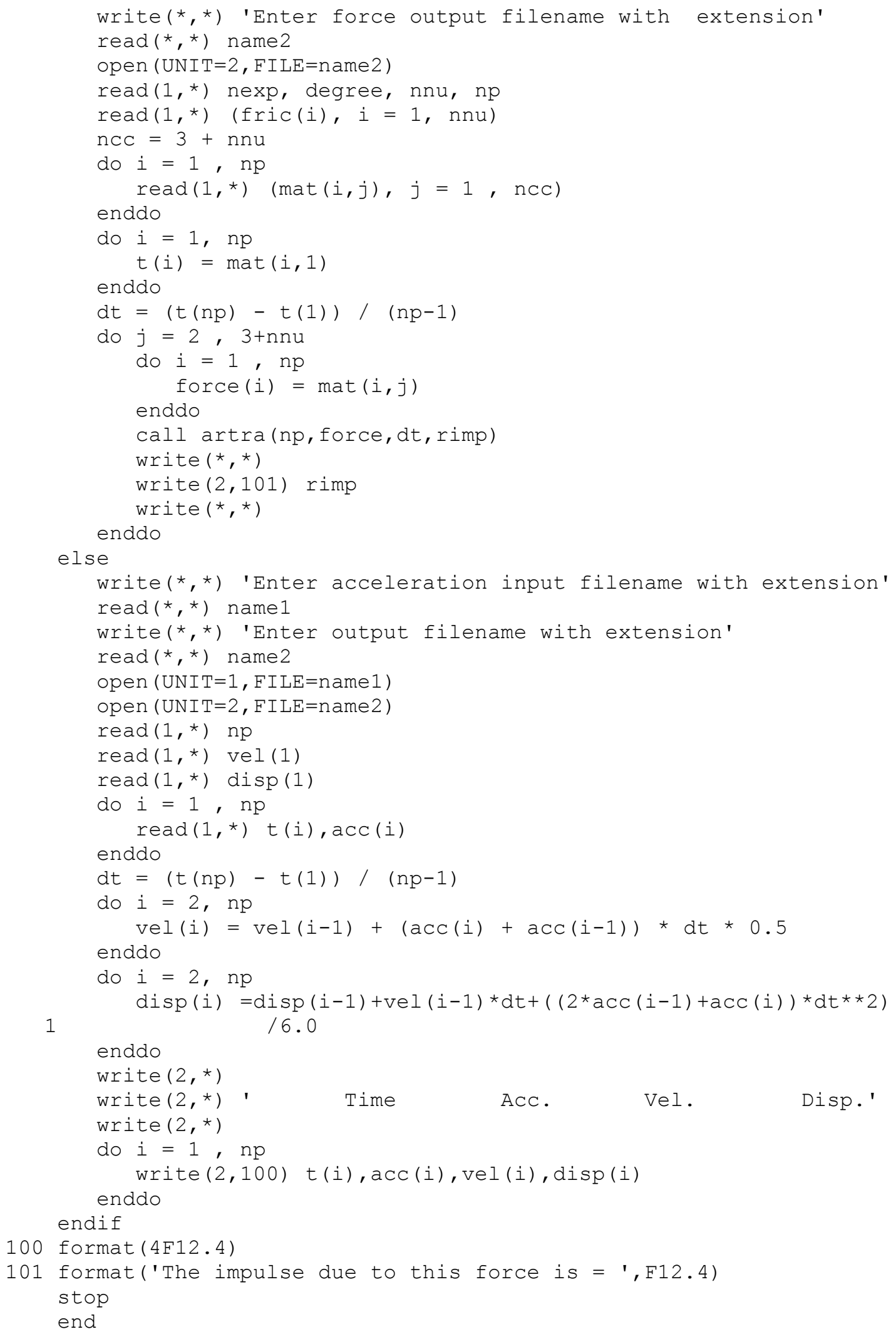




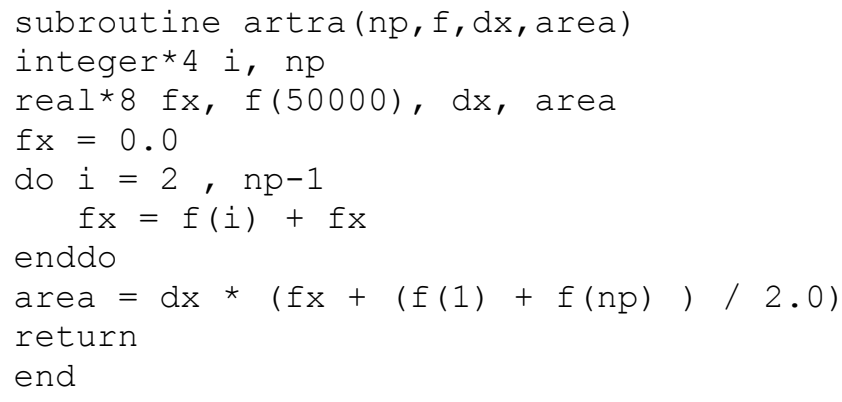

\section{B4. Program to Calculate the Average, Standard Deviation, and Coefficient of Variation of a Set of Data Points and the Slope of a Set " $X$ " and "Y" Data Points}

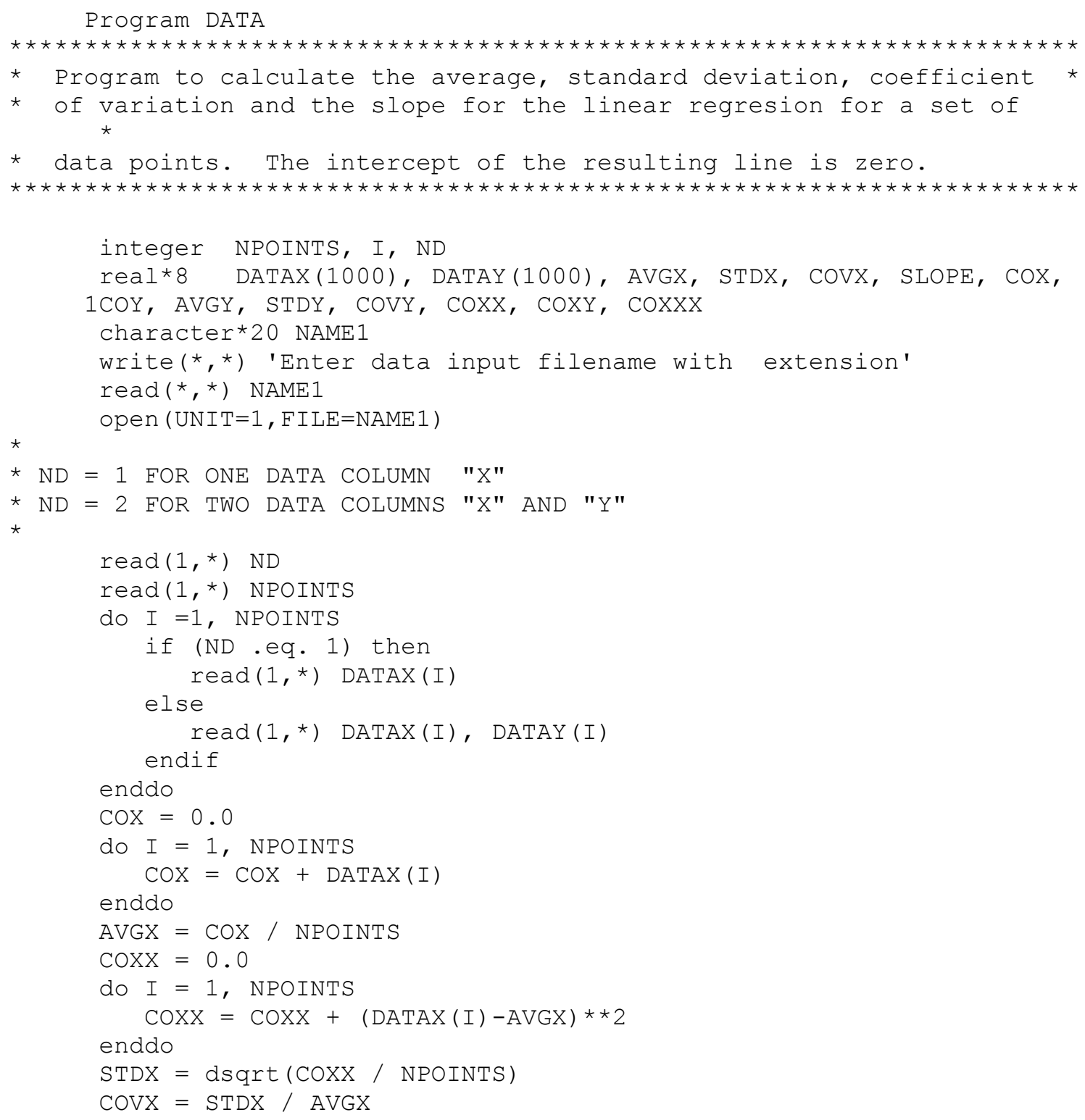




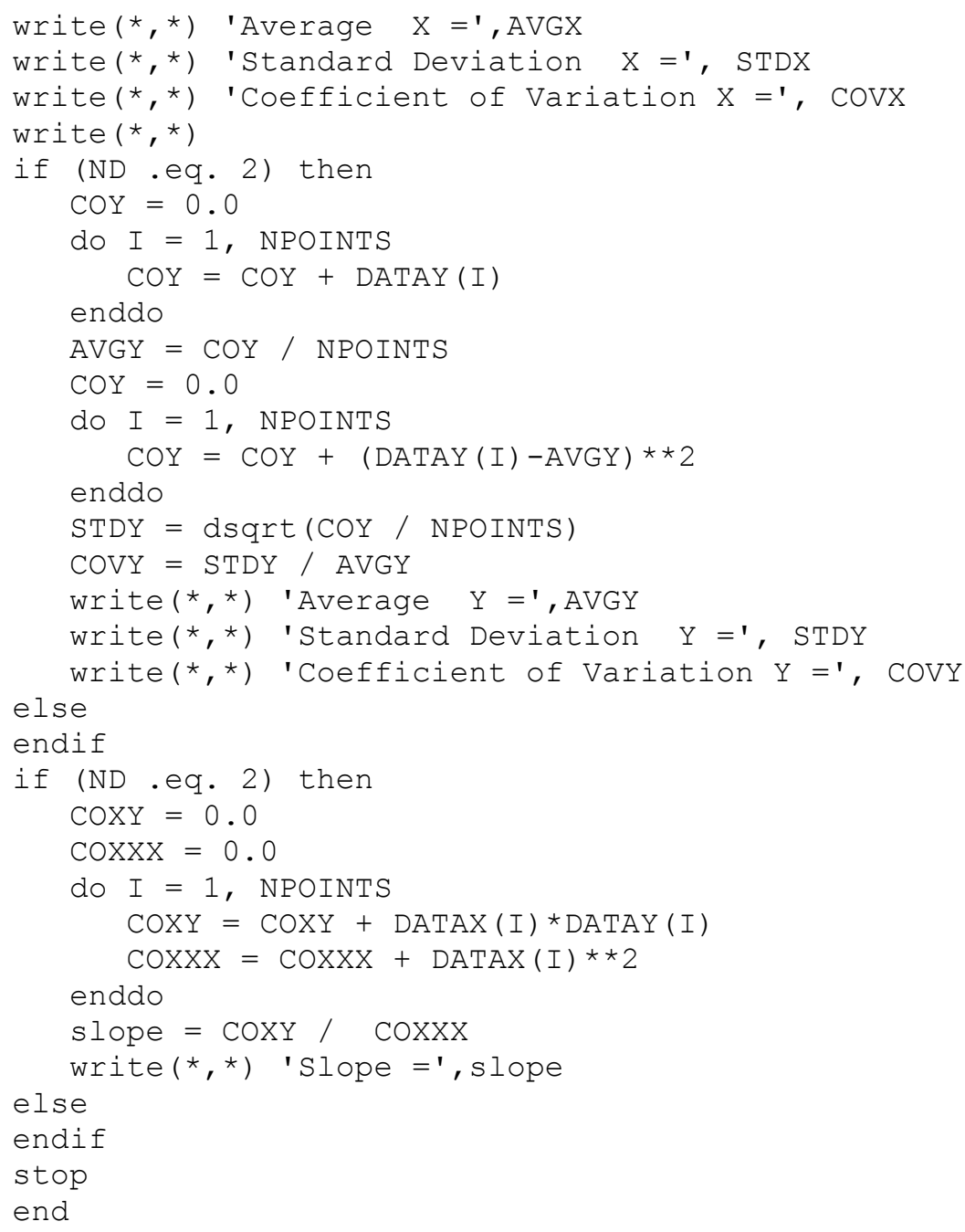

\section{B.5 Worksheet to Calculate the $F_{w}$ Expression for the Assumed Coefficient of Friction Model}

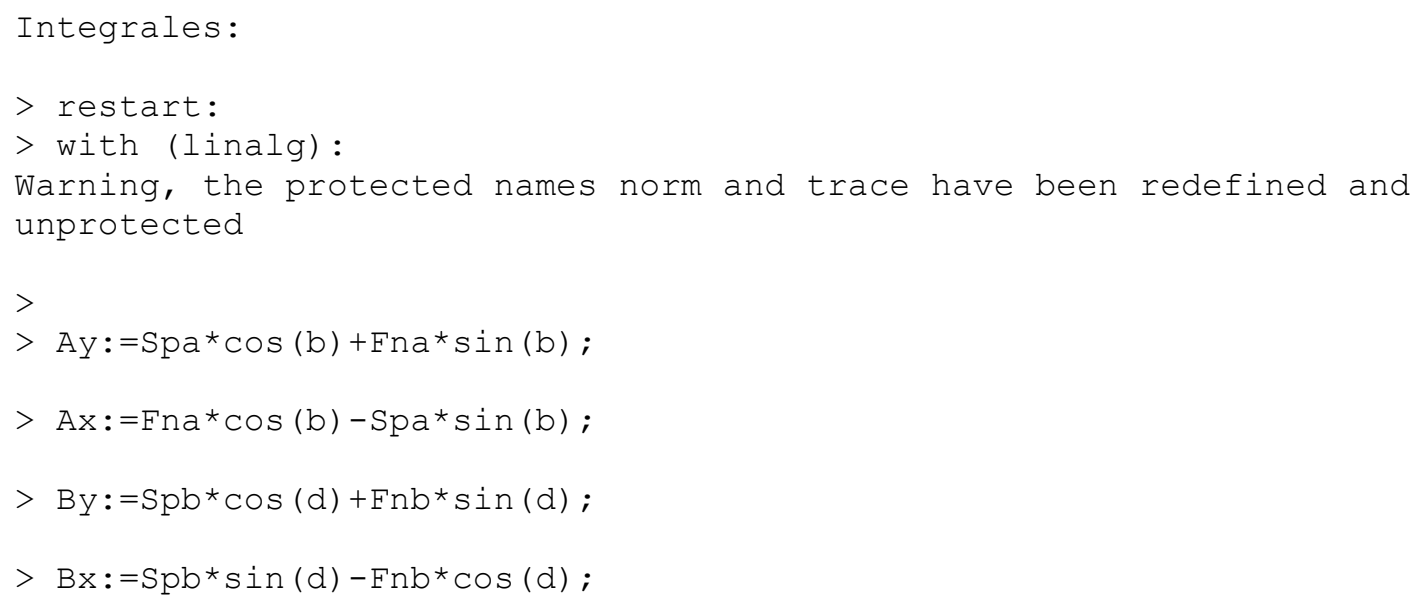




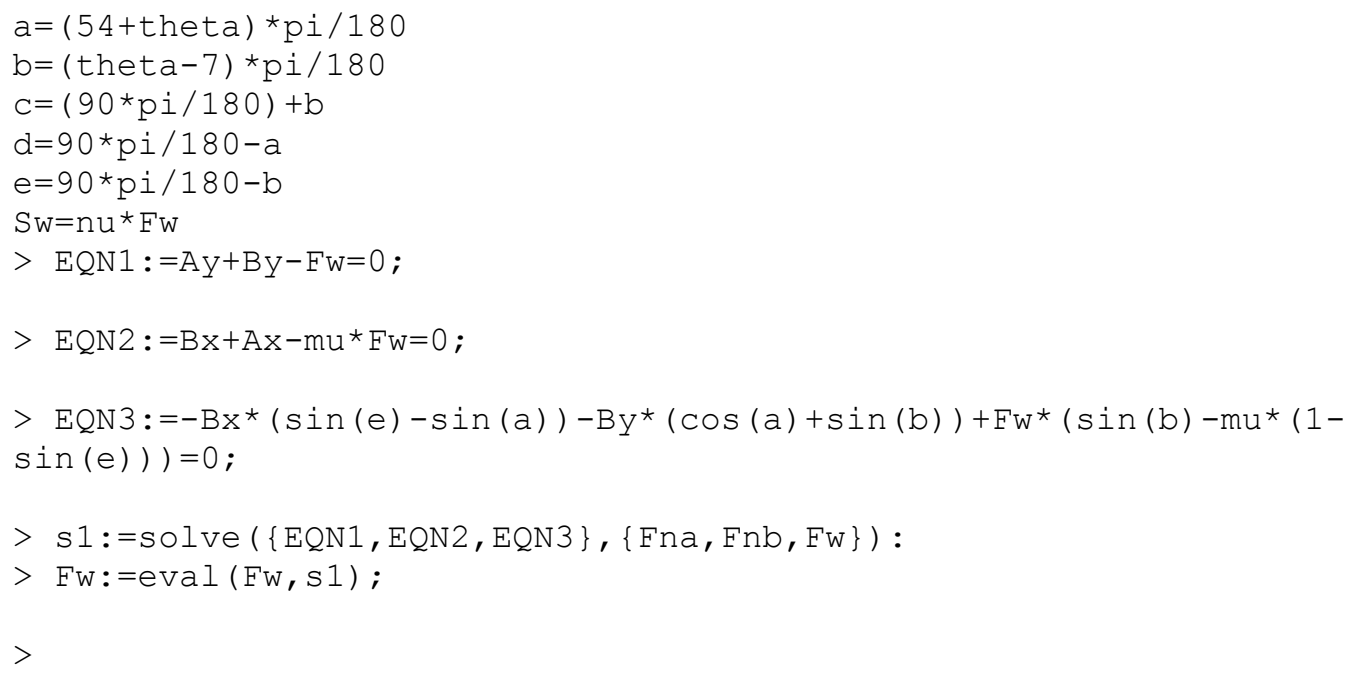

\section{B.6 Worksheet to Numerically Determine $F_{w}$ Using the Energy Model}

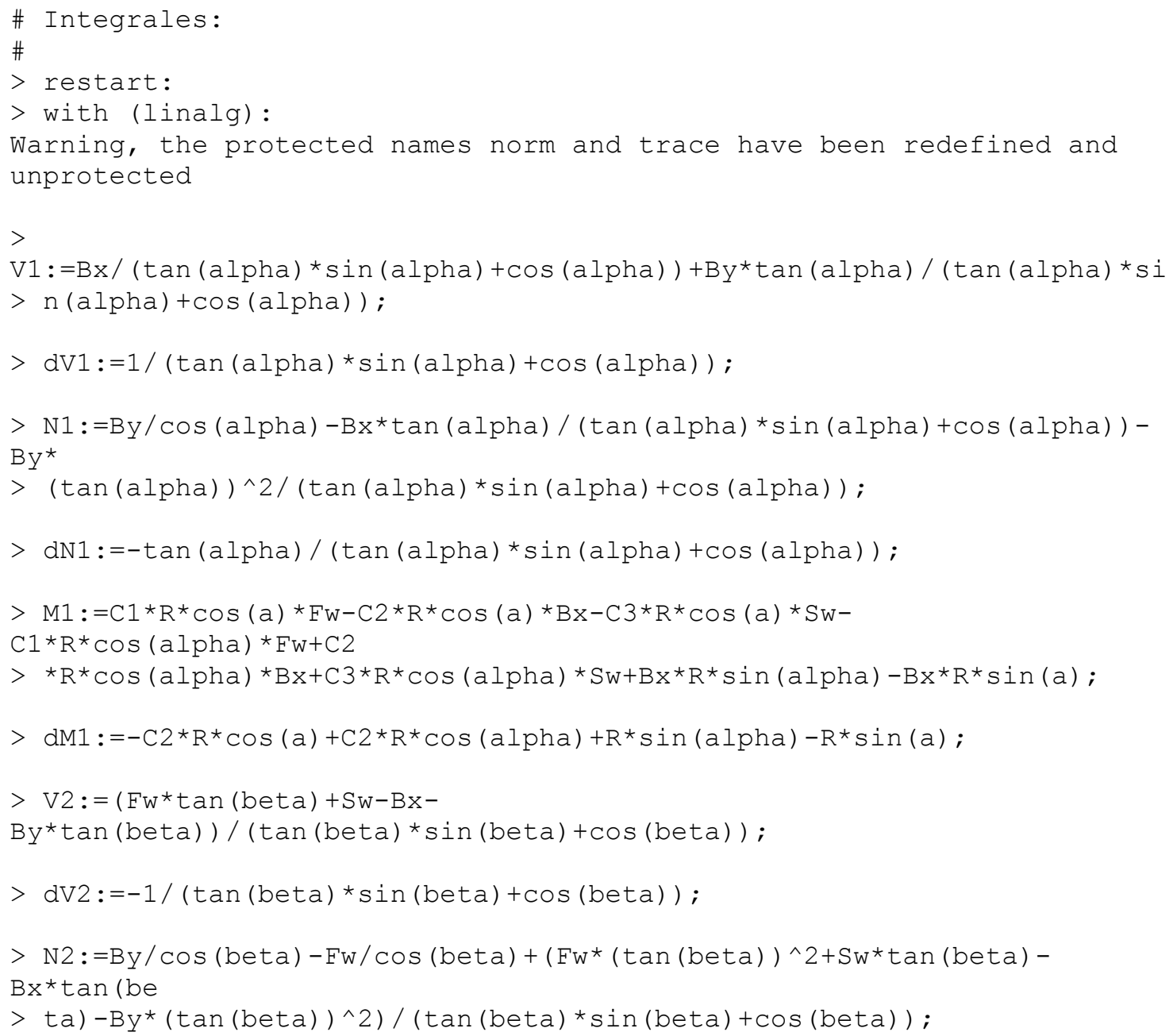




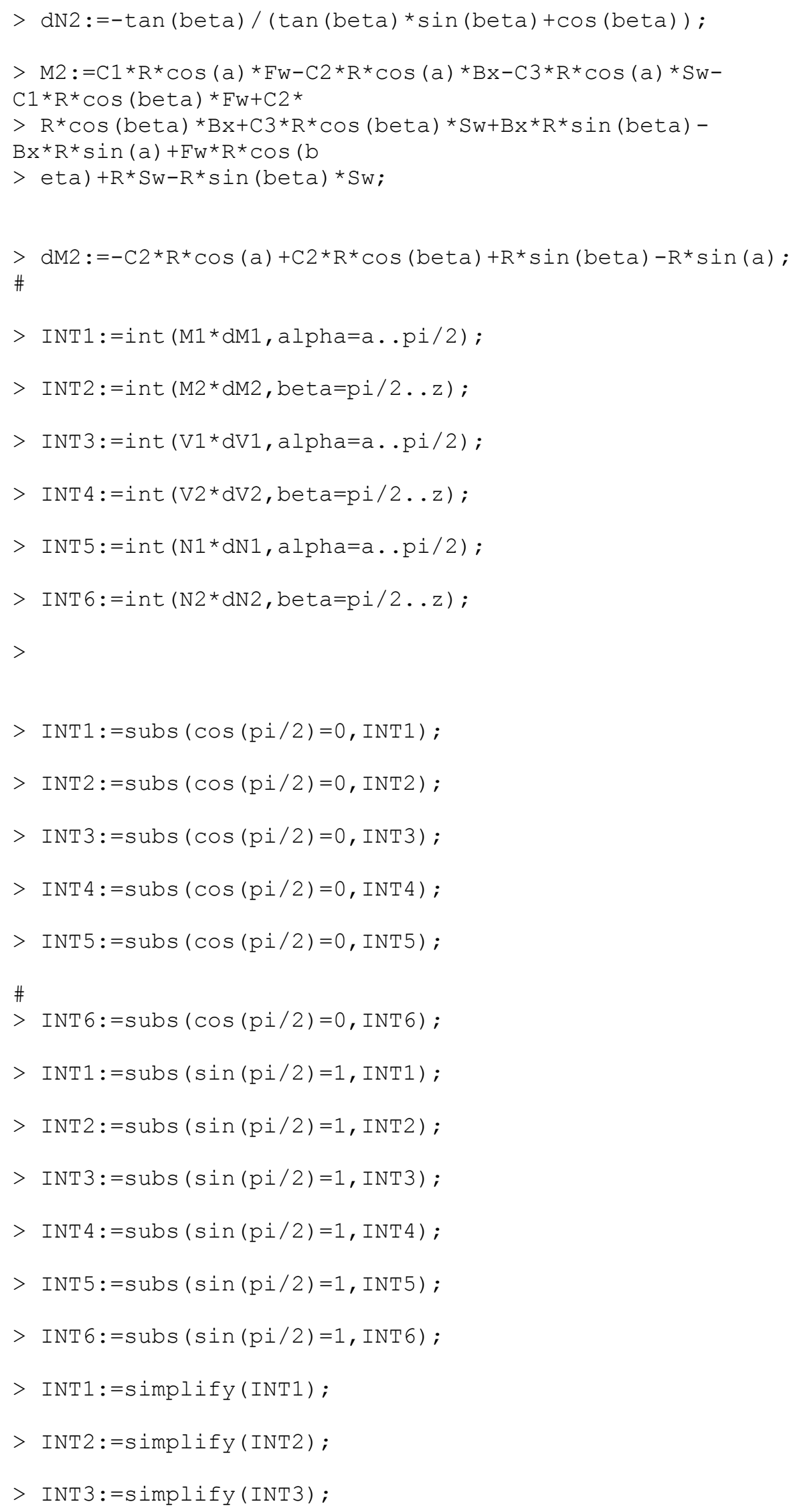




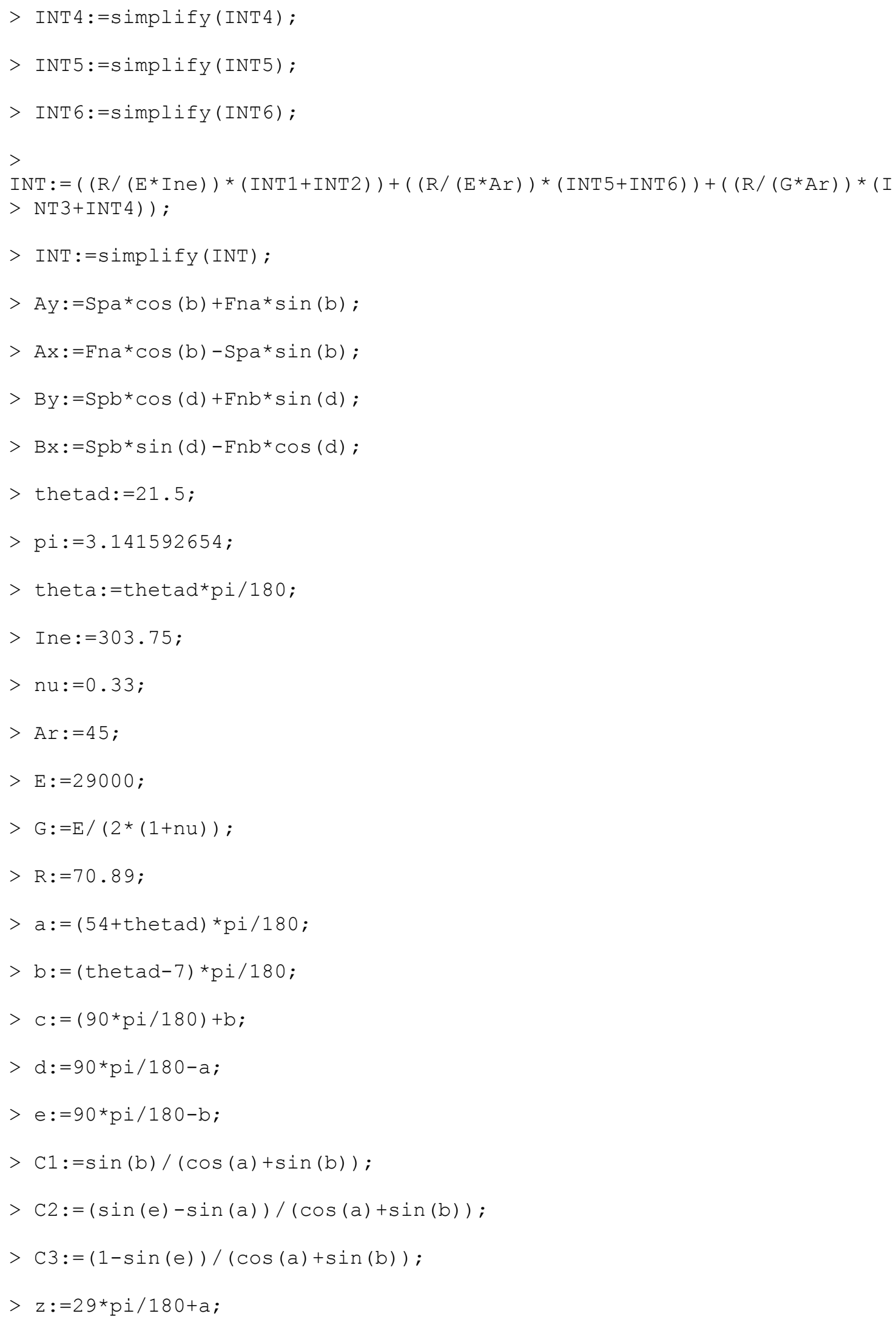




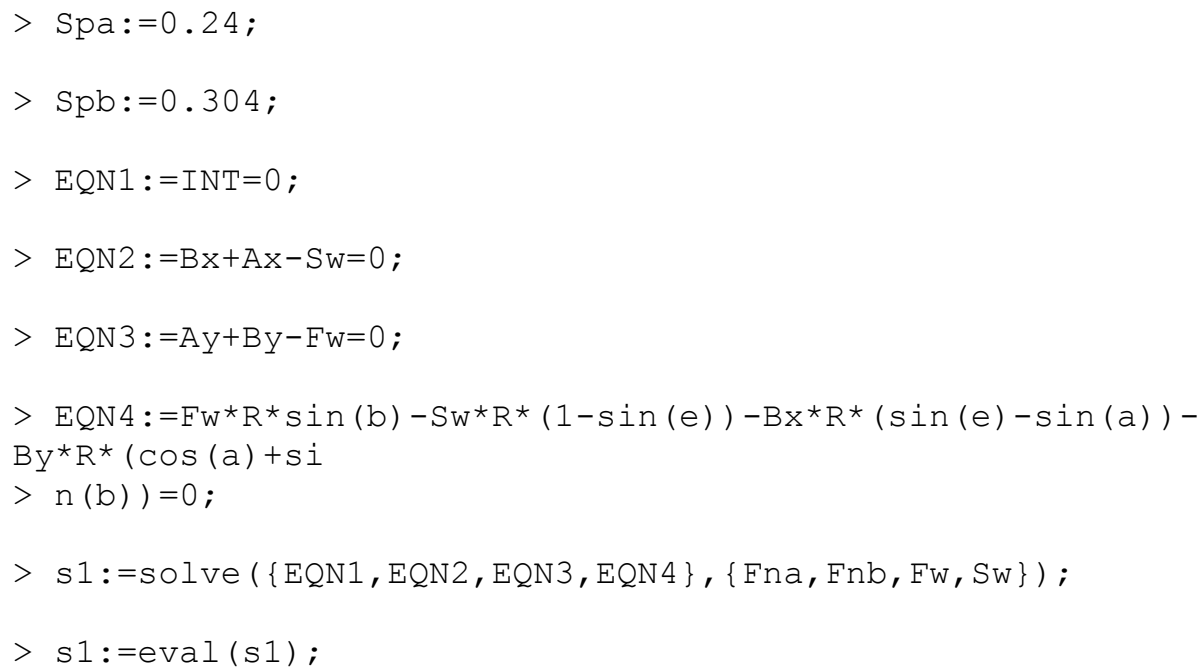

\section{B.7 Worksheet to Determine $F_{w}$ in Terms of Variable Using the Energy Model}

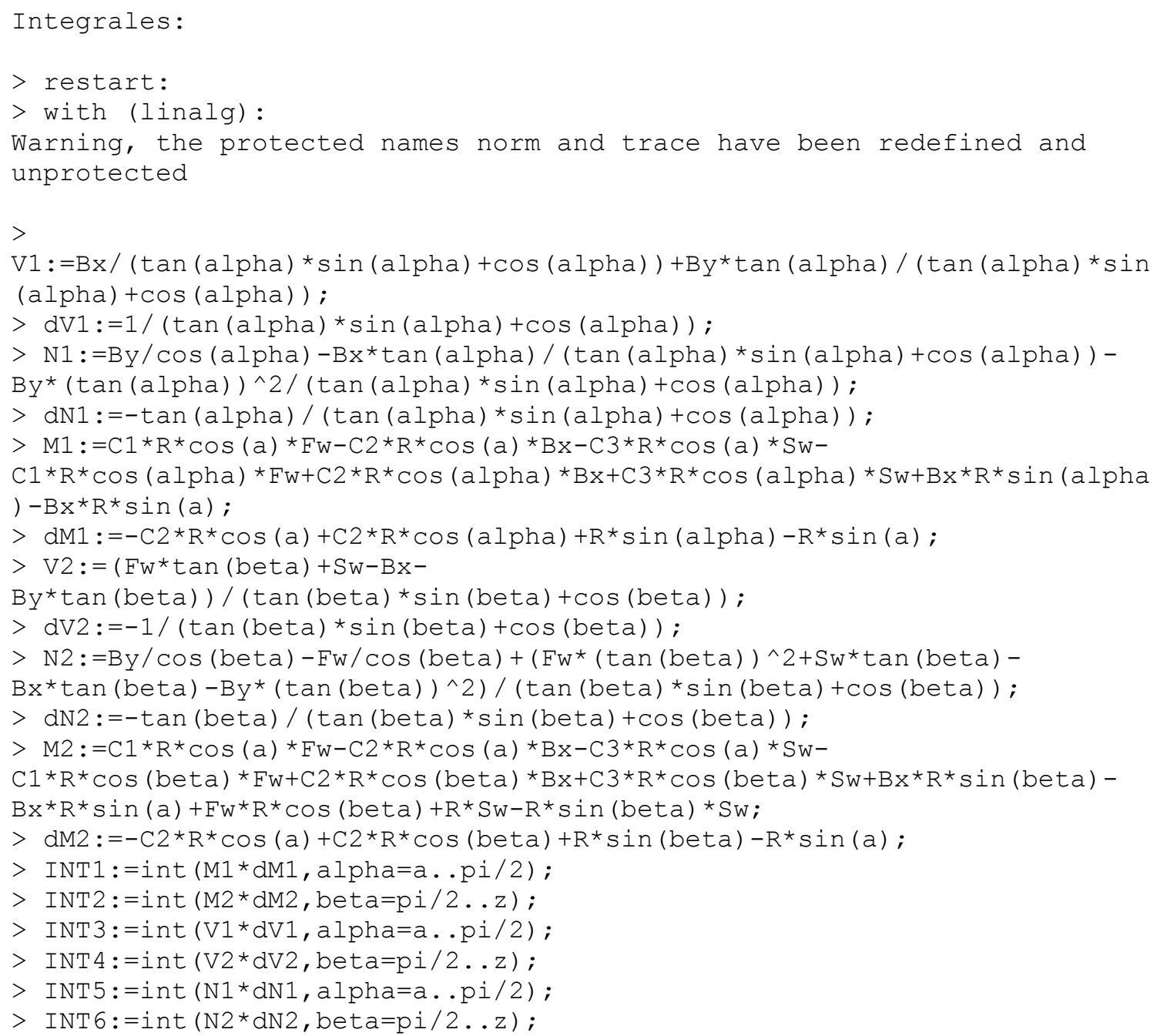




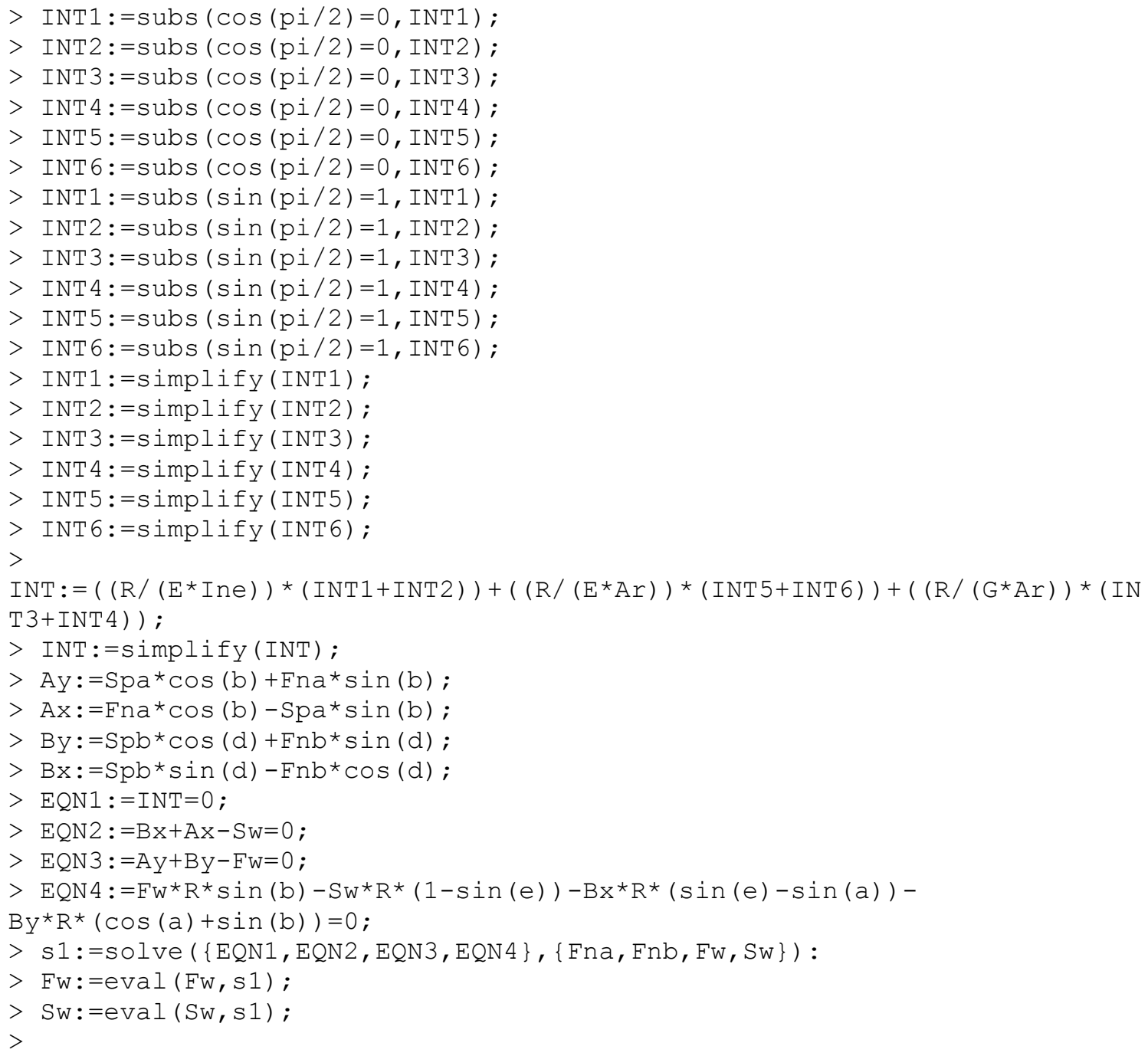




\section{Appendix C Numerical Integration}

One problem in which numerical methods are used is that of approximating the area under the graph of a function $y=F(x)$ from $x=a$ to $x=b$, thus obtaining an approximate value of the integral.

$$
\int_{a}^{b} f(x) d x
$$

One common method is to divide the internal $(a, b)$ into $n$ subintervals, each of length $\Delta x=(b-a) / n$ and then form trapezoids having a base equal to $\Delta x$ and with altitudes given by the values of the function at the beginning and at the end subinterval. This is illustrated in Figure C.1.

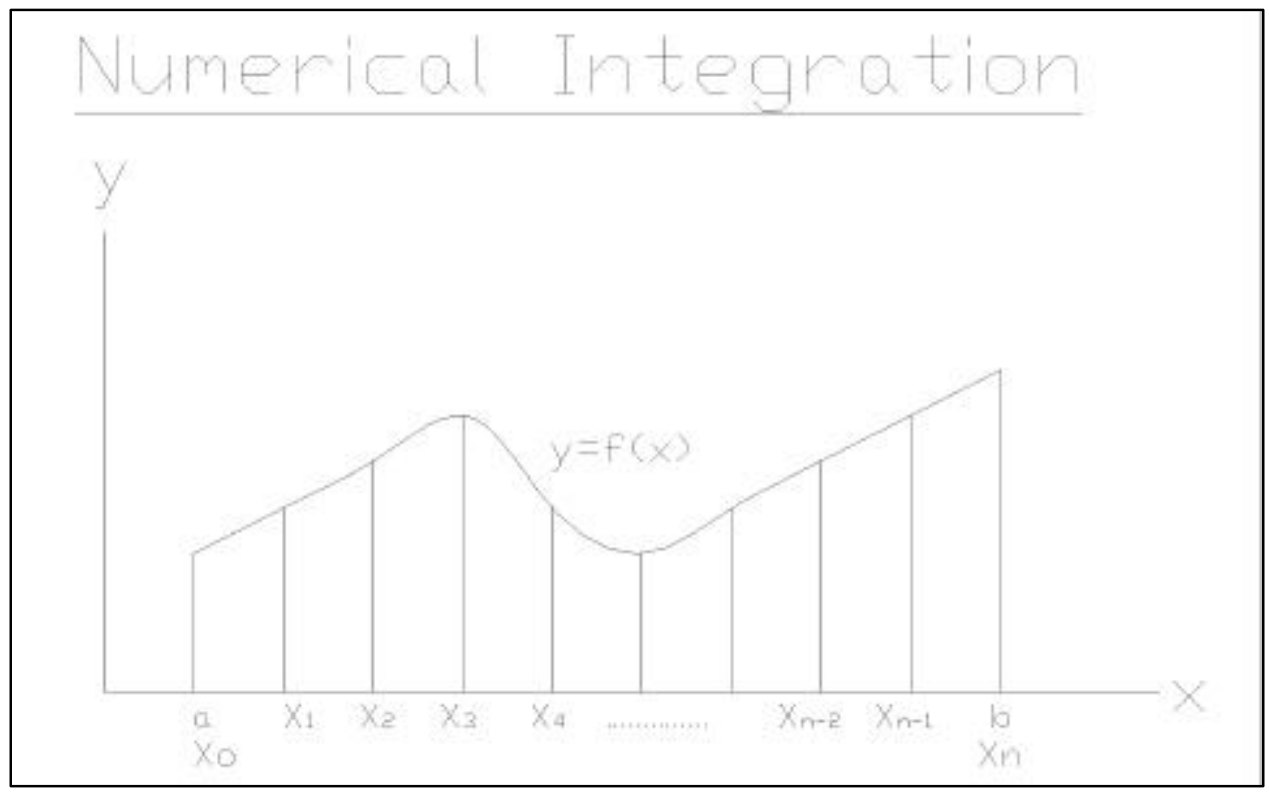

Figure C.1. Numerical integration scheme 
The sum of the areas of these trapezoids is given by

$$
A=\sum_{i=1}^{n}\left[f\left(x_{i-1}\right)+f\left(x_{i}\right)\right] \frac{\Delta x}{2}
$$

which can also be written as

$$
A=\Delta x\left\{\frac{f(a)+f(b)}{2}+\sum_{i=1}^{n-1} f\left(x_{1}\right)\right\}
$$

\section{Example:}

Find the area under the curve $f(x)=x^{2}+x+2$ from $x=0$ to $x=4$.

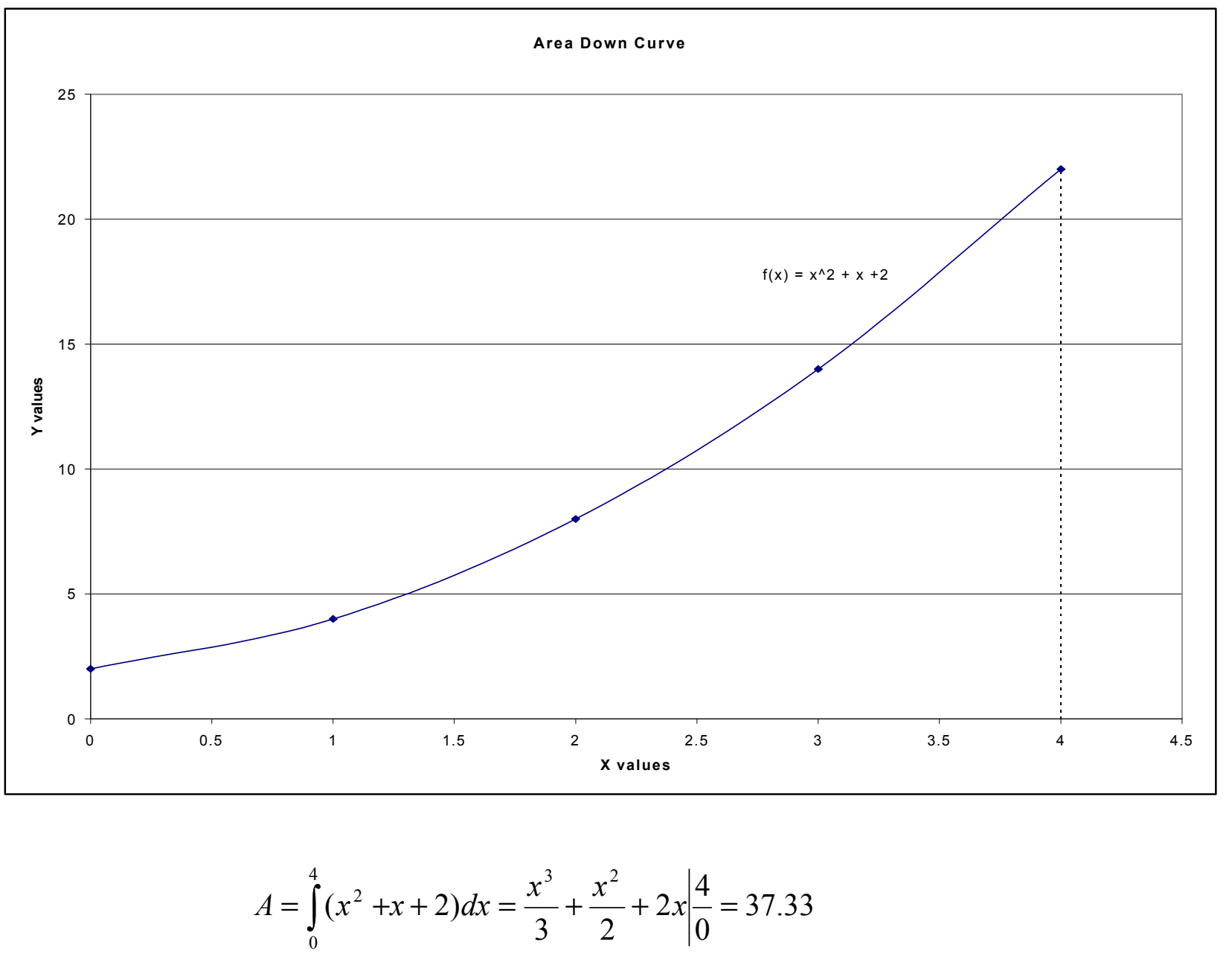

Using num int. for $n=401$ data point (PARABOL.DAT)

$$
A=37.2335 \text { produces a } 0.26 \text { percent error }
$$




\section{Example:}

Find the velocity and displacement time-history from the next acceleration timehistory, if

$V(0)=0 \mathrm{in} . / \mathrm{s}$ and $X(0)=0$ in.

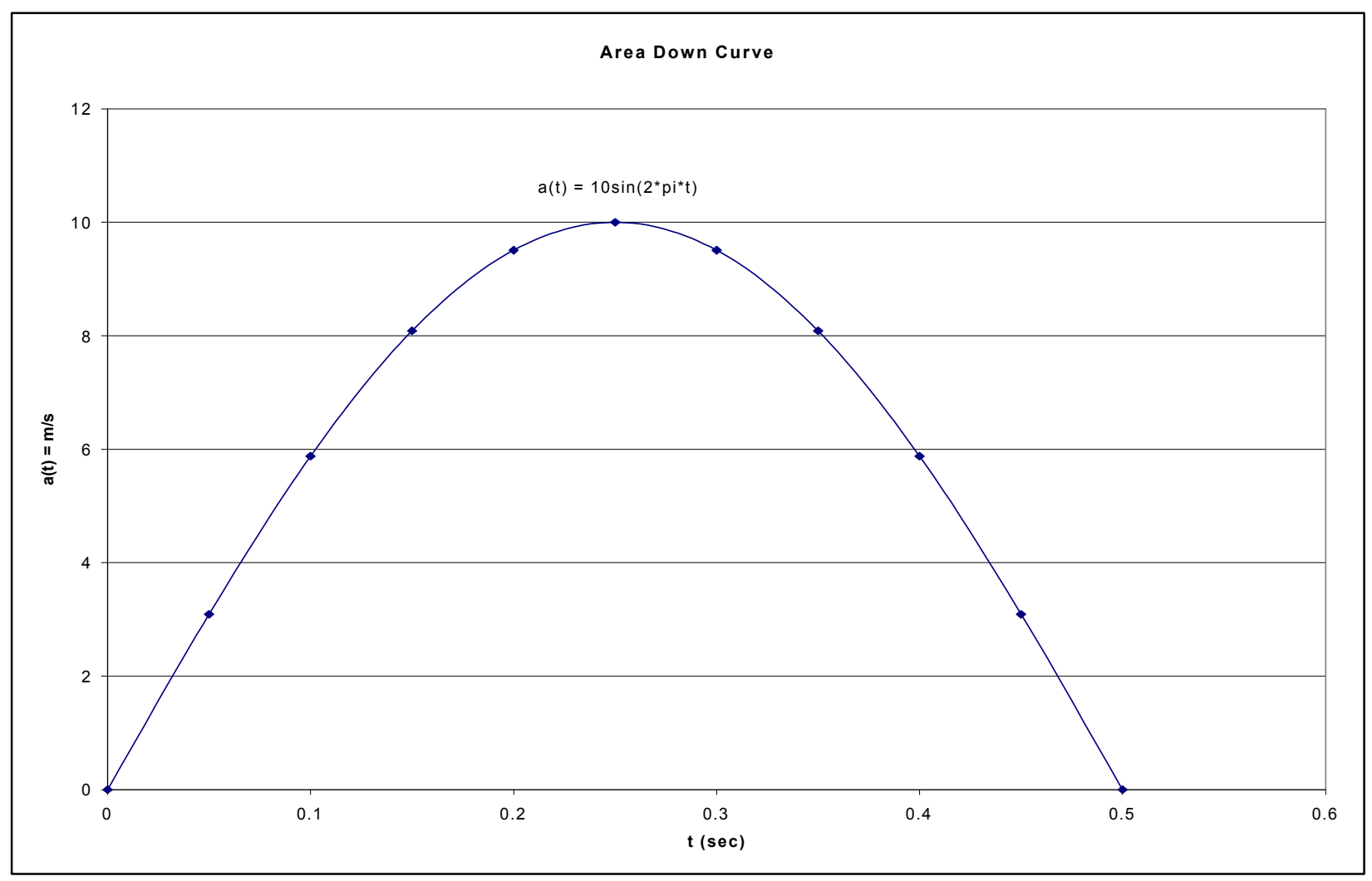

The exact solution is

$$
\begin{aligned}
& a(t)=10 \sin (2 \pi t) \\
& V(t)-V(0)=\int_{t o=0}^{t} a d t=\int_{0}^{t} 10 \sin (2 \pi t) d t=10 \int_{0}^{t} \sin (2 \pi t) d t=\frac{10}{2 \pi}[-\cos (2 \pi t)]_{0}^{t} \\
& V(t)=-\frac{5}{\pi}[\cos (2 \pi t)-1]+V(0) \\
& x(t)-x(0)=-\frac{5}{\pi}\left[\frac{1}{2 \pi} \sin (2 \pi t)-t\right]_{0}^{t}=-\frac{5}{\pi}\left[\frac{\sin (2 \pi t)}{2 \pi}-t\right]
\end{aligned}
$$



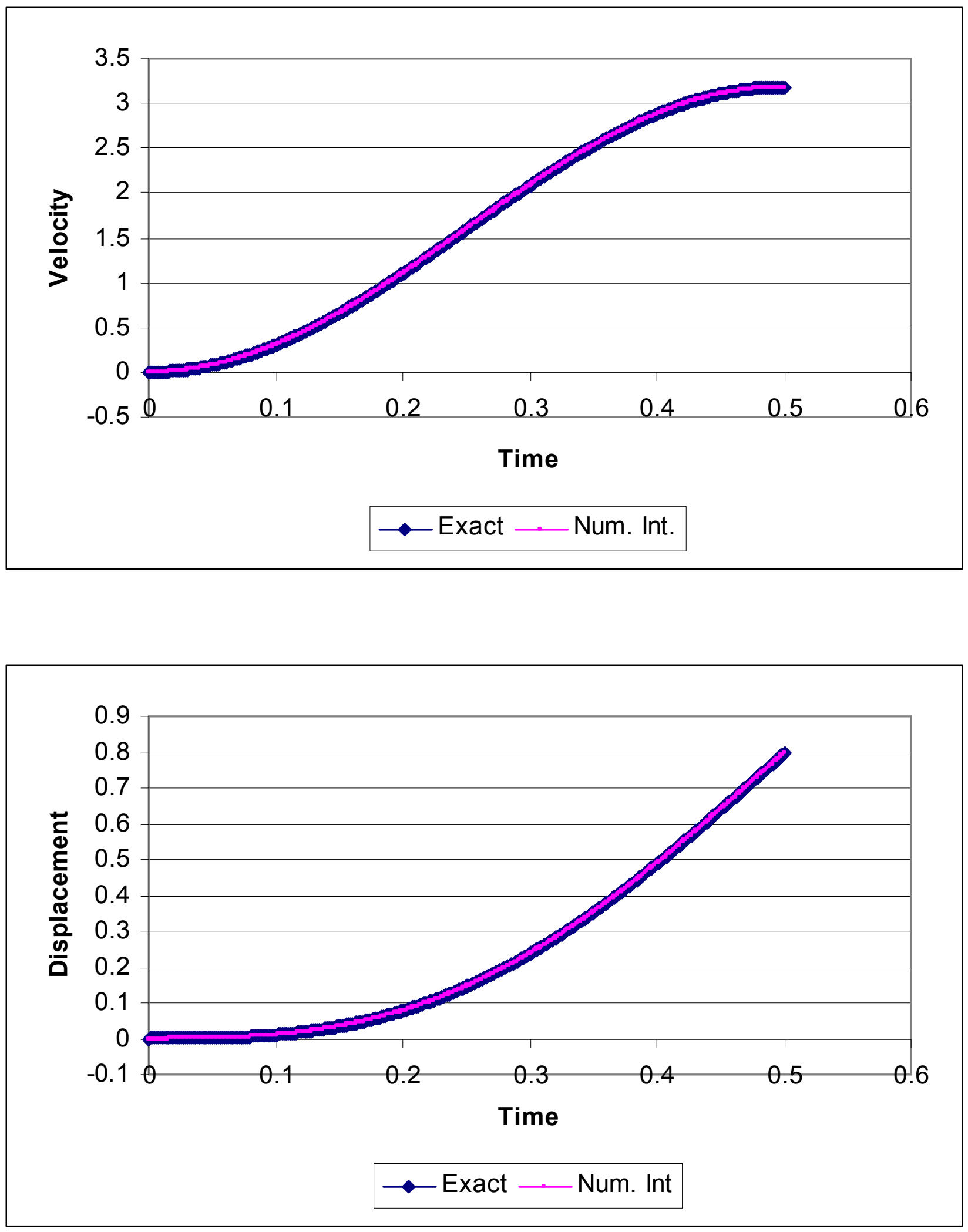


\section{Appendix D Statistical Theory}

\section{D.1 Simple Statistics}

The following information on simple statistics basically follows the information given in Part 4 of Chapra and Canale (1988).

Data are often given for discrete values along a continuum. However, one may require estimates at points between the discrete values. This appendix describes techniques to fit curves to such data in order to obtain intermediate estimates. In addition, there may be a need for a simplified version of a complicated function. One way to do this is to compute values of the function at a number of discrete values along the range of interest. Then, a simpler function may be derived to fit these values. Both of these applications are known as curve fitting.

There are two general approaches for curve fitting that are distinguished from each other on the basis of the amount of error associated with the data. First, where the data exhibit a significant degree of error, the strategy is to derive a single curve that represents the general trend of the data. Because any individual data point may be incorrect, one makes no effort to intersect every point. Rather, the curve is designed to follow the pattern of the points taken as a group. One approach of this nature is called least-squares regression.

Second, where the data are known to be very precise, the basic approach is to fit a curve or a series of curves that pass directly through each of the points. Such data usually originate from tables. Examples of such data are values for the density of water or for the heat capacity of gases as a function of temperature. The estimation of values between well-known discrete points is called interpolation.

The simplest method for fitting a curve to data is to plot the points and then sketch a line that visually conforms to the data. Although this is a valid option when quick estimates are required, the results are dependent on the subjective viewpoint of the person sketching the curve. This is a very common practice in engineering. If the values are truly close to being linear or are spaced closely, such an approximation provides estimates that are adequate for many engineering calculations. However, where the underlying relationship is highly curvilinear or 
the data are widely spaced, significant errors can be introduced by such linear interpolation.

The most common statistics term is the arithmetic mean. The arithmetic mean $(\bar{y})$ of a sample is defined as the sum of the individual data points $\left(y_{i}\right)$ divided by the number of points $(n)$, or

$$
\bar{y}=\frac{\sum y_{i}}{n}
$$

where the summation is from $i=1$ through $n$. The most common measure of spread for a sample is the standard deviation $s_{y}$ about the mean

$$
s_{y}=\sqrt{\frac{S_{t}}{n-1}}
$$

where $S_{t}$ is the total sum of the squares of the residuals between the data points and the mean, or $S_{t}=\sum\left(y_{i}-\bar{y}\right)^{2}$. Thus, if the individual measurements are spread out widely around the mean, $S_{t}$ (and consequently, $s_{y}$ ) will be large. If they are grouped tightly, the standard deviation will be small. The spread can also be represented by the square of the standard deviation, which is called the variance.

$$
s_{y}^{2}=\frac{S_{t}}{n-1}
$$

Note that the denominator in Equations D.2 and D. 3 is $n-1$. This quantity is referred to as the degree of freedom. This nomenclature derives from the fact that the sum of the quantities upon which $S_{t}$ is based is zero. Another justification for dividing by $n-1$ is the fact that there is no such thing as the spread of a single data point.

A final statistic that has utility in quantifying the spread of data is the coefficient of variation (COV). This statistic is the ratio of the standard deviation to the mean. As such, it provides a normalized measure of the spread. It is often multiplied by 100 so that it can be expressed in the form of a percent, as

$$
C O V=\frac{s_{y}}{\bar{y}} 100 \%
$$

That is, it is the ratio of a measure of error $s_{y}$ to an estimate of the true value $\bar{y}$.

Using the $\left(F_{w}\right)_{\max }$ values given in Table 5.3 of the main text (and reported in Table 6.1a, eighth column, in yellow), statistical values are obtained in the following calculations for the data presented in Table D.1. 


\begin{tabular}{|c|c|c|}
\hline $\begin{array}{l}\text { Experiment } \\
\text { Number }\end{array}$ & $\begin{array}{l}\text { Linear Momentum Normal } \\
\text { to the Wall } \\
x_{i}\end{array}$ & $\begin{array}{l}\left(F_{w}\right)_{\max } \text { Table } 5.3 \\
y_{i} \\
\end{array}$ \\
\hline 29 & ( 897.42 & 286.63 \\
\hline 30 & 925.73 & 369.15 \\
\hline 31 & 552.52 & 236.20 \\
\hline 37 & 649.84 & 327.27 \\
\hline 38 & 706.32 & 230.29 \\
\hline 39 & 732.74 & 271.07 \\
\hline 41 & 812.59 & 419.37 \\
\hline 42 & 1025.48 & 577.44 \\
\hline
\end{tabular}

\section{Calculation:}

$$
\begin{aligned}
& \bar{y}=\frac{\sum_{i=1}^{8} y_{i}}{n}=\frac{2717.42}{8}=339.68 \text { kips } \\
& S_{t}=\sum_{i=1}^{8}\left(y_{i}-\bar{y}\right)^{2}=(286.63-339.68)^{2}+(369.15-339.68)^{2} \\
& +(236.20-339.68)^{2}+(327.27-339.68)^{2}+(230.29-339.68)^{2} \\
& +(271.07-339.68)^{2}+(419.37-339.68)^{2}+(577.44-339.68)^{2}=94098.72 \\
& S_{y}=\sqrt{\frac{S_{t}}{n-1}}=\sqrt{\frac{94098.72}{8-1}}=115.94 \\
& \text { COV }=\frac{s_{y}}{\bar{y}}=\frac{115.94}{339.68} * 100=34 \%
\end{aligned}
$$

\section{D.2 Linear Regression and Quantification of Error}

The information presented in this section (on linear regression and quantification of error) basically follows the information given in Chapter 12 of Chapra and Canale (1988).

Where substantial error is associated with data, polynomial interpolation is inappropriate and may yield unsatisfactory results when used to predict intermediate values. Experimental data are often of this type. A more appropriate strategy for such cases is to derive an approximating function that fits the shape or general trend of the data without necessarily matching the individual points. 
One way to determine this line is to visually inspect the plotted data and then sketch a "best" line through the points. Although such "eyeball" approaches have common-sense appeal and are valid for "back-of-the-envelope" calculations, they are deficient because they are arbitrary. That is, unless the points define a perfect straight line (in which case, interpolation would be appropriate), different analysts would draw different lines.

To remove this subjectivity, some criterion must be devised to establish a basis for the fit. One way to do this is to derive a curve that minimizes the discrepancy between the data points and the curve. A technique for accomplishing this objective, called least-squares regression, will be discussed here.

The simplest example of a least-squares approximation is fitting a straight line to a set of paired observations: $\left(x_{1}, y_{1}\right),\left(x_{2}, y_{2}\right), \ldots,\left(x_{n}, y_{n}\right)$. The mathematical expression for the straight line is

$$
y=a_{0}+a_{1} x+e
$$

where $a_{o}$ and $a_{1}$, are coefficients representing the intercept and the slope, respectively, and $e$ is the error, or residual, between the model and the observations, which can represented by rearranging Equation D.5 as

$$
e=y-a_{0}-a_{1} x
$$

Thus, the error, or residual, is the discrepancy between the true value of $y$ and the approximate value, $a_{0}+a_{1} x$, predicted by the linear equation.

One strategy for fitting a "best" line through the data would be to minimize the sum of the residual errors for all the available data, as in

$$
\sum_{i=1}^{n} e_{i}=\sum_{i=1}^{n}\left(y_{i}-a_{0}-a_{1} x_{i}\right)
$$

where $n$ is the total number of points. However, this is an inadequate criterion, which depicts the fit of a straight line to two points. Obviously, the best fit is the line connecting the points. However, any straight line passing through the midpoint of the connecting line (except a perfectly vertical line) results in a minimum value of Equation D.7 equal to zero because the errors cancel.

Another criterion would be to minimize the sum of the absolute values of the discrepancies, as in 


$$
\sum_{i=1}^{n}\left|e_{i}\right|=\sum_{i=1}^{n}\left|y_{i}-a_{0}-a_{1} x_{i}\right|
$$

This criterion also does not yield a unique best fit. A third strategy for fitting a best line is the minimax criterion. In this technique, the line is chosen that minimizes the maximum distance that an individual point falls from the line. This strategy is ill suited for regression because it gives undue influence to an outlier, that is, a single point with a large error.

A strategy that overcomes the shortcomings of the aforementioned approaches is to minimize the sum of the squares of the residuals, $S_{r}$, as in

$$
S_{r}=\sum_{i=1}^{n} e_{i}^{2}=\sum_{i=1}^{n}\left(y_{i}-a_{0}-a_{1} x_{i}\right)^{2}
$$

This criterion has a number of advantages, including the fact that it yields a unique line for a given set of data. To determine values for $a_{0}$ and $a_{1}$, Equation D.9 is differentiated with respect to each coefficient. Setting these derivatives equal to zero will result in a minimum $S_{r}$. Now the equations can be expressed as a set of two simultaneous linear equations with two unknowns, $a_{0}$ and $a_{1}$. These are called the normal equations, and they can be solved simultaneously, producing the following equations:

$$
\begin{aligned}
& a_{1}=\frac{n \sum x_{i} y_{i}-\sum x_{i} \sum y_{i}}{n \sum x_{i}^{2}-\left(\sum x_{i}\right)^{2}} \\
& a_{0}=\bar{y}-a_{1} \bar{x}
\end{aligned}
$$

where ybar $(\bar{y})$ is the arithmetic mean of data points $y_{i}$, and xbar $(\bar{x})$ is the arithmetic mean of data points $x_{i}$. Substituting the computed values for these coefficients into Equation D.5 produces the smallest error that can be obtained.

Recalling that the sum of the squares is defined as

$$
S_{r}=\sum_{i=1}^{n}\left(y_{i}-a_{0}-a_{1} x_{i}\right)^{2}
$$

where the square of the residual represents the square of the vertical distance between the data and another measure of central tendency (the straight line), the standard deviation for the regression line can be determined as

$$
s_{x / y}=\sqrt{\frac{S_{r}}{n-2}}
$$


where $s_{x / y}$ is called the standard error of the estimate. The subscript notation $x / y$ designates that the error is for a predicted value of $y$ corresponding to a particular value of $x$. Also, notice that we now divide by $n-2$ because two dataderived estimates $-a_{0}$ and $a_{1}$-were used to compute $S_{r}$; thus we have lost two degrees of freedom. Another justification for dividing by $n-2$ is that there is no such thing as the "spread of data" around a straight line connecting two points. Thus, for the case where $n=2$, Equation D.12 yields a meaningless result of infinity. Just as was the case with the standard deviation, the standard error of the estimate quantifies the spread of the data. However, $s_{x / y}$ quantifies the spread around the regression line in contrast to the original standard deviation $s_{y}$ that quantified the spread around the mean.

The above concepts can be used to quantify the "goodness" of our fit. This is particularly useful for comparison of several regressions. To do this, we return to the original data and determine the total sum of the squares around the mean for the dependent variable (in our case, $y$ ). As was presented earlier, this quantity is designated $S_{t}$. This is the uncertainty associated with the dependent variable prior to regression. After performing the regression, we can compute $S_{r}$, the sum of the squares of the residuals around the regression line. This represents the uncertainty that remains after the regression. It is, therefore, sometimes called the unexplained sum of the squares. The difference between the two quantities, $S_{t}$ $-S_{r}$, quantifies the improvement or error reduction due to describing the data in terms of a straight line rather than as an average value. Because the magnitude of this quantity is scale-dependent, the difference is normalized to the total error to yield

$$
r^{2}=\frac{S_{t}-S_{r}}{S_{t}}
$$

where $r^{2}$ is called the coefficient of determination and $r$ is the correlation coefficient. For a perfect fit, $S_{r},=0$ and $r=r^{2}=1$, signifying that the line explains 100 percent of the variability of the data. For $r=r^{2}=0, S_{r}=S_{t}$, and the fit represents no improvement.

There exists a special case for a straight line when the resulting equation passes through the origin. That is, the intercept of the resulting equation is set equal to zero prior to regression, the coefficient $a_{0}$ is set equal to zero, and the equation of the line becomes $y=a_{1} x$. This case is important for the barge impact data, as will be discussed subsequently. If the best-fit equation starts at the origin, Equation D.10 transforms to

$$
a_{1}=\frac{\sum x_{i} y_{i}}{\sum x_{i}^{2}} \quad \text { for } \quad a_{0}=0
$$




\section{D.3 Example 1; Linear Regression with Intercept Not Equal to Zero-Linear Momentum Normal to the Wall}

Using the $\left(F_{w}\right)_{\max }$ values given in Table 5.3 (and reported in Table 6.1a, eighth column, in yellow), a linear regression is made to obtain the best-fit straight line, as outlined in the following calculations for the data (see Table D.1).

\section{Calculation:}

$$
\begin{aligned}
& n=8 \\
& \sum_{i=1}^{8} x_{i}=6302.63 \\
& \sum_{i=1}^{8} y_{i}=2717.42 \\
& \sum_{i=1}^{8} x_{i} y_{i}=2236350.39 \\
& \sum_{i=1}^{8} x_{i}^{2}=5137616.654 \\
& \bar{x}=\frac{6302.63}{8}=787.83 \\
& \bar{y}=\frac{2717.42}{8}=339.68 \\
& a_{1}=\frac{n \sum x_{i} y_{i}-\sum x_{i} \sum y_{i}}{n \sum x_{i}^{2}-\left(\sum x_{i}\right)^{2}}=\frac{8 *(2236350.39)-6302.63 * 2717.42}{8 * 5137616.654-(6302.63)^{2}}=0.5544 \\
& a_{0}=\bar{y}-a_{1} \bar{x}=339.68-0.5544 * 787.83=-97.09 \\
& \left(F_{w}\right)_{\max }=a_{1} x+a_{0}=0.5544(m v \sin \theta)-97.09 \\
& S_{r}=\sum_{i=1}^{n}\left(y_{i}-a_{0}-a_{1} x_{i}\right)^{2}=41154.33 \\
& s_{y / x}=\sqrt{\frac{S_{r}}{n-2}}=\sqrt{\frac{41154.33}{8-2}}=82.82 \\
& r^{2}=\frac{S_{t}-S_{r}}{S_{t}}=\frac{94098.72-41154.33}{94098.72}=0.563 \\
& r=\sqrt{r^{2}}=0.75
\end{aligned}
$$


The resulting best-fit straight line using $a_{o}=-97.09$ and $a_{1}=0.5544$ is shown in Figure D.1, along with the standard error of the estimate, $s_{y / x}=82.82$.

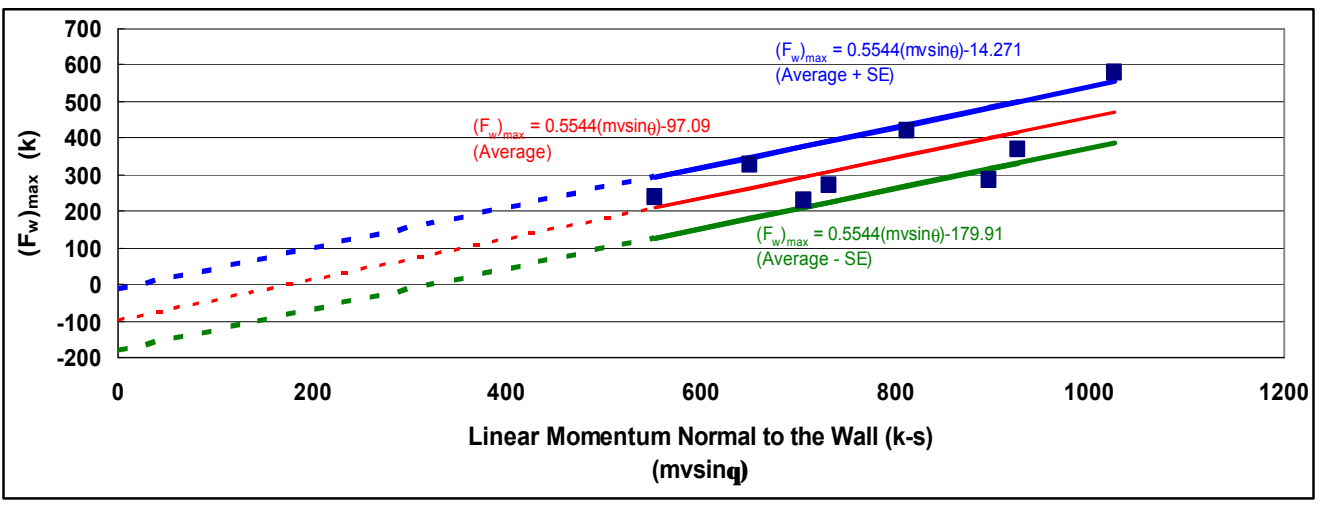

Figure D.1. Empirical correlation between $\left(F_{w}\right)_{\max }$ and linear momentum normal to the wall, straight line with nonzero intercept

\section{D.4 Example 2; Linear Regression with Intercept Equal to Zero-Linear Momentum Normal to the Wall}

Using the $\left(F_{w}\right)_{\max }$ values given in Table 5.3 (and reported in Table 6.1a, eighth column, in yellow), a linear regression with the intercept set equal to zero is made to obtain the best-fit straight line, as outlined in the following calculations for the data (see Table D.1).

\section{Calculation:}

$$
\begin{aligned}
& n=8 \\
& \sum_{i=1}^{8} x_{i}=6302.63 \\
& \sum_{i=1}^{8} y_{i}=2717.42 \\
& \sum_{i=1}^{8} x_{i} y_{i}=2236350.39 \\
& \sum_{i=1}^{8} x_{i}^{2}=5137616.654 \\
& \bar{x}=\frac{6302.63}{8}=787.83 \\
& \bar{y}=\frac{2717.42}{8}=339.68
\end{aligned}
$$




$$
\begin{aligned}
& a_{1}=\frac{\sum x_{i} y_{i}}{\sum x_{i}^{2}}=\frac{2236350.39}{5137616.654}=0.435 \\
& a_{0}=0 \\
& \left(F_{w}\right)_{\max }=a_{1} x+a_{0}=0.435(m v \sin \theta) \\
& S_{r}=\sum_{i=1}^{n}\left(y_{i}-a_{1} x_{i}\right)^{2}=43685.76 \\
& S_{y / x}=\sqrt{\frac{S_{r}}{n-2}}=\sqrt{\frac{43685.76}{8-2}}=85.33 \\
& r^{2}=\frac{S_{t}-S_{r}}{S_{t}}=\frac{94098.72-43685.76}{94098.72}=0.535 \\
& r=\sqrt{r^{2}}=0.732
\end{aligned}
$$

The resulting best-fit straight line using $a_{o}=0$ and $a_{1}=0.435$ is shown in Figure D.2 along with the standard error of the estimate, $s_{y / x}=85.33$.

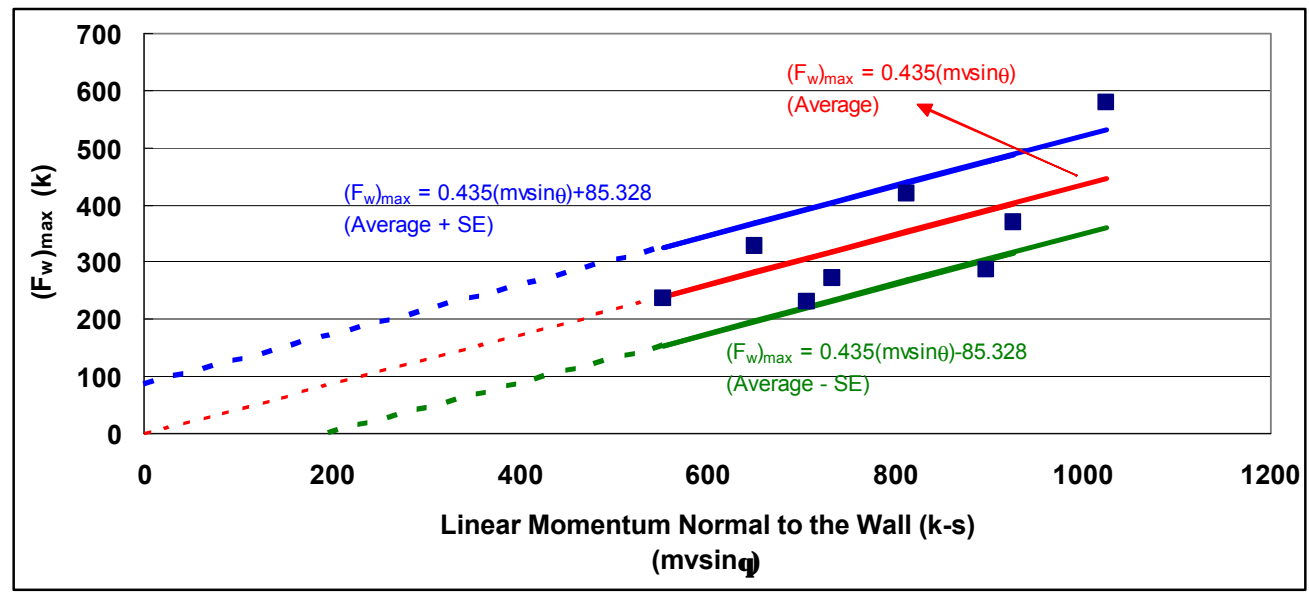

Figure D.2. Empirical correlation between $\left(F_{w}\right)_{\max }$ and linear momentum normal to the wall, straight line with zero intercept

\section{D.5 Example 3; Linear Regression with Intercept Equal to Zero-Kinetic Energy Normal to the Wall}

Using the $\left(F_{w}\right)_{\max }$ values given in Table 5.3 (and reported in Table 6.1a, eighth column, in yellow), a linear regression with the intercept set equal to zero is made to obtain the best-fit straight line, as outlined in the following calculations for the data given in Table D.2. 


\begin{tabular}{|c|c|c|}
\hline \multicolumn{3}{|c|}{$\begin{array}{l}\text { Table D2 } \\
\text { Kinetic Energy Normal to the Wall and Maximum Force } \\
\text { Normal to the Wall for Eight Barge Impact Experiments }\end{array}$} \\
\hline $\begin{array}{l}\text { Experiment } \\
\text { Number }\end{array}$ & $\begin{array}{l}\text { Kinetic Energy Normal to the } \\
\text { Wall } \\
x_{i}\end{array}$ & $\begin{array}{l}\left(F_{w}\right)_{\max } \text { Table } 5.3 \\
y_{i}\end{array}$ \\
\hline 29 & 214.92 & 286.63 \\
\hline 30 & 233.20 & 369.15 \\
\hline 31 & 83.95 & 236.20 \\
\hline 37 & 114.27 & 327.27 \\
\hline 38 & 134.70 & 230.29 \\
\hline 39 & 141.88 & 271.07 \\
\hline 41 & 180.59 & 419.37 \\
\hline 42 & 282.17 & 577.44 \\
\hline
\end{tabular}

\section{Calculation:}

$$
\begin{aligned}
& n=8 \\
& \sum_{i=1}^{8} x_{i}=1385.68 \\
& \sum_{i=1}^{8} y_{i}=2717.42 \\
& \sum_{i=1}^{8} x_{i} y_{i}=513060.46 \\
& \sum_{i=1}^{8} x_{i}^{2}=271180.35 \\
& \bar{x}=\frac{1385.68}{8}=173.21 \\
& \bar{y}=\frac{2717.42}{8}=339.68
\end{aligned}
$$




$$
\begin{aligned}
& a_{1}=\frac{\sum x_{i} y_{i}}{\sum x_{i}^{2}}=\frac{513060.46}{271180.35}=1.892 \\
& a_{0}=0 \\
& \left(F_{w}\right)_{\max }=a_{1} x+a_{0}=1.892\left(0.5 m v^{2}\right) \\
& S_{r}=\sum_{i=1}^{n}\left(y_{i}-a_{1} x_{i}\right)^{2}=46458.89 \\
& S_{y / x}=\sqrt{\frac{S_{r}}{n-2}}=\sqrt{\frac{43685.76}{8-2}}=88.00 \\
& r^{2}=\frac{S_{t}-S_{r}}{S_{t}}=\frac{94098.72-46458.89}{94098.72}=0.5063 \\
& r=\sqrt{r^{2}}=0.7115
\end{aligned}
$$

The resulting best-fit straight line using $a_{o}=0$ and $a_{1}=1.892$ is shown in Figure D. 2 along with the standard error of the estimate, $s_{y / x}=88.00$.

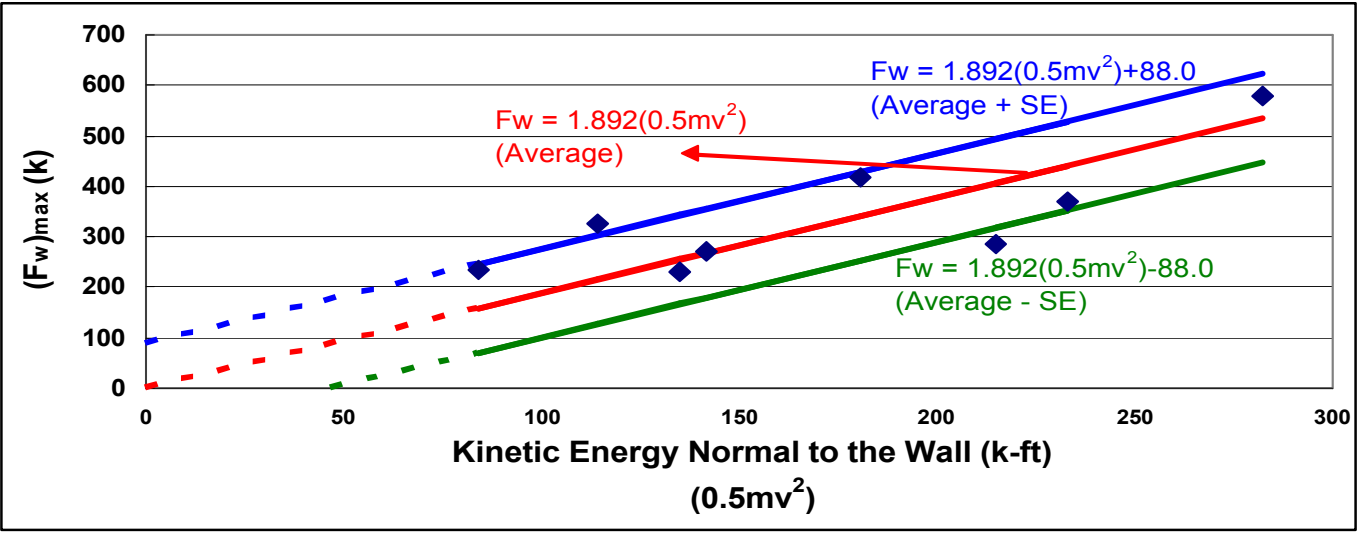

Figure D.3. Empirical correlation between $\left(F_{w}\right)_{\max }$ and kinetic energy normal to the wall, straight line with zero intercept

\section{D.6 Summary and Conclusions}

\section{D.6.1 Linear Momentum Normal to the Wall}

After performing a linear regression of the eight data points obtained from Table 5.3 of the main text (and repeated in Table 6.1a), a coefficient of determination of 0.56 was obtained for the best-fit straight line (with nonzero $a_{o}$ and $a_{l}$ values). The resulting correlation coefficient was 0.75 (Section D.3). These results indicate that 56 percent of the original uncertainty has been explained by the linear model $\left(F_{w}\right)_{\max }=0.5544 * m v \sin \theta-97.09$.

In addition to this model, a second regression was determined based on the constraint of having a value equal to zero for the intercept $\left(a_{0}=0\right)$. In this case, 
the coefficient of determination was estimated as 0.535 , and the resulting correlation coefficient was 0.732 (Section D.4). These results indicate that 53.5 percent of the original uncertainty has been explained by the linear model $\left(F_{w}\right)_{\max }=0.435 * m v \sin \theta$.

From a statistical point of view, the authors concluded that both regression lines are equally valid. There is little difference between the fit of both lines through the data, as reflected by the near match of the values for both the coefficient of determination and the correlation coefficient for the two lines. However, given the complex nature of the events/interactions that transpire when a barge flotilla impacts a lock wall and the gross simplifications introduced by this empirical correlation, a straight line with the intercept set equal to zero is recommended at this time. The rationale is that, from an engineering point of view, if the velocity and, subsequently, the linear momentum normal to the wall are equal to zero, there should be no barge impact force. The authors would also like to note that the amount of data (i.e., eight points) was not sufficient to allow for the fit of a higher order polynomial through the data. Additional barge impact data, should these become available at a later date, may indicate that a higher order polynomial may be warranted.

\section{D.6.2 Kinetic Energy Normal to the Wall}

After performing a linear regression of the eight data points obtained from Table 5.3 (and repeated in Table 6.1a), a coefficient of determination of 0.5063 was obtained for the best-fit straight line determined based on the constraint of having a value equal to zero for the intercept $\left(a_{0}=0\right)$. The resulting correlation coefficient was 0.7115 (Section D.5). These results indicate that 50 percent of the original uncertainty has been explained by the linear model $\left(F_{w}\right)_{\max }$ $=1.892 *\left(0.5 m v^{2}\right)$.

From a statistical point of view, the authors concluded that this regression line does not represent the data points as well as the linear momentum normal to the wall regression line with zero intercept. There is little difference between the coefficients of determination of both models. This difference indicates that the linear momentum normal to the wall approach $\left(r^{2}=0.535\right)$ explains more of the original uncertainty than the kinetic energy normal to the wall approach $\left(r^{2}=0.50\right)$. That is, the closer the correlation coefficient is to unity, the better the model.

Given the complex nature of the events/interactions that transpire when a barge flotilla impacts a lock wall and the gross simplifications introduced by these empirical correlations, a straight line with the intercept set equal to zero is recommended at this time. The rationale is that, from an engineering point of view, if the velocity and, subsequently, the kinetic energy normal to the wall are equal to zero, there should be no barge impact force. The authors would also like to note that the amount of data (i.e., eight points) was not sufficient to allow for the fit of a higher order polynomial through the data. Additional barge impact data, should these become available at a later date, may indicate that a higher order polynomial may be warranted. 


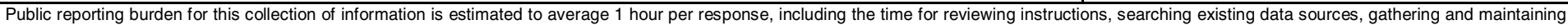

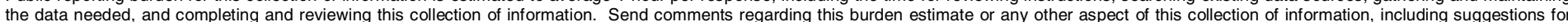

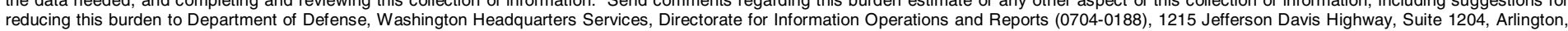

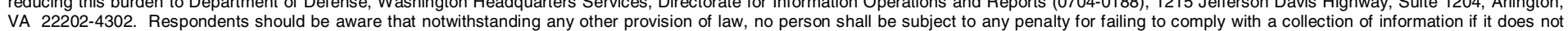
VA 22202-4302. Respondents should be aware that notwithstanding any other provision of law, no person shall be sube
display a currently valid OMB control number. PLEASE DO NOT RETURN YOUR FORM TO THE ABOVE ADDRESS.
1. REPORT DATE $(D D-M M-Y Y Y Y)$ 2. REPORT TYPE April 2003 Final report

\section{TITLE AND SUBTITLE}

Analysis of Impact Loads from Full-Scale, Low-Velocity, Controlled Barge Impact Experiments, December 1998

3. DATES COVERED (From - To)

5a. CONTRACT NUMBER

5b. GRANT NUMBER

5c. PROGRAM ELEMENT NUMBER

\section{AUTHOR(S)}

5d. PROJECT NUMBER

José Ramón Arroyo, Robert M. Ebeling, Bruce C. Barker

5e. TASK NUMBER

5f. WORK UNIT NUMBER

33143

\section{PERFORMING ORGANIZATION NAME(S) AND ADDRESS(ES)}

U.S. Army Engineer Research and Development Center, Information Technology

Laboratory, 3909 Halls Ferry Road, Vicksburg, MS 39180-6199;

8. PERFORMING ORGANIZATION REPORT NUMBER

University of Puerto Rico, General Engineering Department,

ERDC/ITL TR-03-3

P.O. Box 9044, Mayagüez, PR 00681

\section{SPONSORING / MONITORING AGENCY NAME(S) AND ADDRESS(ES)}

U.S. Army Corps of Engineers

Washington, DC 20314-1000

10. SPONSOR/MONITOR'S ACRONYM(S)

11. SPONSOR/MONITOR'S REPORT NUMBER(S)

\section{DISTRIBUTION / AVAILABILITY STATEMENT}

Approved for public release; distribution is unlimited.

\section{SUPPLEMENTARY NOTES}

\section{ABSTRACT}

In 1993, Headquarters, U.S. Army Corps of Engineers, issued the first formal Corps-wide analysis procedure providing guidance for analyzing the effects of barge impact loading on navigation structures. According to the engineering procedure of Engineer Technical Letter (ETL) 1110-2-338, the magnitude of the impact forces generated by a particular collision event is dependent on the mass (including hydrodynamic added mass of the barge flotilla), the approach velocity, the approach angle, the barge flotilla moment of inertia, damage sustained by the barge structure, and friction between the barge and the wall. The analytical method uses the structural interaction mechanism of Minorsky, which provides an empirical relationship between the (nonrecoverable) hull deformation and the energy absorbed in a collision. The relationship between kinetic energy lost in a collision and the volume of in-plane (barge) material damaged is used to determine impact force as a relationship to instantaneous contact area of damaged structure.

Two significant concerns have been raised since the ETL 1110-2-338 procedure was released. First, a key aspect of the ETL 11102-338 engineering formulation is computation of collision energy dissipated in nonrecoverable, plastic hull deformation of (i.e., damage to) the corner of the barge where impact with the wall occurs. However, the majority of the impacts made by barge flotillas transiting Corps locks do not result in damage to the barge structure or to the walls. Second, several engineers who have used the ETL 1110-2-338

\section{SUBJECT TERMS}

Barge

Impact

16. SECURITY CLASSIFICATION OF:

a. REPORT

UNCLASSIFIED
Impulse and linear momentum

Kinetic energy

Rigid wall

(Continued)

UNC

b. ABSTRACT
UNCLASSIFIED

c. THIS PAGE UNCLASSIFIED

19a. NAME OF RESPONSIBLE PERSON

19b. TELEPHONE NUMBER (include

176 area code) 


\section{ABSTRACT}

engineering procedure have questioned the accuracy of the computed results. This report addresses the interpretation of eight of the 44 December 1998 full-scale, low-velocity controlled impact, barge flotilla impact experiments conducted at the decommissioned Gallipolis Lock at Robert C. Byrd Lock and Dam. An easy to use empirical correlation is derived that reports the maximum impact force (normal to the wall) as a function of the linear momentum normal to the wall (immediately prior to impact), using the results from the impact forces measured during these full-scale impact experiments. This new empirical correlation will be used for impacts that do not involve damage during impact to either the corner barge of a barge flotilla or to the wall. An alternate empirical correlation is given for the maximum impact force (normal to the wall) as a function of the kinetic energy normal to the wall (immediately prior to impact). 